\title{
ALFRED BERTRAND
}
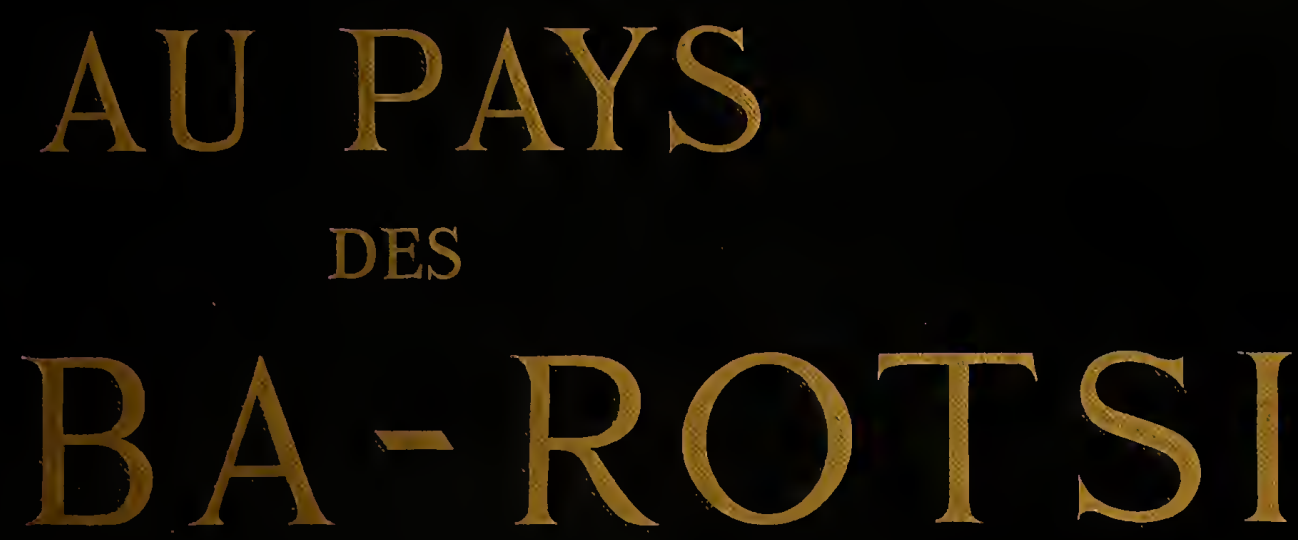

HAUT-ZAMBÈZE

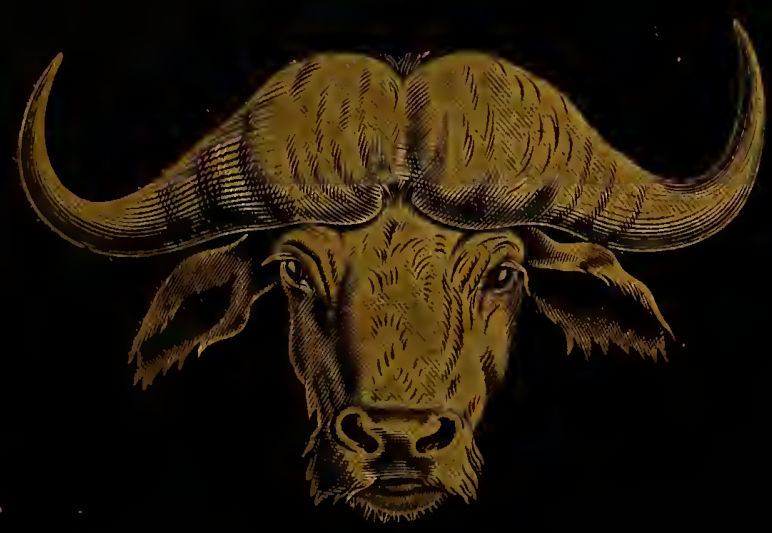

Tlachette \&o $\mathcal{C}^{i e}$. 


\section{Cro

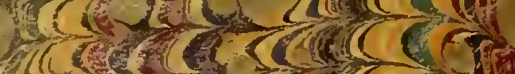

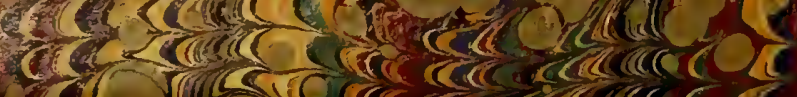

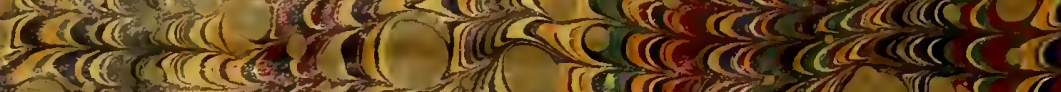
1.

ति

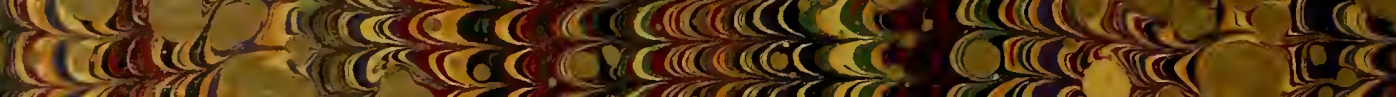

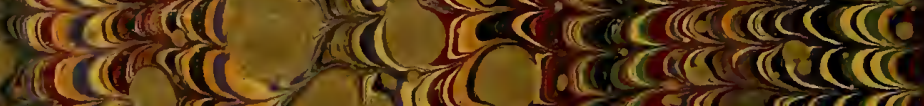

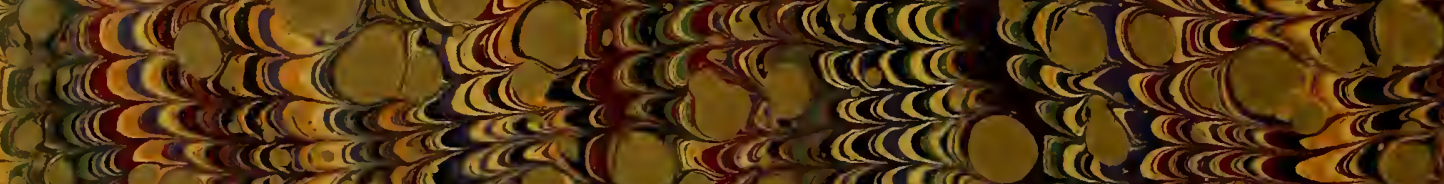

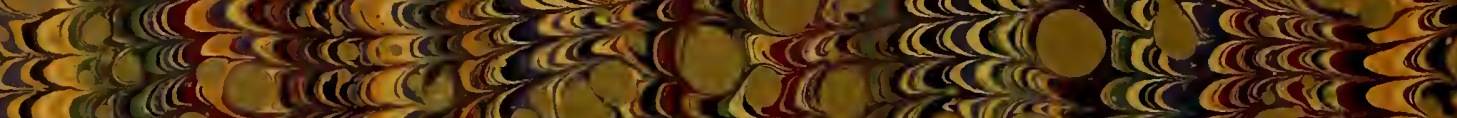

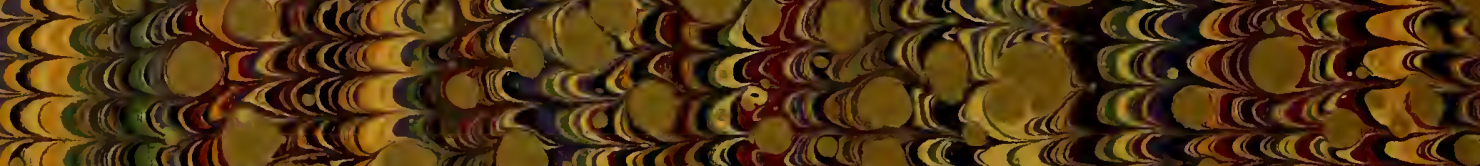

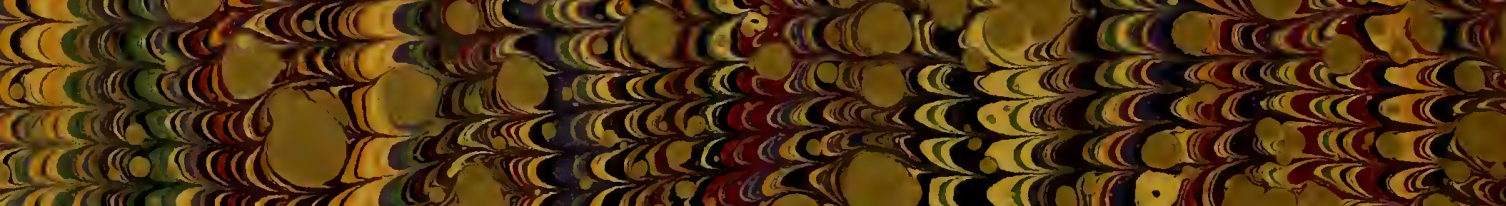

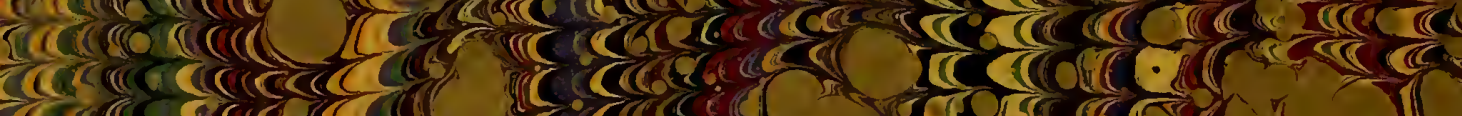

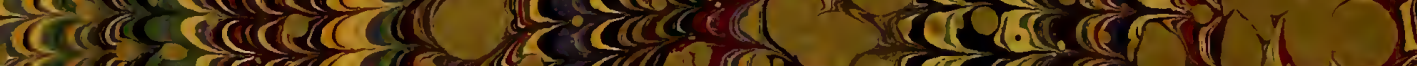

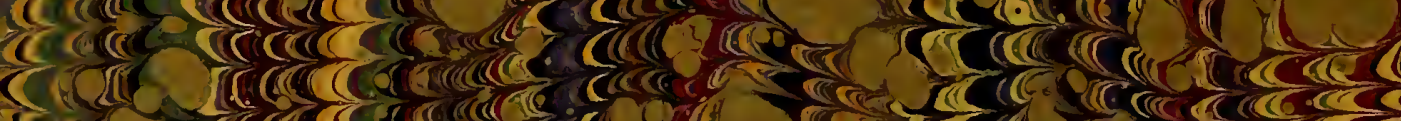

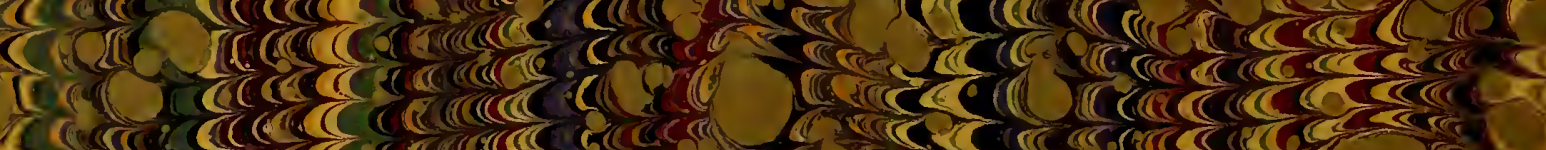

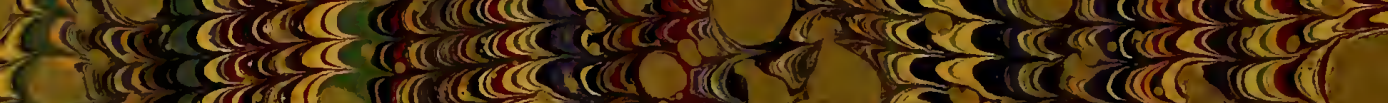

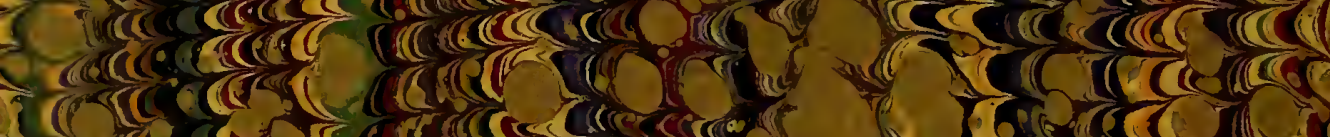

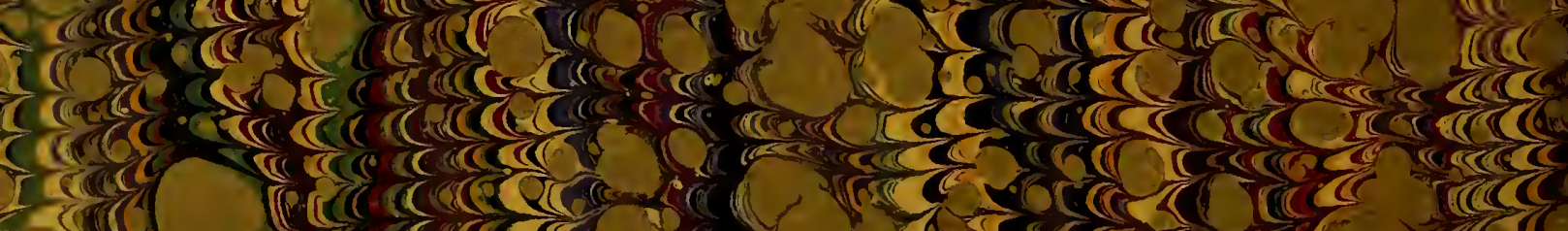
Ir (a)

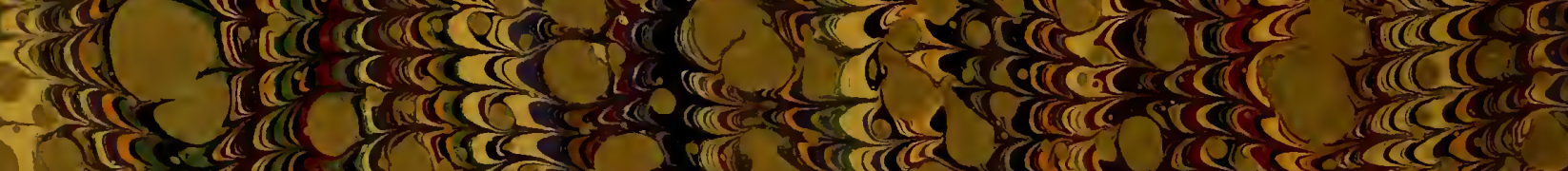

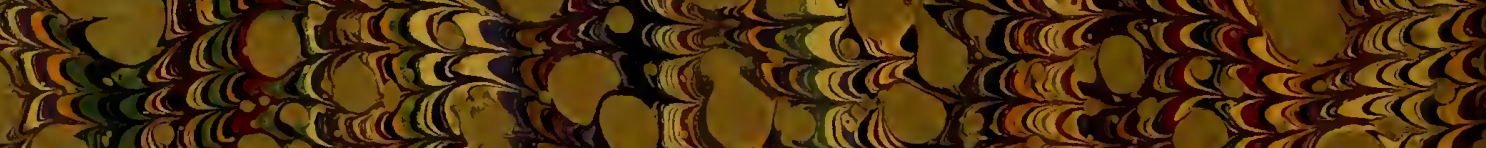
al

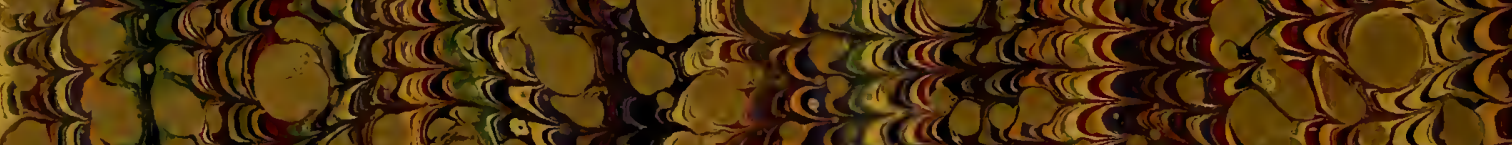

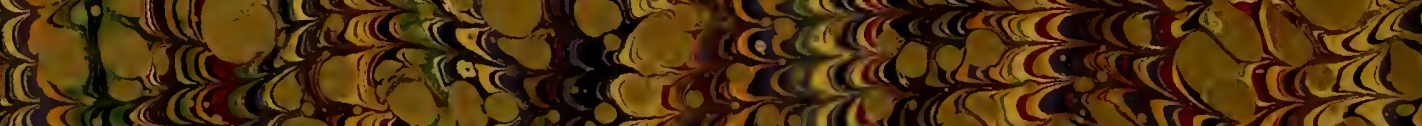

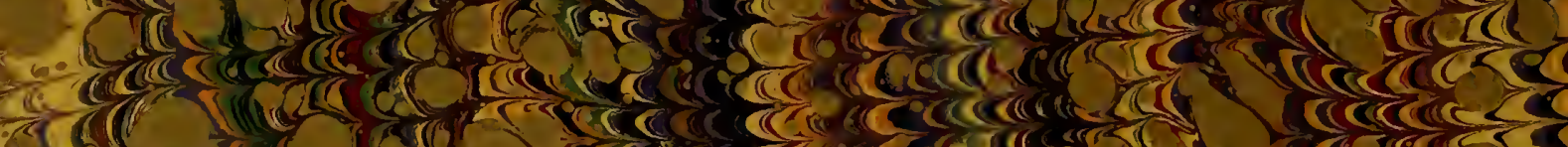

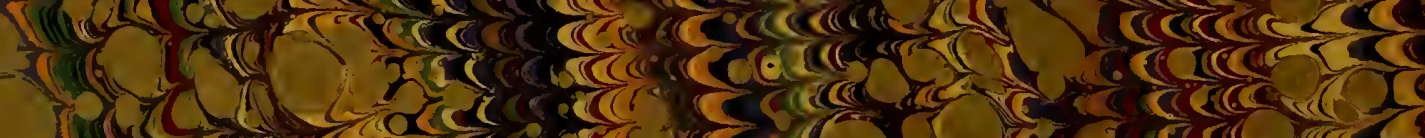

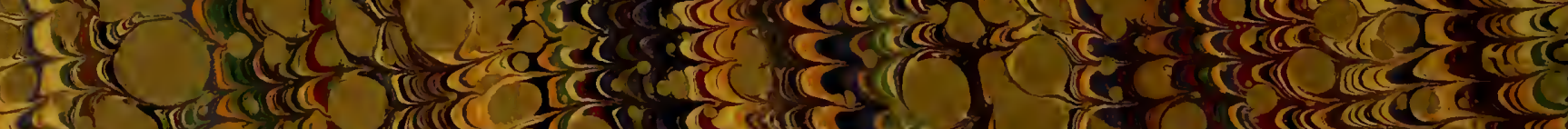

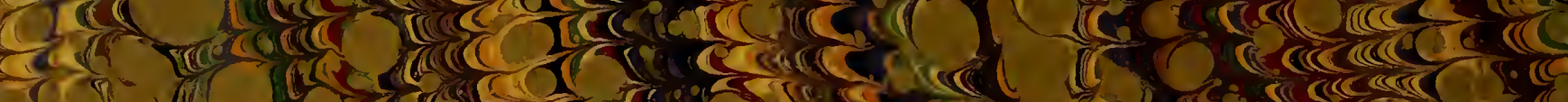
युिएक

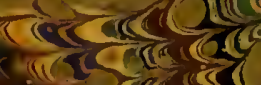

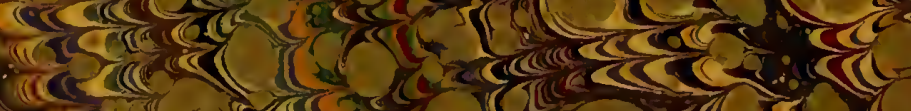

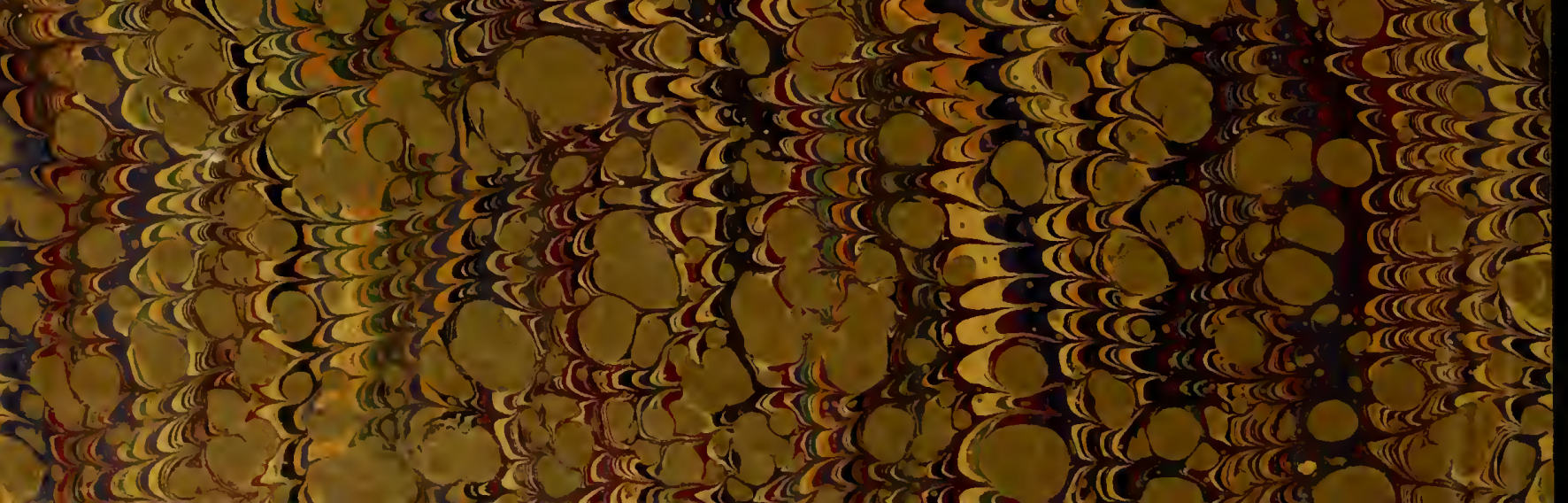

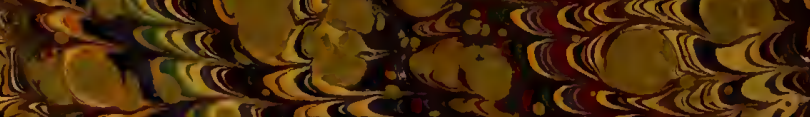

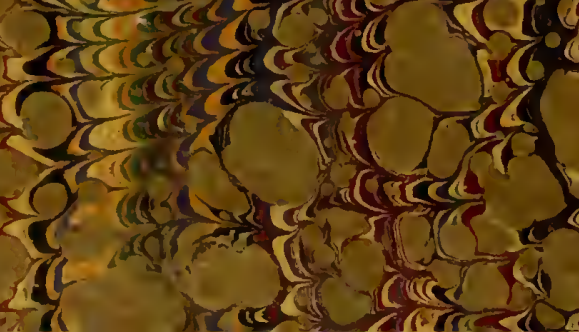

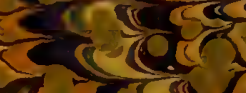






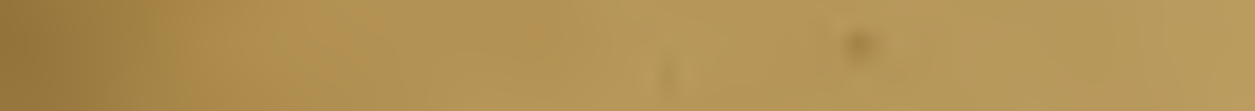







\title{
AU PAIS
}

\section{DES BA-ROTSI}

\author{
H A U T - \% A M B E Z E
}


COULOMMERS

Imprimeric PaUl Bhodard. 



$$
2
$$


DT

756

B5 4

MAA

$$
\text { ALRREDKRTR.INI }
$$

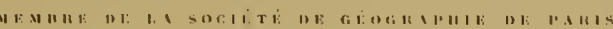

\section{A I PA Y S}

\section{DES B A-ROTSI}

\section{II $\ \mathrm{U} T-\%$ T II B E ZE}

VUYIGE DEXPLOHATUN EN IFHIOUE

ET RETOLR PAR LES CHUTES VICTORL,

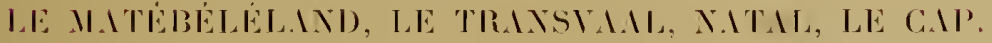

OUVRAGE ILLUSTRÉ DE 105 GRAVURES ET DE DEUX CARTES

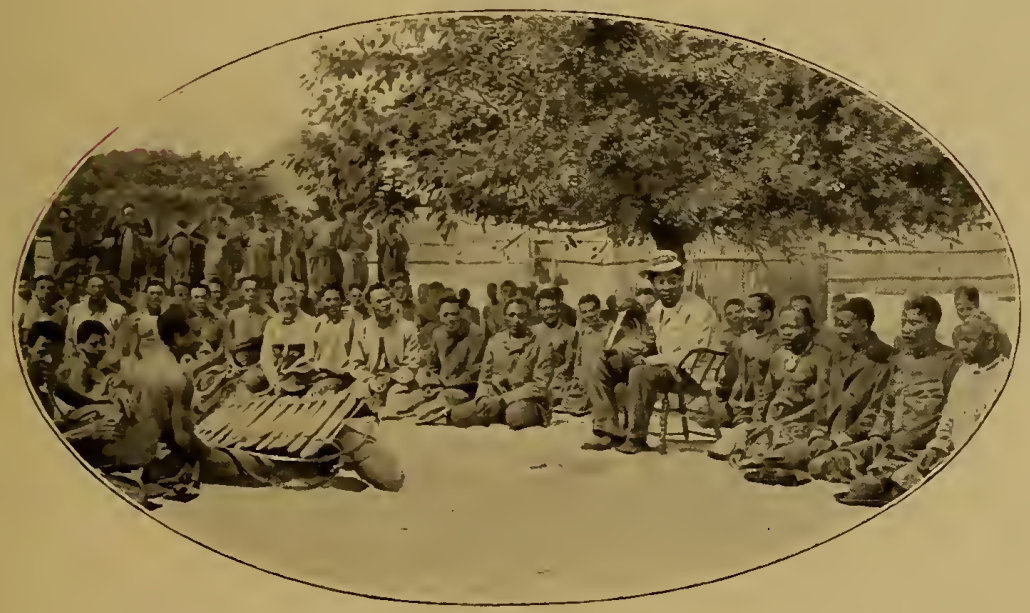

P.IRIS

LIBR.AIRIE H.ICHETTE ET C

79, BOILEIML SIIT-GERMIX, 79

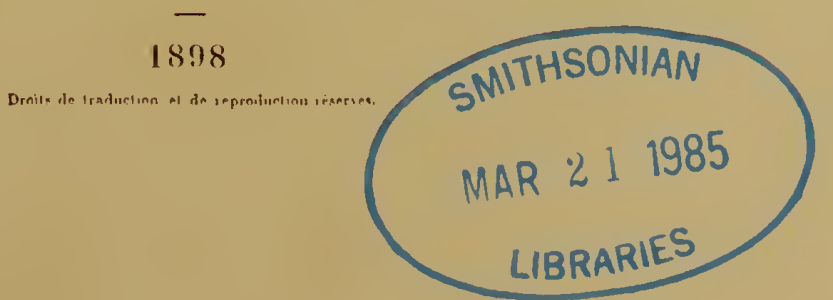





\title{
A MES COMPATRIOTES
}

MM. LES MEMBRES DE LA SOGIÉTÉ DE GÉOGRAPHIE

\author{
DE GENEVE
}





\section{A U PAYS \\ DES BA-ROTSI \\ HAUT-ZAMBËZE}

CHAPITRE I

\section{LA TRAVERSEE}

DE SOUTHAMPTON AU CAP SUR LE " NORHAM-CASTLE "

A prés avoir risité plusieurs régions du monde, j'éprouvais depuis continent d'Ifrique. Cie plan prit corps lorsque M. Percy-C. Reid, ex-officier au $13^{\circ}$ hussards et neveu de Sir Henry Barday, ancien gourerneur du Cap, avec qui j'avais fait il y a quelques années un royage au Cachemire el dans l'llimalaya, me proposa de me joindre ¿ une expédition qui avait comme but de pénétrer dans le Pays des ha-Rotsi, Haut-Zambeze, scuil de l'Afrique centrale, el de reconnaitre une partie de cette contrée. L'organisateur de cette expédition était le capitaine 1 . Saint-llill Gibbons, du $3^{\text {rd }}$ Yorlishire regiment; M. F.-D. Pirie, écossais, complétait notre état-major.

Le capitaine Gibbons et Pirie nous ont précédés de plusieurs 
semaines en Afrique pour acheler les bœufs, les chevaux, les chariots, pour engager le personnel, ele. Nous les retrouverons à Maféling dans l'ouest du Transval, Ierminus actuel du chemin de fer, ì 1400 kilomètres du Cap, où aussitòt débarqués nous nous rendrons, Reid et moi, directemenl.

C'esl de Naféking que notre expédition partira. Pour atteindre le Pays des ba-Rolsi, nous suivrons approximalivement la direction suivante : Molépololé, Palapye au Béchuanaland, el, laissant à l'ouest le désert de Kalahari, nous longerons la partie est du grand lac salé Makarikari pour franchir à son extrémité nord le "Land of the thousand Vleys".

Nous espérons traverser le Zambèze ì la jonction de la rivière Chobé (Linyanti) au commencement de juillet; nous ne tarderons pas alors à nous trouver dans une région vierge.

Ceci dit, je prends mon journal en mains :

$$
*^{*} *
$$

23 mar' 1895. - Nous nous embarquons ì Southampton, à bord du Norham-Castle (Castle-Line). Peu après avoir passé le Solent, nous subissons une mauvaise mer : celle de la baie de Biscaye de fàcheuse réputation.

$$
\text { *** }
$$

26 mars. - Mer démontée; nous avons essuyé deux coups de vent d'une grande violence. Suivant l'opinion de l'un des officier's du bord, le Norham-Castle doit s'estimer heureux de n'avoir pas eu beaucoup d'autres assauls de ce genre, à supporter.

$$
\text { *** }
$$

27 mars. - Les flots se calment; beau soleil. Nous avons été mis en retard par cette tempète, nous tâchons de rattraper le temps 
perdu. Les passagers dont plusieurs n'ont pas paru depuis te commencement du voyage, sortent les uns apress les autres de leurs cabines, plus ou moins pàles; mais d'une manière générale, le mal de mer s'allénue. C'est le moment de faire connaissance. Quarante-deux passager's de première classe sont inserits au registre : hommes d'affaires, ingénieurs, ete., qui vont rejoindre leurs postes; plusieurs officier's qui rallient leurs régiments, parmi eux l'Hon. Capt. W..., fils de Lord $\Lambda$.

$$
* * *
$$

28 mars. - Nous passons ce matin le long des côtes dénudées de l'ìle de Porto-Santo. Le contraste est frappant avec l'ìle de Madère que nous ne tardons pas à avoir en vue. Nous naviguons sur la côt est; les pentes de ses montagnes, d'un beau vert, se détachent d'une manière intense sur le bleu qui nous environne de toutes parts.

Après avoir doublé le cap Garajao, nous entrons dans la jolie baie au-dessus de laquelle s'étage gracieusement Funchal, la capitale de Madère. A peine l'ancre est-elle jetée que nous sommes entourés par une nuée de canots, les uns montés par de jeunes indigènes qui " plongent " pour retrouver les menues pièces de monnaie qui leur sont jetées; les autres par des marchands d'oranges, de bananes, de " custard-apples ". Quelques-uns ont la malheureuse idée, pour vendre plus vite leurs produits, de grimper sans permission le long des bastingages; ils sont reçus un peu rudement par des matelots armés de cordes et postés aux points d'envahissement. Ils doivent ìtre habitués à ce genre de réception et leur: bonne humeur ne se dément pas, mème pour l'homme qui, dans la hàte de rejoindre son canot prend, à la grande hilarité de ses camarades, un bain imprévu.

Le steamer doit relàcher quelques heures pour nous ravitailler en 
charbon. Nous en profitons pour aller à terre et monter par le nouveau chemin de fer, à l'église de Nossa Senhora Monte, trajet ravissant. La ligne se déroule au milieu de jardins plantés de cannes a sucre, de bananiers; voici des camćlias en fleurs; plus loin des enfants nous jettent des roses. De la terrasse de l'église, entouréc de verdure, nous admirons la baie qui śétend a nos pieds. Sur ses eaux tranquilles nous distinguons le Norham-Castle qui semble dormir; c'est bien l'image du " port après la tempète ".

Nous effectuons la descente dans l'une de ces corbeilles en osier appelées " carro ", véhicules rapides, gràce aux routes en pente pavées de galets glissants. Deux indigènes, cordes en mains, courent de chaque còté du " carro " et maintiennent l'équilibre; la vitesse acquise est considérable. Nous avons encore le temps d'aller visiter le marché des fruits et de cucillir des fleurs au jardin de Mill's Hotel, véritable petit paradis avec sa végétation de serre chaude. Les nuages ne nous permettent pas de voir le Corral, l'une des plus hautes montagnes de l'ìle, au sommet de laquelle je grimpai il y a quelques années.

Les vignobles de Madère, jadis détruits par le phylloxéra, sont en grande partic reconstitués.

Funchal s'agrandit; elle compte actuellement 30000 àmes, sur une population totale de 144000 habitants pour l'ìle entière.

Nous regagnons le bord peu avant le départ.

$$
*^{*} *
$$

29 mars. - Beau temps. De bonne heure nous avons en vue le pic de Ténériffe (12000 pieds) qui domine l'ìle, la plus importante du groupe des Canaries. La base en est eachre et nous ne voyons que sa pointe couverte de neige émerger des vapeurs du matin. Dans le courant de l'aprèismidi nous jetons l'ancre pour quelques inslants 
spulement, afin de débarquer deux ou trois passagers, it quelques centaines de mètres de Santiago de Santa-Cruz. Nous ne sommes pas autorisés à aller a terre et c'est du bord que nous jouissons du pilloresque paysage que nous avons sous les yeux. $\Lambda$ distance, ces ritaisons roses, blanches, brunes, encadrées dans la verdure, font le plus joli effet.

Pendant que nous sommes en rade, le Norham-Castle est rejoint comme à Madère, par de nombreux canots dont les possesseurs làchent d'engager les passagers à acheter du tabac et des cigares que l'on dit excellents. Quoique la marchandise ne soit pas la même, ces Espagnols font autant de bruit et de démonstrations que leurs voisins portugais les Madéréens.

Ténériffe a 95000 habitants; sa capitale, Santiago de Santa-Cruz, compte 20000 habitants.

Depuis Ténériffe, nous ne verrons plus la terre jusqu'au Cap.

$$
\text { *** }
$$

30 mars. - Nous passons le tropique du Cancer et cinq jours après, l'équateur. En entrant dans l'hémisphère austral, nous disons au revoir à l'Étoile polaire qui disparait de notre horizon; notre point de repiere sera désormais la Croix du Sud.

Notre activité est actuellement, par la force des choses, tout à fait concentrée sur la vie du bord. Outre le temps consacré au travail et à la lecture, cette vie pour qui sait voir et entendre, offre beaucoup d'intérêt. Les passagers peuvent se mettre au courant des différents services d'un steamer du genre du nòtre, de 4500 tonnes, qui est, jusque dans ses moindres recoins, ćclairé à l'électricité. La discipline est admirable à tous les degrés de l'échelle hiérarchique. D'autres peuvent acquérir des notions d'astronomie, apprendre à 
manier le sextant. Mais lous jouiront du spectacle qu'offre l'Océan dans ses phases diverses, des couchers de soleil sous les tropiques lont la magnificence, ainsi que celle des nuits étoilées, défie toute description.

Le spectacle imprévu ne manque pas non plus : un jour des baleines sont aperçues dans le lointain; des bandes de marsouins viennent se jouer à la surface des eaux; des poissons volants s'élancent d'une vague à l'autre; des oiseaux de mer nous rendent aussi visite de temps en temps.

Le soir, huit musiciens, hommes de l'équipage, font retentir l'air de leurs échos joyeux; en outre, plusieurs séances de musique ont été organisées par des amateurs sans compter les jeux divers et les conversations intéressantes.

Enfin, malgré la chalcur, deux demi-jouruées ont été remplies par - des sports athlétiques que les Anglais ne délaissent jamais sous aucun pritexte, ni sous aucune latitude. Principe excellent : de celte pratique développe non seulement le corps, le maintient en bonne santé; mais elle est aussi une discipline pour le caractère et produit : courage, persévérance, endurance.

Le dimanche, culte dans le graud salon de la poupe. La Bible est placíe sur le pavillon national. Si nous n’avions pas un clergyman passager à bord, le service religieux, suivant l'usage de la marine anglaise, serait célébré par le commandant.

Puisque je parle de l'état-major du Norham-Castle, je ne puis m’empècher, pour faire comprendre la valeur de ces marins, de mentionner la conduite dı premier officier, M. Frank Whitehead qui, pour l'intrépide courage et le dévouement qu'il a déployés le 7 avril dernier, a été récemment en Angleterre l'objet des distinctions les plus flatteuses et méritées at a reçu une médaille d'argent du 
Lloyd, une médaille d’argent de la Fédération des agents maritimes de la Grande-Bretagne, une adresse de remerciements de la "Liverpool Shipwreck and Ifumane Society ". Le Norham-Custle, naviguant près dles còtes inhospitalières du Natal, se trouve it l'aube, en vue d'un quatre-màts échoué sur un récif. De sia màture, les matelots naufragés font des signaux de détresse. Le commandaul Duncan se rend compte que son steamer ne peut pas s'approcher du récif et il fail aussitòt descendre deux bateaux de sauvetage, dont l'un est commandé par Whiteheat, qui juge que ce serait folie d'aborder l'épave. Il se fait alors attacher une corde autour du corps et plonge dans les flots; l'un des matelots naufragés agit de la mème manière. Les deux hardis nageurs se rejoignent et allachent leurs cordes, et dix-sept vies sont sauvées par ce moyen. Le capitaine du quatre-mats, qui n'avait pas voulu quitter son navire avant que tous ses hommes fussent sains et saufs, est lui-mème si grièvement blessé, qu'il ne peut pas ètre sauvé sins un nouveau secours. Une fois de plus, Whitehead se jette i la mer; après une lutte hérö̈que, il parvient à ramener le capitaine vivant.

Nous espérons arriver au Cap jeuti 11 avril. De Southamplon, nous aurons accompli en dix-neuf jours, neuf à dix mille kilomètres, soit environ le quart de la circonférence de la terie. Dans ce courl espace de temps, nous aurons subi l'hiver en quittant l'Europe, le printemps à Madère, l'été sous les tropiques el l'automne au Cap.

$$
\text { *** }
$$

11 avril. - La présence de nombreux oiseaux présage notre prochaine arrivée; des cormorans aussi noirs que du jais, émigrent vers le sud. 
Terre! Voici la ville du Cap si bien située le long de la baie. Elle repose au pied de la montagne de la Table, aux parois abruptes et dont le sommet, ru de la mer, semble plat. Elle est flanquéc par deux autres sommités, la Tète-du-Lion et le Devils Peak.

Dans le lointain, des montagnes estompées par la buée bordent l'horizon et forment un ensemble pittoresque!

La sensation est étrange de se retrouver sur la terre ferme après une longue traversée. Le corps qui s'est habitué au roulis et au tangage, ondule encore pendant un certain temps!

Nous sommes entourés par une foule bariolée, où nous constatons toutes les gammes du noir et du blanc.

La première impression que donne le Cap est celle d'une ville dont le plan a été bien conçu, mais dont l'extension laisse peut-être ¿̀ désirer. Les rues qui se coupent en général à angles droits, sont bordées de maisons aux toits plats.

$$
\text { 米草 }
$$

12 avril. - Jour férié. Nous ne pouvons pas retirer nos colis de la douane. Cette après-midi, course en voiture de trente kilomètres dans les environs de Wynberg, véritable parc coupé par des avenues d'une grande beauté, plantées de chênes, d'eucalyptus, de pins parasols..., avec échappées sur la mer el les montagnes. De nombreuses habitations de campagne entourées de jardins fleuris, se détachent sur ce fond de verdure. Nous admirons un arbuste au feuillage d'argent appelé à juste titre silcer tree.

Ces plantations d'arbres de haute futaie 'd'une si belle venue, sont dues à la prévoyance des premiers colons hollandais. 


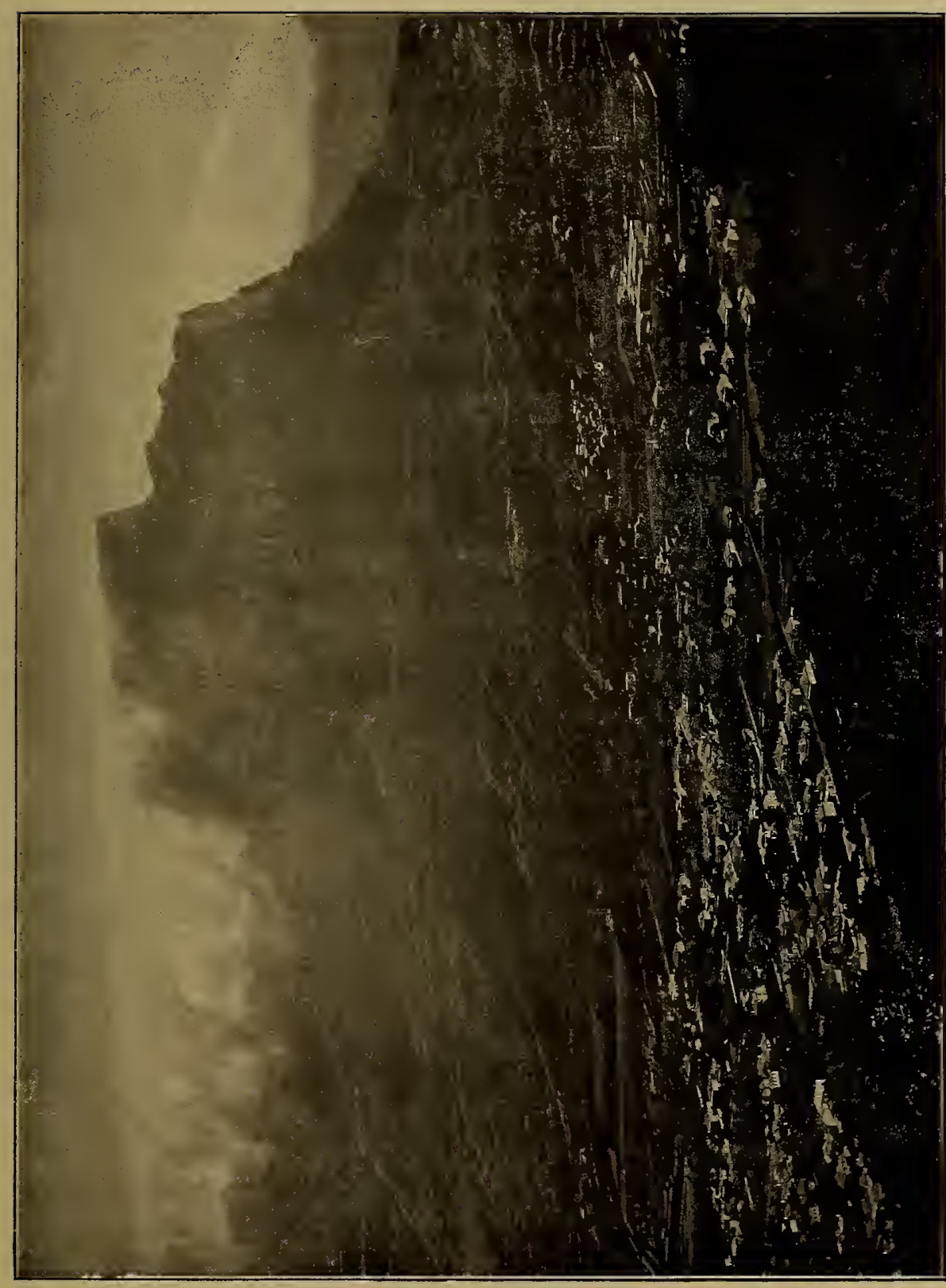

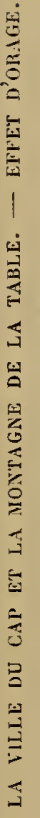

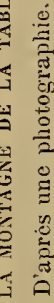





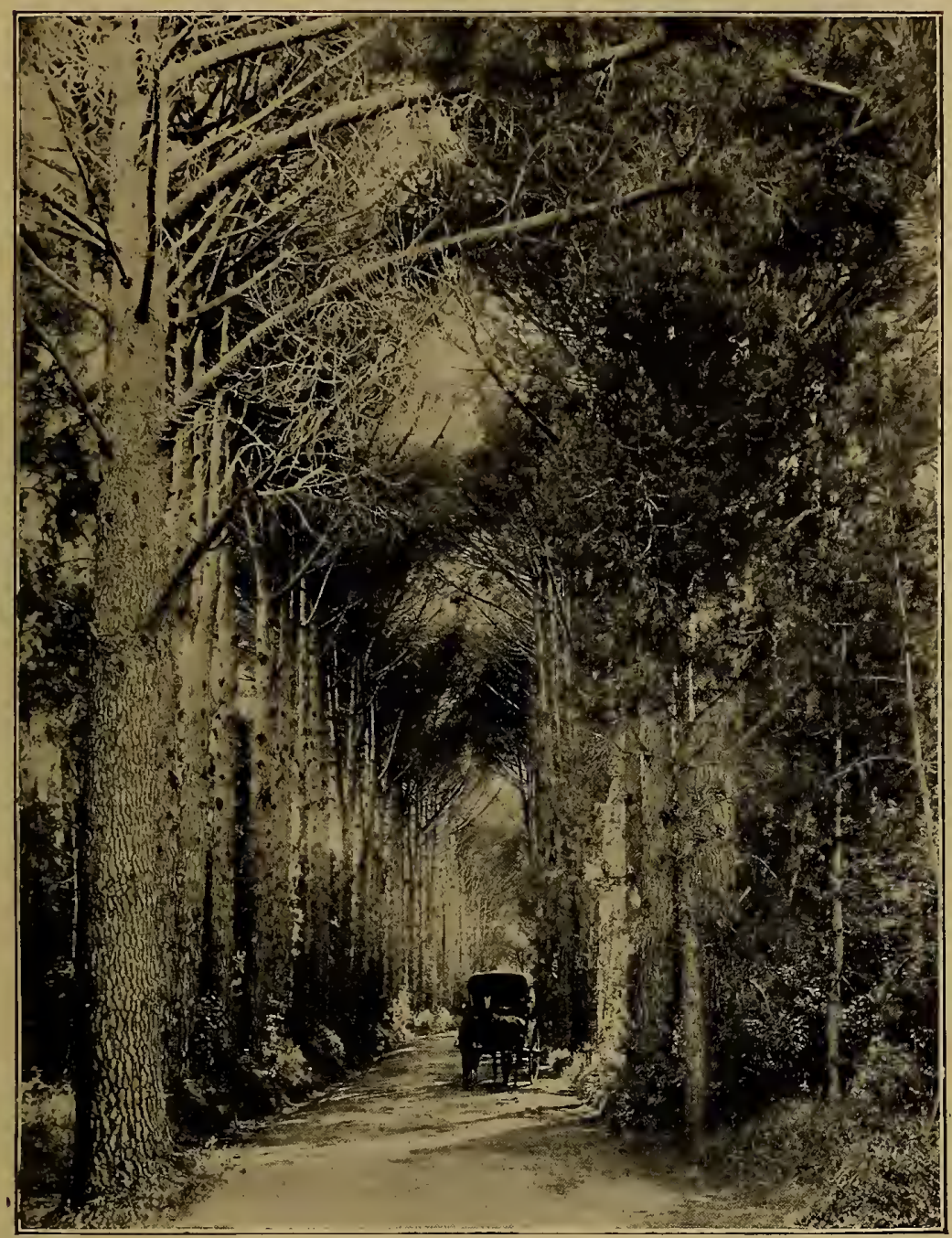

AVEXUE DE WYXEERG.

D'après une photographie.

13 avril. - Il pleut; pluie désirée par les gens du pays. Souvenonsnous que, au Cap, nous sommes à la fin de l'automne; l'hiver est à la porte.

Reid est parti hier ì destination de Johanneslurg (Transvaal). Nous nous sommes donné rendez-vous à Maféking ạu Béchuanaland, ouest du Transvaal, pour mereredi prochain. Je prendrai le train ce 
soir el en trente-six lıeures, je pense arriver à limberley, la ville des diamants ì la frontière du Griqualand et de l'État libre d'Orange, où je m’arrêterai un jour et demi.

Grîce à l'amabilité du capitaine $\mathbb{W}$., qui va occuper une importante sifuation dans la Compagnie sud-africaine anglaise, j’ai obtenu une lettre me permettant de visiter à fond l'une des plus fameuses mines de diamants du monde, la " De Beers Consolidated Mines Limited ». Avant notre départ, nous admirons en suivant AdderleyStrect la rue principale, les belles avenues, encore un legs de la demination hollandaise. Nous passons le somptueux palais du Parlement, la maison du gouverneur qui est très simple et nous entrons dans le jardin botanique, où nous voyons une grande variété d'arbres et de plantes exotiques ou indigènes.

Disons en passant que bien que la ville du Cap ait deux cent cinquante années d'existence, elle a plutòt l'aspect d'une cité moderne.

Avec ses faubourgs, elle compte actuellement 85000 habitants blancs et noirs, représentants de presque toutes les races de l'Afrique méridionale; en outre, passablement de Malais.

Son commerce est considérable. 
CHAPITRE II

\section{AU PAYS DES MINES DE DIAMANTS}

DU C.AP - VIA KIMBERLEY - A MAFÉKING

Wous roici en route, le 14 avril, depuis la veille au soir. D'après
ce que je lis, nous avons traversé la nuil dernière l'une des plus belles partirs du tracé du chemin de fer : montagnes remarquables; districts qui produisent du vin, du blé, des chevaux, des moutons, des bœufs; fermes où sont élevées des autruches; bref un pays fort riche.

Ce matin, nous nous réveillons ì Matjesfontein, à l'entrée du plateau de Karroo que nous franchirons pendant toute la journée et toute la nuit pour arriver demain a limberley.

Ce plateau, malgré son aridité, est coupé ici et là par des oasis; il ne manque pas d'une certaine grandeur.

$$
*^{*} *
$$

15 avril. - Ivec ma lettre d'introduction en poche, je me rends au siège de la “De Beers Consolidated Mines Limited ». Le secrétaire, 
M. W.-H. C..., me remot une carte permettant de visiter en détail cette mine de diamants reitomméc.

Rappelons qur, an mois de mars 1888, M. Cecil-John Rhodes a été le créateur de celte puissante compagnie appelée la "De Beers Consolidated Mines Limited ". Outre les mines de De Beers, elle comprend celles de Kimberley, de Dutoitspan et de Bulfontein el elle détient actuellement le marché des diamants en son pouvoir.

Les renseignements.qui suivent, sont en partie tirés des intéressants rapports qui m’ont été aimablement remis. Je serai bref dans la narration de celte visile.

D’après les études des ingénieurs, on est arrivé à la conjecture que ces mines sont formées par d'anciens rolcans éteints qui ont été remplis, par une pousséc inférieure, de boure volcanique.

Le terrain diamantifire appelé "blue ground ", terre bleue, se trouve donc dans une sorte d'entomnoir.

Suivant le dernier rapport que nous avons sous les yeux, plus de 10000 blancs sans compter les employés supérieurs, et 6600 noirs, travaillent dans ces mines.

Notre guide nous conduit en premier lieu au "compound ", espace clos qui couvre plusieurs acres; pour empècher les vols de diamants, les travailleurs noirs doivent s'y tenir pendant le temps où ils ne sont pas dans la mine. Ils ont huit heures de travail sur vingt-quatre et signent eu général un contrat de quatre mois.

Des constructions d'un élage, en lôle, divisées en chambres conlenant vingt noirs, sont disposées sur les còtés de cette immense cour carrée qui est ferméc par une clòture de fer. Elle contient des magasins qui débitent à des prix très bas des denrées de première qualité; mais aucune boisson alcoolique. Une piscine de natation; un hòpital 


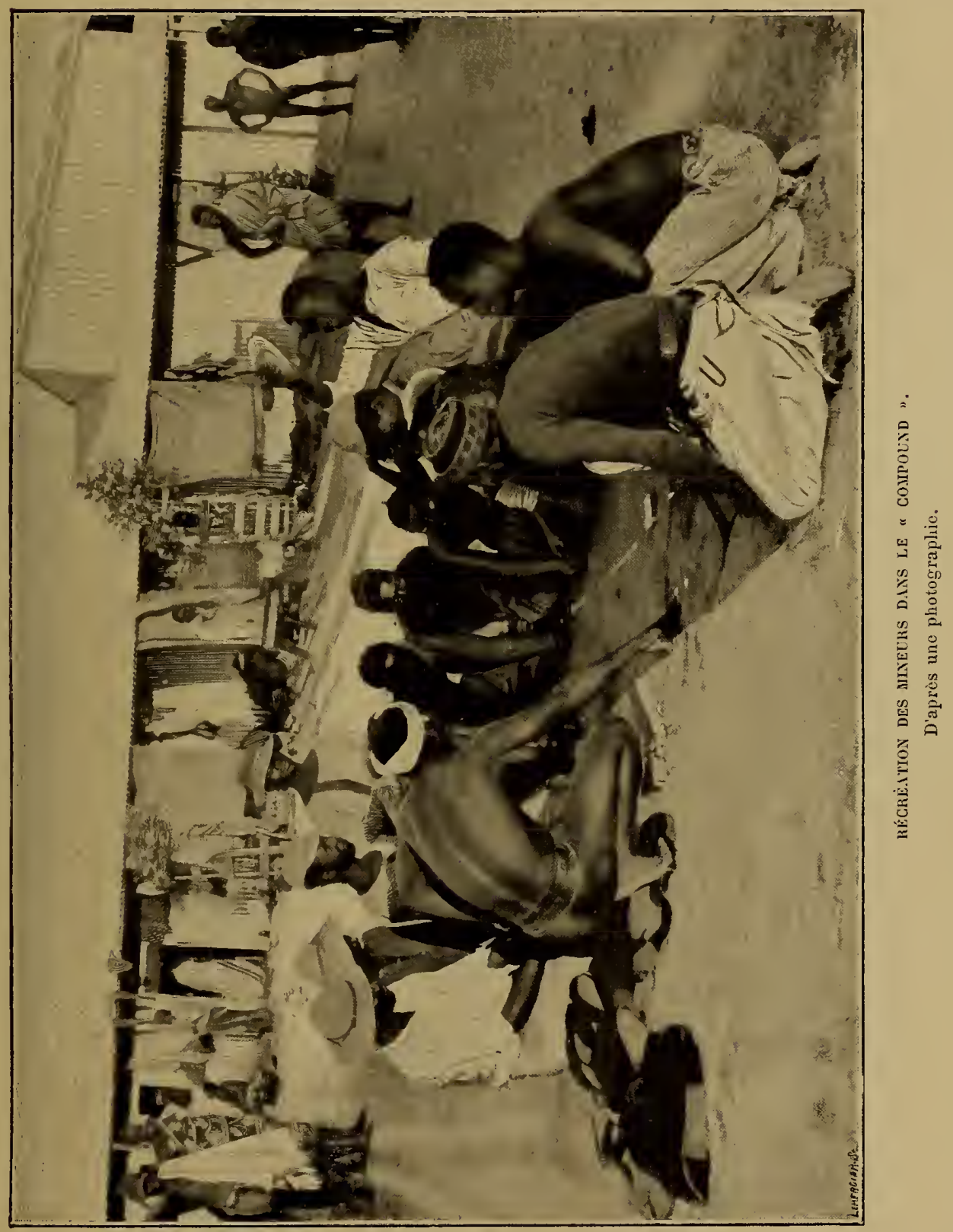



admirablement inslallé. Des missionnaires tiennent des écoles dans le compound.

Des Cafres, des ba-Souto, des Zoulous, des Béchuanas, des ma-Tébélé, des ma-Kalakia, elc., plus ou moins bien drapés dans des couvertures bariolées, font cuire leur repas, lavent leur linge, coupent le bois qui leur est fourni gratuitement par la Compagnie, fument, causent gaiement entre eux. Ce tableau ne manque pas de couleur locale.

Nous arrivons à l'un des puits de la mine. Nous sommes revêtus de costumes spéciaux et nous descendons rapidement dans les entrailles de la terre. Nous nous arrìtons à la dernière galerie (1200 pieds) qui est actuellement creusée dans le roc dur, pour arriver à l'entonnoir où se trouve le terrain diamantifère. Nous visitons ensuite les deux galeries paralkèles, de 960 et 1000 pieds de profondeur, où le terrain diamantifère a été atteint depuis longtemps. Il règne une grande activité dans ces galeries éclairées à l'électricité. La terre diamantifère est amenée par des wagonnets sur rails à un endroit d'où est elle remontée à la surface par une puissante machine, qui épuise l'eau en mème temps.

Nous respirons de nouveau l'air libre et après un bon bain, bien nécessaire, nous continuons notre visite.

Lorsque la terre bleue diamantifère a été retirée du sol, elle est exposće à ciel ouvert à l'action de l'atmosphère qui doit la rendre friable, en plus ou moins de temps. Récemment la Compagnie a été obligée de créer une nouvelle installation de "crushing machines ", machines à broyer, car une partie de la terre extraite restait irréductible à l'action de l'air et du soleil. Ces machines peuvent broyer jusqu’à 1500 tonnes en dix lıeures; la locomobile qui les actionne a une force de 1100 chevaur-vapeur.

Nous regardons ensuite fonctionner la " washing machine ", machine 
à laver, où la matière diamantifère est séparée de la terre ordinaire; puis vient le tour d'une autre machine le "pulsator " qui procède encore it un second triage plus minutieux.

Après ces opérations, ce qui reste de la matière diamantifère passe par les mains des " trieurs " proprement dits. Nous entrons dans une salle, où nous voyons travailler les employés qui sonl soumis ì une surveillance de tous les instants. Il se trie là des diamants dont la valeur monte journellement ì 250000 francs.

Une fois le triage terminé, les diamants sont envoyés chaque jour, sous escorte armée, au bureau principal; là, ils sont délivrés à des experts spéciaux.

Nous finissons cetle intéressante journée en nous reposant à Kennilworth, le village modèle que la De Beers Consolidated Mines Limited a fait construire pour ses employés blancs. Ce village est réellement digne d'admiration.

$$
*^{*} *
$$

16 avril. - Il nous est gracieusement accordé ce matin de visiter le bureau principal de la Compagnie, où nous sommes à même de suivre les diverses phases par lesquelles les diamants doivent passer, avant de parvenir à l'état parfait. Pour les nettoyer, ils sont bouillis dans une solution d'acide nitrique et sulfurique; ils sont assortis par rapport de grandeur, de pureté et de couleur.

La teinte des diamants est variable: elle est blanc pur, blauc opaque, vert, rose, bleu, jaune, brun et orange. Leur grosseur va depuis la dimension d'une tète d'épingle jusqu'au plus gros diamant trouvé, dont le poids brut élait de 428 1/2 karats. Une fois taillé, il pèse encore $2281 / 2$ larats; il a figuré à l'Exposition universelle de Paris en 1889. 
Les petits tas de diamants que nous avons sous les yeux et qur l'on assortit en notre présence, valent 1500000 franes. Un seul de ces diamants d'une belle couleur jaune que nous examinons de priss, est coté à plus de 13000 franes. La dernière opération consiste à répartir les diamauts par lots, qui sont expertisés. Ces lots se vendent it des agents qui habitent la localité, les représentants des principaux marchands de diamants de l'Europe.

La ville d'Anvers a la spécialité de la taille des diamants du Cap.

Kimberley, ville de 13 a 20000 habitants, renferme tout ce que réclame la vie normale. P., l'un des pionnicrs de ce pays, me raconte qu'il est arrivé en 1870 et qu'à l'emplacement de la ville actuelle, aucune maison n'était construite.

A midi, nous montons en chemin de fer; en dix-huit heures nous arrivons à Maféling, le terminus de la ligne. Pays d'herbe où paissent et s'engraissent de nombreux troupeaux de bœufs et de moutons.

Pendant ce trajet nous traversons la rivière Hart, l'un des affluents de l'Orange; nous entrons dans le Béchuanaland.

Nous nous éloignons de la civilisation; les huttes arrondies des villages indigènes deviennent de plus en plus fréquentes; les stations se réduisent à de simples cabanes en tôle, et les gens qui montent en voiture sont d'un aspect de plus en plus pittoresque.

$$
\text { *** }
$$

21 avril. - Maféking, avec les fermes environnantes, possède 2000 à 3000 habitants. Point de départ des caravanes pour l'intérieur. Cachet particulier, soit des habitants, soit de l'endroit lui-mème qui donne l'impression d'un vaste campement, avec un fort mouvement de chariots attelés de longues files de bœufs. Chez les blancs, figures 
énergiques et bronzées qui montrent que le "struggle for life " n'est pas un vain mot dans ce pays.

A l'entréc de Maféling se détachent sur la prairie les tentes qu'habitent pour le moment 150 cavaliers qui font partie de la petite arméc coloniale du Béchuanaland. Très caractéristique, cet. uniforme clair; le feutre brun, entouré de blanc, crânement redressé sur le côté. Troupe d'élite, toujours prète à l'action
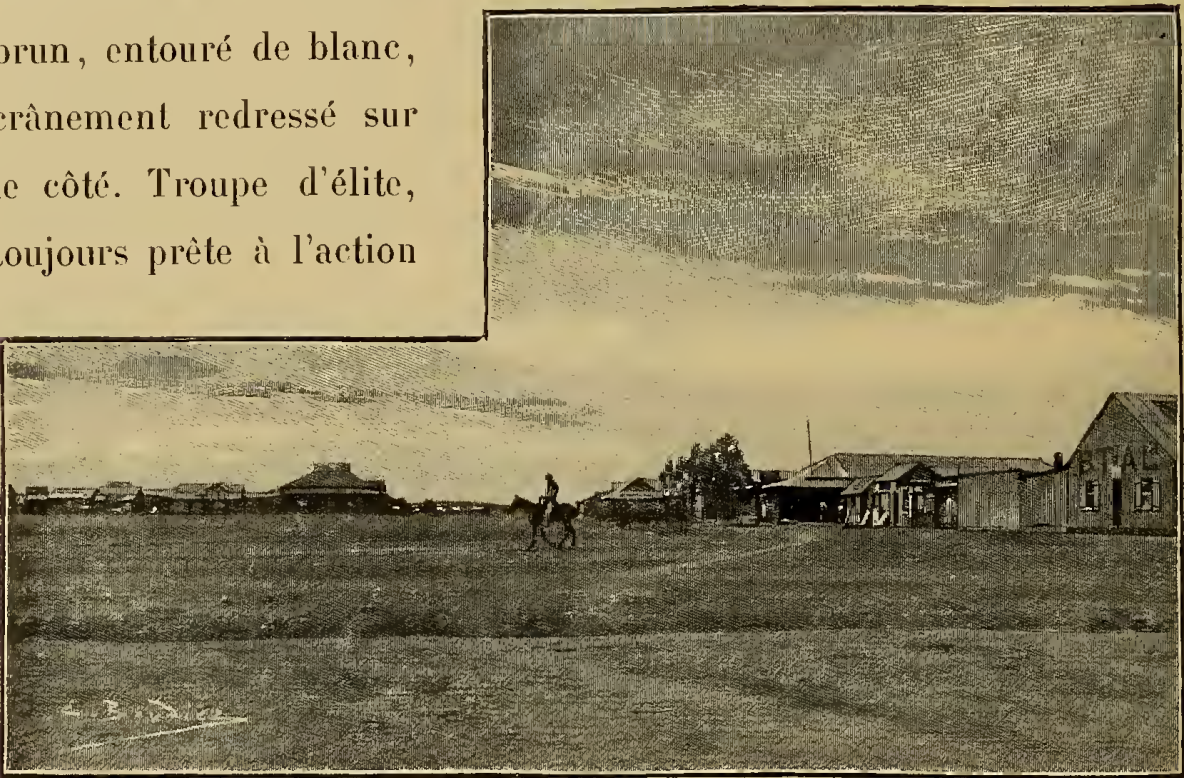

A MAFÉKING, NOTRE POINT DE DÉPART.

Dessin de Boudier. Daprès une plotographie de l'auteur.

et qui atteint un degré d'endurance remarquable. L'un des officiers m'a raconté que le lieutenant P., qui l'année dernière, pendant la guerre contre les ma-Tébélé avait le maniement d'une mitrailleuse Maxim, reçut un coup de feu au bras droit; malgré cette terrible blessure qui a entraîné plus tard l'amputation, il a fait un trajet i cheval durant je ne sais plus combien de jours avant de pouvoir être pansé!

Que d'occupations ces derniers temps! Il est difficile de se rendle compte des préparatifs que comporte une expédition du genre de la 
nòtre. Nous avons comme matériel quatorze chevaux ou poneys uniquement destinés à la selle; trente-quatre boufs de trait et dix-sept ànes de bât. Plısieurs chiens, en particulier une superbe paire de bouledogues pour la garde.

Un grand wagon ou chariot à quatre roues, lequel chargé, pèse près de 7000 livres; deux wagons à deux roues (scotch cart) dont l'ensemble forme une charge de כ000 livres. L'un de ces derniers sous la conduite du capitaine Gibbons, a déjà pris les devants.

La journée d'aujourd'hui a été consacrée au paquetage des chariots et à l'organisation du départ; tout est terminé, nous sommes prêts à entrer en campagne; nous partons demain.

Malgré les fatigues de la journée, sur la demande de l'un des habitants, Reid a pris ce soir au sextant neuf observations, cinq sur Sirius 0 . et quatre sur Arcturus E., afin de déterminer une fois de plus la position de Maféking. 



\section{CHEZ LES BÉCHUANAS}

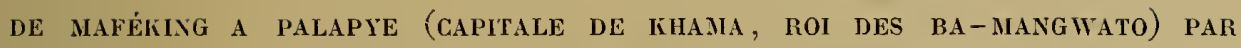
KANYÉ (TRIBU DES BA-RNAKETSÉ), NOLÉPOLOLÉ (TRIBU DES BA-KLÉNA) ET LA ( PISTE DE LA SOIF ), PRÈS DU DÉSERT DE KALAHARI

T E 92 arril nous donnons la dernière main aux préparatifs de départ. Les bœufs sont attelés et essayés; les chevaux et les ânes arrivent au point de rassemblement. Nos hommes sont i leurs postes respectifs. Pour le moment, le personnel se compose d'Adam, de Jacobus, conducteurs en chef (drivers) des chariots; ils sont armés de leurs immenses fouets (le manche a $3^{\mathrm{m}}, 50$ et la lanière plus de 6 mètres de longueur); ils ont la responsabilité des attelages.

Ils sont secondés par deux aides (leaders), Franz et son camarade. Une de leurs principales fonctions est de se mettre à la tête de la première paire de boufs dans les passages difficiles.

Enfin, George et Pony ont la charge des chevaux et des ânes; ce dernier doit en outre, lorsqu'il en aura le temps, nous aider pour faire la cuisine et laver le linge.

En ce qui nous concerne, outre les mille occupations que cela 
entraìne, nous devrons à l'occasion ètre prèts à mettre la main à tout.

A trois heures le signal du départ est donné.

Voici notre ordre de marche : le grand wagon, avec ses huit paires de boufs, forme à lui seul une colonne de 22 mètres; à la suite le petit chariot attelé de quatre paires de boufs; puis vient le troupeau, pour le moment plus ou moins bien discipliné, des chevaux et des ànes, ainsi que des boufs de renfort. Les chiens gambadent à droite et à gauche de la colonne.

Ce qui suit prouvera que, dès le début, les difficultés et les complications d'ordres divers ne nous ont pas manqué pour tenir cet ensemble dans la bonne ligne. Les difficultés, complications et enunis se sont toujours répétés sous des formes diverses, dont, certes, il est bien difficile de se rendre compte au milieu des facilités qu'offre la vie civilisée.

La grande affaire est d'aller toujours de l'avant, sans se laisser rebuter, quoi qu'il arrive; puis de savoir tirer le meilleur parti des circonstances.

Reid, qui a une longue expérience de l'Ifrique, nous est d'une grande utilité.

Enfin, nous sommes en marche; la direction suivie est le nord.

I la tombée de la nuit, le wagon de tête s'embourbe en traversant une plaine marécageuse. Nous doublons les attelages; malgré tous les efforts, impossible de l'en sortir; force nous est d'établir notre premier campement pour la nuit à l'endroit où nous sommes śchoués. Il faut aller dans l'obscurité couper du bois aux buissons voisins at préparer le repas du soir, dételer les boufs, attacher les chevaux autour des wagons, leur distribuer leurs rations de maïs, cte. 
Pendant cette marche, le second " leader ", ainsi que l'un des boufs de rechange disparaissent; nous ne les avons jamais revus.

$$
\text { *** } *
$$

23 avril. - Levés à l'aube; nous voyous les boufs qui paissent déjà. Comme hier soir el les jours qui vont suivre, il faut faire du

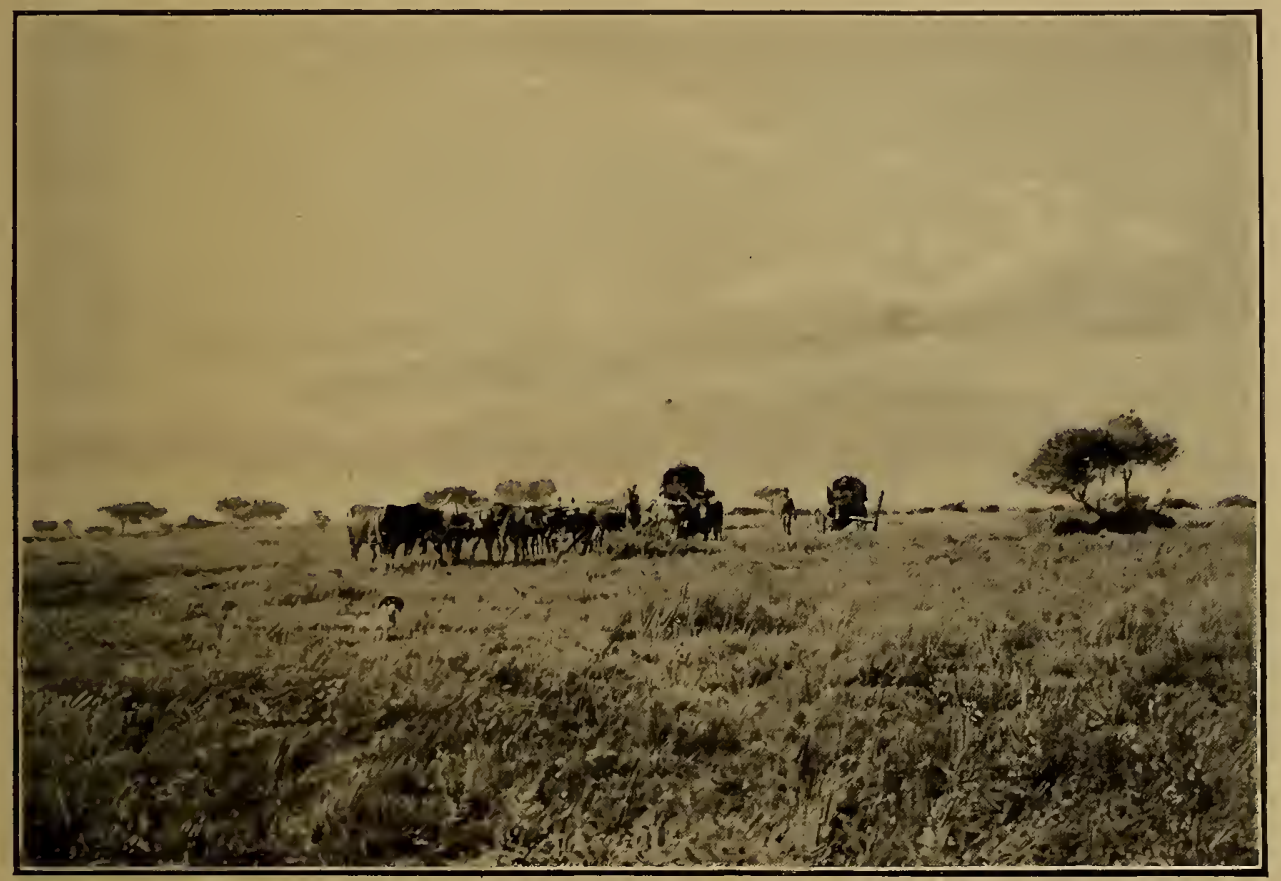

FIN D'UN " TIEEK "

Photographie de l'auteur.

fourrage pour les chevaux, couper du bois pour cuire notre repas, puis mettre tout en ordre au départ. Bientôt, pelle en main, il faut dégager une roue enlizée. Les attelages sont reposés et après un vigoureux effort, nous nous remettons en route. Nous longeons la frontière ouest du Transvaal.

A dix heures et demie, halte! fin du premier " trek ", durée de marche, pour laisser paître nos animaux jusqu'à trois heures 
de l'après-midi, heure ì laquelle nous attelons pour fournir le second " trek " qui nous mène à Ramatlaban, limite de la colonie el du protectorat du Béchuanaland. La pièce de résistance de notre repas du soir se compose de deux canards, tués et plumés en route. Le troisième el dernier " trek" de la journée nous mène jusqu'ì dix heures du soir.

$$
* * *
$$

24 arril. - Il a fait assez froid la nuit dernière; rosée abondante. Nous nous réchauffons en vaquant à nos différentes occupations. Pendant le premier " trek ", la flèche du wagon de tête se casse net au moment où le chariot passait sur une énorme pierre, car pierres et ornières sont les deux éléments dont est formée la " route " que nous suivons.

Nous réparons le dégàt, tant bien que mal, avec une grosse chaìne. Comme hier, nous traversons un pays d'herbes, légèrement ondulé, planté de mimosas et qui nous donne l'impression d'un parc immense. Çà et là, se montrent faisans et perdrix; nous avons vu des sleinbuck (Nanotragus tragulus).

$$
*^{*} *
$$

25 avril. - Deux chevaux et deux ânes se sont échappés la nuit dernière; ils sont heureusement ramenés au campement. Dure journée, trois " trelis "; le dernier nous a menés jusqu'ì dix heures et demie du soir. Ces marches de nuit sont favorables aux attelages, mais difficiles et fatigantes pour nous, car arrivés à l'étape, bien du temps s'écoule arant que tout soit en ordre el que nous puissions aller nous reposer. De plus, des chevaux et des ânes restent en arrière pour brouter et s'égarent dans les taillis. 


$$
*^{*} *
$$

26 avril. - Trois chevaux et six ànes manquent à l'appol ec matin; George et Pony sont envoyés à leur recherche. Au bout de quelques heures, ils nous rejoignent; deux ânes sont définitivement perdus, ainsi que l'un des bouledogues

Dans le lointain, nous avons en vuc les eollines boisées que nous devons tra-

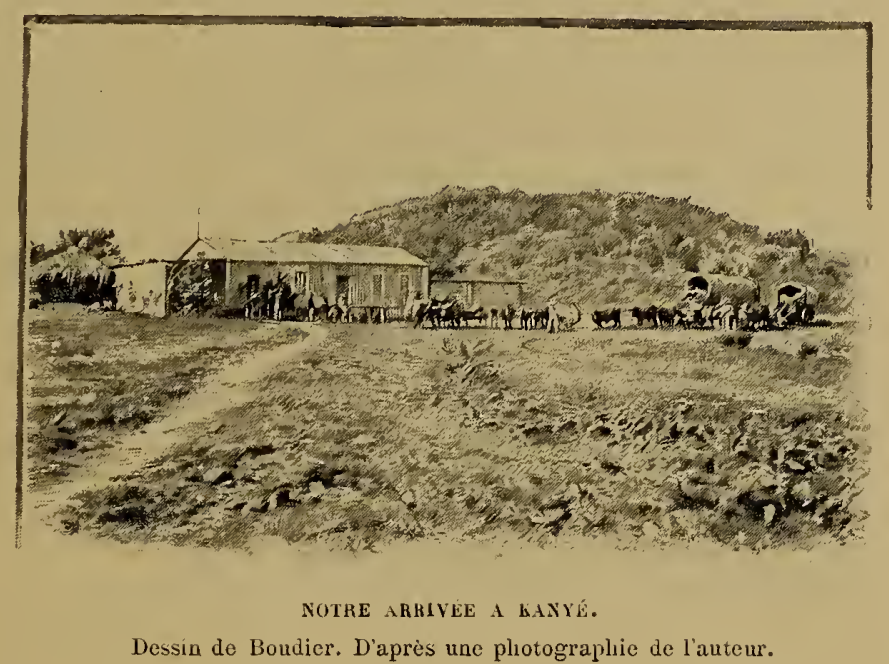
ver'ser pour parvenir demain à lianyé. Nous sommes fortement secoués par les pierres de la route, qui mettent l'intérieur des wagons en désordre.

$$
\text { *** }
$$

27 avril. - Arrivés dans la matincie à Kianyé, dont les huttes rondes de ville indigène, construites en terre rouge avec toits en chaume, sont parsemées au pied et au sommet de la colline. Grande animation; nombreux chariots employés par les trafiquants du pays. Accompagnés par l'un des rares Europécns qui habitent Kanyé, nous montons à la demeure du chef Bathoin pour lui demander l'autorisation de prendre à notre service deux de ses sujets. Il est malheureusement absent pour un certain temps. La demeure du 
chef, situće devant la " place des assemblées ", diffëre de celles de ses vassaux. Elle ressemble à un cottage; une véranda rudimentaire borde une de ses faces. C'est là que nous saluons la princesse, drapée dans des couvertures aux conleurs voyantes et la tête entourcée d'un turban rouge. Elle ne peut répondre ì notre requête sans l'autorisation de son époux. Nous pénétrons dans la pièce d'honneur, où je vois sur une étagère une Bible traduite dans la langue du pays: Bathoin est un chrétien pratiquant.

Sur ma demande, la princesse consent à se laisser photographier, mais elle veut être vètue de ses plus beaux atours. Je devrai repasser plus tard. I l'heure dite, je trouve la princesse affubléc d'une robe de soie crème taillée à l'européenne el d'une coiffure bleue surmontéc par une énorme rose jaune! Combien je regrette le pittoresque costume de tout ì l'heure! Sa belle-mère, en bleu, et sa belle-sœur, en rouge, veulent aussi faire partie du groupe. Ensuite l'exécuteur des hautes-œuvres me demande de le photographicr, puis d'autres. Je crois que toutes mes plaques y auraient passé.

Nous visitons la nouvelle église que le missionnaire Rév. Good fait construire près de la demeure du chef.

Les huttes appartenant ì la mème famille sont entourées de hautes clòtures de branchages; les ricins croissent ì l'état sauvage.

Grande fertilité du sol; dans un jardin nous voyons des graines de légumes importées d'Europe donner d'excellents produits.

Kanyé est la capitale de la tribu des ba-Rnaketsé; son chef Bathoin est indépendant; la tribu a de 7 à 10000 habitants qui s'adonnent à l'élevage du bétail, au commerce des grains, des peaux, etc. Ici nous apprenons que le capitaine Gibbons, qui nous précède de quelques jours avee un petit wagon attelé de huit boufs et de deux chevaux de selle, a 


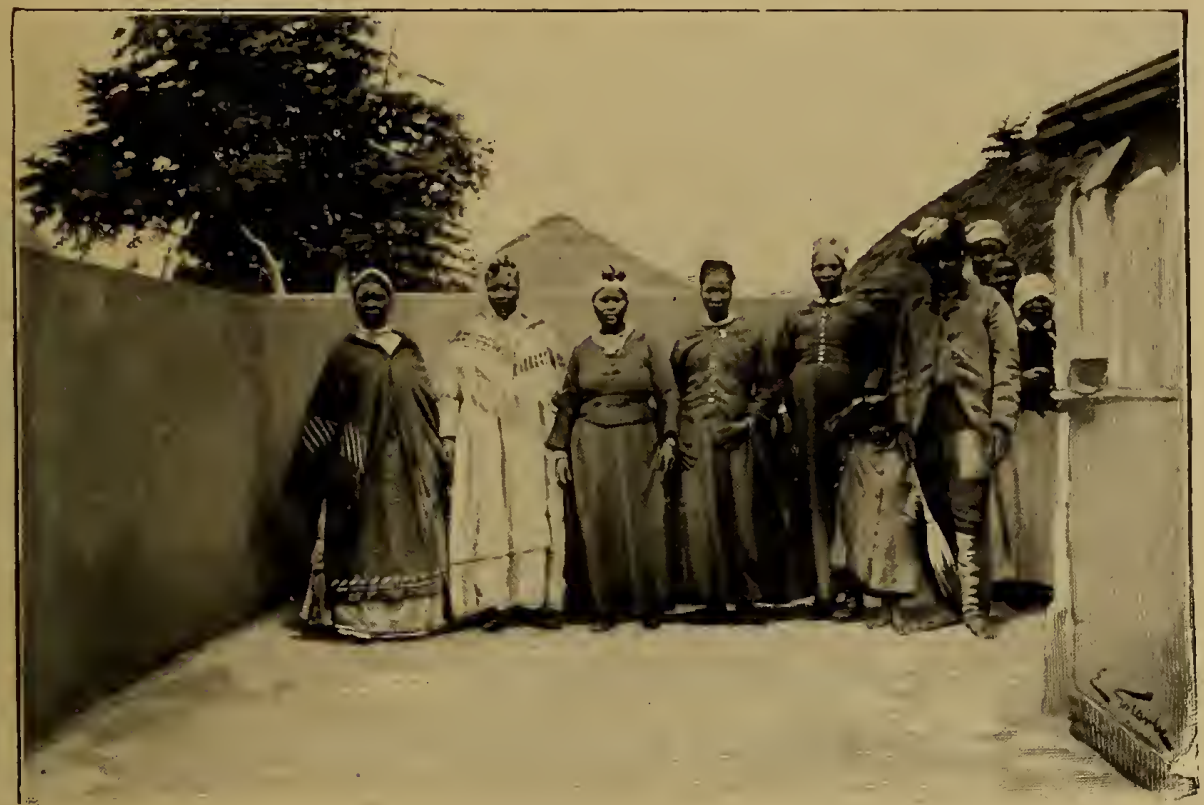

LES PRINCESSES DE KAXYKE.

Dessin de Gotorbe. D’après une plotographie de l'auteur.

eu un accident; son véhicule a versé ; il s'en est tiré avec un doigt écrasé.

Nous partons dans l'après-midi; comme nous sommes sans guides, nous campons pour la nuit près du village de Motschuaneng; les chacals aboient dans les environs.

$$
* * *
$$

28 avril. - Pays ravissant; nous traversons les ramifications des montagnes Makarupa. Des chevaux égarés ne nous sont revenus qu'au milieu de la journée.

En route, nous causions tranquillement, Pirie et moi, installés sur le grand chariot, lorsque nous sommes brusquement projetés à terre. Nous nous relevons sans une égratignure, mais nous voyons avec stupeur notre " arche de Noé " couchée sur le flanc droit: le "driver" n'avait pas su éviter une forte dépression de terrain. Il n'y a pas à 
hésiter : il faut nous mettre à l'œuvre et malgré un soleil cuisant, décharger une partie du contenu. Nous avons beaucoup de peine à relever celle énorme machine qui, heureusement, n'a pas subi dans sa chute d'avarie sérieuse. Au moins deux heures perdues!

$$
\text { *** }
$$

29 arril. - Comme hier, pays pittoresque, montagneux et boisé; nous avons eu ce matin, de bonne heure, la visite de natifs qui nous apportent dans une outre du lait caillé. Cette contrée est parsemée de "cattle posts " où, pendant la saison favorable, les propriétaires envoient leurs bestiaux sous la garde d'esclaves; ces derniers rappellent les serfs russes de l'ancien régime. Malgré la grande abondance de bétail, il est impossible d'obtenir de ces gens du lait frais: ils le considèrent comme malsain. Tout leur lait est caillé; cette opération se fait naturellement car, par principe, ils ne nettoient pas les ustensiles où ils déposent ledit liquide. Nous rencontrons des indigènes montés sur des taureaux; une lanière passée dans les naseaux leur sert de bride; ils les font marcher grand train.

Un vaste nuage de sauterelles passe it notre droite; nous l'avons pris au premier abord pour une épaisse fumée. Enfin, nous avons en vue la pretite ville indigène de Mashupa (Gattin), où nous devons faire une halte; nous n'avons plus qu'une plaine à traverser pour l'atteindre et gagner notre rejas bien mérité. Elle est presque franchie, lorsque subitement nous sommes arrètés de nouveau: cette fois nous sommes ensablés! Les attelages sont doublés pour nous tirer de ce mauvais pas, mais rien n'y fait. Il nous faut dételer, laisser nos bètes brouter et se reposer. Entourés de nombreux indigines curieux et sous un ciel brûlant, nous allumons notre feu, nous préparons notre déjeuner. Puis nous déchargeons l'arrière du wagon, le remeltons sur roues, le 


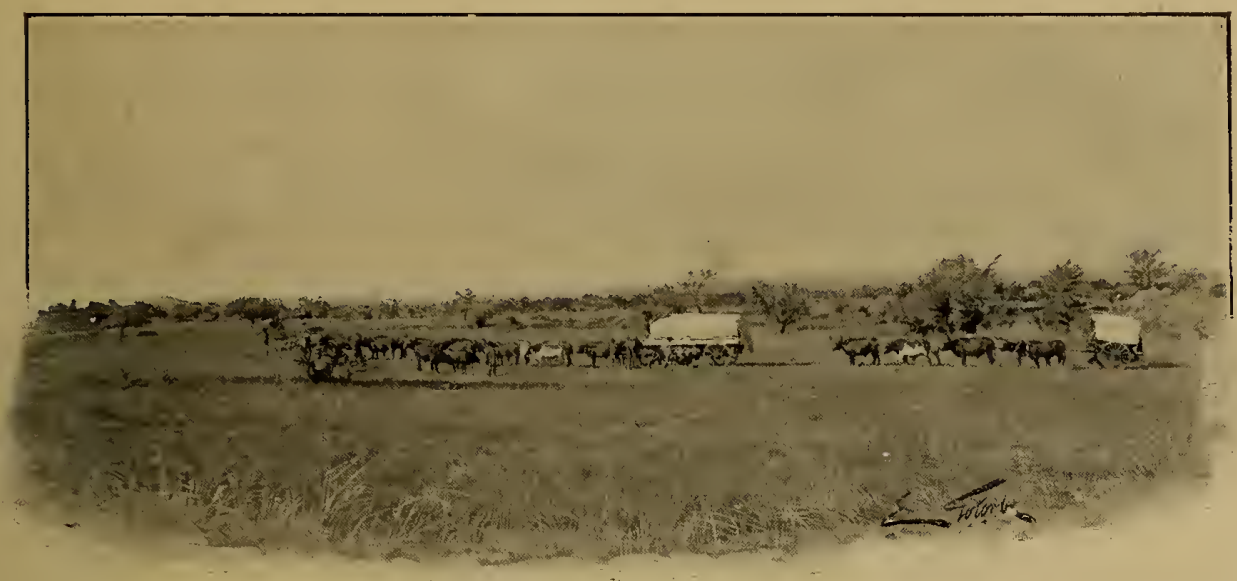

NOS CHA HIOTS.

Dessin de Gotorbe. D'après une photographie de l'auteur.

rechargeons et nous partons, non sans avoir dit son fait à Idam, le conducteur.... Ce qui ne l'empèche pas de nous ensabler une seconde fois dans la soiréc, en passant le lit d'une rivière desséchée.

$$
\text { *** }
$$

30 avril. - Adam s'est enfui pendant la nuit; nous élevons Jacobus dont nous sommes contents, à la dignité de conducteur du grand wagon. Reid, qui n'en est pas à son coup d'essai, prend la conduite de l'autre wagon, puis en route. Nous voulons rattraper le temps perdu et faisons sans accroc trois "treks" dans la journée, augmentée d'une forte marche de nuit. Nous ne regrettons pas Adam, qui n'était pas à la hauteur de sa tâche et qui, se croyant un personnage indispensable, prenait une attitude intolérable.

$$
\text { *** }
$$

$1^{\text {er }}$ mai. - La contréc est plus ouverte; nous marchons dans une longue vallée. Au milieu de la journée nous arrivons à Molépololé, 
situé au sommet d'unr colline, chef-lieu de la tribu des ba-liuéna, (des crocodiles) qui a pour chef Sébélé. Nous avons eu une audience cette après-midi sur la "place des délibérations ".

Au moment de notre arrivée, Son Altesse, entourée d'une vingtaine de ses sujets, se prélasse sur une peau d'antilope. Après les présentations d'usage, nous lui demandons l'autorisation de prendre à notre service quelques-uns de ses sujets; tout fail prévoir une réponse favorable. Son Altesse n'a pas la bonne réputation de son voisin de Kanyé; cependant il n’a fait aucune objection ì ce que je le photographie, ainsi que son épouse; il a daigné même s’intéresser à l'appareil dont je lui ai expliqué tant bien que mal le maniement.

Nous laisserons souffler gens et bêtes pendant quarante-huit heures: nous partirons après-demain matin pour Palapje.

Molépololé a environ 6000 habitants; commerce de grains, de bétail, de peaux d'animaux sauvages.

$$
\text { *** }
$$

3 mai. - Nous quittons Molípololé après avoir décidé de suivre, pour atteindre Palapye, une piste qui n'est pas ordinairement parcourue; elle est appelée la "Thirst route ", route de la soif, car elle n'est pas loin du désert de Kalahari et l'eau y est rare.

Sébélé, chef de la tribu des ba-líuéna, a donné l'ordre à trois de ses sujets, Johann, Jeromea et Jim, de nous accompagner jusqu’à Palapye ; la direction prise est le nord-est. Halte de plusieurs heures à lílippan, village où l'un des frères de Sébélé qui lui fait opposition, s'est réfugié avec ses partisans. Nous recevons la visite de nombreux habitants, hommes, femmes et enfants, qui observent tous nos mouvements. Les détails de la cuisine semblent surtout intéresser les dames de l'endroit, tandis que leurs époux montrent une prédilection particulière pour les 
armes à feu. Les costumes sont en général assez simples; ils se composent de cotonnades et de peaux de bètes sauvages; comme ornements des bracelets aux bras et aux chevilles; pour ces bracelets, le bleu est préféré. Une jeune fille, dont la tête a été entièrement rasée sauf dans la partie supérieure, porte le reste de sa toison crêpue imprégné de graisse.

$$
\text { *** }
$$

4 mai. - Depuis hier après midi, nous traversons un pays boisé et légèrement ondulé. Les attelages enfoncent dans le sable; ils ont peine à avancer; nous regrettons les gras pâturages des jours précédents. Marche de nuit assez dure jusqu'ì onze heures et demie du soir.

$$
\text { ** } *
$$

5 mai. - Nous laissons reposer nos bêtes; nous n'attelons que sur le tard. La proximité du désert de Kalahari se fait sentir et les bœufs continuent à peiner dans le sable. Nous décidons de repartir demain matin à deux heures et demie; nous organisons, ce que nous ferons souvent dans la suite, un service de garde, afin de réveiller en temps voulu gens et animaux.

La ronde entre une et deux heures m'est échue : effet pittoresque du campement éclairé par la lune. Les hommes fatigués reposent près du feu, dans des postures diverses, les chevaux sommeillent, attachés autour des wagons; les bœufs et les ânes paissent dans les environs.

$$
\text { *** }
$$

6 mai. - Peu après le déjeuner, Reid tue d'un coup de bâton un petit serpent à tête plate. Dans le courant de la journée, nous partons 
à cheval, Reid et moi, en reconnaissance pour le puits de Boaténama, qui ne doit pas être très éloigné. Nous rencontrons trois chasseurs indigènes qui ne nous donnent que de vagues renseignements sur le puits en question; c'est en général le cas dans cette contrée, où l'eau est précieuse. Nous finissons par découvrir le puits, ombragé par des mimosas; nous abreuvons les bêtes par escouades; elles ont été privées d'eau pendant vingt-huit heures.

Nous restons deux jours au puits de Boaténama pour refaire gens et attelages; une antilope tuée récemment est un renfort apprécié pour la cuisine. Grande différence dans la température; chaud le jour et froid la nuit.

Ce puits, très ancien, a été réparé par Sćbélé. Il est composé de grosses pierres simplement posées les unes sur les autres; il a environ deux mètres de diamètre sur huit de profondeur.

$$
\text { *** }
$$

9 mai. - Nous traversons une jolie contrée boisée, peuplée de faisans et de perdrix qui forment le menu de nos repas. Elle est parsemée de fourmilières coniques énormes; nous en mesurons une de trois mètres de hauteur et nous arrivons à l'étang de Selynia, où nous trouvons de l'eau bourbeuse, dont il faut bien se contenter. Nous découvrons sur le sable l'empreinte de trois girafes. Puis vient une grande plaine couverte d'herbes jaumies où nous jouissons d'un superbe lever de lune sans crépuscule. Nous apercevons dans le lointain une longue traìnée de fumée; la prairie est en feu.

$$
\text { ** * }
$$

10 mai. - L'eau est rationnée; pas une goutte du précieux liquide ne doil être perdue. $\Lambda$ la tombée de la nuit, les chevaux prennent subi- 
tement le grand trot; ils nous conduisent à une mare que l'instinct de ces pauvres animaux, qui avaient été de nouveau vingt-quatre heures sans cau, leur avait fait pressentir.

L'un de nos chiens, Tobbie, a une prédilcetion marquée pour les chacals; il en a tué trois en deux nuits.

Nous nous sommes aperçus depuis longtemps que les meilleures cartes géographiques de ce pays ne sont qu'ébauchées; elles renferment beaucoup d'inexactitudes.

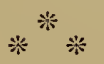

11 mai. - Changement de tableau complet; nous voyageons dans ull pays montagneux, boisé, pittoresque. Avant le déjeuner nous grimpons, en reconnaissance, au sommet d'une colline composée d'énormes blocs de rochers rougeâtres cachés dans la verdure; nous découvrons de là d'autres rangées de collines élevées, les Mangwato Hills. Le silence du matin n'est rompu que par le rappel des perdrix et

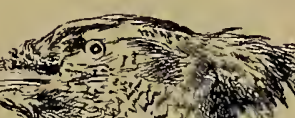
le cri rauque des babouins.

Dans la journée, Reid tue une outarde de vingt livres qui nous procure pour ce soir-là, un excellent souper au campement de Ramanéna d'heureuse mémoire, où nous trouvons de l'eau bourbeuse il est vrai, mais en abondance et où des bergers nous apportent du miel et du laitage.

$$
* * *
$$

12 mai. - Comme hier, ravissante contrée bien boisće, brise rafraîchissante; nous traversons le lit de la rivière Mahalapsi et nous en usons et abusons avec délices; c'est la meilleure que nous 
ayons eue depuis longtemps. Plıs tard, nous traversons aussi la rivière Milti actuellement à sec.

$$
\text { *** }
$$

13 mai. - Nous avons opéré notre jonction avec le capitaine Saint-Hill Gibbons, à trente kilomètres avant d'atteindre Palapye.

$$
*^{*} *
$$

14 mai. - Arrivés aujourd'hui à Palapye, trois semaines après notre départ de Maféking.

$$
\text { *** }
$$

17 mai. - Pour donner du repos à notre caravane, nous sommes restés quelques jours à Palapye ou Palapchwé, la capitale de Khama, le roi de la tribu des ba-Mangwato. Nous en profitons pour changer une partie de notre personnel qui, en raison de ses idiomes, ne nous serait pas utile plus au nord. Les wagons et le matériel sont réparés; nous nous sommes fournis d'un complément de provisions et les démarches nécessaires ont été faites pour aller de l'avant.

Palapye, 25000 h., capitale de la tribu des ba-Mangwato, est située dans une contrée fertile, au pied des collines de Choping (Choping Hills); ses habitants font le commerce des grains et des peaux.

Le puissant chef Khama a été élevé par les missionnaires, successeurs de Robcrt Moffat et de Livingstone qui, comme chacun le sait, ont évangélisé pendant de longues années dans le Béchuanaland.

Khama est un chrétien convaincu et pratiquant. Il exerce une forte et bienfaisante influence sur son peuple dont il est chéri; un grand nombre de ses sujets ont embrassé la foi chrétienne. Au dire de tous, blancs et noirs, Khama est le plus sage, le plus éclairé des 
princes africains; la meilleure preuve en est qu'il ne permet l'introduction d'aucune boisson alcoolique dans son royaume ${ }^{4}$.

lihama nous a fait une visite à notre campement le matin mème de notre arrivée, visite que nous lui avons rendue quelques heures après.

Nous avons trouvé le roi au lékihotla, assemblée délibérative qui, ici, se réunit dans un grand enclos entouré de branchages de plusieurs centaines de mètres de circonférence, où il rend tous les matins la justice.

Khama, entouré d'une trentaine de ses sujets, vient à notre rencontre. Il nous fait asseoir sous un arbre, puis avec les formes d'usage, com-

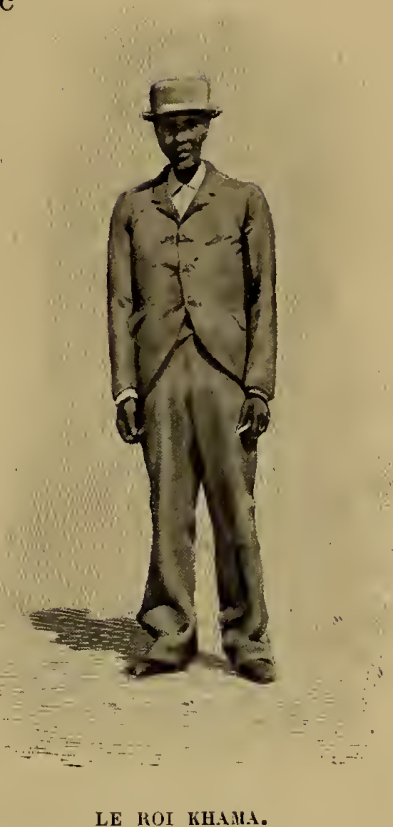

Dessin de Gotorbe. D'après une photographie de l'auteur. mence l'entretien par l'intermédiaire d'un interprète. Nous lui demandons l'autorisation de traverser son territoire et de prendre un certain nombre de ses sujets à notre service. Ces deux demandes sont accordées séance tenante.

lihama est vêtu d'un costume européen; il a dépassé cinquante ans. Expression ouverte et bienveillante; fin et distingué dans toute sa manière d'être. La conversation se prolonge pendant une vingtaine de minutes; puis lorsque nous prenons congé, il nous serre la main à chacun et nous retournons au campement, en suivant les grandes routes de la capitale, bordées de huttes en terre coniques, aux toits de chaume, qui toutes sont protégées par de hautes clôtures. Çà et là,

1. Le roi lihama est venu en Europe dans le courant de l'année 1895, pour exposer cette queslion à la reine Victoria et lui demander son autorisation ainsi que son appui, afin qu'aucune espèce d'alcool ne puisse pénétrer dans son pays. Il a obtenu gain de cause. Cet exemple suffit pour montrer les transformations que peut opérer le christianisme. 
des enfants rieurs jouent par groupes. Des mères de famille qui se suivent à la file, gracieusement enveloppées dans leurs cotonnades, et dont plusieurs portent leur dernier-né sur le dos, comme dans un sac, vont, l'amphore sur la tête, faire leur provision d'eau.

Nous avons le plaisir de rencontrer ici les missionnaires M. et Mme Boiteux, de Neuchâtel, et M. Davit, des Vallées vaudoises du Piémont, récemment arrivés; ils se rendent au Zambèze.

Nous avons aussi l'avantage de faire la connaissance de M. J.-S. Moffat, beau-frère de Livingstone et fils du célèbre savant et missionnaire liobert Moffat, qui a composé l'écriture du peuple Béchuana et qui a traduit la Bible dans leur langue. C'est lui, en outre, qui leur a appris à utiliser les ressources que leur offre le pays, au point de vue de l'agriculture, à capter les sources et à irriguer. De tous temps, les Béchuanas ont été riches en bœufs et vaches, moutons et chèvres. lls se rassemblent auprès de leurs chefs dans les villages, où ils ont leurs champs et leurs jardins. Au delà, existent de vastes pâturages où paissent les bestiaux; plus loin encore, sur les confins du Kalahari ou dans l'intérieur de celui-là, des stations de chasse.

Le Béchuanaland est à l'heure qu'il est entièrement soumis à l'influence politique anglaise; il se divise en "Crown Colony of British Bechuanaland ", qui n'a pas loin de cent mille kilomètres carrés de surface, puis au nord de ce dernier en "Bechuana Protectorate ", dont la superficie excède six cent mille kilomètres carrés.

Les tribus les plus importantes qui vivent sous l'égide du Protectorat, toutes indépendantes les unes des autres, sont les ba-Mangwato (chef Kíhama), les ba-Kalta (chef Lenchwé), les ba-Kúnéna (chef Sébélé), les ba-Rnaketsé (chef Bathoin) et les ba-Malété (chef Ikaneng).

Khama, à la tête de sa tribu des ba-Mangwato, est, parmi ces chefs, de beaucoup le plus influent et le plus important. 
D'après l' "Official Ilandbook " d'où je tire ces détails, suivant le recensement de 1891, la population de la colonie du British Bechuanaland ne compte que 60333 habitants, moins de deux habitants par kilomètre carré!

Quant à la population du Protectorat qui n'est pas connue, car

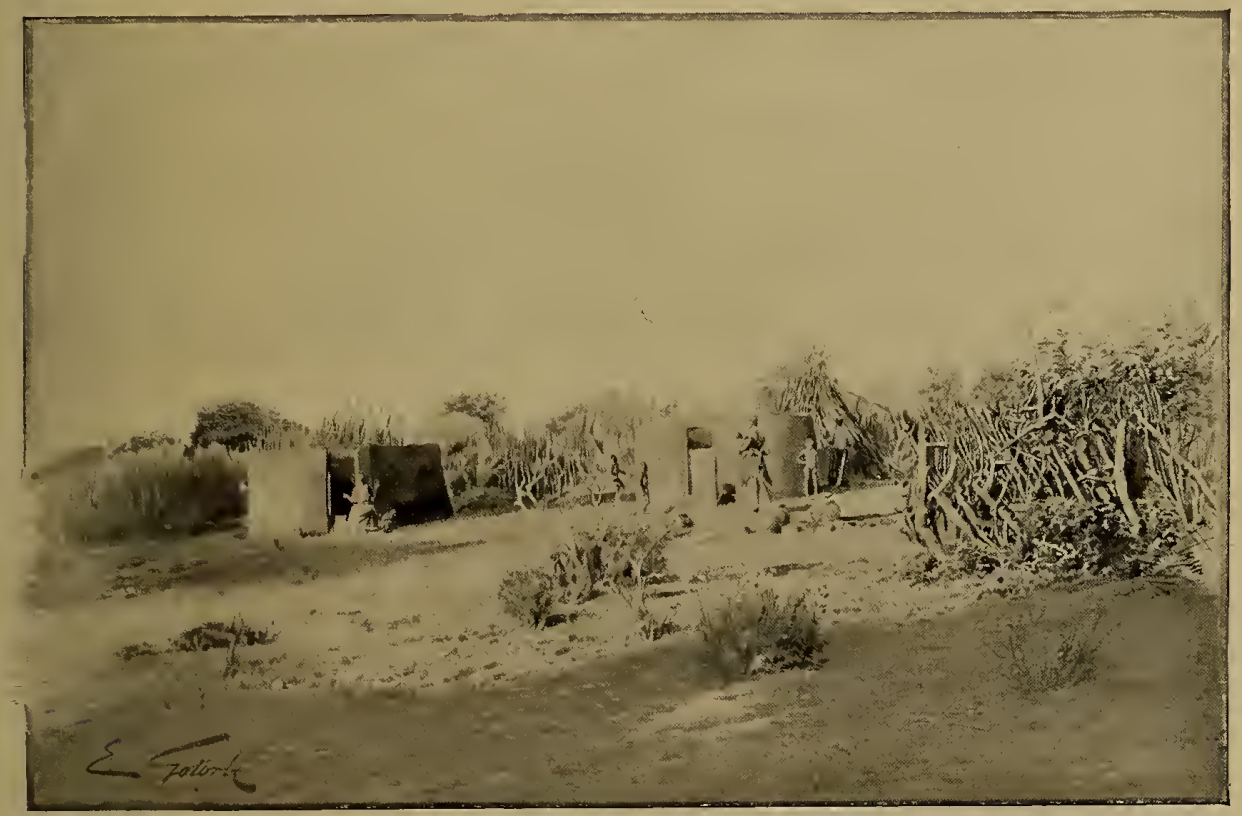

FEMMES CONSTRCISANT DES IIUTTES A PALAPYe.

Dessin de Gotorbe. D'après une photographie de l'auteur.

à coup sûr elle n'a jamais été recensée, elle doit, proportionnellement avec son territoire six fois plus considérable, être encore plus clairsemée.

Actuellement, ces immenses contrées s'organisent peu à peu sans secousses, grâce au système de colonisation anglais, qui est pratique, plein de bon sens et qui sait s'adapter à tous les milieux.

Avant de nous remettre en route, voici la description sommaire de notre wagon, la maison ambulante, où nous allons rentrer. Ses mesures approximatives sont les suivantes : non attelé, six mètres de 
longueur, soit vingt-deux mètres lorsqu'il est précédé de ses huit paires de bœufs, sur deux mètres de largeur et trois de hauteur. Sa caisse en bois repose directement sur les essieux, elle est surmontée d'arceaux couverts d'une triple enveloppe de toile. Sur le devant, une caisse, dont j'ai la clef et dont je suis responsable, renferme les provisions de ménage que nous tenons à avoir sous la main. La caisse nous permet de monter à la chambre à coucher que nous partageons Reid et moi. Cette chambre a deux mètres de longueur sur un mètre soixante-quinze de largeur et quatre-vingt-quinze centimètres de hauteur, ce qui fait que nous ne pouvons y entrer qu'en rampant. Un large cadre de bois traversé de lanières de cuir, la recouvre; nous possédons chacun un " matelas " de liège et quelques couvertures.

De chaque côté, deux râteliers où sont disposées les armes à feu et les ceintures à cartouches; de larges poches de toile renferment les objets de toilette, cartes, lunettes d'approche, etc., sans oublier les nécessaires de couture qui sont très utiles dans un voyage du genre du nôtre. En bas, bagages et provisions. Autour du wagon, extérieurement et au-dessous, sont placés des caisses à outils et des récipients pour l'eau. En outre, la batterie de cuisine est suspendue à droite et à gauche, toujours prête pour le feu du campement. Une large peau non tannée, assujettie au train, contient les haches, pelles, treuils et ustensiles divers. A l'arrière pendent les musettes, où les chevaux reçoivent trois fois le jour leur ration de maïs.

Nous avons reçu le télégramme attendu du Cap; il nous donne l'heure du méridien de Greenwich, ce qui permet de remettre les chronomètres au point.

Tout est prêt et nous partons demain, 18 mai, pour le Zambèze, où nous espérons arriver dans six ou sept semaines. Direction suivie : nord-ouest. Le personnel se compose actuellement de treize hommes; 


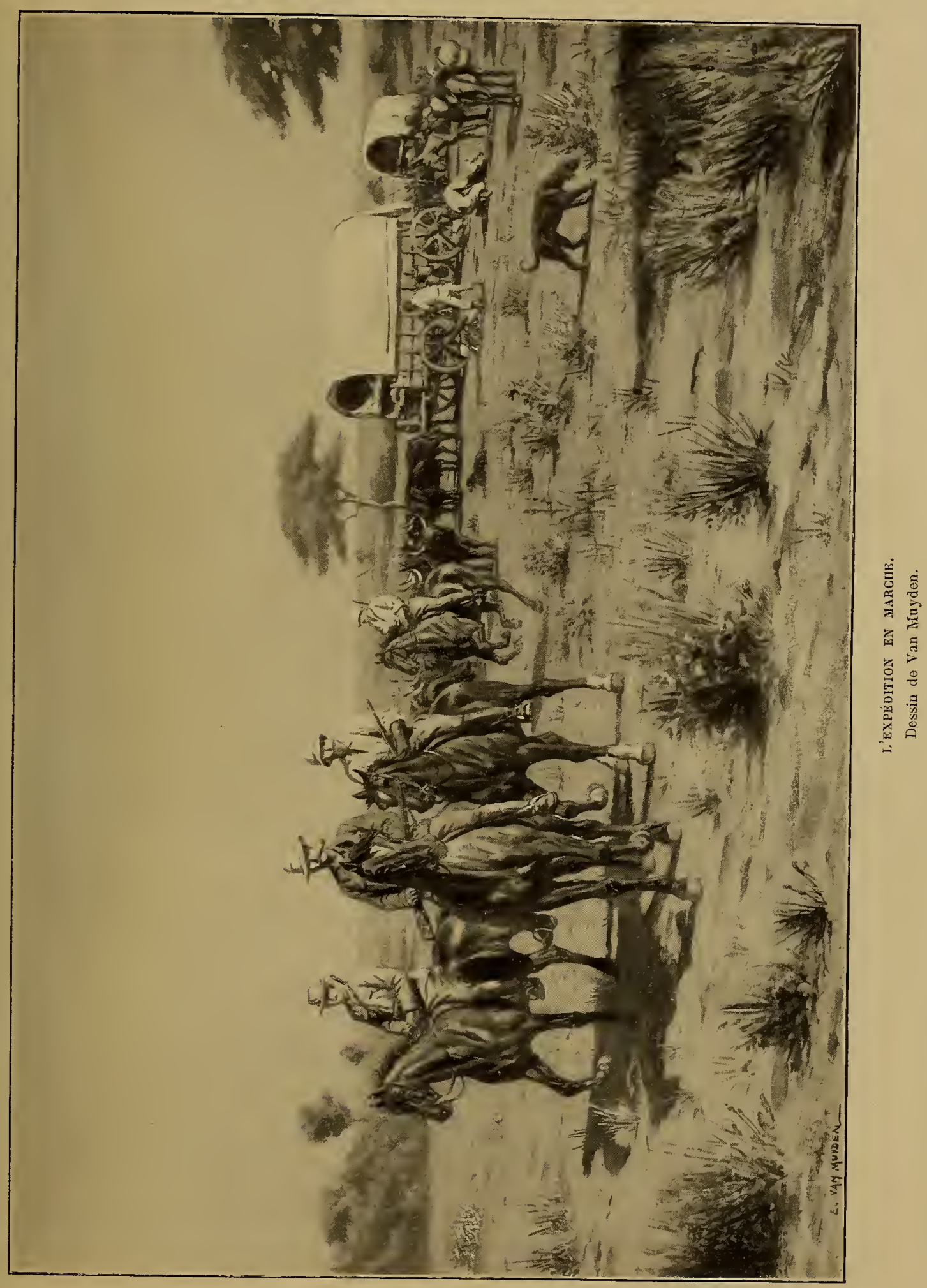



nous avons à l'heure qu'il est, trente-huit bœufs d'attelage, douze chevaux de selle, dix-sept ânes de bât, dix chiens, deux tentes, un canot démontable, un grand wagon à quatre roues, deux plus petits à deux roues, plus un wagon de transport loué jusqu'au Zambèze, pour lequel nous avons fait un contrat et dont l'attelage et les conducteurs ne sont pas sous notre responsabilité.

Voici l'énumération succincte de nos approvisionnements actuels que nous avons omis d'indiquer, lors du départ de l'expédition à Maféking, il y a vingt-cinq jours, et que du reste nous avons renouvelés à Palapye : environ 800 livres de farine de maïs (meale meal); 1200 livres de farine de blé plus ou moins noir et non blutée (Boer meal), qui seront un préciux appoint pour notre nourriture ainsi que pour celle de nos hommes; 1100 livres de maïs en grains, afin de donner dès l'abord un bon fonds de résistance à nos chevaux de selle,... par la suite ils seront obligés de se contenter de l'herbe de la prairie.

Des caisses de conserves diverses; l'une d'elles renferme du jus de citron; un sac de sel, un sac de café, du savon, des allumettes.

Vingt-quatre caisses de rations, préparées avec soin en Europe et qui sont uniquement destinées aux Européens de l'expédition.

Les denrées les plus importantes renfermées dans chaque caisse de rations consistent en quatre livres de farine d'avoine; trois boîtes de lait condensé de Cham; deux livres de pommes séchées; quatre livres de marmelade d'oranges; une livre de beurre danois conservé; deux livres de cassonade, une bouteille de jus de citron, de l'essence de café, une demi-livre de cacao Van Houten; des tablettes de thé comprimé; des tablettes de saccharine qui doivent remplacer le sucre blanc; puis du carbonate de soude et de la crème de tartre, pour faire lever le pain; du poivre, du savon. Chaque caisse de rations pèse quarante livres. 
Un grand nombre de cartouches pour nos armes; des lingots de plomb; de la poudre. Les instruments scientifiques; les appareils et les plaques photographiques; les pharmacies de voyage, où la quinine et la "warthurg tincture ", les deux meilleurs antidotes contre la fièvre, sont en provision; les dosages doivent être faits d'une manière spéciale. Plus de la batterie de cuisine, des outils les plus divers.

Nous sommes, en outre, obligés d'emporter avec nous un fort chargement d'objets d'échange qui consistent surtout en calicot blanc, perles de verre de différentes couleurs et grosseurs, des couvertures; car bientôt les derniers vestiges de la civilisation seront choses passées el, dans la région du Haut-Zambèse où nous nous rendons, l'argent n'a plus aucune valeur. 


\section{AU DESERT}

A tRavers le territoire de KHAMA. - LE GRAND LAC SALÉ MAKarikari

" LAND OF THE THOUSAND VLEYS"

Totre caravane bien reposée et au complet, a quitté Palapye le L 18 mai au soir. Il semble que nos wagons vont se briser en descendant le versant des Choping Hills tellement les pierres sur lesquelles les roues doivent passer sont grosses et rapprochées.

$$
* * *
$$

21 mai. - Après une halte d'un jour et demi sur les bords de la rivière Lotsané (Lotsani), pour donner le temps de rechercher cinq bœufs qui se sont égarés, nous reprenons notre marche.

La direction suivie sera dorénavant et d'une manière générale, le nord-ouest. De plus ou moins près, nous aurons à longer le désert de Kalahari.

C'est au campement de Kabeer que nous avons perdu notre premier cheval, "Mork ", qui a péri de la " horse sickness " endémique dans cette partie de l'Afrique, maladie qui semble affecter les poumons et 
occasionner un empoisonnement du sang. La veille déjà, ses flanes battaient arec violence; fièvre et prostration. Grâce à une forte dose de quinine il semblait mieux, lorsque quelques heures après il est tombé mort pendant qu'il était mené à la main. Première victime de l'expédition!

Après le repas du soir, les cinq sujets que Khama a autorisés à nous accompagner et qui, jusqu'ì maintenant, étaient revêtus de la manière la plus sommaire de quelques peaux de bêtes sauvages, nous demandent des vêtements en avance sur leurs gages. A la lumière du foyer et séance tenante ils revêtent, qui un veston, qui un pantalon. Leur joie se manifeste par de grands éclats de rire, finissant par devenir contagieux. Ces pauvres gens sont des aborigènes conquis par les Béchuanas el réduits par eux en esclavage. Il n'y a pas longtemps qu'ils ne pouvaient rien posséder; tout ce qu'ils gagnaient appartenait de droit à leurs maîtres. Kihama a beaucoup amélioré leur sort.

$$
*^{*} *
$$

22 mai. - Avant d'arriver à Mabelu Pudi, nous faisons une halte pour le déjeuner. Après avoir alluméle feu, nous nous apercevons que nous avons empiété sur la demeure d'un scorpion venimeux que nous nous empressons de déterrer et de tuer; il ressemble à une grosse araignée velue.

A Mabelu Pudi, nous trouvons de l'eau; nous y restons deux jours; des bergers viennent nous offrir cette fois-ci non seulement du lait caillé, mais du lait frais dont nous faisons une ample provision.

Nous déterminons notre position par rapport ì Palapye; la chaîne des montagnes sur le versant de laquelle la capitale est adossée porte mes pensées du côté du Jura. Entre les Choping Hills et nous s'étend 
une grande plaine boisée, légèrement ondulée, d'où s’élève çà et là un mamelon.

Au sommet de la colline où nous sommes postés, superbe position tactique découvrant la contrée avoisinante, nous trouvons les restes d'une muraille qui date probablement du temps où les Béchuanas se sont emparés de ce pajs. Près de là, nous remarquons un cactus mesurant plus de 30 pieds de hauteur.

Nous aidons Reid, ce qui se répétera fréquemment dans la suite, à prendre la latitude du lieu où nous sommes.

La Société royale de géographie de Londres a confié au capitaine Gibbons un sextant, un horizon artificiel, un chronomètre, une boussole prismatique, un baromètre, un hypsomètre. Reid possède en propre le même assortiment, plus un puissant télescope pour relever les occultations; en outre, chacun de nous a en sa possession boussoles, thermomètres, etc., ce qui fait que de ce côtć-là aussi, nous sommes bien fournis. Je dois encore mentionner que Reid emploie un enregistreur très ingénieux, qui s'adapte à l'une des roues du chariot et indique le nombre de tours effectués. Par un simple calcul, il obtient ainsi exactement la distance parcourue d'une étape à l'autre.

Nous sommes rejoints ici par un second contingent de sujets de Khama, appartenant à une caste supérieure; ce qui porte notre personnel à seize hommes, nombre qui s'augmentera dans la suite.

$$
\text { *** }
$$

24 mai. - En quittant Mabelu Pudi, nous remarquons un vol de sauterelles aux têtes et pattes rouges, aux ailes zébrées de blanc et de noir, les arbrisseaux en sont garnis, comme de véritables grappes vivantes; elles détruisent toute verdure sur leur passage. 
Nous traversons une immense plaine accidentée, boisée, éga yée par les gazons encore jaunis par l'hiver et coupée par des collines. Au nord-est, aucun obstacle ne borne l'horizon; les buées du matin nous donnent l'illusion de la mer.

Les paysages africains, pour qui sait voir, varient à l'infini.

Dans la soirée, pendant une marche de nuit très favorable aux attelages, mais malheureusement sans lune, le grand wagon entre dans un trou profond et s'incline sur le còté; nous sommes fortement projetés ì terre; nous nous relevons sans mal sérieux. Les bœufs sont alors dételés et attelés à l'arrière, pendant que du côté opposé, nous tirons tous sur une forte corde, ce qui remet le lourd véhicule d'aplomb.

Peu après, les chiens donnent subitement de la voix. Nous nous hàtons, fusils en mains, vers l'endroit d'où proviennent ces aboiements furieux. Nous les trouvons aux prises avec un porc-épic qui - ne tarde pas à être assommé; plusieurs des chiens sont blessés. L'un a deux piquants dans le còté, il faut à la lumière des lanternes les extraire sur-le-champ, ce qui ne s'opère pas sans gémissements.

Nous décidons de laisser les wagons aller de l'avant jusqu'à Makoa (Makwa) où nous espérons trouver de l'eau, puis de passer la nuit au bivouac pour nous mettre en chasse demain matin de bonne heure. Un " skerm ", abri rudimentaire fait avec des branchages, est rapidement établi; les chevaux sont attachés et nous nous couchons autour d'un grand feu, roulés dans nos couvertures.

$$
*^{*} *
$$

25 mai. - Un fort vent froid du sud-ouest a soufflé pendant la nuit aussi nous n'avons guère dormi. A cinq heures et demie, nous sommes debout et peu après, à cheval. Nous allons, la carabine en main, l'œil aux aguets, tántòt à travers le " bush ", broussailles, 
tantòt à travers les grandes plaines brûlées. Nous galopons une gazelle qui nous échappe; puis dans le courant de la matinée, un gnou (Catoblepas gorgon) ' pesant 300 ì 400 livres et qui, de loin, ressemble à s'y méprendre à un bœuf de petite taille; superbe daus son galop la tète entre les jambes. La bète a été rejetée du côté de Reid qui l'a tuée : fameuse addition a notre cuisine, surtout avec le nombre d'hommes que nous avons à nourrir.

Après six heures de chasse, nous nous rejoignons au campement de Koua (Kiwa) où nous faisons un repas composé en partie de porc-épic bouilli.

A la tombée de la nuit, Pirie n'est pas de retour. Aussi suivant ce que

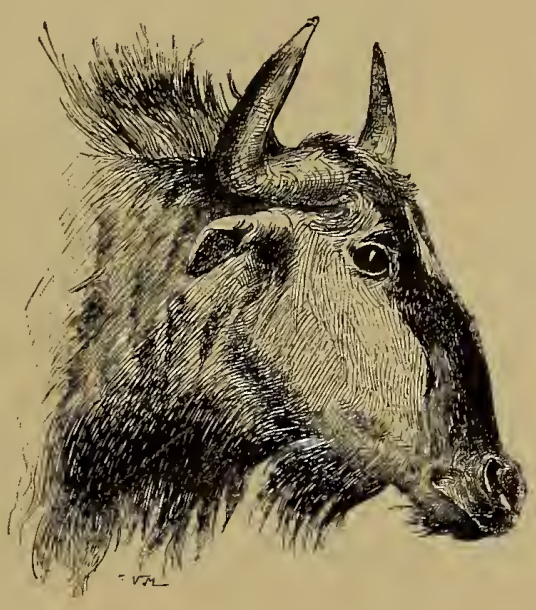

GXOU BLEL, " CATOBLEPAS GORGON".

Croquis de Van Muyden.

Spécimen rapporté par l'auteur. nous arons convenu ell pareil cas, nous tirons de demi-heure en demi-heure, par trois fois, une série de coups de fusil, suivis immédiatement d'une fusée aux étoiles rouges et bleues; à notre divertissement, les hommes effrayés se réfugient sous le chariot.

A dix heures du soir, Pirie n'a pas encore paru; il s'est sûrement égaré.

Nous tenons conseil et nous décidons d'envoyer demain matin au point du jour à sa recherche le plus sûr de nos hommes, Jonnes à cheval, accompagné de deux " bushmen ", qui n'ont pas d'égaux pour retrouver et suivre une piste. 


$$
\text { *** }
$$

26 mai. - Quoique nous soyons sous les tropiques et que nous ayons depuis longtemps passé le Capricorne, il a fait très froid la nuit dernière et le thé que nous avons laissé lier soir dehors, forme un bloc de glace dans chaque tasse; différence extrême avec la température du milieu du jour, où l'ombre est recherchée. Nous ne pouvons pas, malgré la meilleure bonne volonté, avaler notre traditionnelle bouillie d'avoine du matin, car la vase y entre dans une trop forte proportion; il nous faut aussi renoncer aux ablutions les plus élémentaires.

Pirie est revenu au campement cette après-midi seulement à deux lieures. Comme nous le pensions, il a pris hier une fausse piste après la chasse; il est resté vingt-sept heures sans nourriture et dix-sept sans eau!

$$
*^{*} *
$$

27 mar. - I la halté du déjeuner, les biftecks de gnou sont déclarés excellents. Nous rencontrons une caravane de Zambéziens retournant dans leur pays après avoir travaillé aux mines de diamants de Kimberley. Très pittoresques dans leur accoutrement; un mélange de hardes européennes et de vêtements indigènes; chacun d'eux est armé d'un fusil et ils ont un air de prospérité qui fait plaisir. Le danseur de la bande, coiffé d'un chapeau pointu surmonté d'une longue plume, vient égayer notre repas. Il danse sur place; tout en chanlant et en sifflant, il agite une calebasse de la main droite; une clochette pend à son còté.

L'eau, trouvée en très petite quantité et dont nous sommes obligés de nous contenter aujourd'hui, est la plus mauvaise que nous ayons 


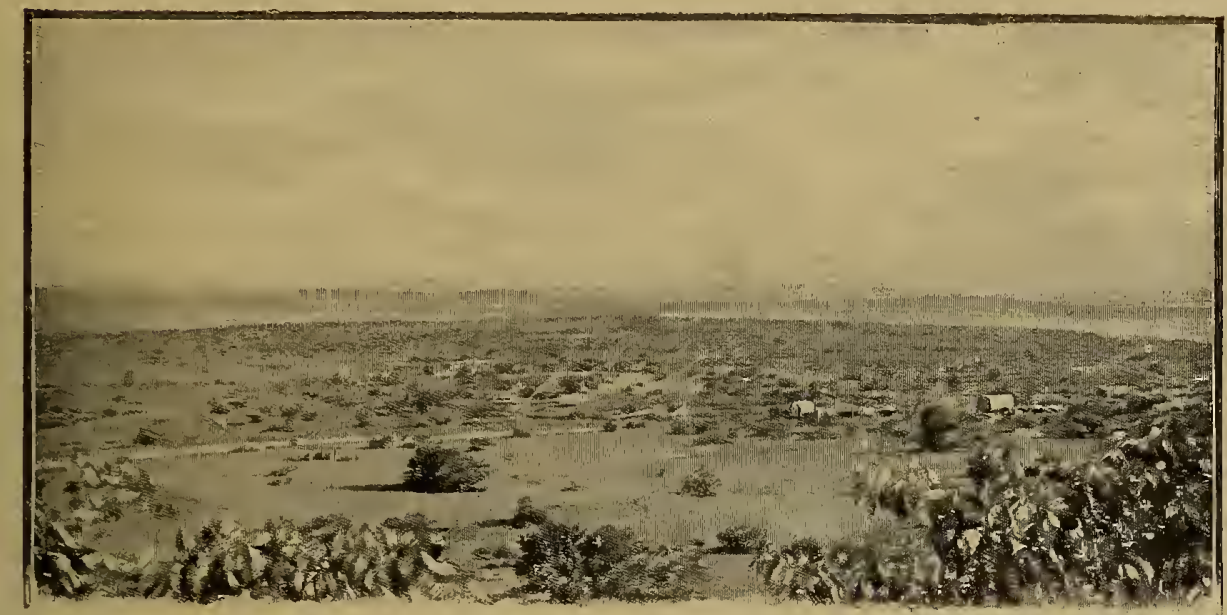

L'EXPÉDITION AVINGE PENIBLEMENT.

Dessin de Boudier. D'après uno photographie de l'auteur.

eue jusqu'à présent. Nous la faisons bouillir, et par trois fois, nous en extrayons une écume verdàtre; malgré cette opération, nous n'avons pour notre thé et pour préparer notre repas, qu'un mélange d'eau et de bouc dont il faut bien nous contenter.

$$
\text { *** }
$$

28 mai. - Puits de Tlalamabélé; nous sommes heureux de pouvoir abreuver les attelages qui ont été privés d'eau pendant trenteneuf heures! Pour contenir l'impaticnce de ces malheureuses bêtes et afin que les plus faibles puissent avoir leur tour, nos hommes les mènent à l'eau par escouades, ce qui ne se fait pas sans peine. Nous continuons notre route le long d'une piste sablonneuse, à travers un pays où les arbres deviennent plus nombreux et plus grands, pour arriver dans la journée au campement de Linokaneng, où nous nous réjouissions à la pensée de trouver de l'eau pure en abondance. 11 faut en rabattre! Ce n'est plus il est vrai, de la bouc liquide, mais hélas! de l'eau grise dont nous sommes encore heureux de nous servir. 
De beaux arbres nous environnent et les sand grouses, l'un des meilleurs gibiers à plumes de cette partie de l'Afrique, ne manquent pas dans les environs.

L'aspect des contrées que nous traversons change continuellement; la marche suivante nous a conduits dans une vallée boisée, entourée de collines à sommets plats, véritable océan de verdure estompé de vert et de jaune. La plupart de ces arbres sont des mopane ou mopani, dont les feuilles - séparées en deux parties — ont la forme d'une paire d'ailes de papillon. Ces arbres sont entremêlés de terribles buissons d'épines d'espèces différentes, dont la plus redoutée est le wachlen bitchie, nommée à juste titre par les Anglais wait-a-bit, "attends un peu »; acérée, recourbée, véritable hameçon qui arrête, déchire tout ce qui se trouve sur son passage. Il m'est arrivé d'être presque désarçonné par l'un de ces buissons de wait-a-bit!

$$
\text { *** }
$$

30 mai. - Nous voyageons en pays ouvert et atteignons la partie sud-est du Makarikari.

Le Makarikari est un lac salé d'environ cent kilomètres de longueur, en grande partie desséché dans cette saison. Les indigènes viennent s'approvisionner de sel sur le bord de ses rives. Nous chassons à cheval l'antilope sur sa surface saline et crevassée. Nous y sommes aussi les jouts du mirage : il nous semble apercevoir dans le lointain de grandes nappes d'eau claire qui s'éloignent à mesure que nous approchons. Illusion!

Dı milieu des herbes où nous campons, sortent des fourmilières arrondies, habilées par des fourmis à tête rouge armées d'un dard. L'intérieur de ces fourmilières est admirablement travaillé; nos hommes les creusent et s'en servent comme de four à pain. 
Nous recevons la visite de trois ma-Saroua, les habitants de cette région; le plus jeune est paré d'un diadème de perles de verre et de nombrenx collier's et bracelets où le bleu domine.

Yous rencontrons aussi une troupe de Zambéziens qui, eux se rendent à Kimberley, maigres, défiants, ne possédant rien que leurs calebasses suspendues au bout de longs bâtons; contraste frappant avec ceux qui ront retrouver leurs foyers après avoir travaillé quelques années en pays civilisé. La contrée que nous traversons est modérément boisée, elle sert de refuge à de nombreuses pintades, excellent gibier, comme on sait.

$$
\text { *** } *
$$

31 mai. - Nous arrivons au puits de Kariba. Les bêtes qui n'ont cu que de l'eau salée hier au soir, peuvent être abreuvées; je parle souvent de cette " cau " qui est l'une de nos plus grandes préoccupalions : savoir de quelle sorte elle sera, où el quand on la trouvera? Les rares indigènes que nous rencontrons ne veulent pas, en général, donner des indications exactes ì ce sujet.

$$
\text { *** }
$$

fr juin. - Excellent repas de grillades d'antilopes et de pintades; dans l'après-midi, nous donnons la chasse à un troupeau d'autruches.

$$
*^{*} *
$$

2 juin. - Nous avons campé la nuit dernière sur les bords de la rivière Simoané, dont malheureusement l'eau est salée et qui comme beaucoup d'autres rivières, est absorbéc par le Makarikari.

Nous avons la bonne fortune de rencontrer le campement de Selihomi, fils unique de Khama, lequel, avec une nombreuse suite, 
revient du nord. Il nous assure avoir tué onze girafes. Ses six chariots sont rangés sur une file le long de la rivière; nous descendons de cheval pour lui serrer la main. C'est un homme de vingt-cinq à trente ans, grand, élancé; il parle quelques mots d'anglais.

Dans le courant de la journée, il nous rend visite à notre campement; il vient à cheval, accompagné de quelques-uns de ses suivants. Il nous amène un moulon gras et nous le remercions en lui offrant du sucre et du café. Ce mouton est le bienvenu et fera une heureuse diversion, car depuis longtemps le gibier forme le fond de notre nourriture.

Sekhomi, qui retourne à Palapye, veut bien se charger de nos lettres. Nous arriverons prochainement sur les bords de la rivière Nata (Métengué).

$$
\text { *** }
$$

3 juin. - Hier au soir, nous avons franchi par une belle nuit claire, l'angle nord-est du grand lac salé Makarikari, en partic à sec dans cette saison. Sous nos pieds, une vaste étendue blanchâtre, sur nos têtes, le bleu du ciel. Dans la soirée, nous faisons halte non loin du confluent de la rivière Shua et de la rivière Nata qui, elle aussi, absorbée par le Makarikari; nous y resterons un ou deux jours.

La viande commence à manquer au campement, ce qui doit être pris en considération; en effet, sans nous compter, nous avons actuellement seize bouches à nourrir et quels appétits! Nous donnons à nos hommes deux livres de farine de maïs journellement, ration qui est supprimée et remplacée par de la viande les jours de bonne chasse. Résultat: économie de trente-deux livres de farine en vingt-quatre heures.

$$
\text { *** * * }
$$

4 juin. - Nous sommes en selle à six heures du matin el partons pour la chasse; le soleil est déjà chaud lorsque nous arrivons à un 
village de ma-Saroua, soil it quelques huttes en branchages, recouvertes d'herbes sèches, disséminćes 'entre les arbres et qui ressemblent à s'y méprendre à des tas de foin; ici et là un " skerm ". Justement dans l'un de ceux-là, nous trouvons groupés autour du feu huit ma-Saroua, probablement les notables de l'endroit. L'un d'eux, le chef, homme jeune encore, semble être tenu en grande estime par ses compagnons.

Ces ma-Saroua sont à peine recouverts de quelques peaux de bètes sauvages; tous ont pourlant des ornements divers en perles de verre ou en métal : boucles d'oreilles, bracelets, colliers, etc. Aux oreilles de l'un des plus àgés pendent deux boutons en cuivre de fabrication européenne, tandis qu'un autre s'est confectionné un bracelet arec une quantité de petits boutons blancs. Plusieurs aussi portent suspendues au cou des amulettes, ainsi qu'une longue alène renfermée dans un étui en bois; ils se servent de cette dernière pour extraire les épines de leurs pieds.

Le chef armé d'une massue, d'une lance, et suivi de trois de ses sujets, prend la tête de notre colonne. Il ne tarde pas à examiner le terrain de tous les còtés pour relever les traces du gibier. Pendant longtemps ses yeux ne quittent la terre que pour scruter l'horizon. Après une longue marche, il monte sur un arbre et nous fait comprendre qu'il a en vue un troupeau de gnous. Carabines en main, nous nous avançons au pas de nos chevaux dans la direction donnée. Les gnous se détachent sur l'herbe jaunie; nous' les royons toujours plus distinctement, ils broutent, au nombre d'une trentaine. Une fois que nous sommes arrivés à quelques centaines de mètres, le troupeau prend subitement le galop; nous faisons de mème. Lancés à fond de train, ces animaux font des circuits et des détours que nous tâchons de couper; ils soulèvent un nuage de poussière, 
véritable charge de cavalerie. Après une chaude poursuite de quelques kilomètres sur cette immense plaine aux herbages desséchés, nous avons la certitude d'avoir de la viande fraîche pour nous et nos gens.

Ensuite, Pirie, Reid et moi, nous nous dirigeons du côté de la rivière, tandis que le capitaine Gibbons s'acharne à suivre quelques bêtes isolées.

$$
\text { *** } * \text { * }
$$

5 juin. - Elles l'ont mené plus loin qu'il ne pensait, car il n'est rentré que de grand matin au campement, après avoir été obligé de conduire son cheval à la main pendant la plus grande partie du retour; de se contenter pour son souper solitaire de la langue de la bête qu'il avait tuée et de se coucher sans couverture à la belle étoile.

$$
\text { *** }
$$

6 juin. - Il nous faut traverser la rivière Nata. Les bœufs ont à peine de l'eau jusqu'aux genoux; mais à en juger par la hanteur et la largeur de ses berges, elle ne doit pas être commode à franchir pendant la saison des pluies. Peu auparavant, la flèche du second chariot s'était cassée, elle dut être réparée sans retard. Nous suivons une piste de sable qui donne beaucoup de peine aux attelages et une poussière épaisse nous enveloppe et pénètre partout. A d'autres moments, nous chevauchons au milieu de grandes herbes roussies, dans lesquelles nos chevaux disparaissent jusqu'au garrot; tantòt enfin, nous traversons de légers renflements de terrain recouvert de broussailles plus ou moins élevées.

$$
\text { *** }
$$

7 juin. - Nous passons toute la journée à la mare de Horns-Vley et établissons le campement sous un grand arbre (Acacia giraffa). 


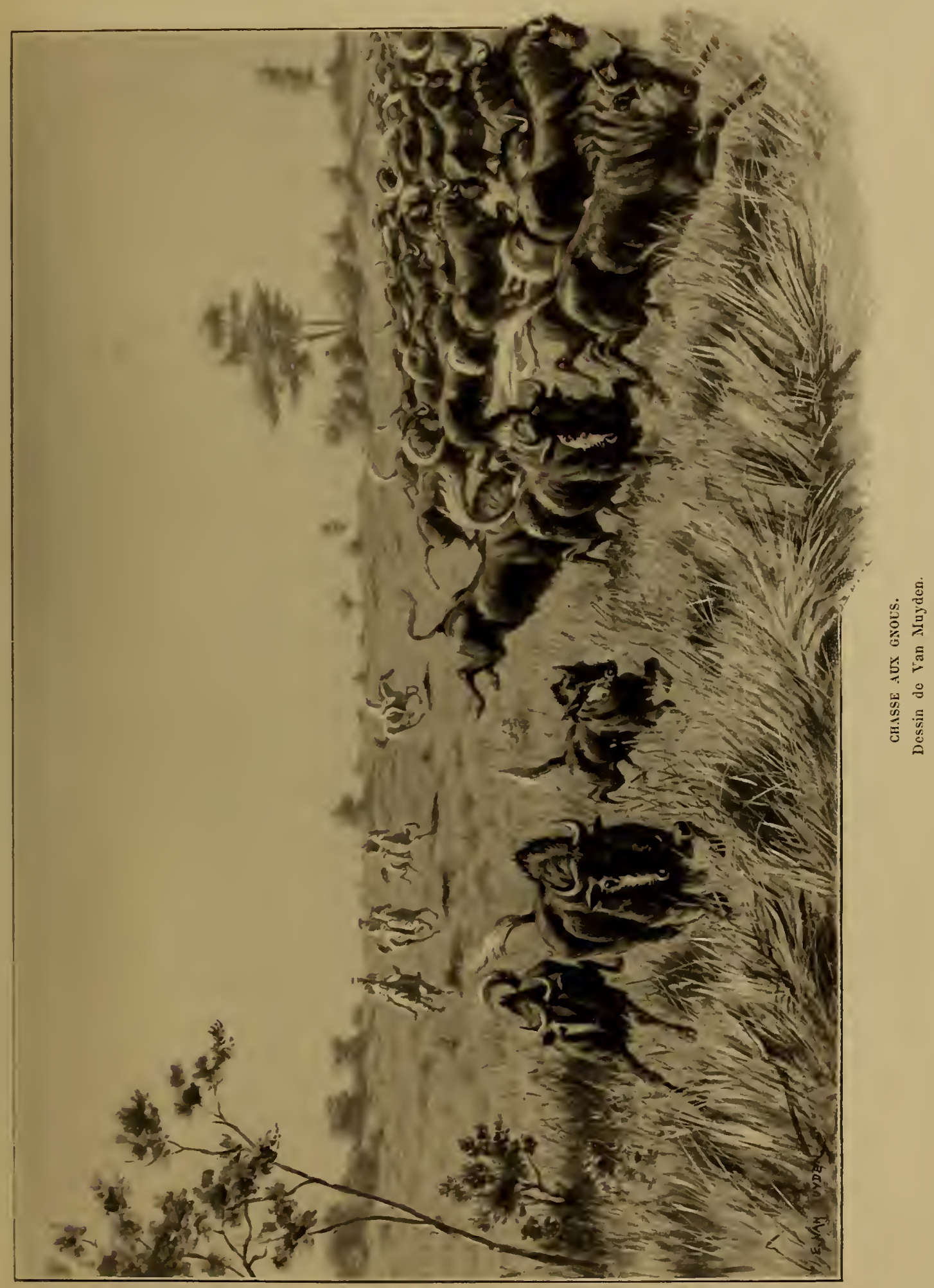



L'un des boufs d’attelage, qui s'étail démis l'épaule, a dù être abattu. Les hommes sont activement occupés à préparer du " beltong ", soit à découper la viande en minces lanières qui sont

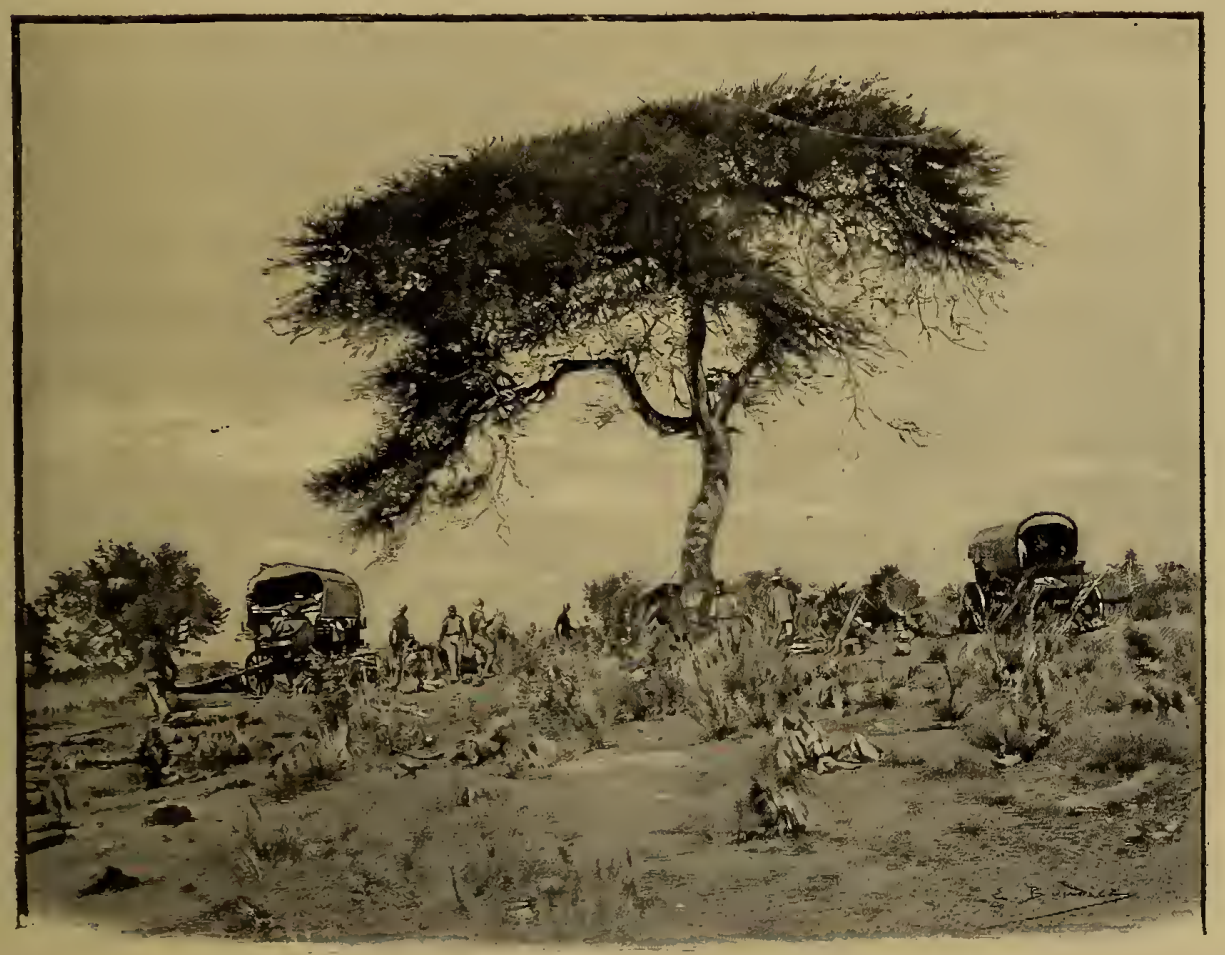

CAMPEMEXT SOUS LX ICAGIA GIRAFFA.

Dessin de Boudier. Daprès une photographic de l'auteur.

saupoudrées de sel, puis séchées à l'air; elles peuvent se conserver ainsi fort longtemps.

Il faut une grande expérience de la vie dans cette partie de l'Afrique pour savoir, tout en les ménageant et en les conservant en bonne santé, tirer des attelages tout ce qu'ils peuvent donner. Parmi les membres de l'expédition, Gibbons et Reid, possèdent cette expérience; nous avons jusqu'ici de bons résultats de marche et de santé. Ce n'est pas une petite affaire que d'organiser les " treks ", de savoir quand il faut 
marcher de nuit, et de calculer les distances afin de trouver de l'eau aux haltes.

Nous nous sommes réparti le travail de manière à ce que l'ensemble fonctionne aussi bien que possible et que chacun de nous ait son service spécial.

$$
\text { *** }
$$

13 juin. - Nous voici à la mare de Tamasetsé (Tamasetsie). Une girafe a été tuée hier; nous resterons ici jusqu'à demain. Les hommes préparent pour notre usage du " beltong " avec cette viande blanche, l'une des meilleures que l'on puisse manger, surtout lorsqu'elle provient d'une jeune bête.

Depuis quelques jours déjà nous ne manquons plus d'eau; nous traversons la contrée appelée " the Land of the thousand Vleys ", pays des mille mares ou étangs, dépressions de terrain où le précieux liquide de qualité plus ou moins bonne, se trouve dans cette saison en quantité suffisante.

Depuis Horns-Vley nous suivons une piste de sable épais qui fait beaucoup tirer les attelages. Cette piste est en grande partic bordée de taillis où les wagons ont souvent juste la place de passer; çà et là il faut couper un arbre. Temps d'épreuve pour les "drivers ", conducteurs. Chaque attelage a son " driver " spécial, lequel armé d'un grand fouet, change continuellement de place. Dans les moments difficiles, il interpelle individuellement sans trêve ni repos ses bœufs, dont chacun a un nom; tantòt il les invective, tantôt il les encourage; les variations de sa voix aiguë changent à l'infini.

Il est secondé par le " leader ", qui marche devant la première paire de bœufs. 


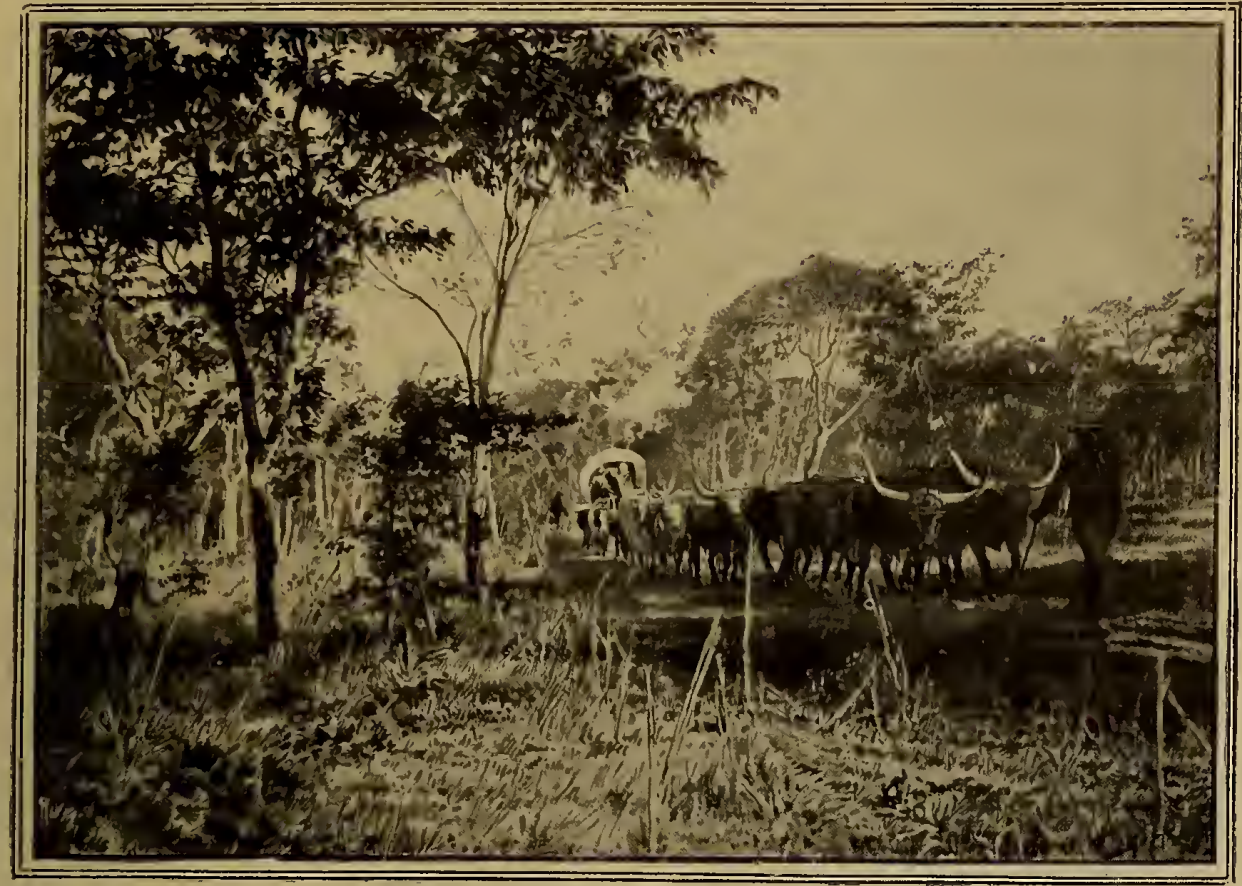

D.ATS LES TAILLIS!

Daprès une photographie de lauteur.

Au moment d'atteler", opération intéressante ì observer, le "leader " reçoit du "driver" ", l'ordre de rassembler les bœufs qui paissent dans les environs. I son tour, aidé par d'autres " boys ", il met les bœufs sur une seule file devant le wagon, cela du côté gauche de la longue chaìne de fer qui part de la flèche et où les jougs sont assujetlis par le milieu. Le " driver" ", avec l'aide de ses hommes, passe une lanière de cuir autour des cornes de chaque animal, puis il choisit les paires qui sont amenées du côté droit de la chaîne et faisant face à leur joug respectif. Celui-ci est alor's placé sur la nuque des bœufs qui forment la paire; le cou de chaque animal est entravé par deux légères palettes en bois enclavées dans le joug. Les seize ou dix-huit bœufs du grand wagon sont ainsi attelés en quelques minutes, non sans force éclats de voix. 


$$
\text { *** }
$$

16 juin. - Nous faisons une halte à la " mare du Baobab ". Un superbe arbre de ce nom, dont le trone mesure près de huit mètres de circonférence, se dresse sur ses bords. La forte toile à voile qui recouvre le grand wagon a été déchirée par les épines; elle doit être réparée d'urgence.

Nous faisons un excellent déjeuner composé ¿de langue rôtie et de biftecks de girafe.

Avant-hier, nous avons pourchassé à cheval un troupeau de zèbres; ces dernier's jours, nous avons à plusieurs reprises relevé des traces anciennes d'éléphants et des empreintes fraìches de lions.

Depuis la mare du Baobab, nous avons de nouveau des éclaircies et la piste de sable alterne avec du terrain plus dur: ondulations de terrain.

Nous passons la ligne de faîte des eaux : au nord s'écoule le Zambèze, au sud le Limpopo. Ce faìte a une altitude de 3000 ì 3500 pieds au-dessus du niveau de la mer.

En observant l'aspect de celte contrée, on se demande si elle n'est pas fondée cette opinion émise, je crois par Livingstone, que le pays situé entre le Zambèze et Shoshong ${ }^{1}$, formait primitivement un grand lac ou mer intéricure qui a été réduit au Makarikari actuel, lorsque cette masse d'eau s'est ouvert un passage du côté de l'océan Indien, à l'endroit appelé aujourd'hui les Chutes de Vietoria (Victoria Falls).

$$
* * *
$$

17 juin. - En arrivant à la rivière Daka, réduite pour le moment à son plus bas niveau, nous lébouchons sur le campement de trois trouvait non loin de Palapye. 
Anglais. Avant d'avoir décliné nos noms et qualités réciproques, nous nous trouvons partageant leur déjeuner. Combien les cœurs s'ouvrent et eomme les mains se tendent lorsque, ì l'imprévu, des Européens se rencontrent dans ces solitudes immenses '!

Ces messieur's, dont deux sont ingénieurs des mines, ont été envoyés

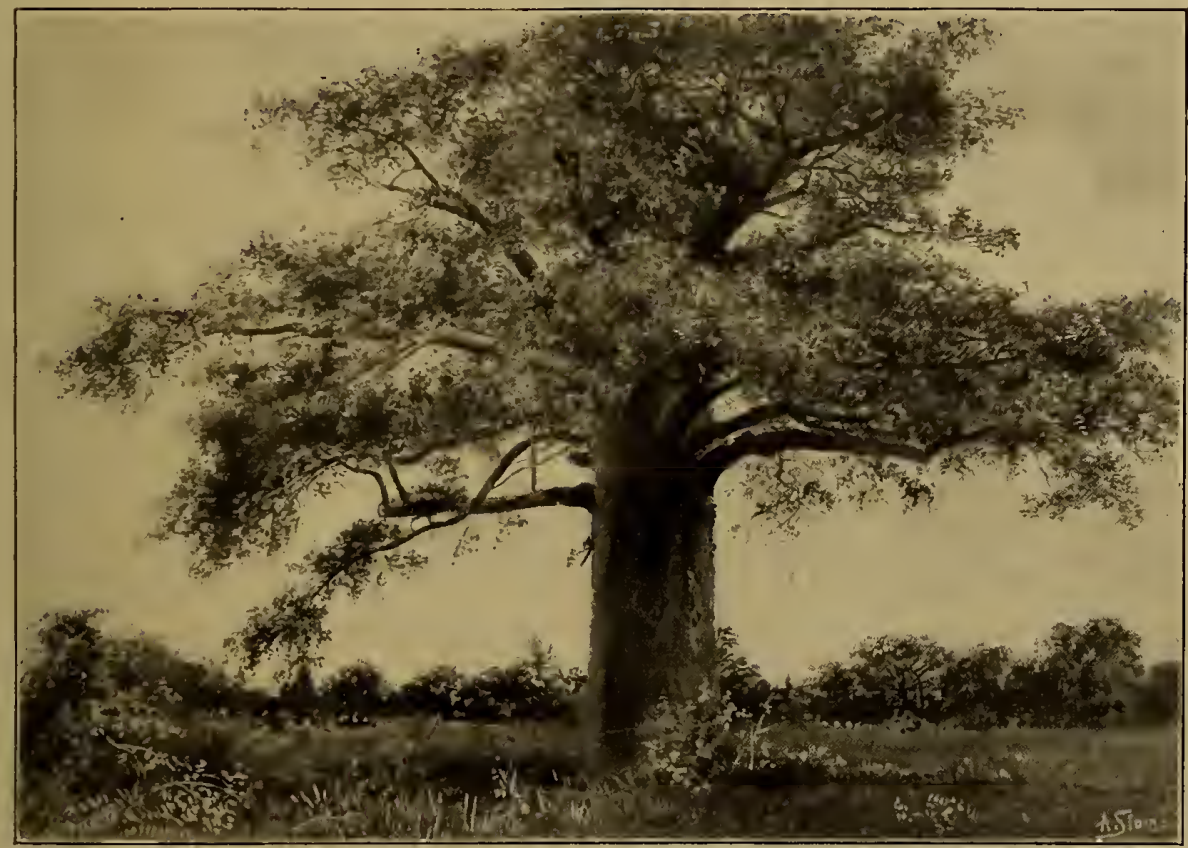

BAOB.AB.

D'après une photographic de l'auteur.

par un syndicat pour " prospecter " le terrain avoisinant le Gway, l'un des affluents sud du Zambèze, au point de vue minier. Que de détails intéressants ils nous donnent! Ce n'est qu'à la nuit tombante que nous songeons à mettre le pied à l'étrier pour rejoindre nos wagons qui nous ont devancés; une heure d'allure rapide nous met en vue de nos grands feux de bivouac.

1. Depuis notre retour, nous avons appris la mort de deux d'entre eux. 
Ils nous ont offert un cadeau, de valeur pour nous inestimable : une marmite! Les trois ustensiles de ce genre que nous possédions avaient été, dans notre vie accidentée, brisés depuis longtemps. Nous avons eu aussi la satisfaction de manger de bon pain : l'un de nos " boys ", qui remplit les fonctions de boulanger, n’arrive avec la farine non blutée dont il dispose, qu'à confectionner une matière aussi lourde que du plomb.

De bon pain et de l'eau potable, deux éléments dont il faut avoir été privé pour les apprécier à leur juste valeur!

Ces trois messieurs n'avaient pas de sextant parmi leurs instruments de précision. Au moyen des nòtres, nous avons pu leur donner la latitude de leur campement.

La "British S.-^. Chartered Company " semble aspirer dans ces parages à de hautes destinées.

Nous avons à plusieur's reprises empiété sur le territoire revendiqué anciennement par Lobengula, le roi des ma-Tébélé, cette race de pillards, d'une cruauté inouïe el qui ne font pas de merci à leurs prisonniers, terreur des tribus environnantes et auxquels les armes coloniales ont infligé une terrible leçon en 1893.

$$
\text { *** }
$$

18 juin. - Depuis Daka, nous cheminons au nord-ouest, à travers une rangée de collines; puis le long d'une vallée qui nous amène, peu après avoir passé le lit de la rivière Matetsi, à Panda-Matenga. De ce plateau, nous avons dans la direction du Zambèze une vue étendue sur la contrée environnante, plaine immense coupée par des ondulations de terrain boisées, dont la verdure sombre se détache sur les tons clairs de la parairie. Depuis notre départ de Palapye, c'est à PandaMatenga que nous revoyons pour la première fois des huttes en terre; 
pendant tont ce trajed nons n'avons rencontré que quelques misílables abris, faits avec des hranchages, des herbes séchées, al qu'habitent les Bushmen, les ma-Saroua. Ce soir-là, nous fètons un anniversaire. Pendant la journée, nous avions eu la bonne fortune de pouvoir acheter un morceau de chevreau; heureuse diversion à notre nourriture dont le fond se composait, depuis quelques jours, de viande de girafe apprètée sous les formes les plus diverses.

$$
* * *
$$

19 juin. - Nous campons dans la prairie à Gazouma-Vley où nous faisons établir des "kraals ". Ici est l'emplacement que nous arons choisi pour renvoyer, une fois arrivés sur les bords du Zambize, les bœufs et une partie des chevaux que nous laisserons, ainsi que les chariots, sous la garde de quelques hommes de confiance. Ils y resteront pendant que nous pénétrerons dans le Pays des ba-Rotsi, après avoir traversé le fleuve. I Gazouma-Vley, il y a de l'eau en abondance et la mouche tsé-tsé, dont la piquire provoque, dans un temps plus ou moins prolongé, la mort presque certaine des animaux domestiques, n'est pas à craindre.

Ces kraals sont des enceintes entourées de branches d'arbres épineux, qui doivent être assez serrées et assez élevées pour que les fauves ne puissent pas y pénétrer; chevaux et boufs y seront enfermés chaque soir.

Notre armement de chasse consiste en cinq " express rifles " et quatre fusils à canons lisses, toutes armes de premier ordre. J'ai aussi emporté avec moi un mousqueton de cavalerie suisse, modèle 1893 ; l'expédition possède en outre quelques "mannlicher ", mousquetons de cavaleric, dernier modèle. 


$$
\text { *** } *
$$

20 juin. - Nous rencontrons une quantité de pistes d'animaux sauvages, girafes, zèbres, etc.; le pays doit être fort giboyeux. J'ai la bonne chance, comme addition à notre cuisine, de tuer un duitier (Cephalophus mergens) antilope dont la chair est excellente.

En poursuivant un troupeau d'antilopes-tsessebe

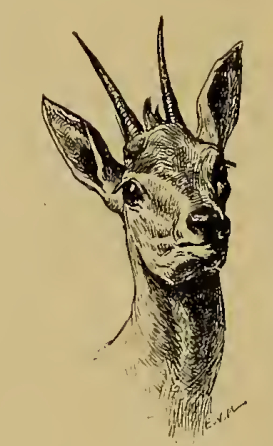

DUTKER, “ CEPHA LOPHUS MERGENS". Croquis de Van Muyden. Spécimen rapporte par l'auteur.

(Alcephalus lumatus), Pirie a fait une chute de

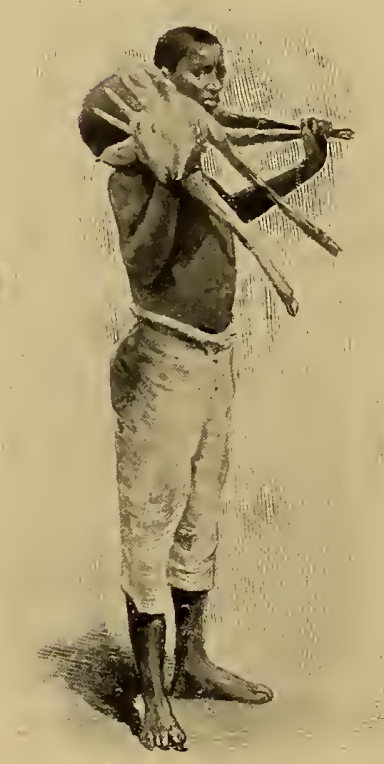

UN DE NOS DINERS

Dessin de Thriat. Dapres une photograplie de l'auteur. cheval. Cet accident est inévitable et nous y avons tons passé, car ces prairies sont parsemées d'une infinité de trous creusés par une sorte de fourmilier. Il est impossible d'éviter ces trous lorsque l'on est lancé en pleine course. Pirie s'en tire avec un pied foulé.

$$
\text { *** }
$$

21 juin. - Nous suivons une piste sablonneuse à travers la forêt, où nous remarquons des orc hidées.

Nous décidons, Reid et moi, de partir à cheval en reconnaissance du côté du Zambèze. Reid se charge de la carabine, moi de la théière et dı sac aux provisions. 
CHAPITRE V

\section{LE ZAMBËZE}

SUR LES BORDS DU FLEUYE. - KAZOUNGOULA, PAYS DES BA-ROTSI

$\mathrm{L}^{\mathrm{s}}$

E 29 juin, peu après minuit, nous sommes en selle. Nous descendons insensiblement dans la vallée pour arriver à Leshoma. La nuit est sans lune. Rien n'est moins commode, équipé de notre sorte, que de galoper dans cette obscurité sur un terrain aussi accidenté.

Iu point du jour, nous sommes salués par les cris peu harmonieux l'une colonie de singes, qui ont élu domicile dans le feuillage d'un superbe mimosa et à six heures, nous arrivons sur les bords du grand fleuve. Pour le moment, une forte buée couvre ses eaux; nous entrevoyons seulement sur l'autre rive la station missionnaire et le village indigène de Kazoungoula, pays du bo-Rotsi ', avec ses huttes en chaume.

1. Après en avoir eonféré avec M. Coillard, haute autorité en eette matière puisqu'il a séjourné près de quarante années en Afrique, j'ai adopté dans eet ouvrage les règles qu'il a proposées en ce qui eoneerne l'orthographe franẹaise des noms des différents territoires, tribus ou peuplades qui se trouvent dans le Pays des ba-Rotsi. Les préfixes a ba ๖ ou a ma » indiquent le pluriel; la préfixe \& mo s'emploie au singulier pour désigner un individu; la préfixe a bo $\triangleright$ dèsigne le pays même. Exemple: les ba-Rotsi - un mo-Rotsi - le pays du bo-Rotsi. Ces préfixes représentent en quelque sorte l'artiele el prennent 
Après nous être réchauffés à un feu allumé avec peine à cause de la rosée abontante, nous tirons des coups de fusil pour attirer l'attention d'un batelier indigène qui nous passera sur l'autre rive. Il finit par répondre à notre appel. Nous le voyons arriver pagayant et debout dans son canot, creusé d'une seule pièce dans un trone d'arbre, long, mince, effilé. Yous avons juste la place de nous y asseoir et ne tardons pas à aborder au Pays des ba-Rolsi.

Nous frappons à la porte des missionnaires, M. et Mme Louis Jalla, originaires des Vallées vaudoises du Piémont, qui nous font un accueil des plus cordiaux et, séance tenante, nous nous asseyons à leur table.

Ils veulent bien nous donner des renseignements précieux; c'est ¿ regret que, dans l'après-midi, nous les quittons et repassons de nouveau sur la rive droite du Zambèze, pour seller nos chevaux et aller à la rencontre de nos wagons, que nous rejoignons dans la soirée à Leshoma.

$$
\text { *** } *
$$

23-24 juin. - Deux journées sont consacrées à faire l'inventaire du matériel, à le diviser en charges facilement transportables qui doivent ètre pesćes; nous laissons en arrière tout ce qui pourrait nous encombrer, ainsi que des provisions que nous trouverons au retour. Les attelages disponibles et la plupart des chevaux sont envoyés de suite à Gazouma-Vley; puis avec ce qui nous est nécessaire, nous effectuons notre dernière étape pour arriver de nuit au fleuve, de manière ì préserver les boufs de la mouche tsé-tsé qui fréquente ces parages.

une minuscule, tandis que le nom propre lui-même est écrit avec une majuscule. Les noms propres entre parenthèses sont écrits suivant l'orthographe anglaise. Ne référant à l'autorité citée plus haut, j'ai aussi employé les mêmes règles pour les noms des tribus ou peuplades qui vivent au sud du Zambèze, exceptè pour quelques-unes d'entre elles, dont les noms ont déjà été francisés. 
Derniere muit passer dans le chariol. De bonne heure le lendemain malin, nous abablissons nos lentes sur la rive droite du Zambize. Pendant deux jours, tout en travailant ferme, nous avous pu admirep lo spectacle que nous avons sous les yeux. Ce beau fleuve qui, it

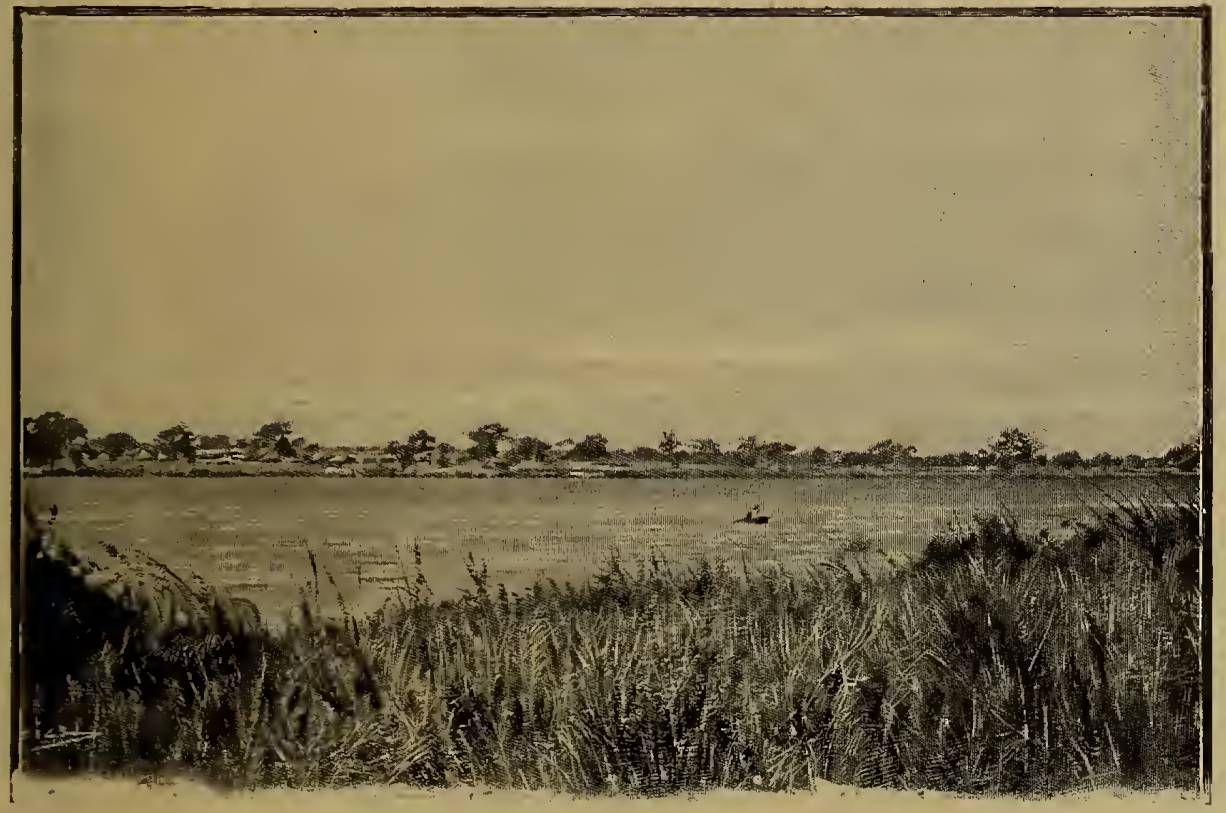

1.E ZaMbèze PIÉS DL CONFLleNT DE LA RIVIERE LINYANTS.

Dessin de Boudier. Dapres une photographie de l'auteur.

l'endroit où nous sommes, mesure entre quatre cents et cinq cents mètres de largeur, roule à cette époque de l'année des eaux aussi bleues que celles du lac Léman. Toujours sur la rive droite, un peu en amont, la rivière Chobé (Linyanti) opère sa jonction avec le Zambèze, les indigènes s'appellent Liambaé, et le fleuve est parsemé de plusieurs îles. Cà et lì un palmier élancé donne la note tropicale; de noirs cormorans, ou des oies au vol plus lourd, cinglent de temps ì autre dans les airs. Vis-it-vis de nous, sur la rive gauche, Kazoungoula (Kazungula) se détache sur un fond de verdure. 


$$
*^{*} *
$$

25 juin. - Après le déjeuner, nous mettons pour la première fois notre canot à l'eau. Il est en toile à voile enduite de caoutchouc, démontable, et pèse cent soixante livres. Nous traversons le Zambèze. Grâce à la bonté de M. et Mme Louis Jalla, nous pouvons acheter de suite treize ou quatore cents livres de sorgho, maïs, millet, arachides; mais il nous faut transporter toute cette cargaison sur l'autre rive. Malheureusement, le vent s'est levé, le fleuve est houleux; les bateliers indigènes refusent de travailler dans ces conditions; d'un autre còté, le temps presse et il est urgent, pour éviter la mouche tsé-tsé, que les boufs retournent ce soir mème à Gazouma-Vley.

Comme notre embarcation, la Zambezia s'est bien comportée, nous nous décidons dans la matinée d'effectuer nous-mêmes ce transport en ramant à tour de ròle, ce qui certes n'était pas sans danger. Tout s'est bien passé et au moment fixé, notre dernier wagon reprenait la route de Gazouma-Vley, avec la nourriture des trois hommes formant notre arrière-garde. Ils devront attendre là notre retour et prendre soin des boufs et des chevaux.

M. L. Jalla nous transmet la bonne nouvelle que, suivant la demande qui lui en a été faite il y a plusieurs mois, le roi Léwanika nous envoie de sa capitale Léalouyi (Lialui), l'autorisation de pénétrer avec armes et bagages dans son royaume du bo-Rotsi.

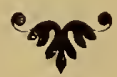


CHAPITRE VI

\section{AU PAYS DES BA-ROTSI. - LA RIVIERE MACHILE}

A Kizoungoula. - Nous rejontons le cours de la rivière Machilé. - ArrivéE A LA SOURCE DE LA RIVIÈRE MACHILÉ, TERRITOIRE DE LA TRIBU DES MA-NKOYA

$\mathrm{L}$ E Zambèze a repris sa physionomie habituelle. Le 26 juin, de bonne heure, le prince Litia, qui est le fils aìné du roi ct le gouverneur de cette partie du pays, met à notre disposition quatre pirogues avec leurs équipages et un chef zambézien; ce dernier tient en mains un court bàton noir, insigne de son autorité. La besogne de la journée consiste à faire passer notre matériel sur la rive gauche du Zambèze, ainsi que les ànes au nombre d'une vingtaine, et les quatre chevaux que nous emmenons avec nous dans cette partie du voyage. La seule manière possible d'amener nos animaux sur l'autre rive, consiste à les mettre de force à l'eau un à un; ils nagent à côté ou derrière le canot, maintenus par la bride. Ensuite vient le tour du matériel et celui de nos gens; nous passerons en dernier.

$$
\text { **** }
$$

27 juin. - Le transbordement a été terminé sans accident hier au soir; nous avons campé pour la première fois sur le territoire 


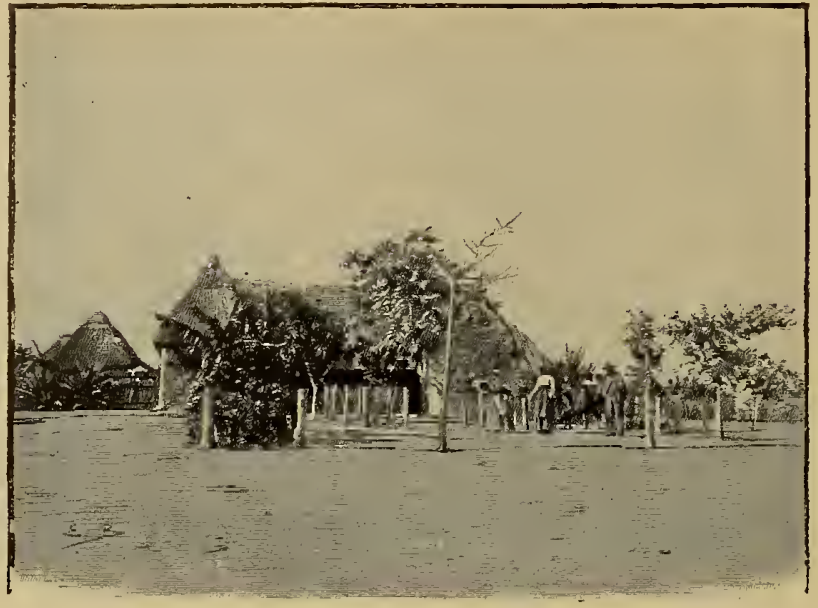

STHION MISSLOXNAIRE DE M. ET $\mathbf{H}^{\text {me }}$ LOCIS JALLA. Dsssin de Boudier. D'après une photographie de l'auteur. de Léwanika, roi des ba-Rotsi. "Tob ", notre chien favori, manque seul à l'appel et nous supposons qu'en allant boire au fleuve, il aura été happé par un crocodile. D'après ce que nous entendons, ces hideux amphibies sont coupables de

beaucoup de méfaits plus graves que celui-là. Nous avons donc eu du bonheur hier avec notre transbordement. Le prince héréditaire Litia qui réside à Kazoungoula vient, accompagné de M. L. Jalla, nous visiter à notre campement, établi non loin de la station missionnaire. Litia inspire de suite la sympathie par son bon sourirce et sa simplicité. C'est un homme d'une grande valeur morale; il s'est ouvertement converti au christianisme. Cette victoire est due à l'enseignement de MM. Coillard et Louis Jalla, qui ont été les intermédiaires dont Dieu s'est servi, pour faire l'éducation de cet lomme actuellement à la fleur de l'àge et sur lequel, étant donnée sa haute position, repose en grande partie l'espoir de la Mission. D'après les sources certaines auxquelles nous puisons nos renseignements, nous apprenons que sa conduite est en parfait accord avec ses convictions chrétiennes. Homme actif et intelligent, il aime à se délasser en travaillant de ses mains le bois et le fer. En ce moment, il se construit unc nouvelle résidence dont il dirige les travaux.

Dans une visite faite presque immédiatement après notre arrivée, j'avais admiré l'extrême propreté du palais en chaume de 
ce prince; la Bible, bien en évidence, occupail la place d'honneur.

J'ai aussi eu l'avantage d'assister à la classe des indigènes dans l'école, organiscée par Mme Jalla ef par Mlle Kiener. Celle-ci, originaire de Dombresson du canton de Neuchàtel, est le bras droil de M. et Mme Louis Jalla. D’emblée j’ai été frappé de l'ordre et de la discipline parfaits qui règnent dans cetle école : ordre el discipline d'autant plus remarquables que, par la force des choses, les élèves sont d'àges très mélangés.

Voici un grand jeune homme barbu, assis "̀̀ côté de petits

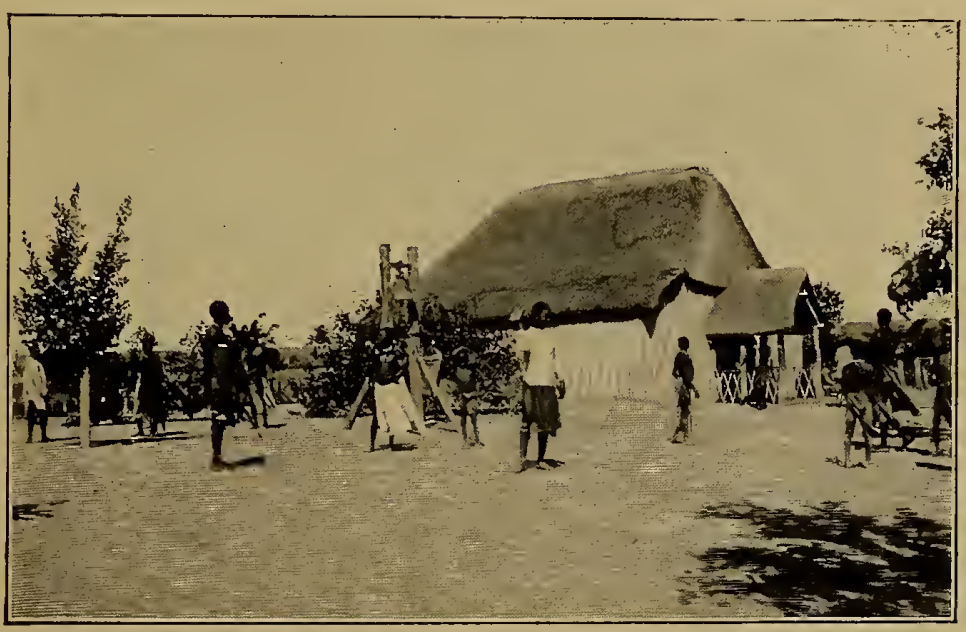

SORTIE DE L'ÉCOLE A KAZOUNGOLLA. Photographie de l'auteur.

enfants; il est fort désireux de s’instruire; ses yeux suivent attentivement les tableaux muraux. Assurément, ces dames ne peuvent arriver à des résultats pareils et tenir tout ce monde aussi bien en mains que par une grande patience, fruit de leur haute piété et grâce à un don tout spécial d'éducation. J'ai entendu là des cantiques qui par leur justesse et l'entrain avec lesquels ils étaient chantés, n'auraient été déplacés dans aucune école du dimanche européenne.

$$
*^{*} *
$$

28 juin. - Pendant plusieurs jours, tout est animation et travail au campement en vue de la continuation du voyage. Celui-ci, suivant les 
contrées à traverser, va se faire d'une manière fort différente. Nous avons vingt-cing ànes de bât, et l'excédent du matériel devra être transporté à dos d'homme, en lots qui n'excèdent pas cinquante livres; il faut donc calculer, diviser et peser. Puis nous devons nous munir de provisions nécessaires pour notre personnel qui sera augimenté.

Il y a eu récemment une famine dans les environs; mais M. Jalla avec sa complaisance inépuisable, nous est encore d'un grand secours en faisant répandre la nouvelle que nous désirons un marché. Des indigènes viennent de fort loin nous vendre leurs produits: millet, sorgho, maïs, fèves de différentes espèces, arachides, qu’ils portent dans des calebasses, suspendues ì l'épaule au bout d'un grand bàton. Quelques beaux types parmi ces Zambéziens, qui s'accroupissent à une distance respectueuse et restent immobiles; le temps ne semble pas avoir de valeur pour eux. L'unité de monnaie dont nous nous servons dans nos transactions est l'aune de calicot blane ${ }^{1}$.

$$
\text { *** }^{*} *
$$

29 juin. - Grande activité. M. et Mme Louis Jalla nous facilitent bien des choses, quoique leurs deux enfants soient malades ils insistent pour que nous partagions leur déjeuner, hospitalité que les uns et les autres nous avons déjà acceptée à plusieurs reprises.

$$
\text { *** }
$$

Dimanche 30 juin. - Assisté ce matin à l'église de la mission au service fait pour les indigènes par M. Jalla. J'ai r’emarqué la tran-

1. La brasse de calicot blanc ou selsiba se mesure en général le long du bras, de l’épaule au bout des doigts. 


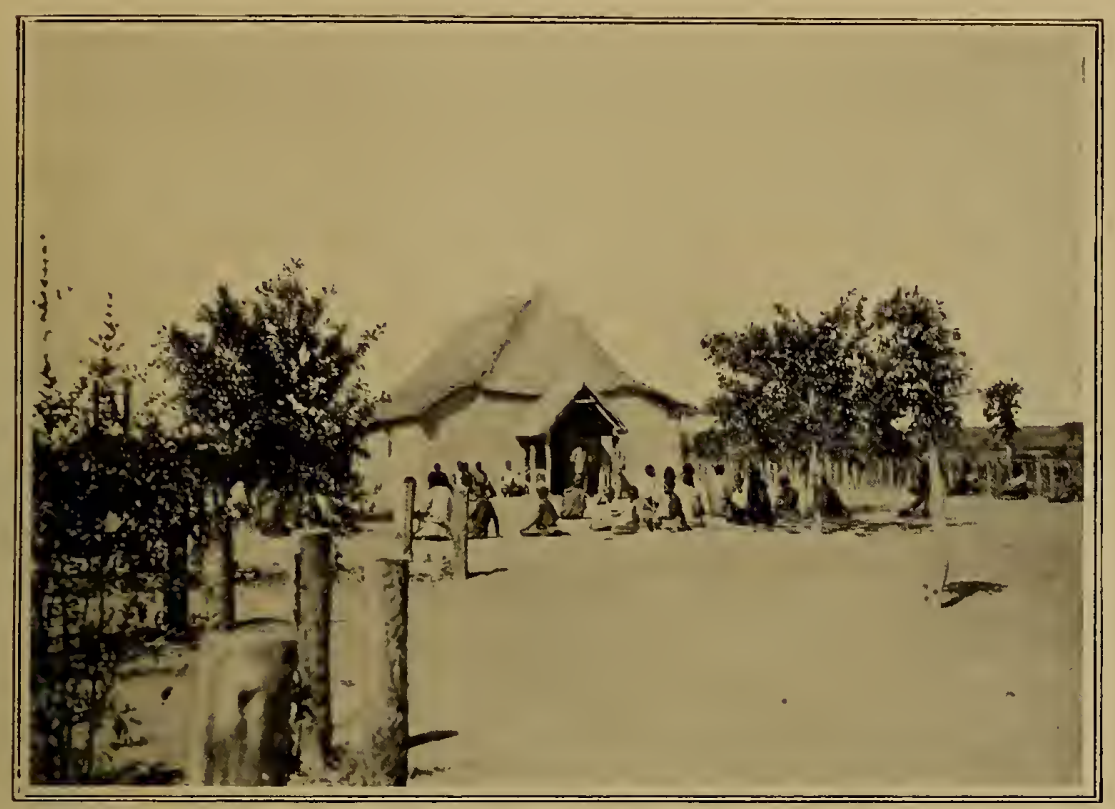

LE PRINCE LITIA SORT IUU TEMPLE.

Plotographie de l'autcur.

quillité el l'attention soutenue de cet auditoire d'environ deux cent cinquante hommes, femmes et enfants, ainsi que la manière dont les cantiques sont bien chantés. J'étais assis non loin du prince Litia qui, à la fin du service, a prié pour que son père, le roi Léwanika, non seulement encourage, comme il le fait depuis longtemps, l'wuvre missionnaire dans son pays, mais aussi pour qu'il se convertisse luimème franchement à l'Évangile. Léwanika est bien disposé; mais jusqu’à présent la polygamie l'a empèché, parait-il, de faire ce pas décisif.

L'histoire de la station missionnaire, intimement liée à la naissance du village de liazoungoula, est remarquable. En 1889, M. et Mme Louis Jalla, qui avaient déjì évangélisé depuis plusieurs années à Séshéké, quelques lieues en amont du fleuve, vinrent fonder cette station, aujourd'hui si florissante. L'emplacement où elle se trouve, n’était alors qu’un champ de maïs. C'est en 1892 que le roi Léwanika 
a ordonné à l'un de ses chefs, Makoumba, de commencer l'établissement d'un village à côté de la station missionnaire. Les huttes rondes en chaume se sont ajoutées aux huttes et la station compte aujourd'hui une population approximative de six cents àmes, sur lesquelles cent quinze hommes et femmes ont déjà déclaré vouloir renoncer aux pratiques du paganisme. Selon toute probabilité, elle aura d'ici à peu de temps un millier d'habitants. Après Léalouyi, la capitale, elle est considérée comme le centre le plus important du royaume, celui d'où viennent les nouvelles; Kazoungoula est aussi la clef du territoire des ba-Rotsi.

Le chef Makoumba' est mort depuis notre arrivée. Selon les coutumes, il a été enseveli quelques heures après le décès et de nuit. Ses femmes l'ont pleuré pendant trois jours; à ce moment leurs chevelures ont été rasées et les différentes huttes appartenant à Makoumba ont été coupées au ras du sol; nous en avons vu les débris hier. L’une de ses femmes, accusée de sorcellerie et menacée d'être jetée au fleuve, vint se réfugier à la mission où elle a été recueillie et nourrie. Personne n'a osé venir la chercher de force, tant est grand auprès de ces païens, le prestige de ces quelques hommes et femmes, esclaves du devoir et qui, en cas d'attaque, ne se défendraient même pas.

Mme Jalla a, dans sa maison entièrement construite par son mari ainsi que l'église, dix jeunes filles indigènes qu'elle forme de manière à en faire pour l'avenir des mères de famille qui soient capables d'élever leurs enfants el d'avoir un intérieur. Il en est de mème, parait-il, dans les autres stations.

Le prince Litia est venu au culte de l'après-midi; à son approche, comme le veut l'étiquette des ba-Rotsi, ses sujets s'accroupissent et frappent lentement dans leurs mains. 


$$
\text { **** }
$$

Lundi $f^{\text {er }}$ juillet. - Nous avons eu le plaisir de recevoir aujourd'hui pour le lunch à notre campement M. et Mme Louis Jalla, Mlle Kiener

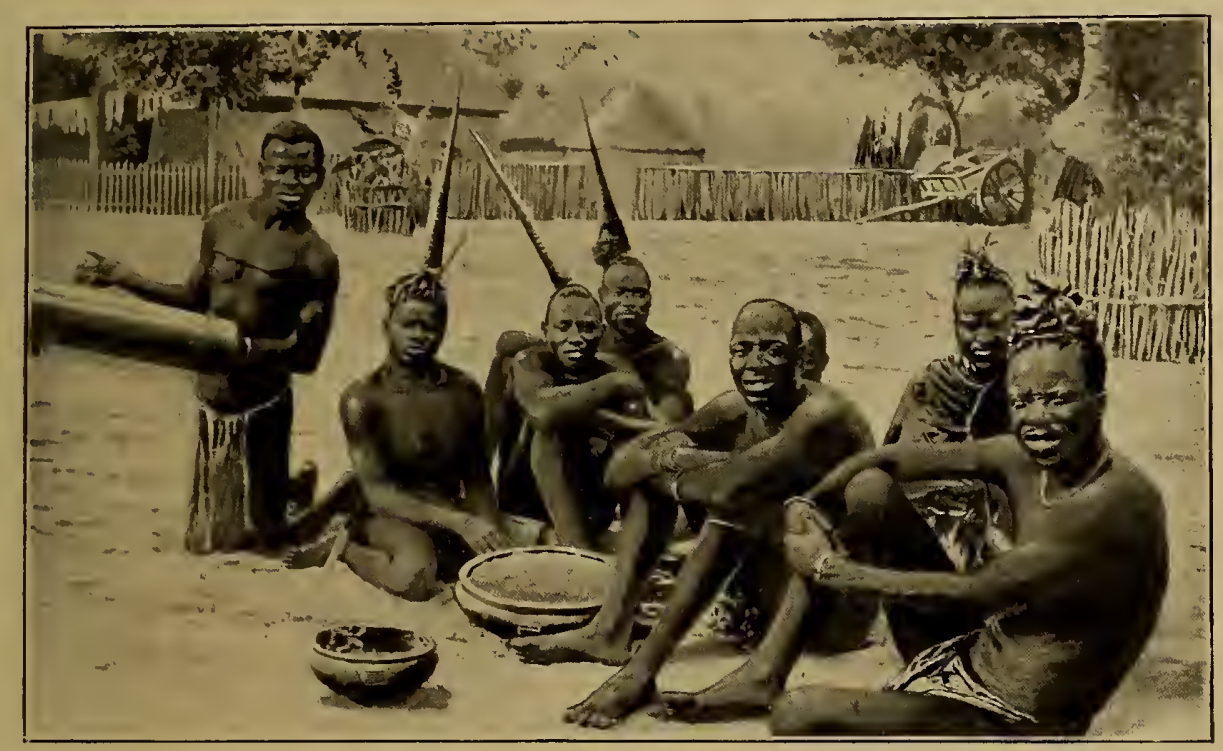

TYPES DE L.A TRHBU DES MLA-SHOCKOCLOLMBOCÉ.

Photographie de M. Colllard. - Reproduction interdite.

et le Rív. Buclienham, ce dernier, missionnaire dans le pays des maShoukiouloumboné '.

Ifin de nous alléger et de pouvoir aller rapidement de l'avant, nous avions laissé en arrière tout ce qui pourrait nous encombrer; ainsi les chaises et les tables de campement. Pour cette invitation, nous y avons suppléé avec des " caisses de rations ". Neuf d'entre elles ont formé la table; d'autres, recouvertes de nos plus belles couvertures en l'honneur des dames, ont fait des sièges fort présentables. Ouelques minutes avant l'arrivée de nos hòtes, nous leur dépêchons un messager

1. Le Rèv. Buckenham est mort à Kazoungoula, le 11 juillet 1896. 
pour leur demander de bien vouloir apporter des couteaux et des fourchettes. Le lunch, création de Reid, a été déclaré excellent; e’est un repas d'adieux. Le menu se compose d'un ragoût d'antilope relevé par des carottes et des fèves conservées, de pommes séchées en marmolade et d'un soi-disant pudding au riz. Les crus généreux, d'usage en pareille occasion, sont remplacés par l'eau relativement fraîch o du Zambèze, ainsi que par du thé et du café.

Nos préparatifs de départ sont terminés; il faut se remettre en route.

Il nous sera difficile d'oublier ces quelques jours passés à Kazoungoula, près de la station missionnaire; son aspect gracieux, l'excellent accueil reçu et la bonne atmosphère respirée. Une véritable oasis dans le désert!

Nous partons demain, direction nord, à destination de la rivière Machilé (Machili) dont nous voulons atteindre la source. Notre personnel se compose de vingt-cinq hommes; nous le renforcerons à mesure que nous avancerons. Nous avons en outre vingt-cinq ànes de bàt, six chiens et quatre chevaux de selle; selon toutes probabilités, ces derniers devront être sacrifiés.

Le capitaine Gibbons, pour une exploration différente de la nôtre, se dirige à l'ouest en remontant le cours du Zambèze. Nous espérons nous rencontrer plus tard ${ }^{1}$.

$$
* * *
$$

2 juillet. - A deux heures de l'apr'ès-midi, dernière inspection passée avant le départ de Kazoungoula. Les charges ont été pesées et sont distribuées aux hommes qui, patiemment accroupis, attendent d'être appelés par leur nom pour s'avancer et recevoir leur lot, du 
poids d'environ cinquante lirres; ils portent ee poids sur l'épaule, ígalement réparti aux deux extrémités d'un long bàton. Les ànes sont bitcis al chargés de quatre-ringt-cing à cent vingt livres; nous montons à cheval el la caravane serpente bientòt à travers la grande plaine.

Temps d'épreure que ees premicrs jours de marche, avant que chacun sache bien ce que l'on attend de lui et surtout qu'hommes et biles soient de nouveau habitués à la faligne. En outre, les charges des ànes sont attachées arec des cordes d'herbes tressées, qui se rompent continuellement. Lorsque nous aurons tué du gros gibier, nous utiliserons leur peau pour faire des lanières solides. Il faut faire appel ì sa patience, en voyant à tout bout de champ une caisse ou un ballot jeté à terre et l’animal déchargé, joyemx d’ètre débarrassé de son fardeau, fuir au galop.

Nous faisons halte dans un bois de mopané; la tente est rapidement dressce, les charges mises en ligne, et voici Jonnes le cuisinier, qui nous annonce la nouvelle très bien reçue que " la table est servie ".

Cotte phrasc est un peu prétentieuse car, je l'ai dit, afin de nous alléger, nous avons laissé à Kazoungoula avec les derniers vestiges de civilisation, tout ce qui pourrait nous encombrer ct c'est désormais le sol qui nous sert de table et de sièges.

$$
*^{*} *
$$

3 juillet. - Sur pied avant le solcil, nous levons le camp immédiatement. Deux chevaux se sont égarés pendant la nuit; Piric et moi nous attendrons le retour des hommes envoyés sur leurs traces. Après ce retard, nous passons près du village de Mombava, composé de quelques huttes; nous en voyons de loin les habitants. Grande chaleur; nous campons près de la rivière Ntengué (Intangwi). 


$$
\text { *** } *
$$

4 juillet. - Après avoir éprouvé les mèmes difficultés que les jours précédents, nous passons la nuit sur les borrls de la rivière Nguézi (Umgwezi). Trois de nos hommes sont blessés par la marche; une fois de plus, j'ai en les soignant, l'occasion de mettre en pratique les excellents enscignements du docteur qui a fondé à Genève l'ouvre des Samaritains.

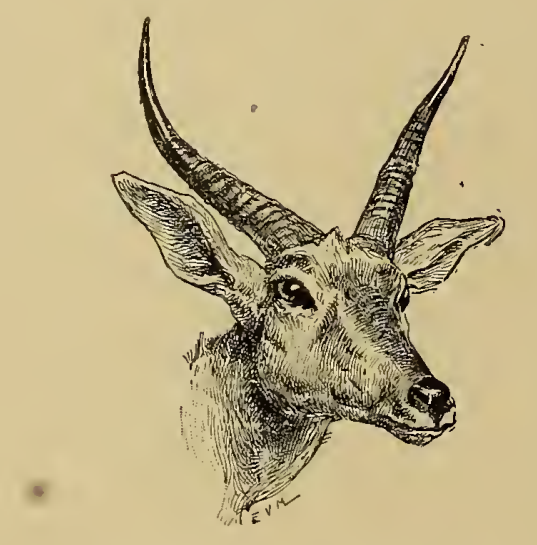

REE1)BUCK, "CERYICAPRA ARCNDINACEA". Croquis de Van Muyden.
pécimen rapporté par l'auteur.

$$
*^{*} *
$$

5 juillet. - Levés de nuit, nous partons de bonne heure; nous voulons atteindre aujourd'hui la rivière Kasaia; nous traversons alternativement de grandes plaines et des espaces boisés d’où surgissent quelques superbes baobabs. Nous arrivons à destination dans le courant de l'après-midi; le dernier des hommes nous rejoint à 7 heures du soir et nous décidons de faire là une halte de deux jours, car il nous faut absolument des lanières de gros cuir et de la viande pour tout notre monde. En route, nous avons recruté huit nouveaux porteurs, ce qui fait, sans nous compter, trente-trois hommes à nourrir.

$$
\text { *** }
$$

(j) juillet. - Nous tuons un zèbre, un gnou et, pour ma part, j’ajoute à notre garde-manger deux reedbuck (Cervicapra arundinacea) antilopes aux formes élégantes, dont la chair est excellente. Toutes les mains disponibles sont activement occupées à préparer du "beltong" et à confectionner des lanières. 
Nous sommes dans le pays des lions; d'après ce que l'on nous dit, il y a dans les environs une lionne avec ses lionceaux, fort dangereuse: un nègre, la veille de notre arrivée, a failli ètre sa victime.

$$
\text { *** }
$$

7 juillet. - Dimanche, jour de repos. Les chiens n'ont pas eu un instant de tranquillité la nuit dernière; les chevaux et les ânes, renfermés en leur habituelle enceinte de branchages, dans le " kiraal ", ont manifesté une grandle inquiétude. Les fauves rôdaient autour de notre campement.

Après le repas du soir, Pirie fumait tranquillement sa pipe au coin du feu, lorsque subitement il sortit de sa béatitude par la piqûre d'un scorpion apporté probablement avec le bois nécessaire au foyer. Ces animaux malfaisants se logent souvent entre l'écorce et l'aubier; la chaleur les fait sortir de leur refuge.

$$
\text { *** }
$$

8 juillet. - Après une nuit aussi agitée que la précédente, nous faisons aux premières heures du jour, transporter à dos d'hommes les charges des ànes sur la rive droite de la rivière Kasaia, dont les berges sont assez escarpées; à cette époque il est facile de la traverser à guć. Les ânes, qui décidément n'aiment pas l'eau, sont passés un ì un, non sans une résistance désespérée. Nous reprenons la marche à travers une belle végétation de palmiers et de baobabs; nous passons près d'un troupeau de gnous qui broutent sans méfiance.

$$
*^{*} *
$$

9 juillet. - Nous campons sur la rive droite de la rivière Machilé, affluent du Zambèze dont nous avons projeté, comme nous l'avons 
dit, de remonter le cours jusqu'à sa source. Ciette rivière n'est que pointillée sur les meilleures cartes géographiques; nous sommes done en région non exploríe.

Pendant cette dernière marche, nous avons fait une halte près d'un village entouré de plantations de millet, de maïs, de courges. Nous remarquons des plates-formes élevées de quelques pieds audessus du sol; des femmes y sont occupées à trier du maïs. Les animaux domestiques sont représentés par des petites chèvres blanches et noires, des poules, et des moutons a grosses queues. Nos gens fatigués de la nourriture animale qui compose presque exclusivement leur alimentation journalière, $y$ échangent avec les habitants une partie de la venaison qu'ils ont reçue en partage, contre des arachides et du millet.

Deux de nos porteurs, lesquels à notre insu étaient restés en arrière de la colonne se sont enfuis en abandonnant leurs charges. Une caravane peut ètre mise dans un grand embarras lorsque, comme cela a déjà eu lieu pour d'autres expéditions, les porteurs désertent en masse. Nous espérons qu'avec les précautions prises, ce ne sera pas notre cas. Du reste, nous avons un certain nombre de Béchuanas, de Bushmen, de ma-Saroua, dont la patrie au delà du Zambèze est bien éloignée; ils partagent nos peines et nos joies depuis longtemps; bref, s'ils nous abandonnent, nous aurons les ânes comme dernière ressource.

Reid qui est en avant, force à cheval un éland ${ }^{1}$ (Oreas camna), très forte bête qui contrairement aux autres espèces d'antilopes, n’a pas une allure rapide. Son poids doit atteindre un millier de livres; l'épaule à elle seule en pèse quatre-vingts. La viande de l'Oreas canna

1. Ne pas confondre avec l'élan des pays du Nord. 
rappelle celle du bouf; sa graisse nous est précieuse car nous pouvons, sans trop de répugnance, l'employer pour les besoins de notre cuisine.

Nos hommes font des lanières avec le cuir du gros gibier tué récemment. Pour suppléer à l'opération du tannage, ils procèdent de la manière suivante: après avoir découpé sur le corps de l'animal, des bandes de quelques centimètres de largeur et aussi longues que possible, ils font passer cette lanière par-dlessus une branche d'arbre élevé; puis ils relient les deux extrémités. Entre ces deux extrémités, ils placent une grosse pierre, puis, au-dessus, un fort bâton. Tout en chantant et par le moyen de ce bâton, ils tordent ces lanières autant que faire se peut. Ils les laissent se détendre d'ellesmêmes et recommencent leur torsion

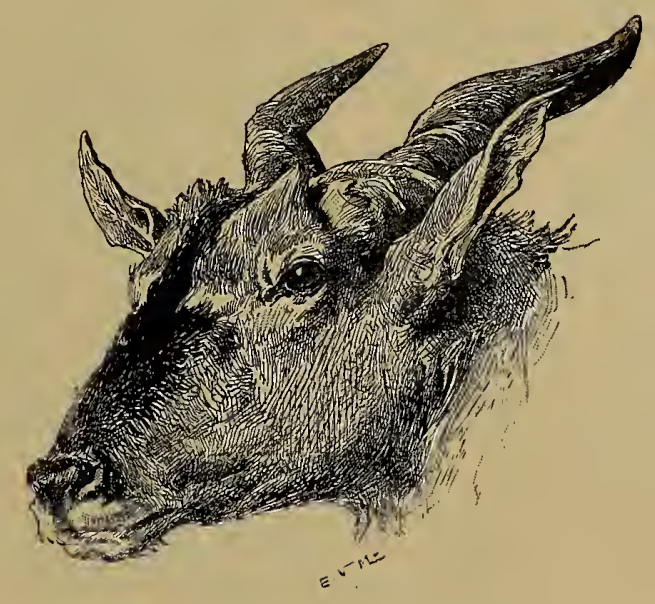

LIVINGSTONE'S ELAND. "OREAS C.TXXA. " Dessin de Van Muyden. Spćcimen rapportó par l'auteur. jusqu’à ce que le cuir arrive au degré de flexibilité voulu.

A l'endroit où nous sommes, la rivière Machilé peut avoir, à en juger par ses berges, entre 250 à 300 mètres de largeur; son étiage est actuellement très faible; le volume des eaux doit être considérable pendant la saison des pluies.

Jusqu'à maintenant, nous avons aperçu des animaux sauvages isolés, ou par petits groupes. Ensuite et pendant quelques jours, nous traversons une zone où, magnifique spectacle, nous rencontrons par centaines des gnous et des zèbres. Ces deux espèces d'animaux semblent avoir une sorte d'affection marquée l'une pour l'autre et sont fréquemment en compagnie. Rien de plus intéressant que d'observer, prise 
sur le vif, la manière de vivre de ces animaux. Les zè̉bres m'ont semblé faire le service de garde avec beaucoup de sagacité; dès qu'ils aperçoivent quelque chose d'insolite ou au moindre bruit, ils se placent en terrain ouvert comme de véritables sentinelles.

En remontant cette portion de la Machilé, l'aspect du terrain fait

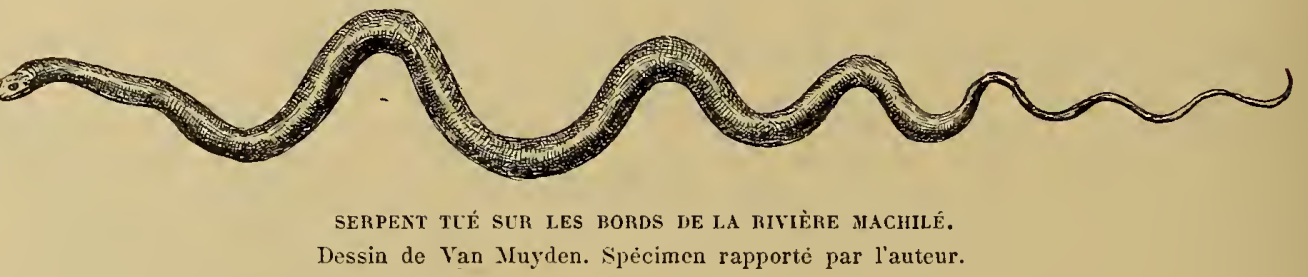

penser qu'une bonne partie du pays contigu à la rivière doit être plus ou moins envahie par les eaux, pendant la saison des pluies.

Le repos des nuils a élé fréquemment troublé par les ricanements des hyènes qui viennent ròder près de nos campements; les chiens leur répondent avec acharnement.

$$
\text { *** }
$$

12 juillet. - Après nous être remis en route et au moment de faire une nouvelle halte, nos hommes tuent à quelques pas de la tente un serpent, paraît-il venimeux, de $2^{\text {"x }}, 40$ de long ${ }^{~}$. lls nous apportent des poissons ainsi que des tortues d'eau. Nous avons établi notre campement sur une éminence de terrain entourée de palmiers nains; cet emplacement doit former une île pendant les pluies. Nous apercevons des lechwe (Cobus leche), ces antilopes aux longs pieds qui vivent volontiers dans les endroits humides. Depuis plusieurs jours nous enten-

1. Ce serpent nous intéresse par sa structure. Sa tète est petite; son corps se termine graduellement par une pointe à peine plus grosse qu'une aiguille à tricoter. J'en ai rapporté la peau, quoique nos hommes aient manifesté une grande répugnance à l'écorcher. 


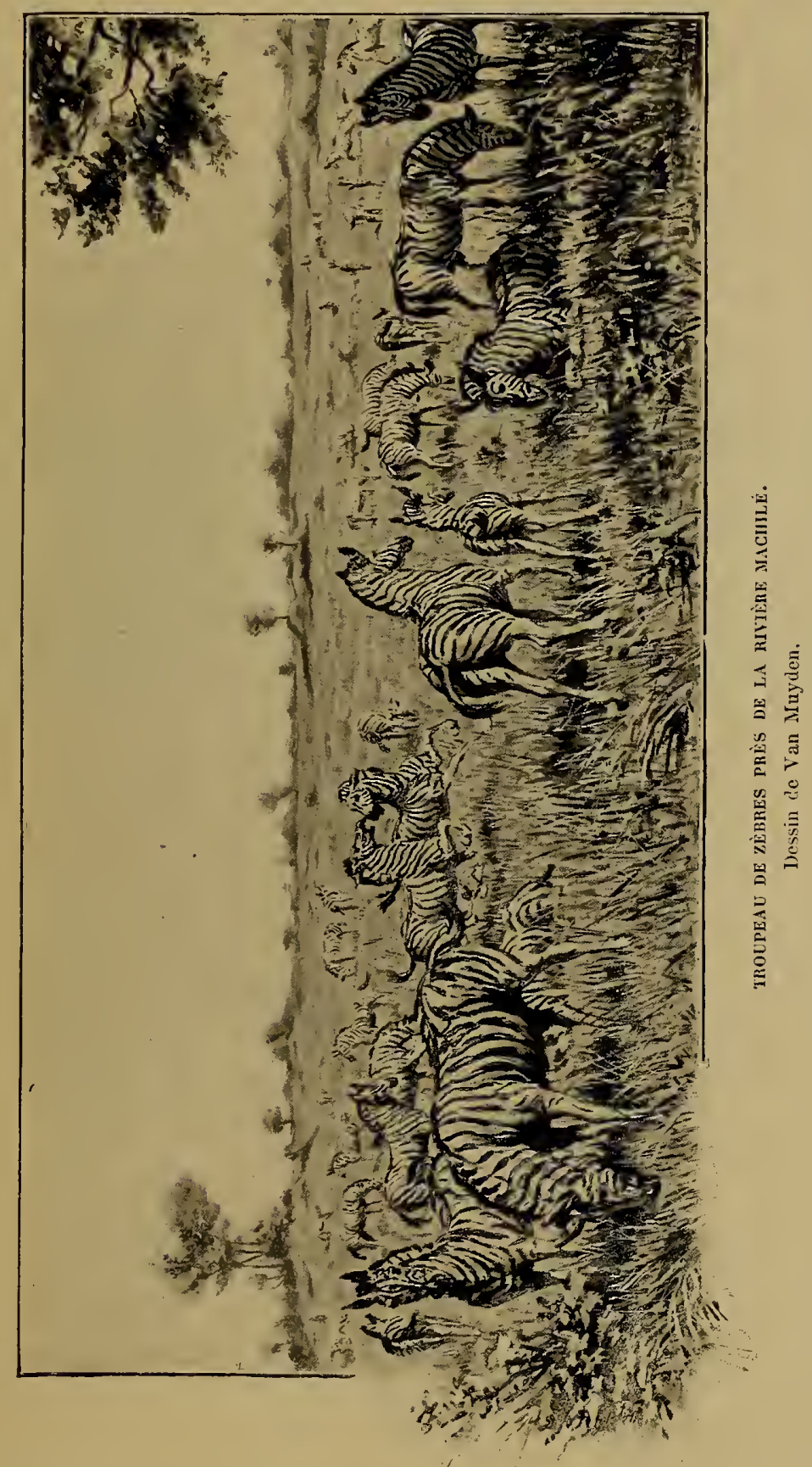





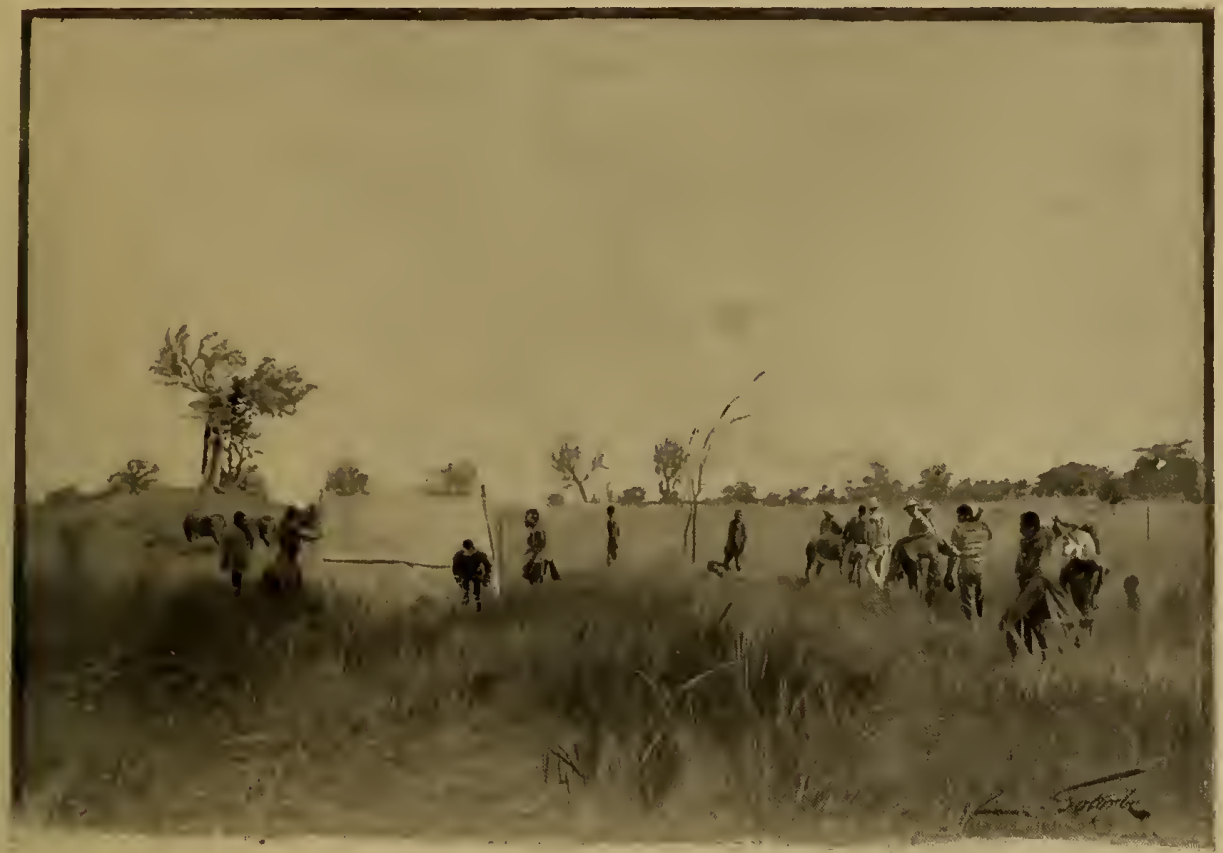

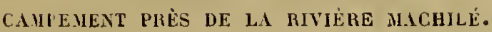

Dessin de Gotorbe. D'après une photographie de l'auteur.

dons le grognement des hippopotames : je vois en longeant la rivière un de ces animaux qui disparait; il est remplacé à quelques minutes d'intervalle par un crocodile dont la tète hideuse seule émerge de l'onde. Cà et lì de grands échassiers se promènent, qui n'ont pas l'air d'ètre surpris le moins dı monde par notre présence.

$$
\text { *** }
$$

16 juillet. - Nous campons au-dessus de la grande plaine, autrement dit le lit de la rivière, où, à cette époque de saison sèche, l'eau peu profonde ne fait que serpenter. Il faut pourtant s'en défier, car des roseaux et des herbes aquatiques masquent souvent des trous où il est facile de s'embourber. I maintes reprises nous en avons fait l'expérience.

Kilass Africa, ancien chasseur d'éléphants que nous avons engagé 
pour un certain temps, nous rejoint ici. II remplira les fonctions de sous-officier auprès de nos hommes. Comme le cuisinier Jonnes, il est d'origine hottentote, un " yellow man ", homme jaune. Il est accompagné de trois serviteurs indigènes qui, chaque soir, lui construisent un "skerm " où il a toujours sa carabine à portée de la main. Il se suffit complètement à lui-mème et il est homme de ressources.

Nous jouissions dans l'après-midi d'un moment de repos, lorsque soudain, une paire de lions est signalée dans les environs du campement; nous sautons sur nos rifles et les poursuivons dans la brousse épineuse. Reid a la bonne fortune d'abaltre la lionne presque à bout portant; la bète agonisante trouve encore la force de mordre Swatt, un épagneul, le plus courageux des chiens. Il faut quatre hommes pour transporter le fauve, ì la grande joie de nos gens qui se forment en cortège et entonnent un chant de victoire, répétant, comme un refrain : "Le grand chef est mort, il ne reviendra plus ".

Cette superbe lionne mesure deux mètres cinquante-trois centimètres de la pointe du mufle au bout de la queue; de l'extrémité de la patte au garrot, sa hauteur est de quatre-vingt-cinq centimètres; le tour de sa taille compte un mètre neuf centimètres; enfin les canines de sa mâchoire supérieure ont près de quatre centimètres et demi de longueur. Ce qui frappe surtout, en l'animal une fois dépouillé, c'est la puissance des membres antérieurs, la largeur des pattes, armées de griffes acérées.

$$
\text { *** }
$$

17 juillet. - La victoire de la veille a été chèrement achetée. Pendant la nuit, deux de nos chevaux, celui de Reid et le mien, ont été 


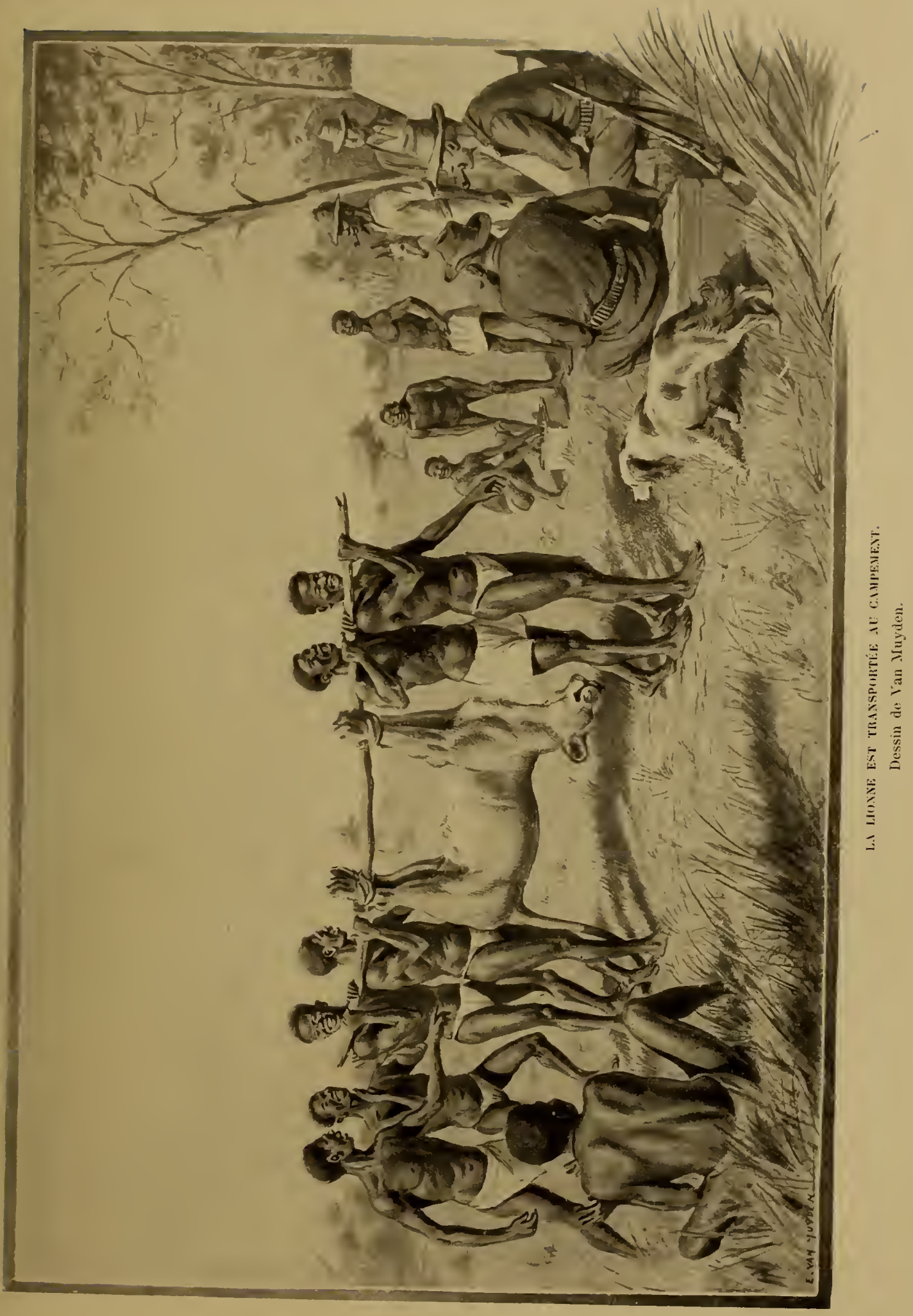



Ggorgís par le compagnon de la lionne. Paure " llelp ", si vif at si gai, je ne croyatis pas le mouler hier pour la derniere fois!

Les faces du lion nous permettent de le poursuive; mais la brousse est tellement épaisse que nous ne pouvons pas l'alleindre. Il est probable que le fauve viendra, a la tombée de la muil, se repaitre de lit chair de sés victimes, aussi nous lirons au sort pour désigner celui d'entre nous trois, qui devara se meltre à l'affüt et venger nos devaux; je suis désigné.

Peu avant cing heures, je sor's du campement, mon " express rifle" it balle explosible sur l'épatule el prends seulement avec moi l'un de nos jeunes porteurs armé de deux lances. Arrivé sur le bord de lit rivirre où gisent, au milieu des roseaux, nos deux chevaux, j'installe mon alfùt sur un arbre qui commande el surplombe l'endroit où se trouve le eadavre du premier cheral. Je m'établis à califourchon sur une grosse branche; mon "boy" se perche un peu au-dessus de moi.

Arant la nuit tombante el en attendant le fauve, jo parcours tout en ayant l'ail et l'oreille aux aguets, un numéro déja très ancien du Journal de Genive que je n'avais pas encore eu le temps de lire. Le erépuscule se fait peu à peu; voici la première étoile. Le grand silence n'rst troublé que par le bruissement des insectes, qui ressemble à celui des grillons ou des cigales. La nuil se fail de plus en plus noire et sur son perchoir, mon "boy " soupire profontément. Après plusieurs heures dialtente vaine, je descends de mon poste sans que le lion ait paru; mais non sans avoir entendu les sinistres appels des hyènes et les glapissements des chacals, accourus à ce festin improvisé et qui broient les os des malheureux compagnons de nos bons et de nos mauralis jour's. Jamais je ne vis un pas plus allongé que celui de mon " hoy ", rentrant sain et sauf au campement! 


$$
\text { *** }
$$

18 juillet. - Cetle nuit, hyènes ou chacals, ont fait rage et nous avons élé réveillés plisieurs fois. Ce matin, il ne reste rien du cadavre de la lionne, lout a disparu. Nous confions nos brides el nos selles à des indigènes qui doivent les transporter à Kazoungoula et puis... en route! Désormais la marche sera notre unique moyen d'avancer, il ne nous reste plus qu'un seul cheval. Nous suivons les taillis plus ou moins épars, entremêlés de gros arbres qui bordent la rivière; nombreuses empreintes de lions ainsi que des traces fraîches de buffles. Celle fois-ci, nous dressons notre tente près de la rive. Nous finissions notre repas, lorsque nous entendons le groguement d'un hippopolame. Prenant nos armes, nous sommes bientòt à proximilé de la bête qui est inquiète; elle renifle et aspire bruyamment l'eau. Pour nous, impossible de rien voir, l'obscurité est trop grande. Au repas du soir, nous avons mangé du zèbre, chair qui n’est point à dédaigner comme on serait tenté de le croire.

$$
* * *
$$

19 juillet. - Nous sommes obligés d'abréger les souffrances du dernier cheval; il n'y a plus d'espoir pour le pauvre "Tomy " qui a élé piqué par la tsé-tsé, cetle mouche meurtrière. Elle provoque dans un délai plus ou moins long la morl de presque tous les animaux domestiques. Chevaux et borufs, une fois piqués, meurent rapidement, tandis que les ânes peuvent vivre encore pendant des mois ${ }^{1}$. Fait vraiment curieux, la tsé-tsé se trouve surtout dans les parages fréquentés par les buffles; le gibier ne semble pas êlre affecté par sa piqûu’e.

1. Les animaux domestiques qui résistent à ce venin sont en infime minorité; on les appelle a salled "et ils prennent une grande valeur. 


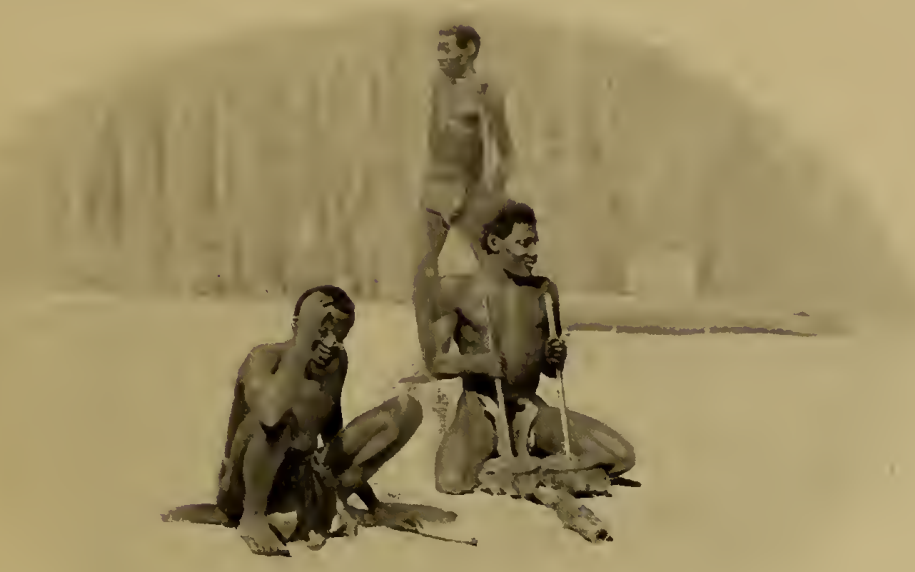

FOLGEROXS MA-TOTELA.

Dessin de Thiriat. D'après une photographic de l'auteur.

Dans une expédition du genre de la nòtre, il faut être préparé d'avance à tous les accidents qui ne manquent pas de survenir; nous allons donc de l'avant avec entrain! Un porteur a encore pris la fuite aujourd'hui.

Nous arons été plusieurs fois témoins de grands incendies de prairies qui sont superbes pendant la nuit; ils détruisent quantité d'insectes. La régétation est si puissante que l'herbe ne tarde pas à repousser sur ces espaces calcinés; il n'en est pas de mème des arbres qui périssent aiusi en grand nombre.

Les variétés de fourmis sont nombreuses; deux fois déjà, dans l'espace de quelques heures nos bagages ont été attaqués par les termites.

En chasse, je rencontrai une colonie de singes au pelage gris brun et au museau noirìtre, dont j’ignore le nom.

$$
\text { *** }
$$

20 juillet. - Le paysage change continuellement d'aspect. A l'endroit où nous nous trouvons aujourd'hui la rivière coule au 
fond d'une vallée surplombéc par des collines basses, dont le sommet seul est couronné d'arbres. Un coude aceenturé la fait remonter dans la direction nord et le pays, surtout sur la rive droite, ne tarde pas à s'ouvrir de nouveau; nous distinguons dans le lointain une série d'ondulations de terrain boisć; c'est là que j'eus encore la bonne chance de tuer un reedbuck (Cervicapra arundinacea) et que Reid abattit un oribi (Nanotragus scoparius), l'une des plus petites antilopes connues.

$$
\text { *** }
$$

21 juillet. - Un troupeau de gnous ayant eu l'idée de s'avancer trop près de notre campement, dut subir les conséquences désastreuses de sa curiosité; il a approvisionné largement notre gardemanger. Ici nous remarquons de grosses fourmis noires, à tête plate armées de pinces, dont elles savent se servir à nos dépens.

$$
* * *
$$

23 juillet. - Nous traversons à gué deux affluents de la Machilé, qui ne sont pas indiqués sur nos cartes, et que les indigènes appellent Kanimba et Kamakara. Ma caisse à munitions, sans grand dommage heureusement, tombe à l'eau à celte occasion.

Nous passons près de quelques huttes; elles sont en chaume et entourées, probablement par crainte des fauves, d'une haute clòture.

J'observe près de lì un forgeron indigène. Il confectionne ce qui semble être une hache; une grosse pierre lui sert d'enclume, son aide attise le feu en faisant fonctionner un soufflet plus que rudimentaire.

Le minerai de fer doit donc exister dans le pays?

Plus loin, voici une vaste plantation de melons d'eau et de courges. 
Une femme est en train de les couper en petits quartiors qu'olle fait sécher au soleil.

Nous avons parmi nos porteurs senlement deur ba-Rotsi de la tribu régnante; les aulres appartiennent aux peruplades soumises : ma-

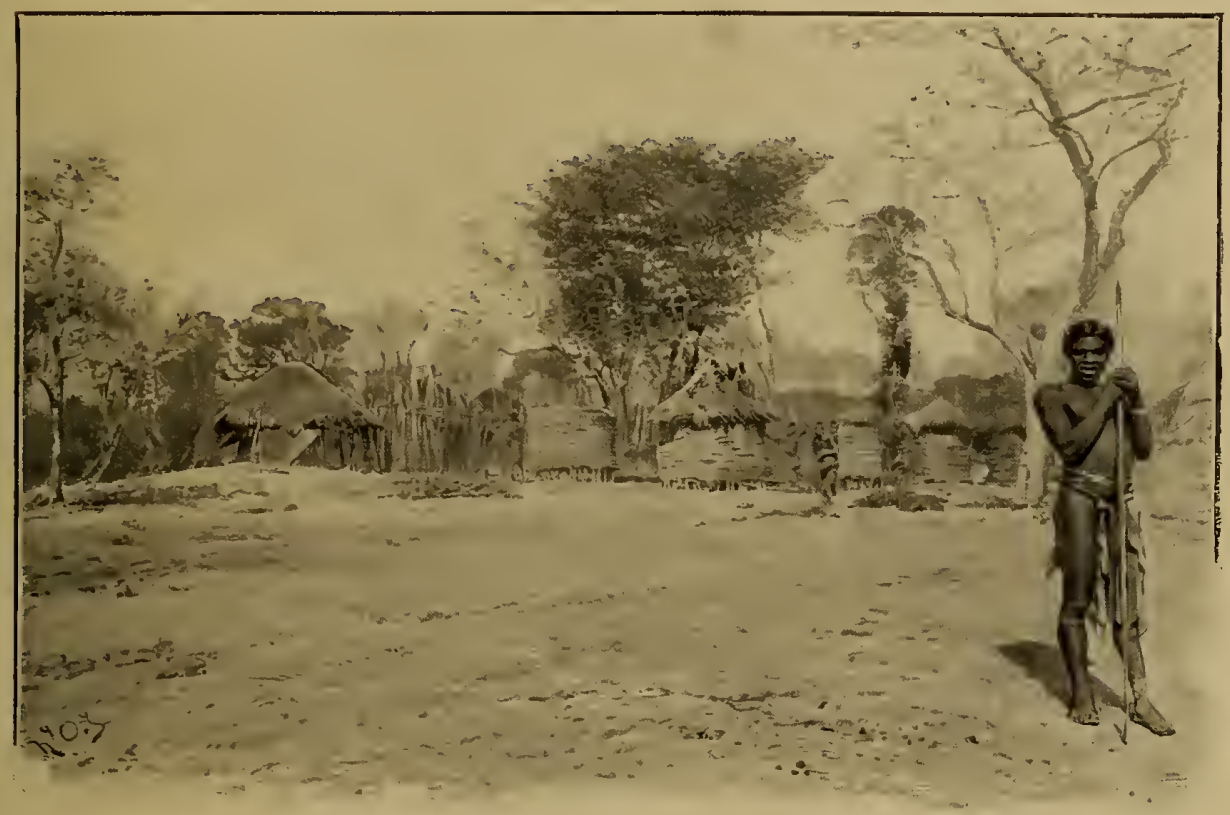

VILLAGE MI-TOTELA ET GRENIEHS I GRAMS.

Dessin d'Oulevay. D'après une photographic de l'auteur.

Totéla, ba-Toka, etc. Nous avons même un mo-Shoukouloumboué (nord-est); il est privé de ses quatre incisives centrales et latérales supérieures. Suivant l'usage, un jeune homme de celte région ne pourrait pas songer à prendre femme, s'il ne procédait pas au préalable à cette opération, car, disent les ma-Shouliouloumboué (Mashikolumbwe), ces dents ressemblent ì celles du zìbre.

Arrivé à l'étape, chaque groupe s'établit à part, ce qui fait que le soir notre tente est entourée par six ou sept feux de bivouac; cela ne les empèche pas de se rendre visite mutuellement pour rire et causer. A la lueur des flammes, nos hommes se racontent les faits et incidents 
de la journée avec force interjections et exclamations; ils imilent à la perfection les cris des animaux. C'est le moment où ils aiment à priser du tabac cultiré dans le pays; il leur tire les larmes des yeux lant il est fort. Il en résulte des maladies des organes visuels; la petite vérole a aussi souvent pour leur rue des suites fàcheuses.

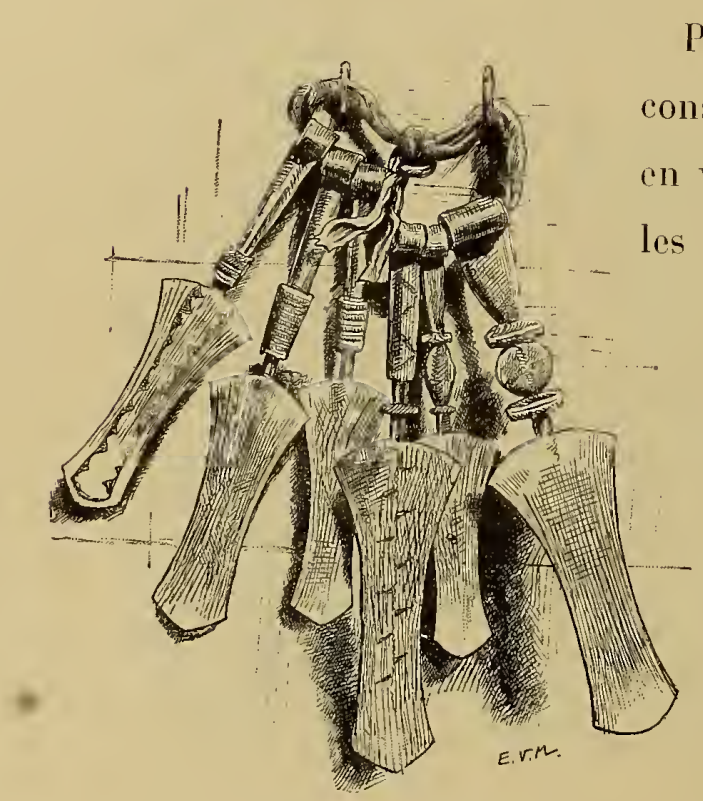

HOCCHOIRS DE POCHE MUHLENES.

Croquis de Van Muyden. Collection te l'auteur.

Puis ils préparent leur nourriture qui consiste, lorsque la chasse est abondante, en viande qu’ils grillent simplement sur les charbons ardents, ou suivant les circonstances, en sorgho, maïs, millet et arachicles, dont ils sont très friands ${ }^{\text {. }}$.

J'observe l'un de nos hommes qui fait de la musique à sa manière; l'instrument rudimentaire se conpose d'une planchette à rainures qu'il frotle avec un morceau de bois; il en tire des sons distincts, mais nullement liarmonicux.

Si au point de vue physique les types varient beaucoup entre eux, il n'en est pas de même de l'habillement, dont la pièce principale est un pagne relenu ì la ceinture par une peau de serpent. Les plus fortunés y ajoutent une dépouille de bète sauvage ; ils se parent volontiers de colliers, boucles d'oreilles, bracelets, ele. N'oublions pas l'une des particularités, unique en son genre, de la toilette cependant si simplifiée, des ba-Rotsi : le mouchoir de poche. Celui-ci consiste en une mince lamelle de fer linement travaillé avec manche du mème

1. Dans la langue du pays : sorgho = mabele; maïs $=$ mponyé; millet $=$ maoutsa; arachides $=$ masambané. 


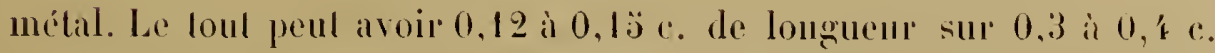
de largent. Cet objel so porte suspendu au cou pall des fibres végétales ou des nerfs. Ils sen servent, pour se moncher, romme d'un ressorl avec une extrème dexlérili, ce qui, au feu de bivouac, j’en pnis parlep de visu, n’est pas chose plaisante! Nous constatons que res samvages

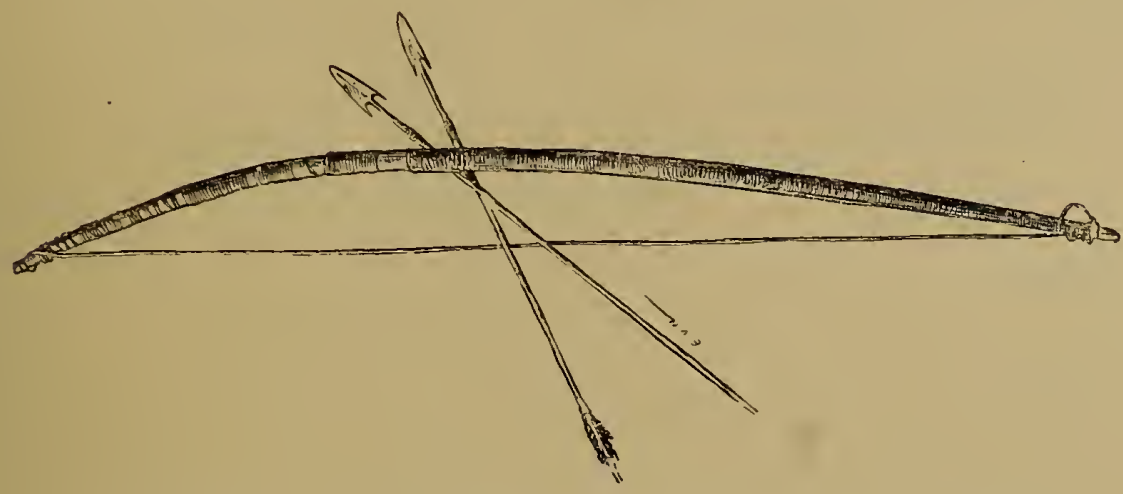

AHG ET FLẺCHES EMPOISONAÉES ÉCH.NGÉS SLR LE TELRITOIRE DE LA TRIBU DES M.L-NKOYA. Croquis de Van Mayden. Collection de l'auteur.

ont su perfectionner le mode de se moucher que pratiquent encore, en pays civilisés, certains habitants des campagnes.

Presque tous sont armés de longues lances, plus ou moins barbelées.

Les transactions effecluées avec les rares indigènes que nous rencontrons, se règlent au moyen de la brasse de calicot blanc (setsiba) qui est la monnaie courante, el avec de petites perles de verre opaques et blanches; c'est ainsi que récemment nous nous sommes procuré des aufs.

Dans les rencontres, nous sommes salués par le mot de louméla, qui veut dire : "bonjour " ou plus exactement " au revoir ". Lorsque ces indigènes sont armés, ils déposent leurs lances à distance respectueuse jusqu'ì ce qu'ils soient interpellés, sans jamais montrer le moindre signe d'impatience. Ils apportent lenrs produits dans des calebasses suspendues au bout d'un long bàton. 
La calebasse joue un grand ròle dans ce pays, non seulement pour le transport des grains et liquides, mais aussi comme ustensile.

$$
\text { *** }
$$

24 juillet. - Sur les deux rives de la Machilé s'élendent des collines basses; elles laissent entre elles et la rivière un espace ouvert assez étendu.

Un indigène que nous croisons, me donne un morceau de chou de palmier, blanc et tendre. qu'il vient de couper et qui est agréable it manger.

$$
* * * *
$$

25 et 26 juillet. - Campement non loin de l'embouchure de la rivière Ramaroba (Wamaroba), l'un des principaux affluents de la rive droite de la Machilé. Nous sommes sur le territoire de la tribu des ma-Nkoya, soumise par les ba-Rotsi et nous recevons la visite d'un certain nombre d'entre eux. Ils nous vendent du sorgho el du micl sauvage; ils acceptent comme payement des perles de verre blanches et opaques. Plusieurs sonl armés d'ares et de flèches; quelquesunes de ces dernieres sont empoisonnées. Nos collections s'enrichissent de quelques spécimens de ces armes.

Ces ma-Nkoya ont un type spécial. Leur abondante coiffure crépue et luisante, est étonnante; l'usage fréquent de l'huile de ricin, dont ils cultivent la plante prìs de leurs huttes, donne a leurs cheveux un lustre pariculier.

Leurs dents sont souvent limées et très poinlues. Quelques-uns. chose rare pour des nègres, ont des moustaches et mème de la barbe.

Pour la premiere fois, nous voyons des indigìnes qui se servent de cauris, coquillages, comme ornements, ce qui prouve que les métis 
portugais arrivent ici; les gens du pays les alpellent mombreri. Les mat-Nhoya ne possident pas de bétail, pas míme de chères ou de moutons; ils vivent du produit de la chasse.

Yos hommes s'emparent d'un iguane, dont ils s'empressent do manger les aufs.

Apres conseil tenu, eomme les ànes retardent notre maredic en avant, nous nous déeidons de les laisser à l'endroit où nous sommes sous la garde de Mokelou, un Béchuana en qui nous avons confiance, et

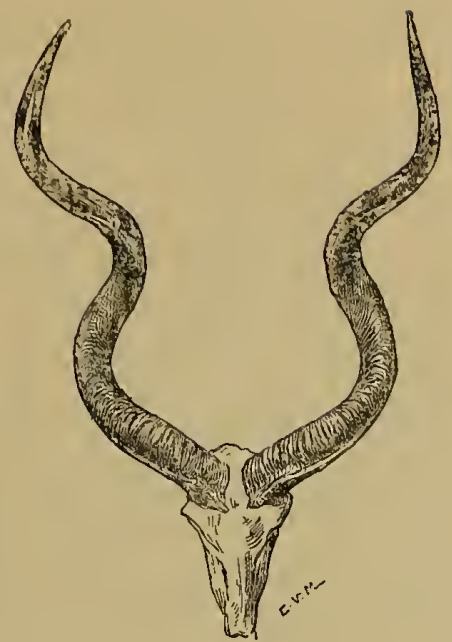

KOODOO. "STREPSICEROS KLDE " Croquis de Van Muyden. Specimen rapporté par l'auteur. quelques lommes. La nourrilure ne manquera pas it nos lommes car, pendant ces trois jours, nous avons liré diverses antilopes, toutes de grande taille : mentionnons l'antilope noire (IIippotragus niger), le koodoo (Strepsiceros kudu), dont les belles cornes en spirale ont plus d'un mètre de longueur; le uaterbuck (Cobus ellipsiprymnus), au port majestueux, aux formes presque parfaites; le bubale (Alcephalus lichtensteini), dont la tête allongće rappelle un peu celle du zèbre; ces deux dernières antilopes sont inscrites à mon actif. Une partie de celte viande est boucanće et il y aura du beltong pour plusieurs jours.

Mème dans les endroits où le gros gibier est abondant, il faut en général se donner beaucoup de peine el de fatigue pour l'ipprocher.

$$
\text { *** }
$$

$2 i$ juillet. - Direction nord-est. Afin de couper un coude prononcé de la rivière Machilé, nous traversons une rangée de collines et nous nous arrètons prè̀s d'un cours d'eau que les indigènes désignent sous le 


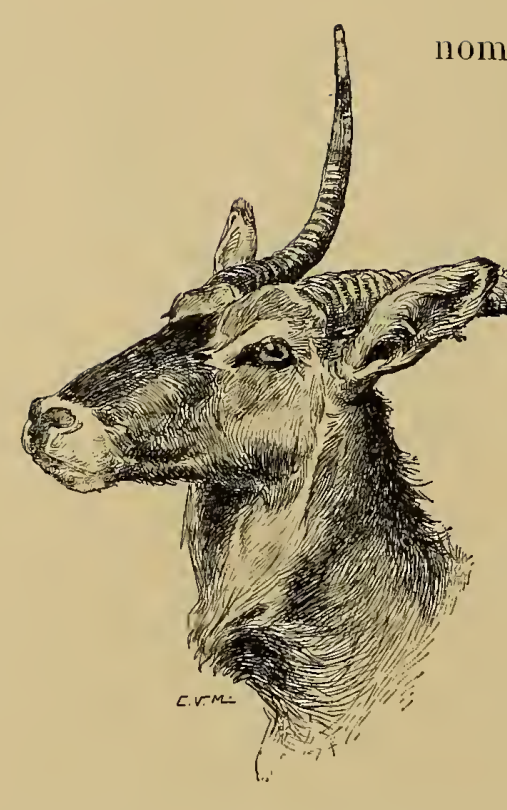

om de Citapo, non figuré sur aucune carte. Voici WATERBLCK, " COBUS ELLIPSIPRYMINLS" Cruquis de Van Muyden. Spécimen rapporté par l'auteur. de dépouilles de chasse. Nous présumons que c'est le lombeau d'un chef el que ces hultes lui appartenaient. Plus loin nous rencontrons un mo-Nlioya, lequel, vu sa suite nombreuse, doit être un personnage important. Nous nous asseyons dans l'herbe et une conversation s'engage; une poignée de tabac lui fait grand plaisir. Quelques-uns de ses hommes ont leur pagne fixé à la taille par de larges ceintures de cuir artistiquement confectionnées. Nombreux visiteurs au campement, en particulier deux joueurs de lambour qui font plus de bruit que de musique, en frappant alternativement leurs instruments aux formes bizarres, avec les paumes des mains ainsi qu'avec les doigts.

Tous les jours nous voyons des pièges qu'emploient les indigènes pour capturer les pintades, lapins et autres pelits animaux. Elles sont ingénieuses. Sur les sentes que suit le gibier, ils creusent des trous au-dessus desquels ils placent des nœuds coulants, tenus par des perches tendues; quand le nœud coulant est touché, l'animal est pris ou assommé par un morceau de bois habilement disposé.

Nous passons aussi près de vastes fosses, souvent couvertes de feuillages, où viennent quelquefois se faire prendre de grands animaux; il faul s'en méfier. 


$$
\text { *** } *
$$

98 juillet. - Nous continuons la traversée des collines.

En route nous voyons un serpent, fort dangereux, dont Ḱlass

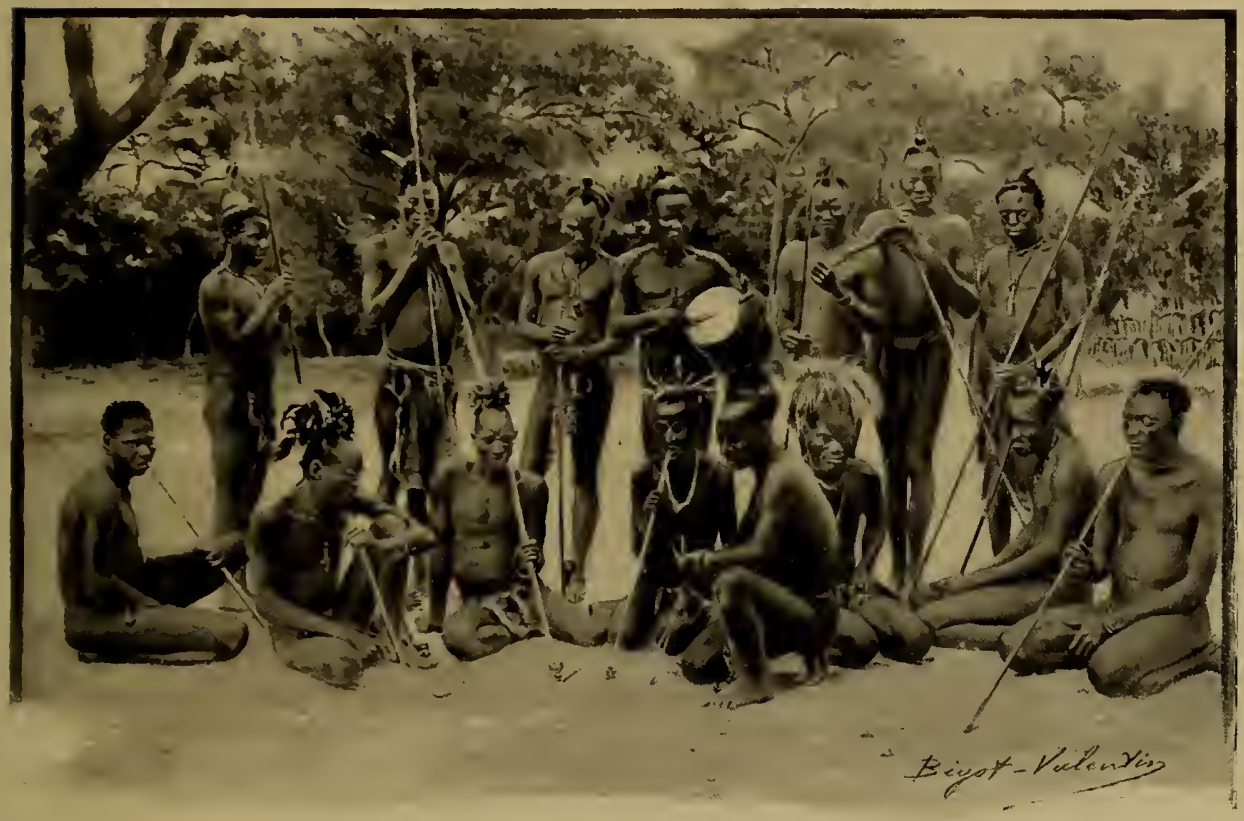

TYPES DE L.I TRHBU DES MA-NKOYA.

D'après une photographie de M. Coillard. - Reproduction interdite.

Africa nous conseille de ne pas nous approcher.

Au milieu de la journée, nous campons de nouveau sur la rive de la Machilé.

$$
*^{*} *
$$

30 juillet. - Après un jour de repos, nous reprenons notre marche. Quatre ma-Nkoya s'engagent pendant quelque temps à notre service. Nous remontons un marécage, en partie à sec, dans cette saison; il est entrecoupé de mares dont l'eau est souvent traîtreusement cachée par d'épais roseaux; sur la rive droite, affluent nommé liakoma par 
les natifs. Puis, ee qui nous réjouit, le paysage change à son avantage : les vallons aux versants boisés, aux courbes gracieuses, ont des lignes qui ne manquent pas de grandeur dans l'horizon étendu.

Aujourd'hui, commencement d'insubordination parmi les porteurs; l'instigateur du mouvement, Mobana, a ćté mandé devant nous, et comme après un interrogatoire serré, il n’a pas pu justifier sa conduite, un chàtiment devait s'ensuivre. Aussi, le calicot qu'il avait reçu en avance de ses gages lui est retiré et brûlé séance tenante, aux yeux de tous. Ses camarades sont, en outre, informés que ceux qui ne voudront pas lenir leur contrat n'ont qu'à partir immédiatement; aucun n'a bougé.

Forte chaleur pendant la journée.

$$
\text { *** }
$$

31 juillet. - Froid la nuit dernière et gelée blancho.

La nature du pays nous fait présager que nous approchons du but.

Nous nous élevons rapidement, les ravines sur les deux rives diminuent en importance, les mares deviennent de plus en plus rares, la dépression formée par la rivière se nivelle peu à peu, jusqu'au moment où, dans le courant de la journée, nous arrivons sur un terrain entrecoupé de bouquets d'arbres et toute trace de la rivière disparait. Nous sommes à la source proprement dite, qui est formée de deux embranchements distincts, tous deux asséchés à cette époque de l'année. L'aspect de la contrée environnante indique que, pendant la saison des pluies, la Machilé reçoit un volume d'eau considérable.

Nous touchons la ligne locale du faite de partage des eaux des l'ivières rejoignant le Zambèze au sud, et de celles qui, se dirigeant au nord-est, se jettent dans la rivière liafoukué (Kafukwe); celte der- 


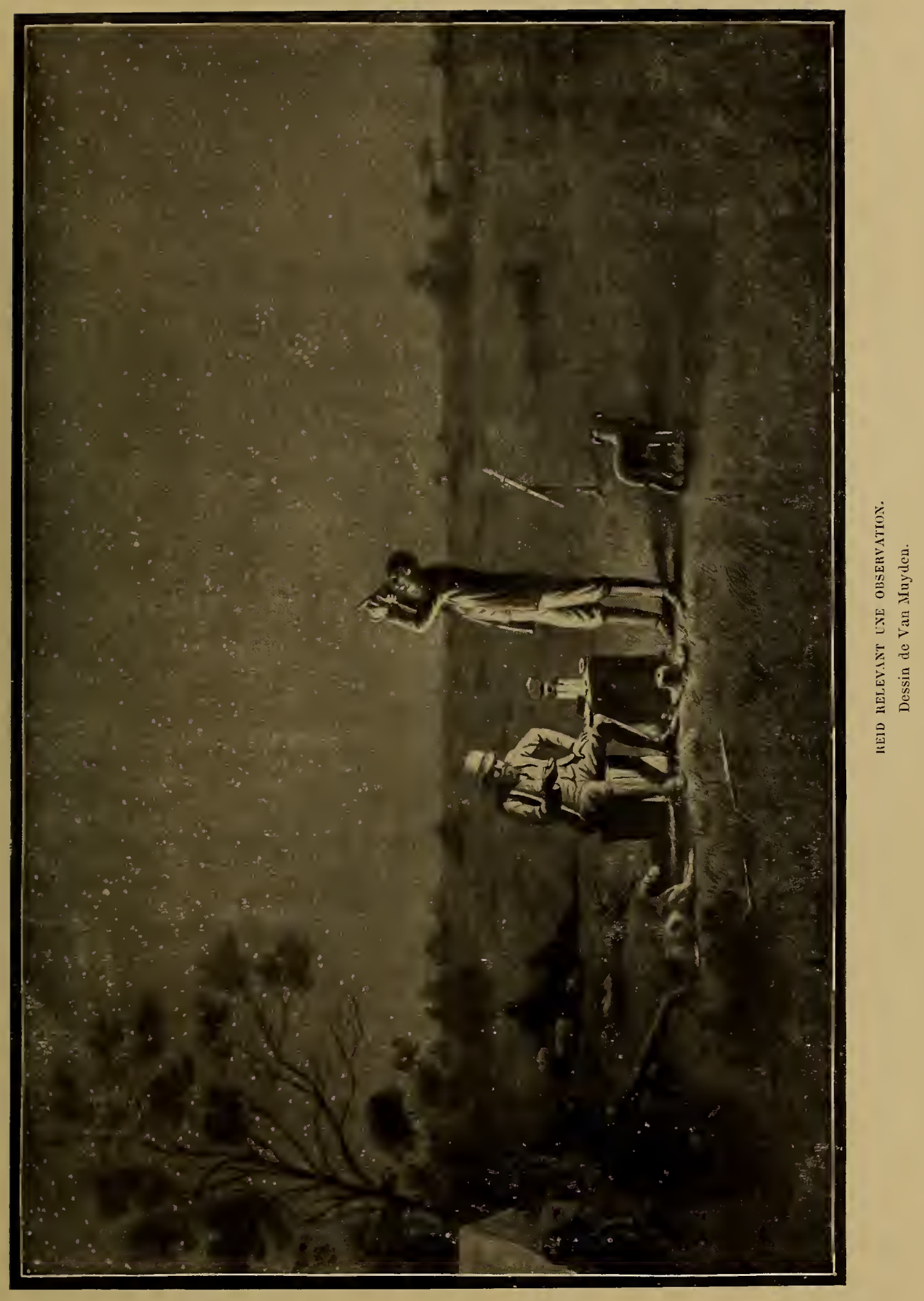



uière opère sa jonction avec le Zambèze trois cents ou quatre cents lilomitres plus ì l'est.

La position de la source de la rivière Machilé n’a été, à notre connaissance, relevée encore par aucun Européen. Nous sommes tous les trois en bonne santé et d'autant plus heureux de la réussite de notre projel que lors de deux précédentes expéditions en Afrique, Reid a été arrèté une première fois par la désertion en masse de ses porteurs: et la seconde fois, cloué par la fièvre; il est resté trois jours sans connaissance; il a ru la mort de bien près.

Reid, pourru d'excellents instruments, a pris sur le parcours un grand nombre d'observations concernant la latitude des points importants. A maintes reprises j'eus, en lisant le ehronomètre, l'avantage de collaborer à son travail lorsque, armé du sextant, il prenait par les belles nuits tropicales l'altitude d'une étoile, ou qu'aidé d'un puissant télescope, il relevait une occultation. L'une des dernières observations nous a donné $16^{\circ} 8^{\prime} 8^{\prime \prime}$ de latitude sud; la source de la rivière Machilé elle-mème se trouve par $16^{\circ} 9^{\prime}$, de latitude sud, ì une allitude d'environ 3900 ì 3930 pieds anglais, soit de 1190 ì $1200 \mathrm{~m}$. ${ }^{1}$.

Reid considère la tàche qu'il s'était imposée en grande partie comme terminée; aussi, tout en chassant et accompagné de Pirie, il retournera plus ou moins directement dans les environs de liazoungoula, où nous nous donnons rendez-rous pour plus tard.

Quant à moi, je suis décidé à traverser le Pays des ba-Rotsi, direction N.-0., jusqu’à Léalouyi (Lialui), la capitale, résidence du roi Léwanika et de M. Coillard, le missionnaire bien connu; puis de descendre le Zambèze en canol jusqu'à Kazoungoula et de visiter aussi les stations missionnaires. Dix-neuf porteurs indigènes

1. Pour plus de détails techniques sur celte partie de l'exploration, voir le second appendice. 
sont mis à ma disposition; je prends en outre avec moi Klass Africa, le chasseur d'éléphants hottentot déjà nommé, accompagné de ses serviteurs, ainsi que Watcher et Koudoumann, tous les deux Béchuanas.

Outre les provisions nécessaires, armes, munitions, tente et ustensiles, j'emporte soit comme monnaie d'échange, soit comme présents aux chefs, cent cinquante mètres de calicot blanc, vingt-cinq livres de perles de verre aux teintes variées, vingt-quatre couvertures, six douzaines de mouchoirs aux nuances vives, des couteaux, du fil, etc. Les charges sont réparties entre les hommes; tout est prêt pour le départ. 


\title{
A TRAVERS LE ROYAUME DES BA-ROTSI
}

\begin{abstract}
Traversée du paYs des ba-rotsi Jusqu'a léalouYt. - la rivière nJokio,

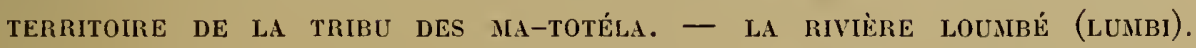
- la rivière louti (LUi), territoire de la tribu des ata-iólaNgoi (MAITENGA). - SÉFOULA
\end{abstract}

$\mathrm{F}$ ORTE gelée blanche la nuit dernière et abondante rosée ce matin, $f^{\text {er }}$ aoút. Dernier repas pris ensemble et dernière poignée de main à Reid et à Pirie; je pars à la tête de mes vingt-cinq hommes, chiffre qui, suivant les circonstances, variera plus ou moins. Le mème soir, je campe sur les bords de la rivière Kakoma, affluent de la rive droite de la Machilé.

Dorénavant, d'une manière générale, la direction suivie sera le nord-ouest.

Je traverse dans la matinée, la rivière Ramaroba (Wamaroba), alluent de la rive droite de la Machilé. Actuellement elle forme un marécage qui nous donne passablement de peine et où nous enfonçons dans la rase jusqu'aux genoux. Ivant d'y arriver, nous franchissons une colline où nous trouvons des traces fraìches d'élands (Oreas canna); 
je les suis avec quelques hommes; malheureusement le vent nous est contraire.

La marche de l'après-midi nous mène au vallon où devrait couler le Kamitué (Kamitwe), rivière marécageuse qui n’offre pas les mêmes difficultés que celles rencontrées ce matin. Puis nous reconnaissons un autre cours d'eau, la Kamanga qui 'rejoint probablement le Njoko, direction surl-ouest. Après avoir gravi la sixième colline de la journée, nous sommes dans le bassin hydrographique du Njoko et à la nuit tombante, le campement est établi sur le versant de la ravine qui sert de lit à la Mania, affluent de la rive gauche du Njoko. Pendant ces deux premières journées nous n'avons rencontré aucun être humain, ni ancune habitation; le gros gibier qui, à cette époque de l'année, doit se trouver dans d'autres parages, est très rare; aussi, après la forte marche d'aujourd'hui, les hommes sont-ils forcés de s'étendre auprès des feux, sans avoir mangé.

Comme à l'ordinaire, forte chaleur pendant la journée.

$$
*^{*} *
$$

3 août. - Nous suivons la Mania et nous arrivons à un rassemblement de huttes appelé Méori; ces villages sont désignés par le nom de leur chef. Leur vue cliarme mes hommes. lls pressent le pas et pensent sûrement aux provisions qu'ils trouveront dans les calebasses aux flancs rebondis que je ferai vider pour eux; mais que de patience il faut avoir! Nous ne sommes qu'au début de la matinée et à deux heures seulement, il est possible de faire une abondante distribution de nourrilure. En premier lieu, le chef doit être averti de mon intention de tenir un marché, nouvelle qui est répandue parmi les habitants. Suivant qu'ils y sont disposés ou non, ils vont chercher les denrées nécessaires, lesquelles doivent être encore parfois préparées. Enfin, lıommes et f'emmes 
arrivent un par un, ils s'accrompissent à distance, immobiles. Peu à peu, ils déposent devant moi les récipients, plats en bois ou calebasses, dans lesquels ils apportent du sorgho, des arachides. Les uns désirent ètre payés avec des perles de verre bleu, d'autres avec des perles blanches et ils sont loin d'ètre toujours faciles à contenter.

Nous passons la limite qui sépare la tribu des ma-Nlioya de celle des ma-Totéla. Actuellement ces derniers vont encore chez leurs voisins les ma-Nkoya, échanger des houes contre des esclaves. Sept houes sont en général considérées comme l'équivalent d'un être humain! Le campement est établi pour le lendemain, jour de repos, sur la rive gauche du Njolio en aval

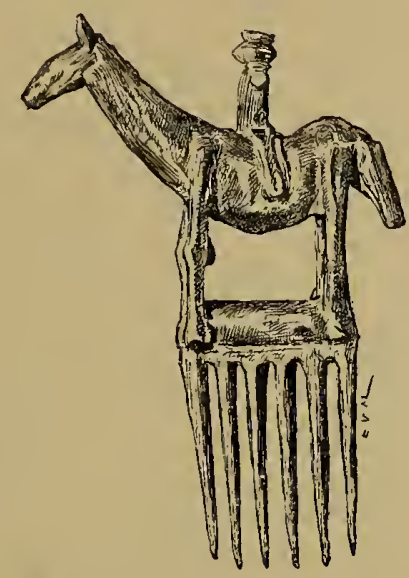

PEIGNE EN BOIS SCULPTÉ, ÉCUANGÉ SUR LES BORDS DE LA RIVIĖRE N.Joko.

Croquis de Van Mruyden, collection de lauteur.

du confluent de la Mania, au milieu de superbes motsaoli ou massivi, arbre de port majestueux, au feuillage vèrt foncé, qui rappelle le chène. Cet arbre porte un fruit rouge de la forme d'un haricot aplati, fort gouté des indig̀̀nes.

$$
*^{*} *
$$

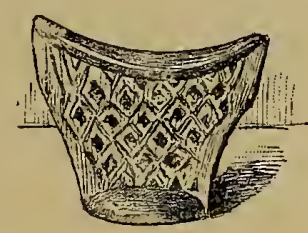

OREILLER EN BUIS SCLLPTÉ, ÉCHAXGÉ SLR LES BORES DE LA RIVERE NJOKO.

4 août. - Paysage gracieux que celui offert par la vallée où coule le Njoko, entourée de collines Croquis de Van Muyden, collection de lauteur.

boisées sur les flancs desquelles se détachent, comme de larges taches brunes, de nombreux villages. Près de ces derniers, de grands espaces brûlés indiquent leurs plantations. Pour les établir, les nègres commencent par arracher l'herbe, la mettent en tas et la brûlent, puis ils travaillent la terre. En se rapprochant, l'on voit de toutes parts 


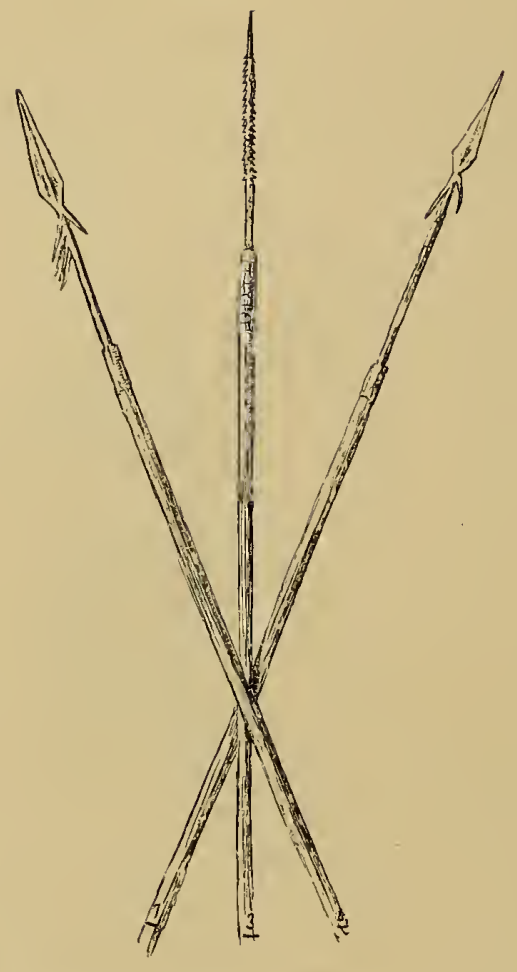

LAxCES de GleRHe, DE CHASSE ET DE PÊCHe, B́CHANGÉES AYEC LES INDIGẼNES.

Croquis de Van Muyden. Collection de l'auleur.

des troncs d'arbres aux branches calcinées, restés au milieu de ces terrains cultivables.

Forte affluence de visiteurs qui nous offrent de la farine de sorgho et du lait caillé; ils désignent celui-ci sous le nom de mafi. Il faut se passer de viande, car l'on n'apporte au campement que des poulets étiques, des œufs trop vieux et des chèvres sans chair. Quelques-uns de ces indigènes peuvent rester là à muser pendant des heures; décidément, le temps ne doit pas avoir la même valeur pour eux, que pour nous. Très observateurs, ils ont une grande mobilité d'expression; le rire vient facilement sur leurs lèvres. Je

suis étonné de rencontrer chez beaucoup d'entre eux des traits qui, sauf leur peau noire, rappellent le type juif. Les ma-Totéla s'arrachent souvent les deux incisives centrales supérieures.

Voici près de moi des hommes dont chaque touffe de cheveux est terminée par un cône régulier de pâte brune, composée d'arachides écrasées. C'est un moyen, selon eux, de faire pousser leur chevelure; la préparation de cette coiffure demande deux jours et doit durer plusieurs semaines; aussi, sacrifiant leurs aises à leur vanité, se servent-ils comme " oreiller" " d'un petit chevalet de bois, qui rappelle celui qu'emploient les Japonais. Costume réduit à sa plus simple expression; comme armes, plusieurs des hommes portent, outre la lance barbelée, une lance plus fine et effilée qui leur sert à prendre 
le poisson. Je puis m'en procurer quelques-unes en les échangeant contre de grosses perles bleu clair très demandées.

Cette après-midi, visite à la demeure du chef Siboupa. Une enceinte, forméc de trones d'arbres et haute de deux ou trois mètres, renferme une grande hutle centrale, entouríe de onze plus petites; elles sont rondes, construites en roseaux et recouvertes de chaume. Un tambour long et évasé est suspendu ì un arbre, tout près d'un paquet de lances.

Extérieurement it l'entrée, un toit abrite un établissement de forgerons el vis-ì-vis, les greniers ì grains, petites constructions

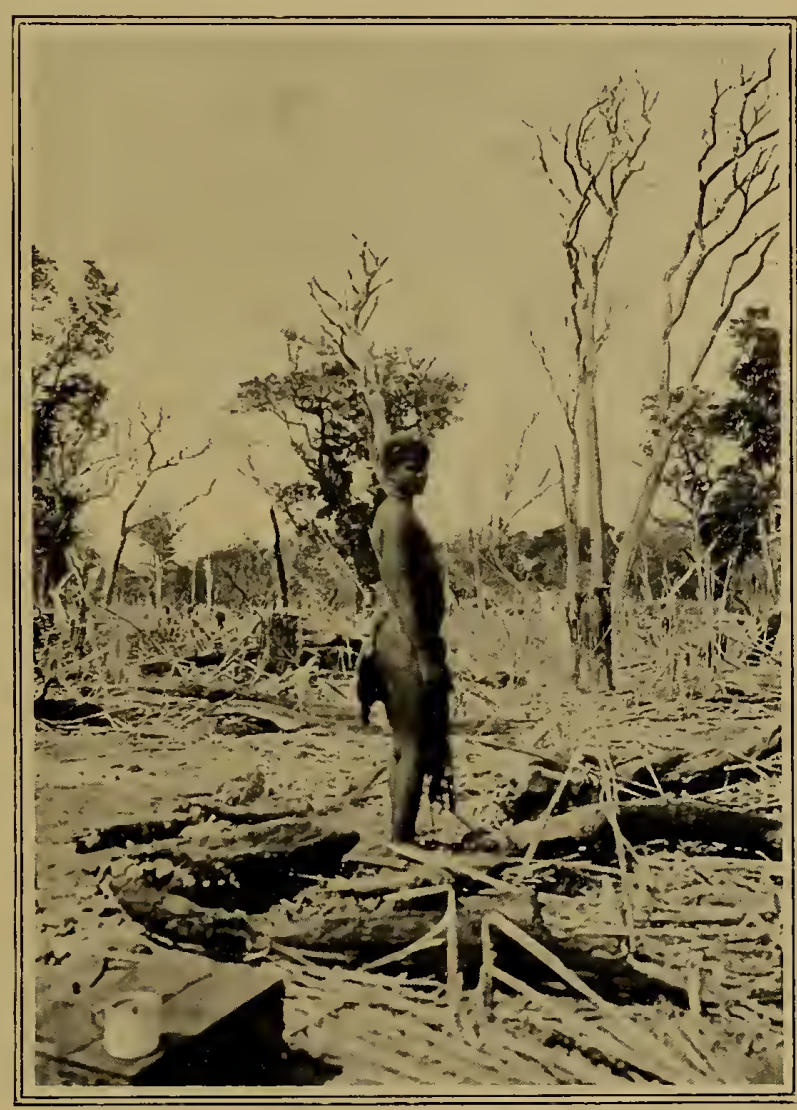

TYPE MA-TOTÉLA.

D'après une photographie de l'auteur. qui ne reposent pas directement sur le sol. Elles font songer à de vastes ruches. Une femme pile du sorgho dans un grand vase de bois.

Plus loin au bord de l'eau, le gros bétail composé de deux races différentes : les petites vaches bien musclées, au poil ras, aux cornes courtes, sont de race ma-Shoukouloumboué; les autres, beaucoup plus fortes, appartiennent ì la race du bo-Rotsi proprement dite. Plusieurs de ces bètes ont les oreilles découpées artificiellement. 
A la tombéc de la nuit, j'entends les sons assourdis d'un insurument recouvert de peau, sorte de tambour allongé, musique qui annonçait une danse pour la soiréc au groupe de huttes voisin. Comme je savais qu’en pays sauvage, ces réunions sont une cause de désordre et que je voulais garder mes hommes en mains, je leur interdis de s'y rendre, en les avertissant que je ferai, en personne, des rondes dans la soiréc et que ceux qui ne répondraient pas à l’appel, devraient se considérer comme n’étant plus à mon service. Ledit appel s'est fait à un moment inattendu... chacun était présent. Il faut traiter ces nègres comme de réritables enfants, e'est-i-dire avec justice; mais avec une grande fermelé, autrement la débandade ne tarderait pas à commencer.

$$
\text { *** }
$$

5 aoút. - Nous passons sur la rive droite du Njoko; l'eau nous effleure à peine les genoux. Pendant la saison des pluies, il est navigable jusqu'au Zambè.

La population des environs vient assister à notre passage ainsi que les deux chefs Manimboula et Maioia; ce dernier est plus vètu que la généralité de ses sujets : une chemise de flanelle recouvre ses épaules.

Nous croisons un troupcau allègrement conduit au pàturage par de noirs berger's, armés de lances, la tète ornée de plumes; ils lirent de leurs pipeaux des sons joyeux.

Tisite à un chef nonmé Souroukouroukourou qui habite non loin de là; en attendant son relour de la forêl, nous nous asseyons près de ses greniers à grains et voyons, suspendus à des perches, trois gros rouleaux de sorghho, ingénieusement enlacés de lianes. C'est le tribut qui sera envoyé au roi Léwanika. Enfin, voici Souroukourouliomrou lui-même. C'est un vicillard, et il est escorté de trois jeunes 


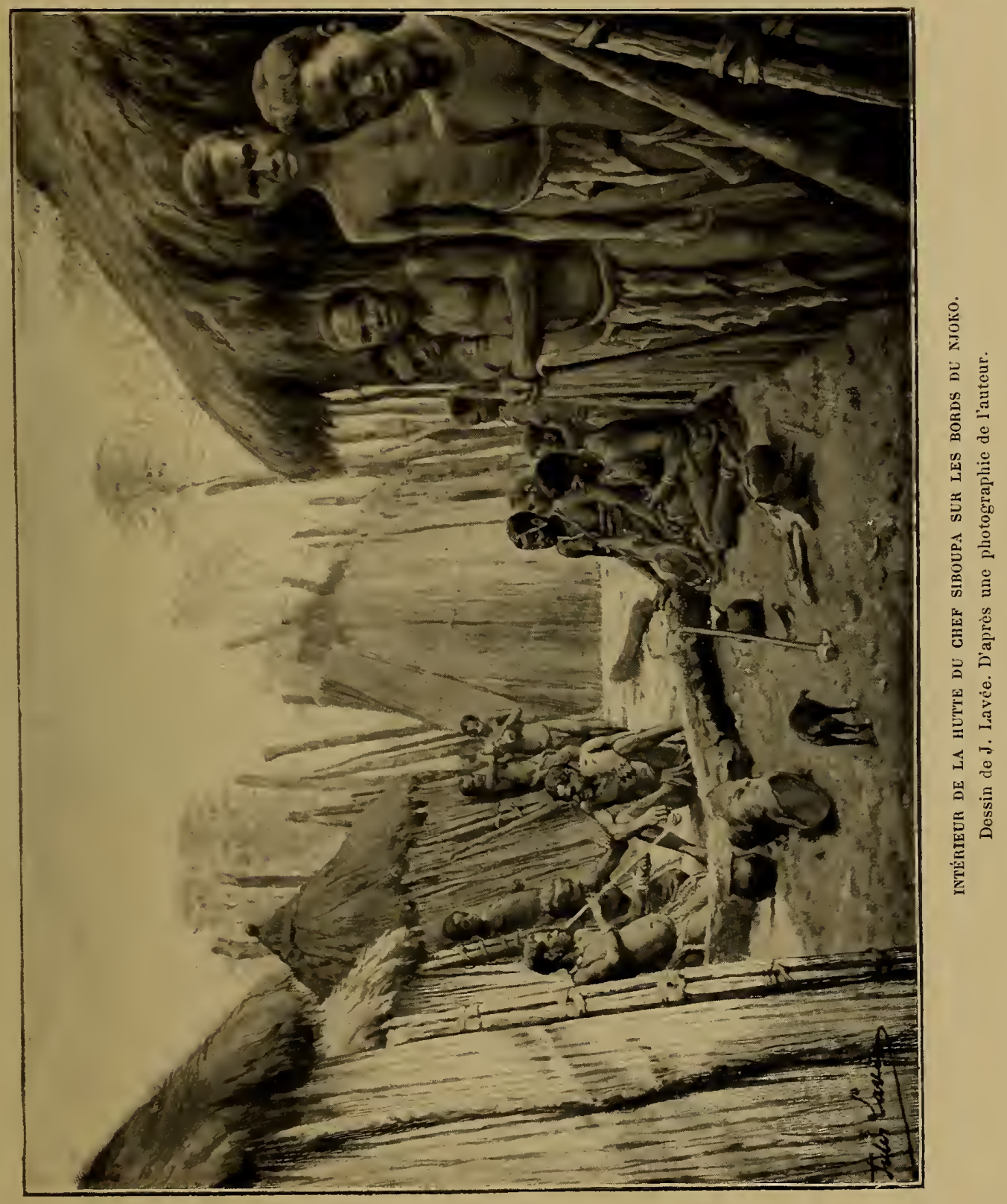



hommes; il nous donne un guide. Dans l'après-midi, nous marchons it travers une forèt de laute futaie. Sans avoir trop à souffrir de la vase liquide de ses rives, nous passons la rivière Kambona, affluent de la rive droite du Njoko, et campons sur ses bords.

Suivant la règle, aussitòt arrivés au campement choisi, chacun a sa

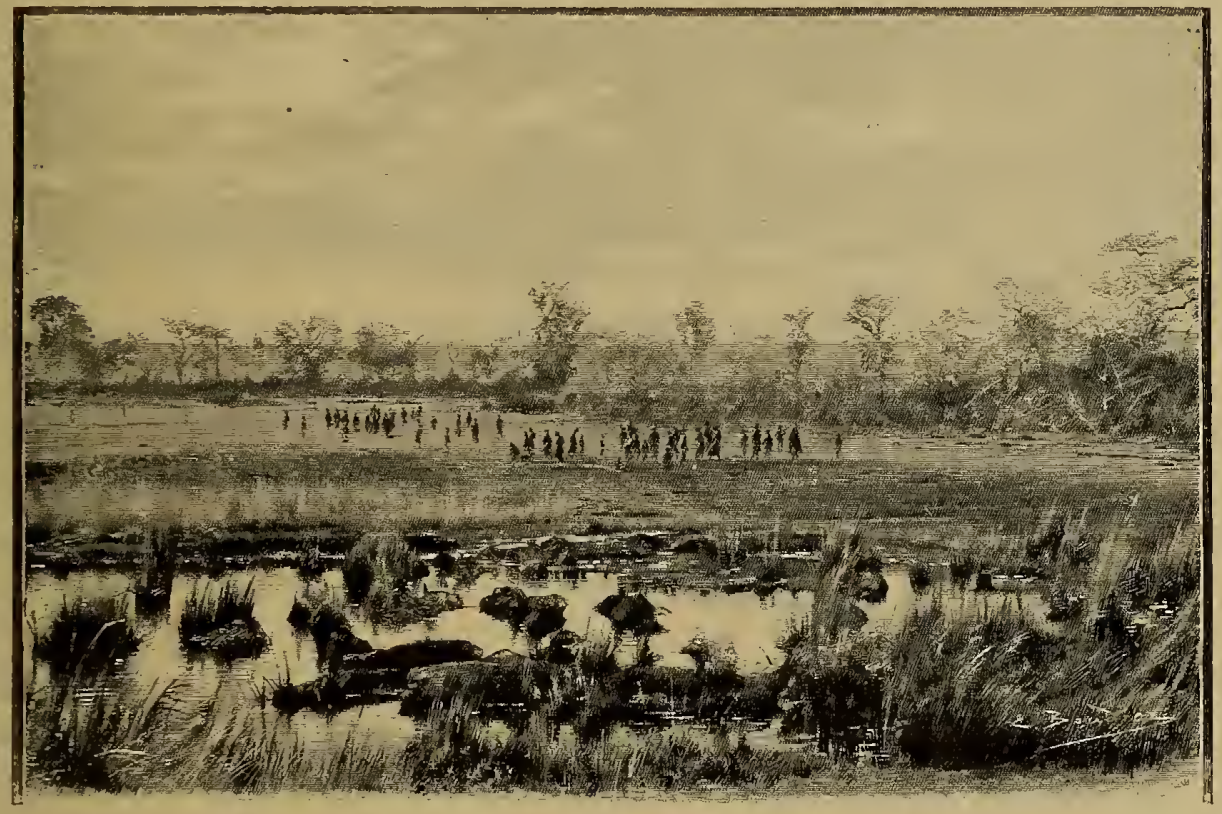

INDIGEXES ASSISTANT AU PASSAge DU NJOKO.

Dessin de Boudier. D'après une photographie de l'auteur.

tàche; les uns ont la responsabilité de la tente qu'il faut leur apprendre à élever rapidement, tandis que d'autres ront faucher des herbes desséchées qui seront étendues sur le sol, couper du bois et chercher de l'eau. Puis les grands feux ne tardent pas à briller. Les hommes aiment à se rassembler par tribus; il y a de la sorte cinq ou six groupes. C'est le moment de la distribution de la nourriture; un individu par escouade est désigné pour la recevoir.

Tous alors sont occupés à la cuisine; après le repas, les causeries recommencent et ainsi que je l'ai dit, ils se racontent entre enx les 


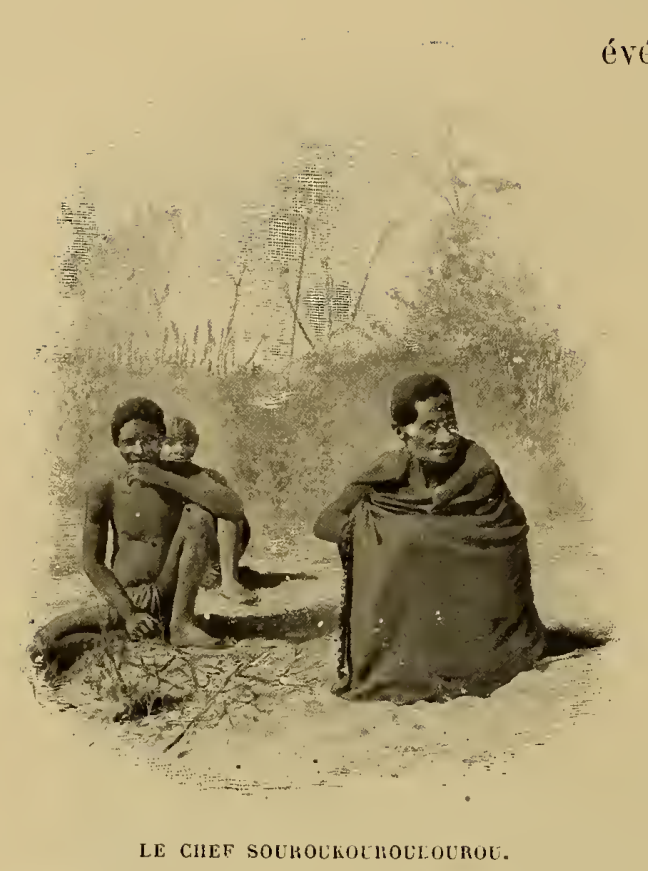

Dessin de Thiriat. D'apres une photographie de lauteur.

événements de la journée. Peu à peu, ils s'étendent auprès du feu; quelques-uns n'ont pas même une peau de bète sauvage pour protéger du froid de la nuit leurs corps presque entièrement nus; aussi s'approchent-ils si près des tisons que plusieurs portent des traces de brîlures profondes. Deux ou trois d'entre eux possèdent un instrument de musique qu'ils appellent liangombio: des lamelles de fer, inégales, figurent dix notes; clles sont fixécs à une mince planchette de bois qui repose à son tour sur une calebasse évidée. Ils accompa- gnent ainsi des mélodies fort douces et tristes qui ne cessent parfois que bien avant dans la soirée. Les feux sont alimentés pendant la nuit et en cas de réveil, il est rare de ne pas entendre encore ici et là des chuchotements.

Le porteur Liponé et l'un de ses camarades sont malades de la fièvre; je les traite avec de fortes doses de quinine. Ils sont incapables de porter leurs charges et j'ai la chance de pouvoir aujourd'hui engager deux hommes nouveaux; parmi cux Litaba dont, outre le pagne, l'équipement de voyage se compose d'une sorte de couvrechef, tressé avec la fibre du palmier.

$$
\text { *** }
$$

6 août. - Nous arrivons à un ravissant petit lac d'environ un demi-kilomètre de longueur, aux eaux d'azur et cntouré de verdure. 


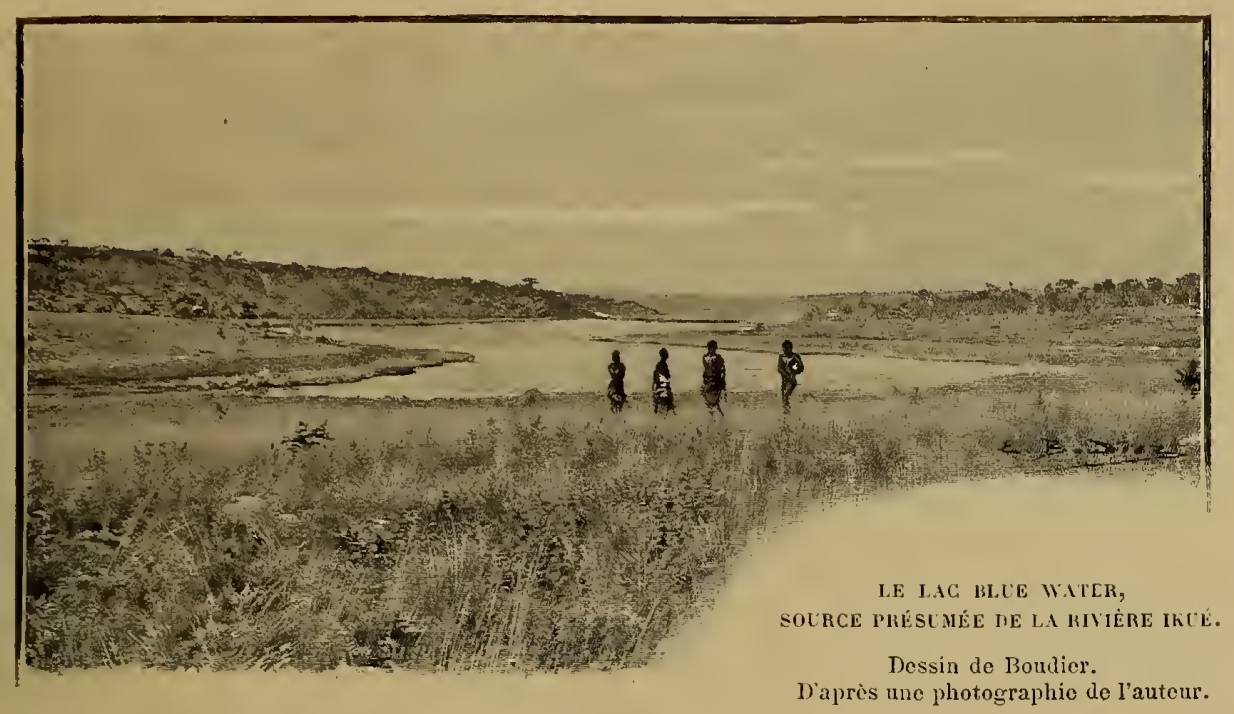

Je lui donne le nom de "Blue Water "; e'est dans ce lac que la riviere lkué (Iliwe), afluent de la rive droite du Njoko, doit prendire sa source. Le paysage, sauf l'absence des sapins, rappelle certains sites du Jura. Je ne crois pas trop m'avancer en disant que ce lac ne figure encore sur aucune carte géographique.

Priví de viande depuis plusieurs jours, j’appréciais fort une pintade tuée hier au soir, lorsque arrive de la part du chef Souroukouroukourou, homme prévoyant, un second guide qui doit servir de compagnon de route au premicr; son nom est Damousiba. Ses cheveux, entrelacés de fibres végétales, forment une infinité de petites tresses, tandis que le sommet de la tète de son camarade est modestement orné d'une touffe de plumes.

Accompagnés de ces nouvelles recrues, nous longeons une longue colline et nous rejoignons le vallon où coule la liuemba (Kwemba), autre affluent de la rive droite du Njoko. Après avoir enfoncé dans un terrain mouvant, spongieux, avec le sentiment désagréable qu'il serait possible d'y disparaitre en entier, nous pensions pouvoir fran- 
chir aisément la Kuemba; nous nous sommes trompés, car l'eau touche aux épaules.

Parvenu sur l'autre rive, je dois surveiller le passage, faire secourir les plus timides ou les plus faibles; quelques-unes des charges qui doivent être portées sur la tête courent de grands risques, surtout la caisse qui contient mes plaques photographiques. Avec de la patience, tout se passe pourtant sans accident.

$$
\text { *** }
$$

7 aoút. - Froid la nuit dernière. $\mathbf{\Lambda} 6$ h. 30 ce matin, le thermomètre marquait seulement $+2^{\circ}, 5 \mathrm{C}$.

Comme à l'ordinaire, la tente doit être repliée rapidement. Les charges qui chaque soir, sont disposées en ordre sur ses côtés, sont reprises et consolidées par leurs porteurs respectifs, toujours les mêmes. C'est à ce moment aussi que les hommes malades se présentent. Après un léger repas, les ustensiles de cuisine plus que primitifs sont lavés, et il faut se remettre en marche. Suivant les circonstances, je prends la tête ou la queue de la colonne. Illass Africa me sert d'interprète pour transmettre les ordres; il m'a dit avoir eu à maintes reprises de la difficulté à comprendre tel ou tel des hommes, tant les dialectes parlés varient. Les hommes, il est vrai, appartiennent à des tribus différentes; outre Klass Africa, qui est Hottentot, Watcher et Koudouman qui sont des Béchuanas, ils se partagent en ba-Rotsi, ba-Toka, ma-Totéla, ma-Schoukouloumboué, ma-Mbounda et maNkoya. Ils varient aussi comme types.

Pendant la marche, deux hommes sont spécialement attachés à mon service : Picaniné, un mo-Rotsi, solide gaillard, porte mes fusils de rechange et ma cartouchière. Outre une peau de bète sauvage fixée sur ses épaules, il s'affuble d'un long chapeau pointu 
orné sur les còtés de deux plumes plus longues encore. Puis Sibette, garẹon déluré et intelligent, toujours gai et content, qui en génćral ne s'cmbarrasse ni d'une peau de bête saurage, ni d'un chapeau; mn morecau de cotomade retenu ì la ccinture par une dépouille de serpent lui suffit; mo-Schoukouloumboué de naissance, il. a été toul jeune enlevé de son pays natal dans une raziia. Il a la responsabilité de mon appareil photographique lequel, malgré toutes les péripétics endurées, est encore intact. Cet heureux résultat est dû pour beaucoup à la grande obligeance de M. le directeur du

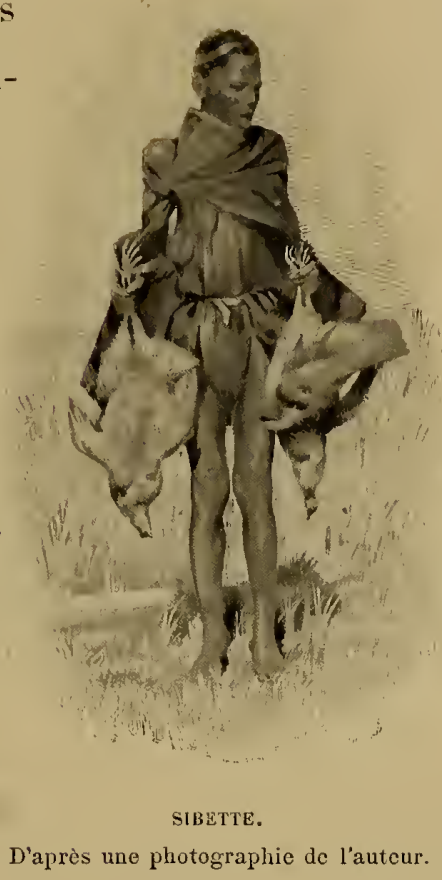
Comptoir suisse de photographic à Genève qui l'a fait emballer, ainsi que les plaques, d'une manière très ingénieuse. Ce pholosphère 9/12 est un instrument d'exploration parfait : léger, solide, simple et pratique dans son maniement. Il prend en outre peu de place.

Ce matin, autre colline étendue à traverser, qui nous mène à la vallée du Njonjo, affluent probable de la rive gauche de la rivière Loumbé Lumbi). A l'endroit où nous nous trouvons el dans cette saison sèchc, elle peul avoir dix ou douze mètres de largeur; belle eau claire, profonde et à fort courant. Impossible de la traverser à gué : nous trouvons heureuscment quelques perches assujetties par des lianes et qui forment un pont branlant; il faut le passer avec précaution. Une fois de plus, toutes les charges arrivent à l'autre bord sans accident.

Lors de la première halte de la journée, je venais de terminer un repas plus que frugal lorsque renfort inattendu, l'un des ma-Nlioya, 
en général très habiles dans cette recherche, arrive avec un délicieux rayon de miel saurage. 11 avait suivi le skessou (Euculus indicator), cet oiseau intelligent qui, par ses appels, attire l'attention du voyageur. Il vole près de lui et s’il est suivi, il le mène à l'endroit où se trouve du miel. Son manège n'est pas tout ì fait désintéressé car les rayons une fois enlevés de l'arbre, il se régale des larves et débris. Les indigènes recherchent très volontiers le miel.

Six des hommes arrivent avec un retard de deux heures; ils ne peuvent pas le justifier et comme ils sont de vigoureux gaillards, ils devront sous notre surveillance, prendre la tète de la colonne lorsque nous nous remeltrons en route.

Lors de la marche de l'après-midi, autre colline interminable au pied de laquelle nous trouvons le Kaponi, actuellement à sec; dans la saison des pluies il rejoint probablement le Njonjo, traversé ce matin.

Voici les noms donnés par les indigènes à quelques-unes des nombreuses essences qui d'une manière plus ou moins intermittente, peuplent les forèts : le majestueux motsaoli ou massivi, dont le bois est très dur, a déjà été nommé. Le moboula rappelle l'érable ou le charme; il est bon pour la menuiserie et porte un fruit comestible à noyaux. Le motondo au feaillage clair est à fibres droites et est employé pour la fabrication des manches de houes, de haches. Le mokoa, moins beau que les précédents, ne porte pas de fruit; les indigènes s'en servent pour la fabrication des rames et ustensiles de ménage. Puis vient le majongolo, qui sert à confectionner des cuillers; il a des fruits comestibles. Nombreux moholouholou; cet arbuste, qui a l'apparence du prunier, porte de gros fruits ronds à écorce dure; les indigènes en font une grande consommation dans le pays; les Européens devront s'en méfier, crainte de la dysenterie. 


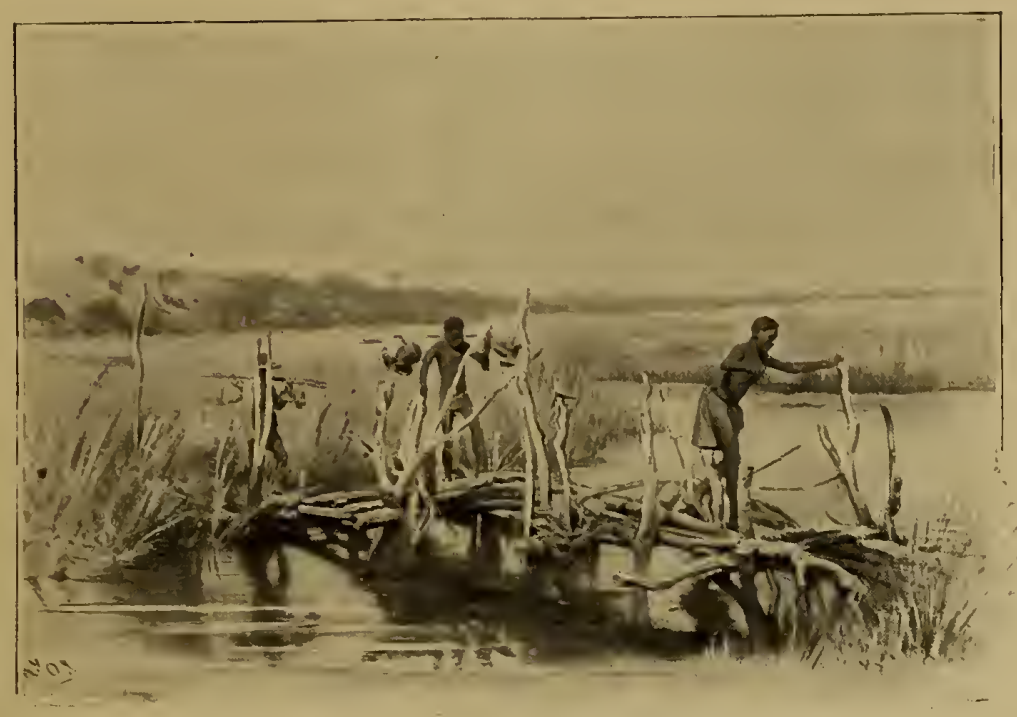

PASS.GE DE LA RIVIERE NJOXJO SLU DES BRAYCIAGES.

D'après une photographic de l'auteur.

Le șstème employé ce matin a bien réussi car malgré une forte marche et une chaleur extrême, je n’ai eu aucun traìnard et nous avons pu arriver à la halte.

$$
\text { *** }
$$

8 aoüt. - La nuil dernière, des termites ont commencé ì attaquer l'une des courertures déposées dans la tente. Nous traversons au milieu de la journée le marécage formé par le Masetti, non loin de son confluent avec la rivière Loumbé; cette dernière coule au milieu d'une large vallée qui, à cet endroit, n’est pas aussi altrayante que celle du Njolio, mais les lignes d'horizon sont plus grandes.

Ces sauvages ont une manière ingénieuse de créer des jardins ou plutòt des plantations qui sont franchement surélevées; la terre enlevée laisse à l'entour une tranchée.

Nous entrons au village du chef Nayoumba (Naiumbo), où il faut tenir un marché afin de nous procurer des vivres. Le chef, escorté par 
dix de ses sujets, ne tarde pas trop à faire son apparition. Il ne semble pas personnifier la franchise. Après les salutations d'usage, il commence par me dire que le grain est très rare, qu'il ne peut pas m'en fournir. Il en faut pourtant, car j’ai là derrière moi une trentaine d'affamés et il me reste une unique calcbasse d'arachides. Rien de mieux ¿ faire que de patienter : assis sous un arbre, je fais apporter le sac qui contient les perles de verre, puis comme à l'ordinaire en pareille occasion, je place en évidence des colliers bleus, blancs, noirs. Le cercle se resserre, mes objets d'échange sont discutés, c'est bon signe; enfin, j’entends les femmes qui pilent du sorgho. Le ravitaillement sera assuré! Mayoumba lui-mème disparait; il revient avec un chevreau noir porté sur les épaules de l'un de ses suivants. ll me le présente comme un cadeau personnel. Un couteau lui est aussitòt offert cn retour. Iu bout d'un certain temps, j’ai devant moi plus de nourriture que les hommes n'en peuvent emporter.

Visite à la demeure du chef. Pour la première fois dans cette contrée, je vois des huttes avec des murs en terre. Des enfants au ventre proéminent, résultat d'un mauvais régime, jouent près de là.

Mayoumba, momentanément, est plein d'égards. Mais, sachant par expérience, qu'il n'est pas bon d'avoir son campement près d'un village, je décide de passer cette après-midi mème sur l'autre rive de la rivière Loumbé.

Nous avous vu dans ces parages la piste que suivent les missionnaires du Zambèze, lorsqu'ils se rendent par voic de terre de Kazoungula à Léalouyi, piste que nous traverserons dorénavant à plusieurs reprises. Mayoumba lui-mème nous sert de guide; nous piétinons longtemps dans une boue marécageuse avant d'arriver à la rivière proprement dite, que nous traversons facilement, grâce aux deux canots d'un batclier amené par le chef. 
lilass Ifrica souffre ce soir dr la fière oceasionnéc par les fréquentes traversées d'eau de de marécages effectuécs ces derniers lemps. Culte circonstance moblige à ne pas poursuire des gnous aperegus dans les envilons: mais it sulveiller mes lommes de près. ***

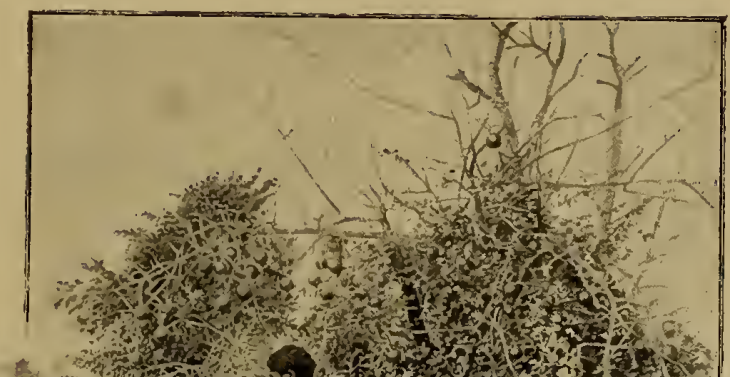

9 couit. - Il faut renoncer is arancer. Klass Ifrica est aujourd'hui très malade: je lui administre de fortes doses de quinine ot de calomel. Il passe la journée élendu, dans un

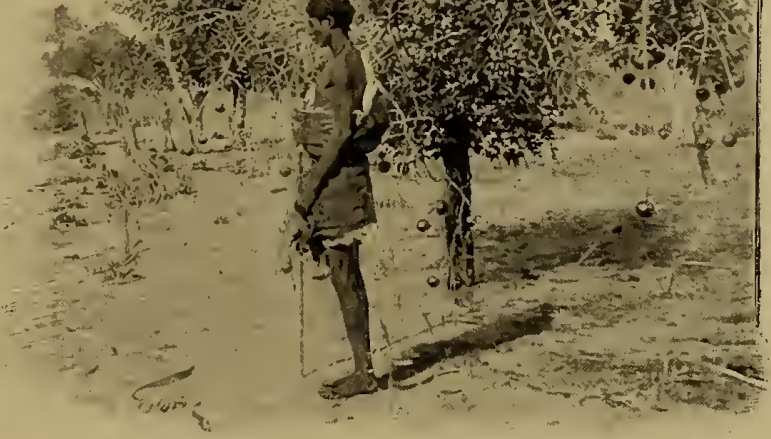

état de torpeur, semi-inconscient et pouvant à peine remuer.

La maladie de Kilass Africa, en me forçant de m'arrêter, me met dans une situation difficile et inquiétante. En effet, lorsque ces indigènes ne travaillent pas, ils se démoralisent facilement. Dans ce cas, des désertions en masse sont à craindre; clles causent la ruine d'une expédition. En outre, je compte qu'au train dont mes trente hommes font disparaître les vives et malgré les provisions achetées le jour préédent à Mayoumba, il ne me reste plus que pour quarante-lunit heures de nourriture, soit deux ealebasses de sorgho, deux de fìves et une d'arachides. Sur mon ordre, l'un de mes hommes, Mabona, traverse le Loumbé à la nage afin de solliciter de 
Mayoumba une nouvelle entrevue; le chef se garde bien de répondre à mon invitation.

Trois des porteurs ont déscrté ce matin et je les laisse courir. Je ne suis pas fàché d'être débarrassé de Mabenga et de Liboué, dont j'étais lọin d'être satisfait; quant au troisième, le petit Liponé doux et tranquille, il était trop faible pour sa tâche. Depuis plusieurs jours déjà, il ne faisait que suivre la caravane et sa charge avait été répartie entre ses camarades.

Ces raisons connues, je ne quitte le campement que peu avant le coucher du soleil pour tâther de surprendre des lechwe (Cobus leche), antilopes qui vivent près des marécages. Comme elle serait bienvenue, de la viande fraîche! Je ne tarde pas à enfoncer jusqu'aux genoux dans un terrain spongieux et jarrive presque à portée d'un groupe de ces bètes qui sont au repos... lorsque je suis subitement arrêté par un coude de la rivière, infranchissable en cet endroit. A mon retour, j’apprends qu'un autre des porteurs, Jacob, ainsi que les deux guides donnés par Sourouliourouliourou, ont profité de celle courte absence pour déguerpir de leur côté. Je suis, en somme, aussi lıeureux du départ de Jacob que de celui de Mabenga et de Liboué. J'avais été obligé de les remettre, à maintes reprises, sévèrement à l'ordre el la disparition de ces indisciplinés renforcera, je l'espère, l'ensemble de la caravane. Quant à mes guides, ils ont probablement le mal du pays et nous nous passerons de leur concours. Néanmoins, ma position n'est rien moins qu'enviable.

$$
\text { *** }
$$

10 août. - A 6 heures ce matin, le thermomètre placé sur une caisse devant ma tente indiquait $+1^{\circ} \mathrm{C}$. Au même emplacement et exposé au soleil, il marquait hier après-midi $+42^{\circ} \mathrm{C}$. 
II ! a un peu de mienx dans l'élat de liksss Afriea; après une

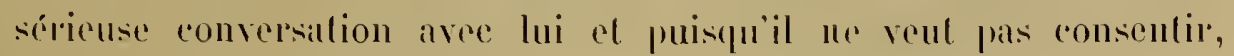
comme je le lui ai proposci, à aller seul au sud avec quelques hommes, il comprend qu’il y a urgence à marcher de l'avant, car nous ne pourrous pas nous ravitailler avant deux on trois jours. Ipresi

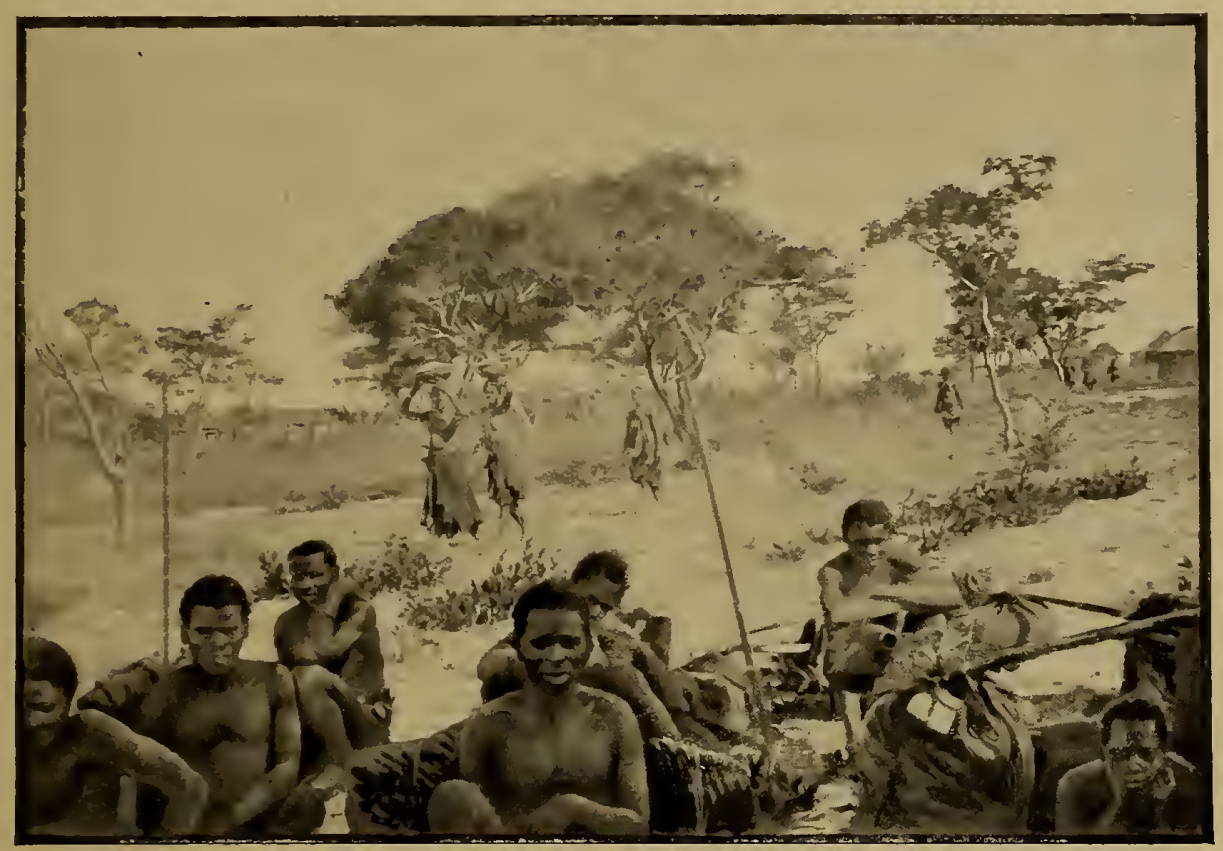

LX M.NiCUE AU WLLAGE DU CHEF MAYOLMB..

Dessin de Bigot-Valentin. D'après une photographie de l'auteur.

les désertions d'hier, les clıarges sont réparties à nouveau et je constate à ce moment que j’ai strictement le nombre d'hommes nécessaire. Nous formons au total une colonne de vingt-trois hommes.

Pendant la journée, la nature du pays change, les collines sont plus éloignées les unes des autres, elles sont aussi plus étendues et forment des plateaux. Près de la petite lagune Musana, nous voyons les empreintes d'éléphants. Irrivés ì la lagune Kamba (Kambai), aux ondes bleues, je fais remplir les calebasses des hommes; nous 
n'aurons point d'eau ce soir. En Afrique, il est urgent de régler ses étapes sur les emplacements où l'on pense trouver ce liquide indispensable; les hommes souffrent plus de sa privation que de celle de la nourriture.

Après avoir traversé une plaine boisée, campement sous un beau motsaoli. lilass est de nouveau bien souffrant ce soir! il ne peut plus avaler de quinine, elle lui occasionne des troubles nerveux, j'essaie, suivant un conseil qui m'avait été donné avant mon départ, des frictions de sulfate de quinine en poudre sous les aisselles; je le réconforte aussi avec ce que j'ai de plus reconstituant comme nourriture.

$$
\text { *** }
$$

11 aoút. - Le sulfate de quinine a produit bon effet et nous pouvons continuer la marche; alternances de grandes plaines et d'espaces boisés; nous avons en vue deux lagunes et nous passons la nuit non loin de la seconde.

$$
*^{*} *
$$

12 août. - Le thermomètre ce matin ì 6 heures, est descendu à zéro, quoique comme à l'ordinaire, la chaleur se fasse fortement sentir pendant la journée. Ces grandes différences de température qui se succèdent d'une manière aussi rapide ne sont pas précisément hygiéniques!. Même nature de pays qu'hier; en outre, sable fatigant pour la marche. Nous trouvons de l'eau fraiche dans un puits, avant d'affronter une grande plaine couverte de termitières aussi dures que le roc.

Je touche à midi le bord de la rivière Motondo, où j'attends mes hommes qui arrivent successivement. Deux ma-Nkoya, Gonéna et Malia, me font perdre l'après-midi; ils n'apparaissent qu'après cinq heures du soir et comme l'un d'eux portait ce qui était indispensable 


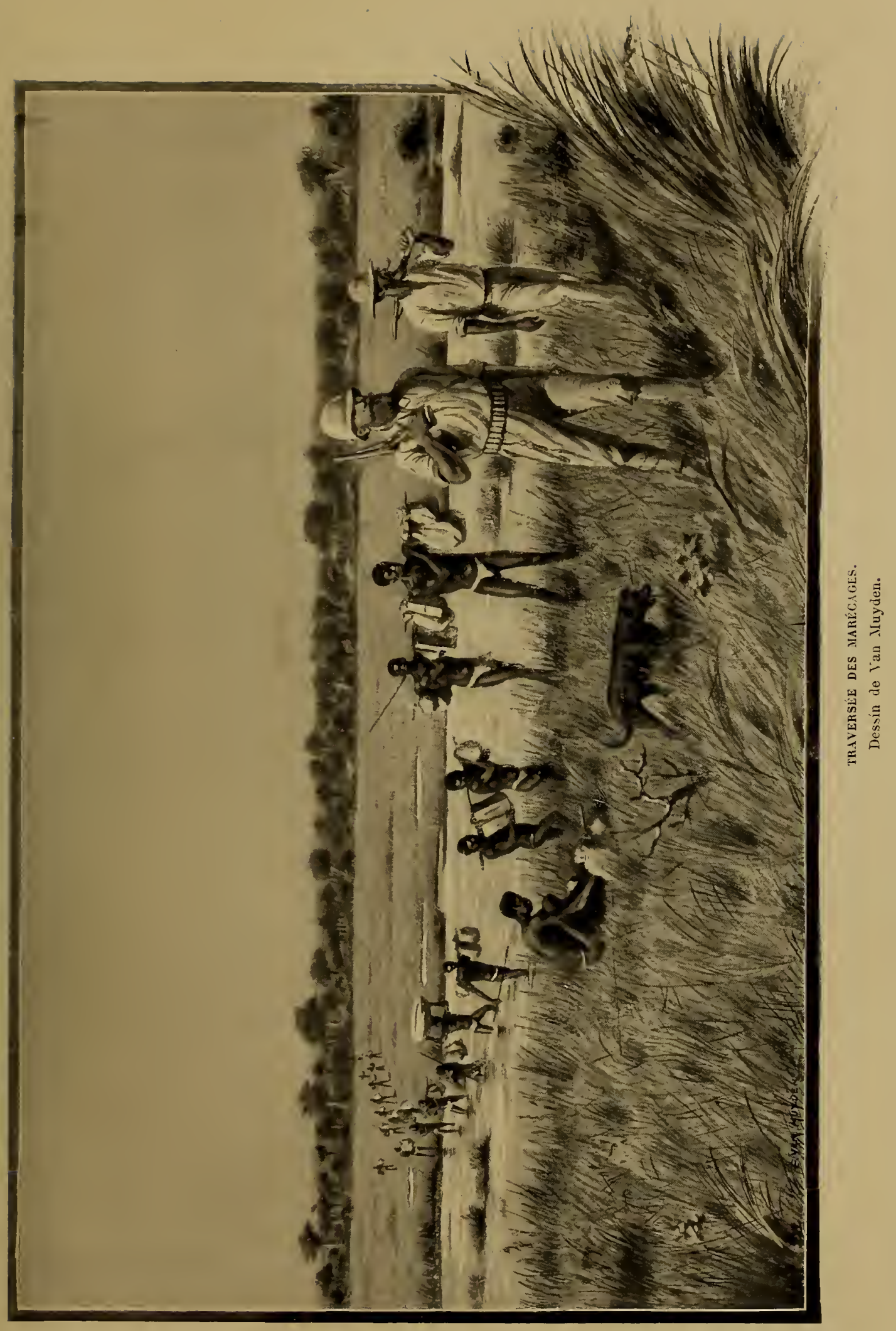



pour la cuisine, mon déjeuner n'est prèt qu’à six heures du soir.

Ivant tout, les deux coupables doivent comparaître devant moi. Il est essenticl, si l'on veut arriver au but proposé, de réprimer loute tentative de désordre avec justice ef fermelé. Les bommes sont rassemblés et ils sont informós que la conduite de leurs deux eamarades nous empèchera tous d'alteindre aujourd'hui un village, où nous aurions trouvé de la nourriture en abondance.

Iprès avoir entendu leurs mauvaises excuses, les deux ma-Nkoya feront ce soir leur feu de bivouac à l'écart el ils ne selont pas compris dans la distribution de ce qui reste de grains.

Puis, en marche! Le soleil est lájà bas à l'horizon, le crépus-

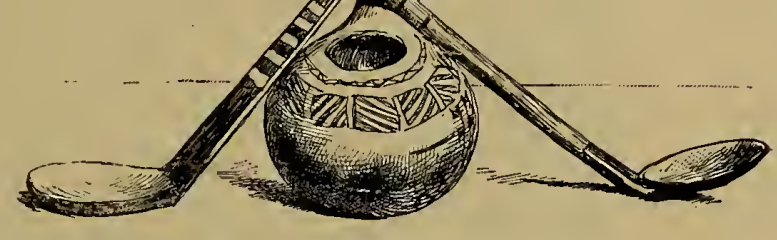

CAI.EBASSE A BOIKE ET CUILLEHS INDIGENES. Croquis de Tan Muyden. Collection de l'auteur. cule s'évanouit bien vite et nous aurons juste le temps avant la nuit, de passer sur la rive droite du Molondo, affluent du Louyi (Lui). Demain matin, au déparl, l'eau serait trop froide. Nous foulons bientòt les herbes marécageuses, ensuite nous enfonçons dans la vase et des flaques où l'eau finit par arriver à la ceinture. Le tout peut aroir sept on huit cents mìtres de largeur. Une fois l'autre rive atteinte, les grands feux du campement qui ne tardent pas à briller sont, chacun le comprendra facilement, contemplés avec entière satisfaction. La dernière calebasse d'arachides est partagée entre les hommes.

$$
*^{*} * *
$$

13 août. - De bonne heure nous arrivons au vallon où coule la rivière Louyi (Lui); là encore, il faut plonger dans la boue visqueuse, 
glissante ef traverser des mares où l'eau arrive aux genoux. Près de la rivière profonde, nous voyons arec plaisir un indigène accourir du village voisin. Pour une poignée de perles blanches, il nous passe les uns après les autres sur la rive opposée; son canol a été creusé dans un trone d'arbre.

L'un des porteurs, mo-Shoukouloumboué de naissance, profite de

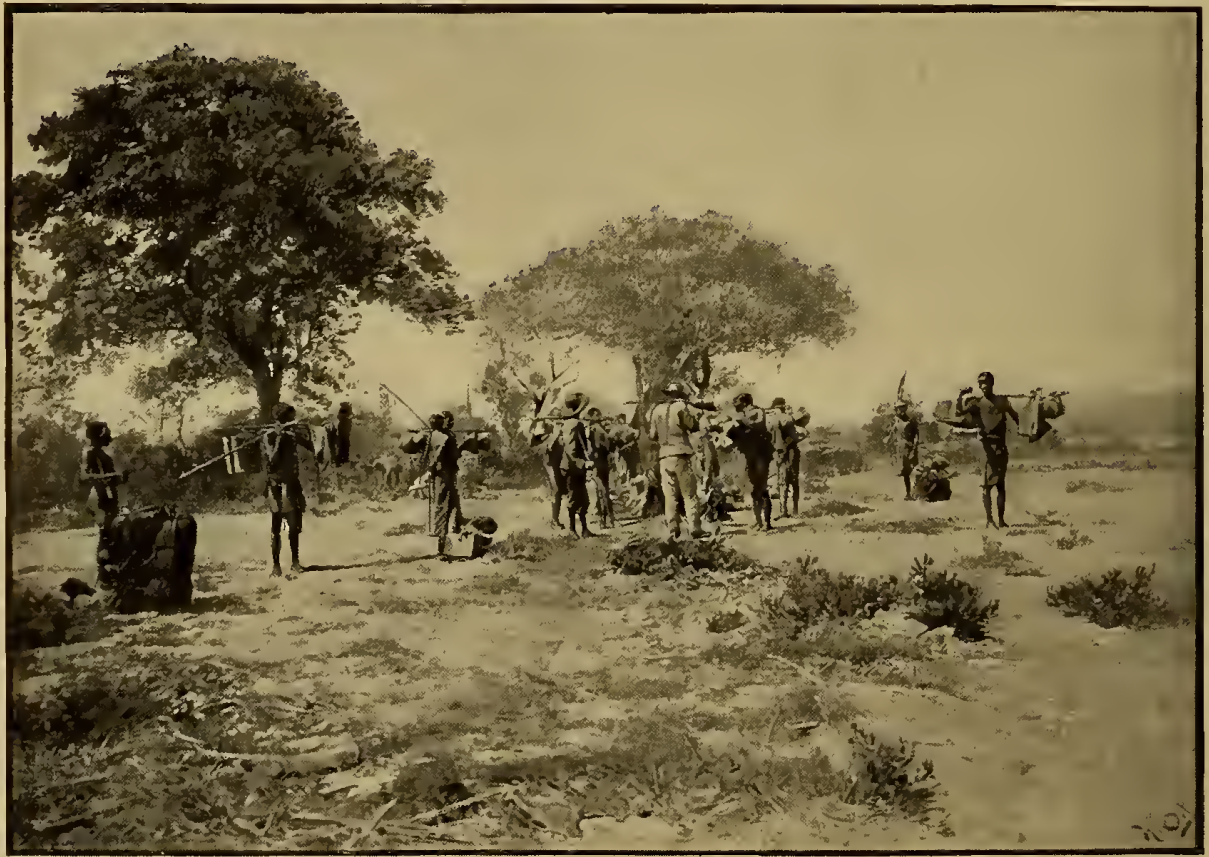

UNE IILLTE:

D'après une photographic de l'auteur.

ce moment de repos pour faire du feu à sa manière. Il introduil une longue baguette de bois très dur qui finit par s'user comme un crayon, dans un morceau de bois tres sec; il la fait tourner vigoureusement entre ses mains, en tenant à proximitr des fibres régétales desséchées, lesquelles ne tardent pas à s'enflammer. La seconde općration consiste à mettre un peu de tabac dans un roseau; il en bouche l'une des extrémités avec de l'herbe, puis de celle 
pipe improvisée, il tire aree délices deux ou trois boullées de fumée el il passe l’instrument à ses amis parliculiers, qui en usent de mime.

Ein somme, ces lommes fument pert; ils préférent le tabac à priser, cultivé et préparé dans le pays. Il joue un grand rôle dans lent existence; lorsque en royage, ils reneontrent des personnes de leur commaisinnce, apriss s'itre accroupis el, selon l'usage, avoir frappé des

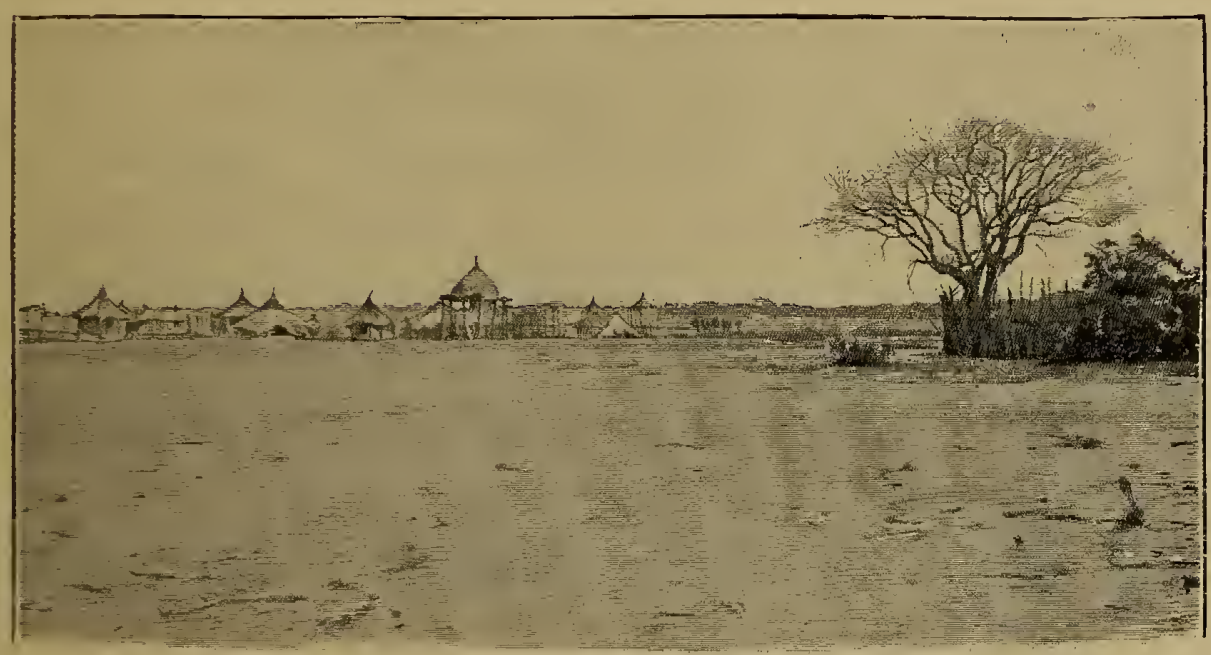

IX PAYSIGE IU P.IYS DES BA-ROTSI.

Dessin de Boudier. D'après une photographie de lautaur.

mains, ils soffrent du tahac qu'ils portent dans une petite gourde suspendue ajleur ceinture; ils en versent dans la paume de leurs mains et chacun en prend une pincée.

Je ferai remarquer ici que les salutations souvent fort bizarres des indigènes de ces contrées, varient à l'infini suivant la position de l'individu et le genre de relation que l'on entretient avec lui. C'est ainsi que, lors d'une rencontre, je n’ai pas pu m'empêcher de sourire en royant l'un de mes hommes cracher aimablement sur l'épaule d'un passant; signe d'amilié qui, certainement, serait peu apprécié (en Europe. 
Nous sommes sur le territoire de la tribu des ma-Kuangoa (Makwenga) qui possèdent du gros bétail; ils travaillent aussi le fer.

Nous voici établis sous de superbes motsaoli, mais je ne puis pas donner à manger à mes hommes! Il ne me reste rien. Picaniné est envoyé deux fois au village voisin afin d'informer les habitants que nous désirons acheter des vivres. Les heures se passent et rien n'arrive; le retard est encore plus grand qu'à l'ordinaire. Il paraît que dans celle partie du pays, les indigènes de peur de pillage, liennent leurs provisions non près de leurs habitations, mais au loin dans la campagne. Une file d'hommes et de femmes, portant des calebasses el de grands plats de bois, se montre enfin dans la plaine. Ils arrivent ayant à leur tête leur chef Moamanomné. Cette fois-ci ce sont les petites perles opaques qui seront en faveur. Les naturels apportent du lait caillé, du sorgho et des patates douces; Moamanomné m'offre comme présent un panier de ces dernieres; il semble satisfait de recevoir à son tour un objet europíen.

Une abondante distribution de patates est faite aux hommes et le sorgho est gardé comme réserve; en route ensuite jusqu'à la tombée de la nuit.

$$
\text { *** }
$$

14 août. - Longue colline de sable; des perruches verles volent de branche en branche. A la halte du matin, Klass Africa arrive en retard; nouvel el violent accès de fièvre; il est faible comme un enfant, un rien le ferait tomber. Il faut le couvrir de ses couvertures, lui donner un réconfortant, malgré tout, il tombe dans un état de torpeur. A quatre heures seulement, nous pouvons nous remettre en route pour traverser la grande plaine au bout de laquelle se délache le village de Célibélo (Shiribero). Je puis m’y procurer quelques poules. 
qui sont capturées sous mes yeux par des cufauls, fort joyeux de celle besogne. Nous eampons non loin de la lagune Nanjólua. Klass Africa est à boul de fores; les frictions de sulfate de quinine doivent ètre recommencées.

$$
\text { *** }
$$

15 août. - Les frictions au sulfate de quinine réussissent décilé-

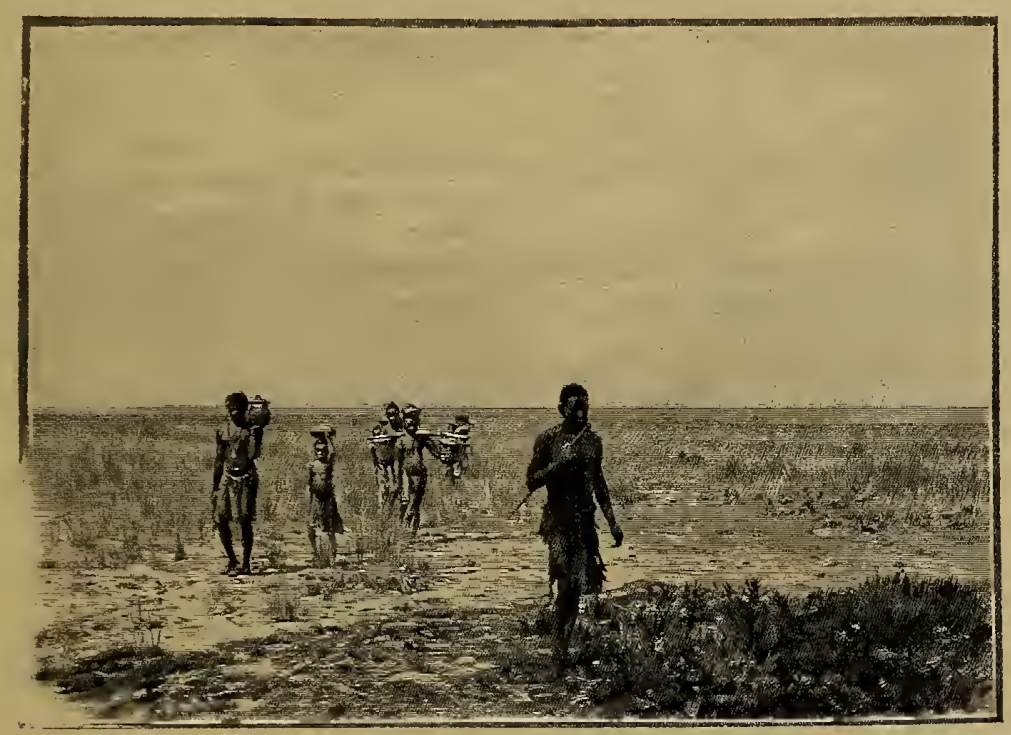

MES HOMMES DANS LA GRANDE PLAIYE DU BO-ROTSI. . Photographie de lituteur.

ment à Klass, ce matin il est beaucoup mieux; nous pouvons partir à l'heure habituelle.

Le pays se peuple de plus en plus; dans la matinée, nous longeons un village, où avec des perles blanches, nous obtenons en abondance des patates séchées et du manioc (mangia). J'observe près de là un indigène qui, avec un instrument des plus primitifs, taille dans un bloc du bois appelé mokoa une tubana, jarre à lail, il vient d'en terminer une et il me la cède contre un mouchoir rouge. Beaucoup de gros bétail. 
Une fois notre repas, composé de patates bouillies et de lait caillé, terminć, nous nous remettons en route; nous laissons à l'ouest une plaine où se groupent les huttes rondes de plusieurs grands villages.

Les femmes travaillent dans les champs. Elles se servent de courtes houes el sont forcément pliées en deux pour leur besogne. Plusieurs portent leurs enfants attachés derrière leur dos dans une peau; on n’aperçoil, de ces négrillons, que la tête. Par une forte chaleur, nous montons, pour finir la journée, une longue colline de sable, très dur à la marche: nous bivouaquons près de la lagune lkuloé (lkulve).

$$
\text { *** }
$$

16 aoüt. - Au départ, autre colline plus ou moins boisée: j'y tue deux pintades. Nous aboutissons dans la matinée au vallon de Séfoula (Sefula), où coule la rivière du mème nom. Nombreux villages et grande activité dans les champs. C'est M. le missionnaire Coillard qui, en apprenant aux habitants à dériver les eaux de ce vallon, a rendu beaucoup de terrain à la culture.

Au milieu du jour, nous arrivons ì la station missionnaire de Séfoula elle-même, située au sommet du coteau et fondée en 1886 par M. Coillard. Ciest là que se trouve la tombe de Mme Coillard, la fidèle et intrépide compagne de cet hérö̈que missionnaire. Cette station sera occupée par M. Davit, récemment arrivé d'Europe et que nous avons eu le plaisir de voir à Palapye. M. Coillard a continué sa marche en avant; il est actuellement à Léalouyi, la capitale du royaume des ba-Rotsi et la résidence du roi Léwanika. Il est secondé par M. et Mme Adolphe Jalla.

Une scierie a été établie à Séfoula pour les besoins de la mission; c'est dans celte station que M. Coillard désirerait fonder une école pour former des évangélistes indigènes, ainsi qu'une école industrielle. 


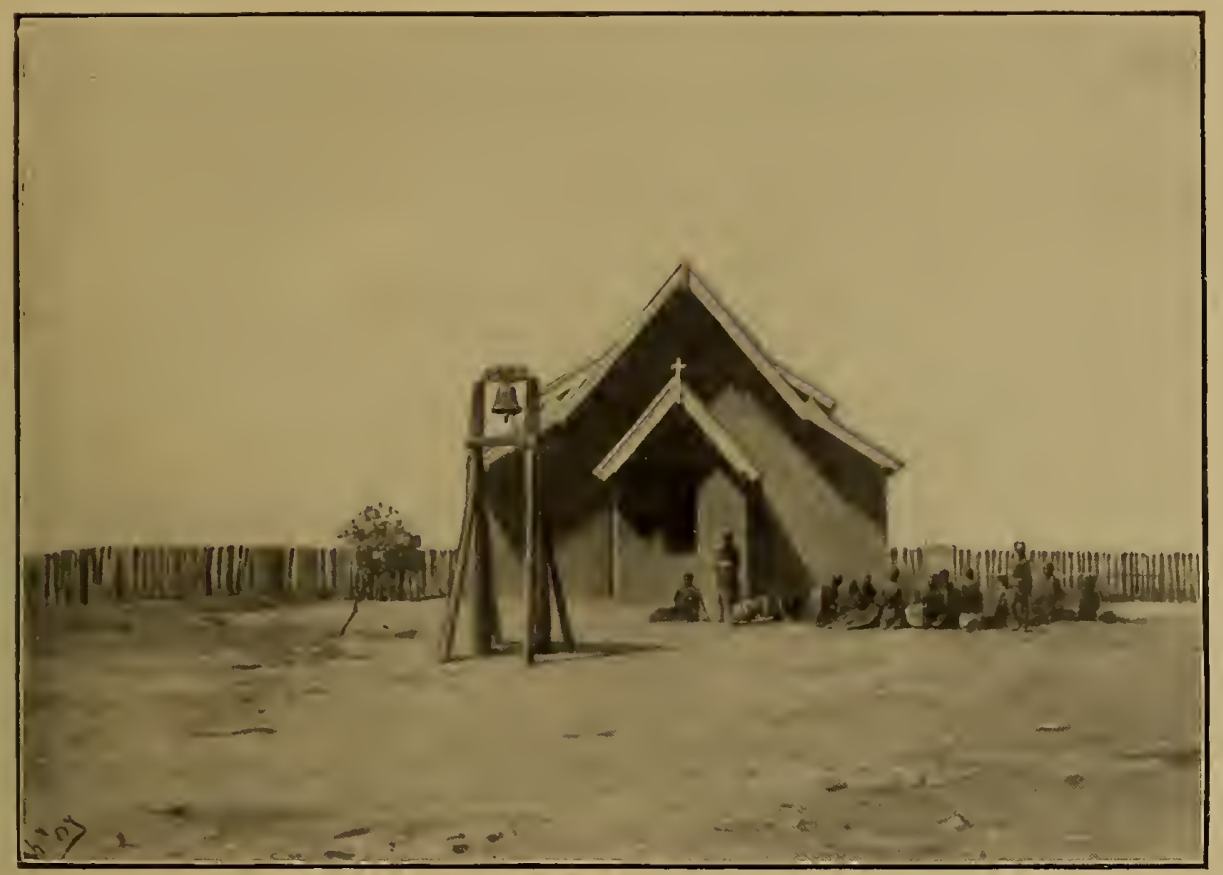

L'ÉGLISE de la STATION MISSIONXIRE DE LÉALOUY APPARAIT AU LOIN COMINE UX PHARE... D après une photographie de lauteur.

Les évangélistes noirs du lé-Sonto que nous rencontrons à Séfoula nous facilitent toutes choses.

$$
\text { *** }
$$

17 août. - Réveil à trois heures et quart. Une heure plus tard, nous sommes en route et foulons bientôt la grande plaine qui sépare Séfoula de Léalouyi: elle est sous l'eau pendant la saison des pluies. Pour cefte raison, les villages sont tous construits sur des éminences de termin. Plısieurs marécages. Dans la seconde moitié de la roule, nous franchissons la rivière Néboubéla. Elle ne manque pas de grandeur, cette immense plaine qui bordée à l'est et à l'ouest par une chaîne de collines, semble ètre un ancien lac desséché.

Enfin nous apercevons la station missionnaire, dont l'église apparaìt au loin comme un phare; les grandes huttes de Léalouyi (Lialui) se 
dessinent de plus en plus distinctement. Nous avons aussi réussi celte partie de notre expédition; une dernière halte pour remettre tout en ordre et nous touchons à la station missionnaire, où je reçois de M. Coillard, actuellement malade, ainsi que de M. et Mme Adolphe Jalla, un accueil qui me fait bien vite oublier les difficultés passées. Après avoir reconnu avec mes compagnons la source de la rivière Machilé, premier but que nous nous proposions, j’ai traversé le Pays des ba-Rotsi pour aboutir à Léalouyi, la résidence du roi Léwanika; mon second but a été ainsi heureusement atteint.

Pour résumer, je dirai que cette dernière traversée peut se diviser en deux sections distinctes:

$1^{\circ}$ La contrée, encore inexplorée à cette latitude, et située entre la rivière Machilé et la rivière Loumbé, se compose d'une succession de collines boisées, entrecoupées de vallées et de vallons où coulent les affluents des trois rivières Machilé, Njolio et Loumbé lesquelles, d'une manière générale, se dirigent du nord au sud pour aller se jeter dans le grand fleuve.

$2^{\circ}$ Parvenu sur les bords du Loumbé, je m'élais rapproché du Zambèze, lequel, ainsi qu'il est facile de le voir sur la carte, forme une grande courbe de Kazoungoula à Léalouyi, et j'avais croisé la piste que suivent les missionnaires, lorsqu'ils se rendent par voie de terre de l'une à l'autre de ces stations.

La nature de la contrée est différente, les mouvements de terrain sont plus étendus, les rivières sont moins nombreuses. L'une des plus importantes est le Motondo, ainsi que le Louyi (Lui), dont les eaux se réunissent plus au sud pour aboutir bientôt au fleuve. Çà et là de grandes lagunes parsèment cette région. Quelques-unes d'entre elles communiquent, me dit-on, avec le Zambèze dans la saison des inondations; elles en reçoivent alors l'excédent. 


\section{LE ROI LENWANITA \\ ET LE MISSIONNAIRE COILLARD}

A Léalouti, CaptTale de rol Léwanika. - Nalolo, résidence DE LA REINE MOLOUAÉ

D Maxche 18 aok̂t! Je suis réveillé au son joyeux d'une cloche. Point de longues marches aujourd'hui et point de marécages. Ce matin jassiste à l'école du dimanche tenue à la chapelle par Mme Jalla, qui, aidée des évangélistes noirs, instruit quatre-vingt-dix a cent enfants et adultes; beaucoup de discipline et d'attention. Plus tard, M. Adolphe Jalla fait la prédication et quoiqu'il ne se soil pas encore décidé à se convertir , le roi Léwanika prend place à la droite de l'estrade... Quel progrès! C'est lui qui il y a peu d'années encore, commandait, dans une seule journée, l'égorgement de seplde ses chefs !

Trois cent cinquante à quatre cents personnes composent l'auditoire, y compris le premier ministre et plusieurs des dignitaires du royaume. I sa sortie du temple, selon l'usage du pays, les sujets du roi s'accroupissent et frappent lentement des mains. Le roi assiste aussi au culte de l'après-midi. 
Nous prenions le repas du soir, lorsque Léwanika m’a envoyé comme cadeau une énorme calebasse de lait caillé, et, à l'adresse de mes hòtes, un morceau de jeune hippopotame ròti; cette viande tendre et savoureuse, lorsqu'elle provient d'un jeune animal, ressemble à la chair du porc.

$$
\text { *** } *
$$

19 aoûl. - Aujourd'hui lundi, accompagné de M. Ad. Jalla qui veut bien m’introduire, je me rends à Léalouyi pour remettre au roi les cadeaux que je suis chargé de lui offrir au nom de l'expédition et lesquels, selon l'étiquette, doivent ètre présentés lors de la première visite. Ils consistent en un mousqueton de cavalerie mannlicher, dernier modèle, avec cartouches; des couvertures, des mouchoirs de couleur et des objets d'habillements. Nous suivons la grande chaussée établie par M. Coillard; elle est coupée par un pont de bois au-dessous duquel passe le canal et relie la station missionnaire ì la capitale. Cette cliaussée permet seule une communication suivie avec Léalouyi, lors de la saison des inondations (mounda); à cette époque il faut traverser en canot la plaine qui se trouve sous l'eau.

Nous laissons sur notre droite un groupe de huttes, les greniers du roi. Nous approchons et traversons la place publique, parsemée d'arbres à caoutchouc. C'est là que le roi rend la justice lui-même. Nous arrivons à l'entrée de la résidence, entourée d'une haute palissade en roseaux; cette résidence, siluée au milieu de Léalouyi, est séparée des huttes des chefs et des sujets par une large allée circulaire.

Dans ce pays où l'ordre hiérarchique est très sévère, les lıuttes diffèrent de grandeur suivant l'importance des chefs. Il en est de même pour toutes les relations de la vie; un inférieur, par exemple 
u’a pas le droil d'avoir des armes ou des plats aussi bien orués que ceux de son supérieur en grade.

Une ouverture átroite, pratiquín dans le rideau de roseans, nous mène ì une cour intéricure centrale. Voici la demente de Léwanika; contrairement aux usages du pays, elle est rectangulaire, les mur's sont construits en terre batlue mélangée de bouse de vache, laquelle tient lieu de chanx. Dix-lıuit piliers de bois soutiennent in toit de chaume qui forme un auvent. Vis-à-vis et de l'autre côté de la cour', le liashandi, chambre privée du roi. Autour de la maison royale proprement dite, le harem, grandes liutles rondes, hautes d'une dizaine de mètres et admirablement construites; quoique

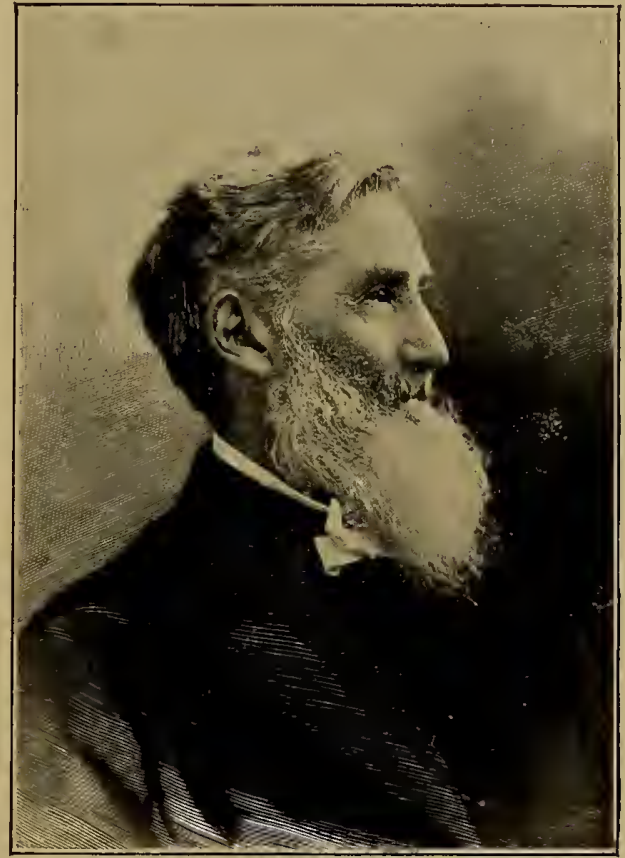

M. LE MISSIONNAIRE COILlaRD.

D’après une photographic de M. Boissonnas à Genc̀re. comprises dans l'enceinte de lat résidence, chacune est entoarée d'une palissade élevée; tout est tries propre.

Le roi est polygame; cette condition ne lui a pas permis jusqu'a maintenant de se convertir au christianisme, quoiqu'il le protège dans son pays et qu'il fréquente assidìment le culte.

Iu point de vue politique, chacune de ses femmes représente un groupe de vassaux ou une tribu.

Nous sommes reçus par Léwanika dans un hall couvert et tapissé de nattes; il nous fait asscoir à ses còtés. Homme dans la force 


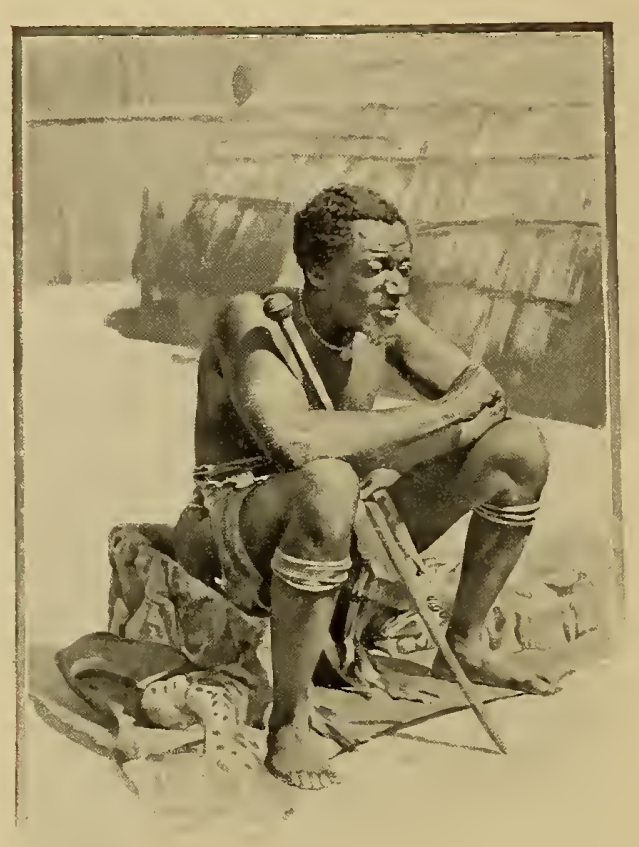

I.E ROI LE WANIKA ALTREFOIS.

D'après une plotographie de M. Coillard. Reproduction interdile. de l'ìge, grand et corpulent: sa figure est rasée, sauf une petite barbe noire. Il est vètu pour la circonstance d'un habillement quadrillé; il tient à la main, en guise de chassemouches, une queue de gnou ornée de perles de verre. L'expression de sa physionomie est très mobile. Les cadeaux sont disposés devant lui; puis, toujours par l'obligeant intermédiaire de M. Ad. Jalla, je le remercie au nom de l'expédition, de nous avoir laissé pénétrer sur son territoire. Il me

pose des questions sur l'itinéraire parcouru et me dit qu'il est disposé à me donner, au point de vue géographique, des indications sur son pays. Il me fixera un jour à cet effet.

Le mécanisme du mannlicher qui lui est expliqué, l’intéresse, car il est chasseur. Il en est de même de l'appareil photographique qu'il désire examiner de près; il me donne l'autorisation de le photographier.

Nous étions déjà hor's de l'enceinte, lorsque nous fùmes rejoints par l'un de ses serviteurs, nous apportant de sa part deux larges ombrelles pour retourner à la station. Limable attention, vu la forte chalcur. Des deux hommes que j'avais emmenés avec moi et qui portaient les cadeaux, Sibette, a été pris d'une telle frayeur à la vue du roi, qu'il s'est enfui; l'autre, Koudouman, nous attend dans la posture la plus humble. 
Lriwanika donne libre accis dans sa résidence à M. Coillard ailssi qu’à 11 . et à Mme Mcl. Jalla. Jari le privilige d'areompagner ars derniers dans la fouméc missionuaire qu’ils font régulièrement à Léalonyi. Nous entrons dims la demeure de plusienrs des femmes du roi ; en particulier dans celle de la reine Longa, yui nous recoit, aceroupie sul ses nattes, dans un pavillon très bas. Elle est drapée de cotonnades aux couleurs royantes; ses bras sont ornés de

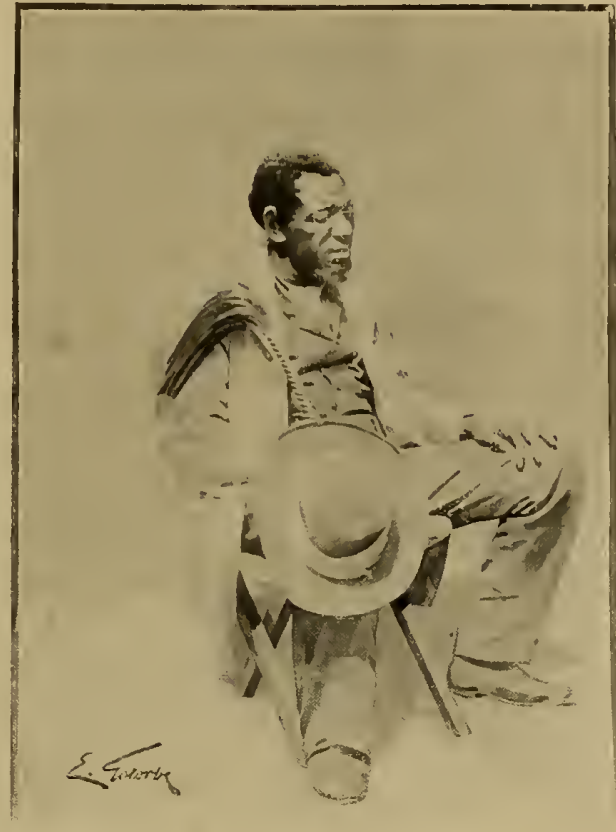

LE ROI LÉWANHA ALJOCRD'HLI. D'après une photographie de M. Coillard. Reproduction interdile. superbes bracelets d'ivoire. Ses serrantes, ou plutòt esclaves, car elles sont loin d'être libres, travaillent aux fourrures de leur maitresse, près de la grande hutte. Longa veut bien, elle-même, nous faire les honneurs de son habitation. Toutes les huttes du harem se ressemblent : au centre, la chambre principale, couverte de nattes; elle est haute de plus de cinq mètres et entourée d'un corridor circulaire.

Iutre visite à liatolia, soeur cadelte du roi; son mari occupe le troisieme raug dans le royaume. Parmi ses suivantes, Mme Jalla trouve l'une de ses jeunes élèves fort occupée à un ouvrage de couture... contraste amusant avec son costume pittoresque.

L'usage reut que les maitres de la maison saluent d'abord et cela seulement lorsque leurs visiteurs sont assis s'ils ont apporté leurs sieges, ou sinon accroupis par terre. 


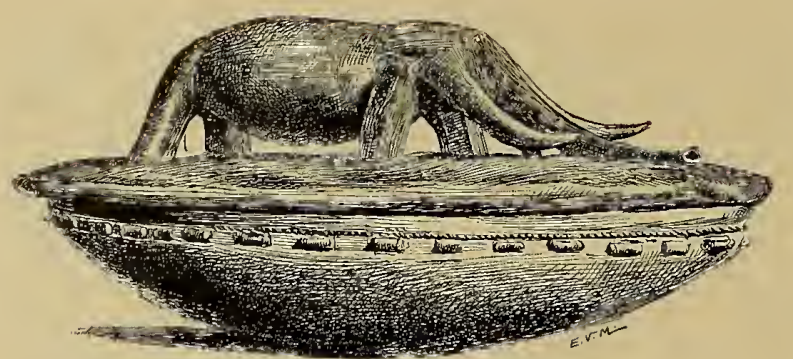

PLAT ROYAL EN BOIS SGULPTÉ CÉDÉ PAK LE ROI LÉWANIKA. Croquis de Van Muyden. Collection de l'auteur.
Puis nous pénétrons dans un autre intérieur, chez la princesse Mokena; ses yeux sont entourés de grands cercles noirstracés artificiellement, ils se détachent sur le brun très

foncé de la peau; une raie noire traverse aussi le front et partage le nez en deux parties égales.

En revenant à la station missionnaire, nous rencontrons sur la chaussée l'un des rameurs de la barque royale; il est coiffé d'un couvre-chef rouge. L'honneur de promener le roi sur les ondes n'est pas sans inconvénients. Comme il faut ramer très vite, lorsqu'un des bateliers montre de la lassitude, il est, sans autre cérémonie, jeté à l'eau; un canot de la suite du roi vient le recueillir.

$$
\text { *** }
$$

21 août. - Le roi m'envoie un bœuf gras; c'est un riche présent; la famine règne dans les environs et les sauterelles ont ravagé cette partie du pays.

Katoka me fait aussi parvenir une grande jarre de maïs.

J'ai le privilège d'avoir presque chaque jour des entretiens fort intéressants avec M. Coillard, quoiqu'il soit très souffrant et qu'il ne puisse pas quitter sa hutte.

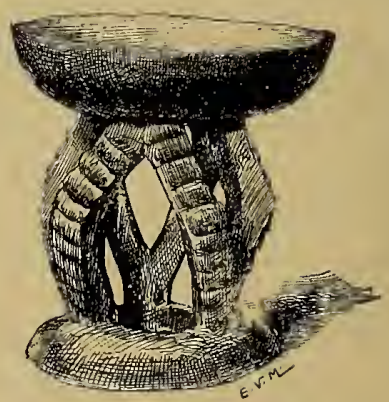

SIEGE EN BOIS SCLLPTÉ CÉDÉ PAR LE ROI LÉWANIKA.

Croquis de Van Muyden. Collection de l'auteur. 


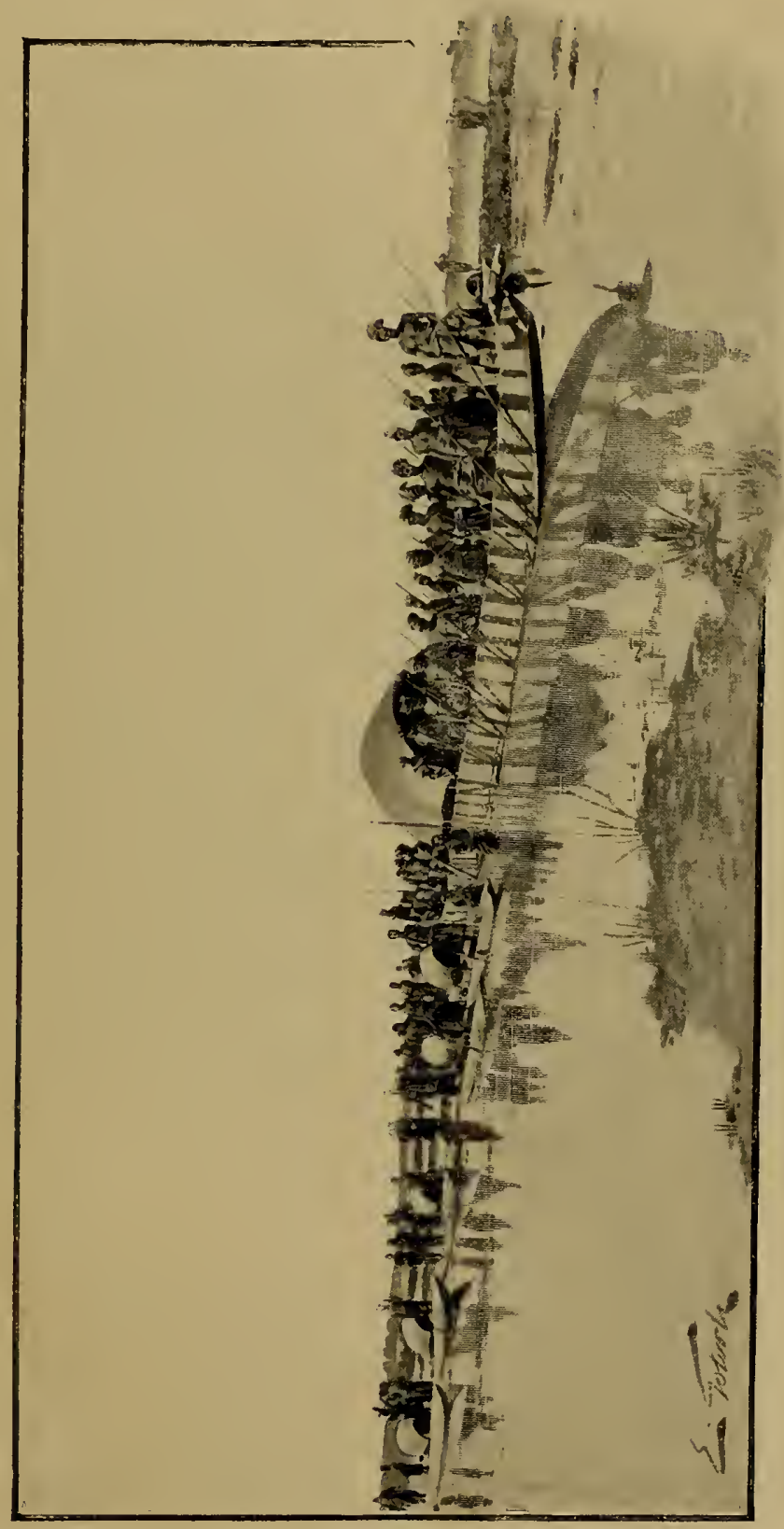

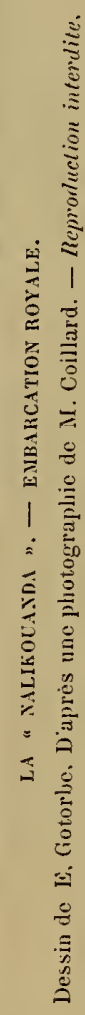





$$
* * *
$$

9y août. - Léwanika n'a pas tarelé à indiquer une apròs-midi où il consentirait à me donner les renseignements demandés. Malgré ses occupations de chaque instant, M. II. Jalla, avec son obligeance habi-

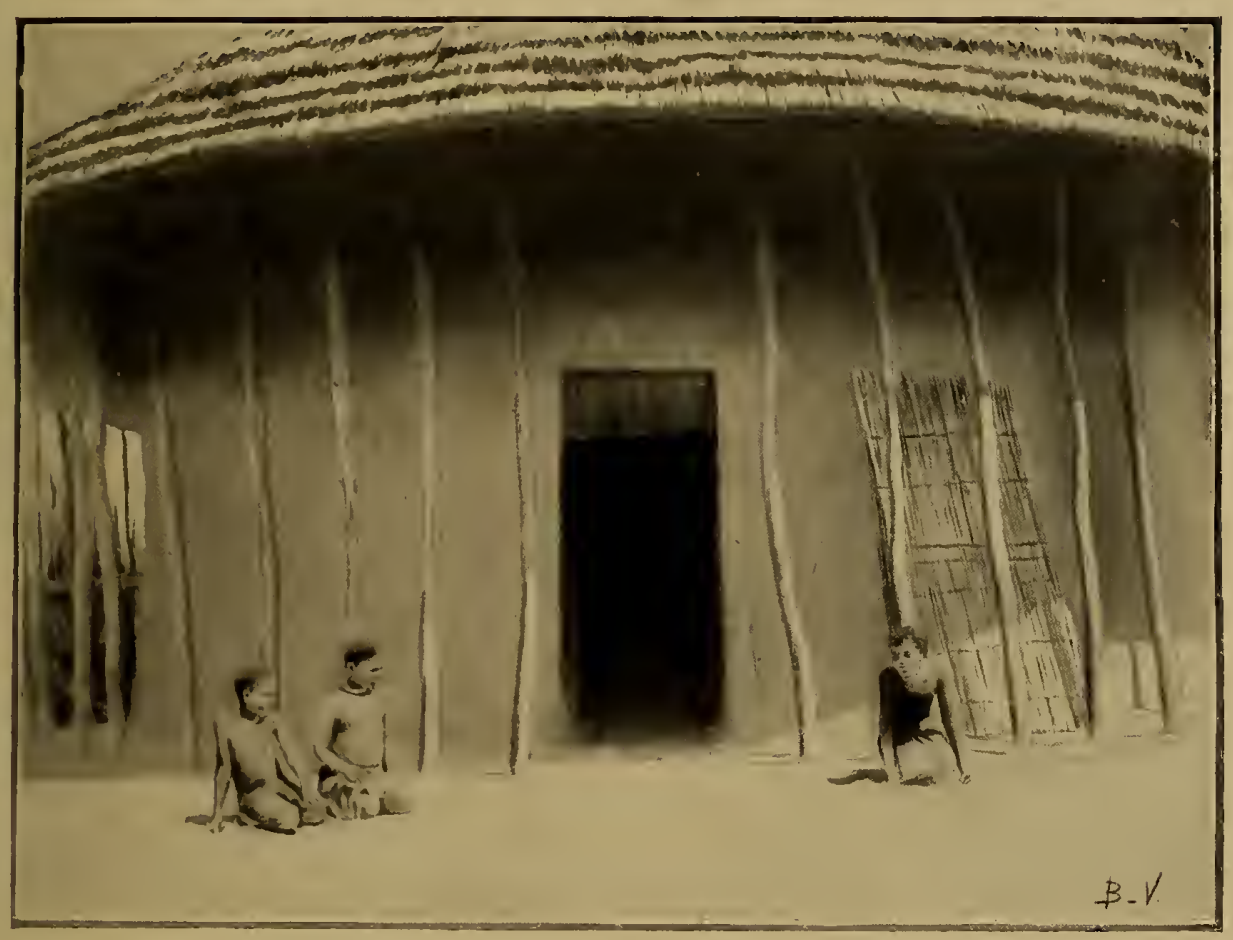

L'UNe des hUTTES DC haREM Royal.

Daprès une photographie de l'auteur.

tuelle, veut bien m'accompagner et me servir encore d'interprète. Nous trouvons le roi dans le kashandi qui est construit d'après l'ancien modiele des habitations des ba-Rotsi, très usité avant que les ma-Kololo eussent envahi le pays; les ba-Rotsi, conservateurs, continuent à construire leurs demeures d'après l'ancien style. La forme de colte construction peut être comparée à celle d'une coque de bateau renversée qui serait coupée au-dessous des bastingages. Sauf les sou- 
bassements, les parois du kashandi royal sont faites en roseaux; pour les consolider on emploie, de plus, des roseaux noirs et blancs tressés en gros faisceaux; un auvent supporté par des piliers de bois en fait le tour. Deux petites portes basses, parallèles, y donnent accès. Léwanika nous fait asseoir l'un à sa droite et l'autre à sa gauche; le long de la paroi principale, plusieurs dignitaires sont accroupis sur des nattes, en particulier le gambéla Séopi, premier ministre, personnage replet dont la tête grisonnante est recouverte d'un bonnet de couleur. Il ne porte d'autre vêtement aujourd'hui qu'une large pièce d'étoffe bleu foncé, enroulée autour de la taille; à son cou pend un collier de grosses perles de verre bleu, d'où se détache un koupa, coquille polie qui a représenté pendant longtemps la valeur d'un esclave.

Nos cartes de géographie sont déposées devant Léwanika; la boussole l'intéresse. Après plusieurs questions, le roi me confirme ce qu'il avait déjà dit auparavant, c'est que, ì sa connaissance, liitinéraire que j’ai suivi entre les rivières Machilé et Loumbé n'a pas encore été exploré à cette latitude.

Dans la seconde partie de cette séance géographique d'un nouveau genre, Léwanika me donne des renseignements intéressants sur les frontières de son royaume, en particulier sur la frontière nord, très peu connue, qui sclon toute probabilité se trouve proche de la ligne de partage des eaux du Congo et du Zambèze, ainsi que sur les tribus qui l'habitent et qui sont moins connues encore. Il avait convoqué à cet effet, quelques chefs ou sujets. Ils sont lì, accroupis dans la cour, attendant qu'ils soient mandés par le roi. Ils entrent alors à genoux, s'inclinent profondément en frappant des mains, puis s'accroupissent sur leurs mollets. Séagika, le secrétaire du roi, se tient devant lui et prend part à la discussion, ainsi que le gambéla Séopi et d'autres encore. Comme je l'ai dit, le roi Léwanika me donne surtout l'énumé- 
ration des tribus qui habitent dans le noed de son royaume : j'écris sous la dictéc de .1. A. Jalla ces noms el ces indications. Le roi avait pris la précaution de marquer ou de fare marquer a la eraic sur le sol de la salle le tracé sommaire d'une partie de ses états.

Lorsque Léwanilia adresse la parole à l'une des personnes présentes, clle doit baltre des mains. S’il éternue, tout le monde, excepté nous, bien entendu, bat des mains. De ma place, je vois les plats du diner royal passer dans la cour el les indigènes qui se trouvent sur leur passage frappent des mains; il en est de mème pour tout ce qui appartient au roi. Comme dernière question, je demande à Léwanikia quel est le nombre de ses sujets.

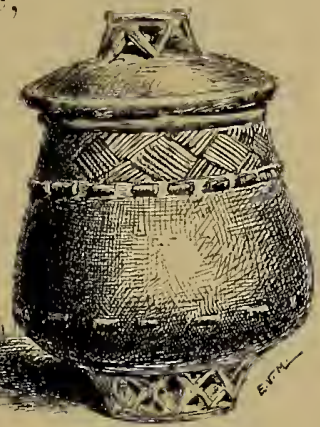

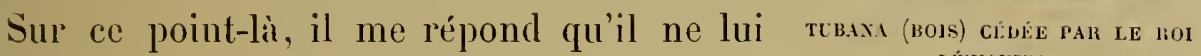
est pas posisible de me donner un chiffie, Croquis de Van Yuyden. Collection mème approximatif.

Le solcil est sur le point de se coucher, lorsque nous quittons le kashandi. En traversant la place publique, nous voyons de grands tambours allongés, qui vont ètre battus en l'honneur du renouvellement de la lune. Les danseurs, revêtus de queues de léopards, reprennent déjà leurs exercices chorégraphiques, de véritables dislocations.

Nous sommes au commencement du mboumbi, de la saison chaude; novembre est le mois le plus cliaud de l'année; à celte époque le thermomètre a enregistré, paraìt-il, jusqu'à $+48^{\circ} \mathrm{C}$. à l'ombre. Les nuits sont fraiches et l'écart de température entre le jour et la nuit est en moyenne de 20 degrés centigrades.

Une autre fois, j'assiste à la chapelle au service du soir pour les catéchumènes, présidé par M. Jalla. Parmi les assistants se trouve la jeune ex-reine Nolianga, qui vient volontairement de quitter le 
harem, afin d'embrasser la foi chrétienne; elle perd de ce chef la plupart de ses avantages matéricls.

Les catéchumènes indigènes se sont divisé Léalouyi en deux parties, où ils vont régulièrement évangéliser, pénétrant malgré les mauvais traitements, chez les habitants les plus hostiles.

Que dire aussi de cette école si bien tenue! Quelle vie de dévouement que celle de ces missionnaires dont tous les instants sont si occupés! Ils trouvent encore le moyen de soigner des malades. La venue d'un médecin-missionnaire serait accueillie avec joie. Au point de vue matériel, que d'obstacles à vainere! Comme dans les autres stations du Zambèze, la maison rectanģulaire qu'habitent M. et Mme Arl. Jalla, ses dépendances, l'église, ont été construites par eux-mêmes '. T'u les dégàts causés par les termites, les toits en chaume sont à réparer fréquemment; il en est de mème des murailles. Tout doit être prévu et calculé d'avance; les caisses envoyées d'Europe mettent, pour arriver à destination, une année et quelquefois davantage.

Avec cela, comme ils sont joyeux, nos missionnaires, hospitaliers, et bons!

Nouvelle visite à Léwanika; il savait mon désir d'assister à une séance du léklıotla, où il juge lui-mème. Quoique la journée soit déjà avancée, il fait donner le signal par le tambour. Précédé d'un joucur de sérimba et d'un porteur de siège, il se rend à la place publique, où il s'assied au pied d'un arbre à caoutchouc; nous nous plaçons près de lui. Ses musiciens, dont les instruments sont figurés par des tambours, des liangombio, des sérimba, ce dernier est composé de calebasses évidées, surmontées de planchettes de bois sonore qui sont frappées 
avec mn petil matean, vout à dislance respectueuse, se melle en face de lemr anguste mailm.

Les likomboa, serviteur's personnels du roi, at les membres de la famille royale se rangent d'un còté; le premior ministre at les dignitaires de laulre. De toutes parls dábouchent des chofts at des sujels

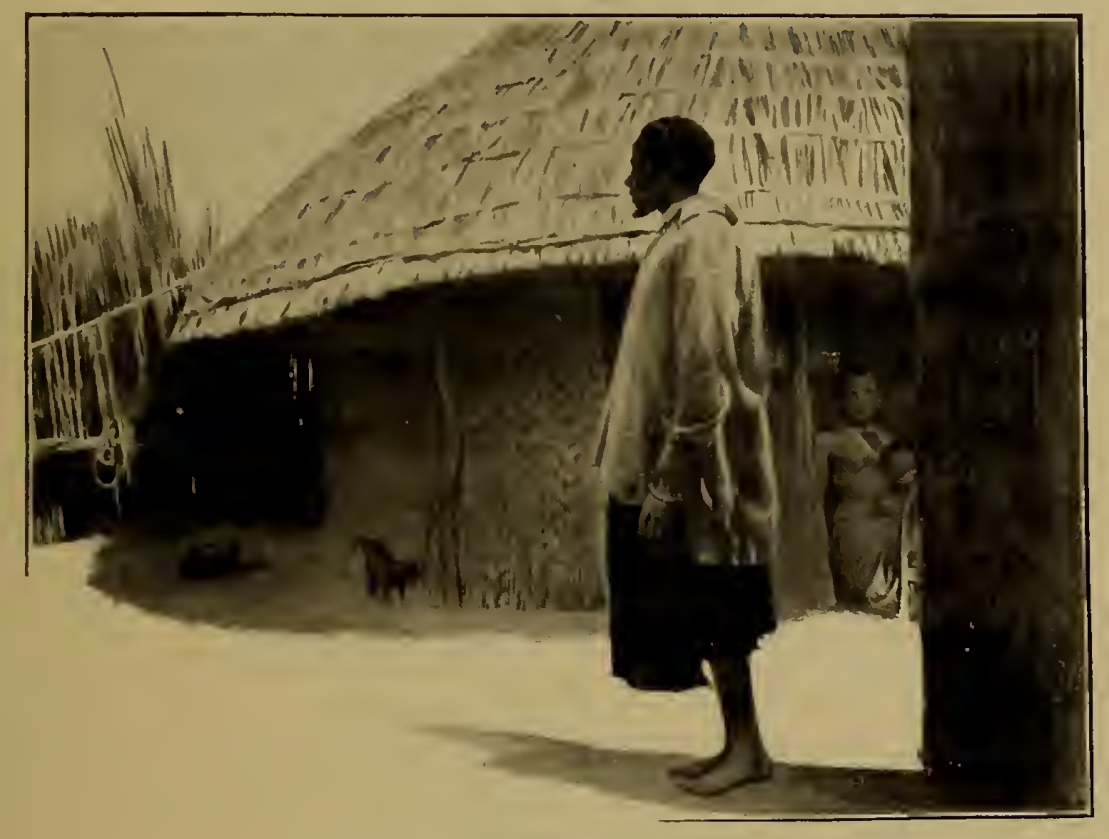

L'LX DES CONSELLLES WU ROI LÉWANIK.1.

D'apris une photographie de l'auteur.

qui se groupent suivant leur degré hiérarchique. Les femmes n’ont pas le droit de paraitre sur la place publique pendant la duréc dı léliliotla. Bientòt plus de deux cents hommes sont accroupis sur lo sable... Tous, en arrivant, se metlent ì genoux, s’inclinent profoudément en frappant des mains. C'est l'hommage appelé licandéléla.

Les indigènes, à leur retour de voyage, viennent ì une centainu de mitres faire le shoaléla levant le roi, salutations très compliquées, entremèlées de cris et où le front touche souvent la poussière. En voici un qui arrive de loin, et il demande au roi de pouvoir con- 
server une peau de bête sauvage qui lui a été donnée en route; sans ce consentement le présent reviendrait de droit au souverain.

Tableau caractéristique qu'éclairent les derniers feux du soleil couchant!

Au lékholla, les questions importantes sont soumises au roi; ses jugements font loi. Il représente à lui seul le tribunal, la cour d'appel et la cour de cassation. Inutile de dire que l'encre et que tout genre de procédure sont inconnus en ces parages! Ne se produit-il jamais aucun déni de justice, c'est une autre question!

Mais que de progrès déjà accomplis! Il faudrait des pages pour parler de l'influence bienfaisante du christianisme qui, peu à peu, pénètre et modifie toutes choses! M. le missionnaire Coillard, ce courageux champion de la cause de l'Évangile, a ouvert le pays il y a une dizaine d'années et c'est lui qui a fondé, en 1892, cette station aux portes de Léalouyi, forteresse du paganisme dans cette partie de l'Afrique. Il est admirablement secondé par ses collaborateur's.

L'infanticide, qui se pratiquait alors ouvertement dans la capitale, se cache aujourd'hui. De deux jumeaux, l'un était mis à mort; il en était de même des enfants de faible constitution.

Il est aussi parvenu à supprimer le supplice terrible de l'eau bouillante. Le malheureux accusé d'avoir jeté un mauvais sort à l'un de ses semblables, devait tremper ses mains dans de l'eau en ébullition; il était ensuite placé de force sur un chevalet et un violent poison lui était administré; après d'horribles souffrances, il était brùlé vif au milieu des imprécations de la foule qui l'entourail; il y aurait long à raconter sur le chapitre de ces horreurs.

Le roi Léwanika était très superstitieux. $\Lambda$ l'emplacement du temple où il se livrait à ses pratiques superstitieuses, existe maintenant un atelier. Le roi y travaille lui-même de ses mains. I son arrivée, M. Coillard 


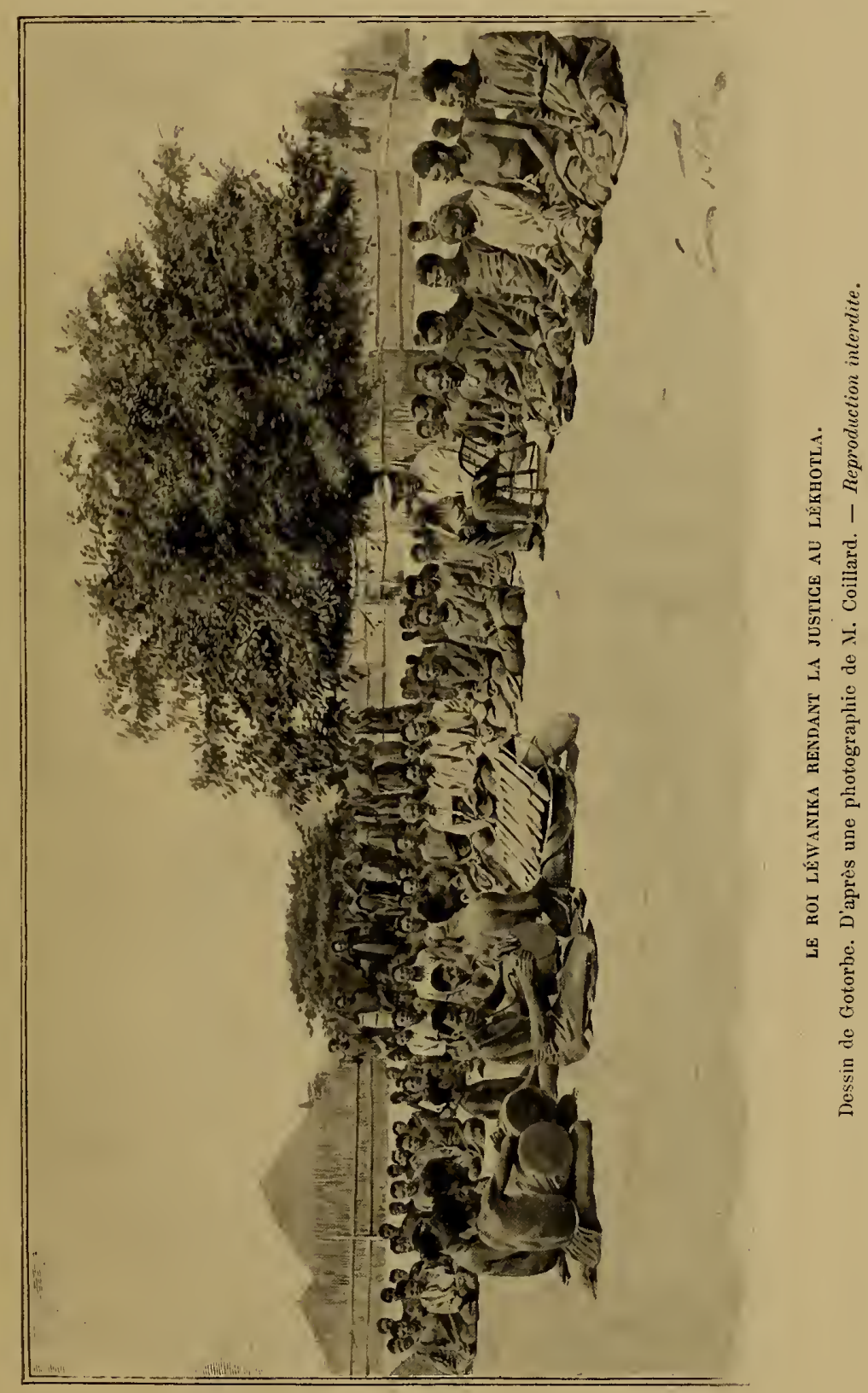



a eucore vin des lianes tendues depuis la résidence royale jusquian dehors de Léalouyi, dans le but d'arrèter les mauvais esprils.

Les ténèbres sont épaisises el les diflicullés nombreuses, mais ces hardis pionniers de l'Évangile penvent déjà enregistrer bien des victoires.

M. Coillard excree un grand ascendant sur Léwanika; un marchand d'esclares, métis porlugais que j’ai vu l'aulre jour, est arrivé ici aver l'intenlion de demander au roi l'autorisation de traverser son pays pour aller plus à l'est s'approvisionner de sa triste marchandise. Le roi qui, en cela, agissait contre son propre intérêt matériel, car le marchand d'esclaves lui aurait offert évidemment de riches cadeaux, ne lui a pas permis de continuer sa route et l'a forcé ainsi à ballre en retraite. N'est-ce pas là, parmi beaucoup d'autres exemples, une preuve remarquable des résultats merveilleux obtenus sur ce roi sauvage par les enseignements de M. Coillard!

Lorsque mon séjour sera terminé, je descendrai le Zambèze en canot jusqu'à Kazoungoula, voyage dontj'entends dire des merveilles; je visiterai aussi les stations missionnaires de Nalolo et de Séshéké.

$$
\text { *** }
$$

3 septembre. - Le roi Léwanika a mis à ma disposition un léger canot de chasse, monté par de vigoureux bateliers qui font voler mon embarcation. De cette manière, pour répondre à l'aimable invitation que m’ont faite M. et Mme Béguin de visiter leur station, je puis franchir en un jour la distance qui sépare Léalouyi de Nalolo.

Nalolo, station dépendant de la mission du Zambèze, a été fondée en 1894, par M. et Mme Bíguin, de Neuchâtel. Mme Béguin est la fille de II. le professeur et pasteur Charles Porret, de Lausanne. Je suis confondu en pensant qu'une année à peine s'est écoulée depuis que M. Béguin dressait sa tente sur la grève du grand fleuve. Aujourd'hui. 
il habite une maison construite de ses mains et, dans peu de temps, il inaugurera son église dont la construction avance rapidement.

Un superbe drapeau fédéral orne la muraille principale de la pièce qui sert de salle à manger et à maintes reprises, des chants patriotiques se sont fait entendre dans cette enceinte. Combien à des milliers de lieues de la patrie, l'on est agréablement surpris par ces mélodies connues et aimées!

Nalolo estl'un des centres les plus importants du royaume des ba-Rotsi, résidence de la reine Moliouać, sœur aìnée du roi Léwanika. Anomalie bizarre : dans cette contrée où comme dans tous les pays non chrétiens, la femme occupe une position très dépendante et inférieure à celle de l'homme, la sœur aìnée du roi a les mèmes prérogatives que son frère, les mêmes tributs lui sont payés.

LA REINE MOKOCAÉ, DE NALOLO. Photographie de M. Coillard. Reproduction interdite.
Comme le veulent les usages du pays,

M. Béguin m'a conduit ce matiı auprès de la reine Moliouaé; nous la trouvons au lékhotla, où elle préside en plein air les délibérations et où elle rend la justice. Accroupie sur une natte, elle nous fait asseoir près d'elle; après les salutations, elle me fait savoir qu'elle est de cinq années plus âgée que son frère, le roi Léwanika. L'expression de son visage, comme celle de son frère, est très mobile. Elle est vètue de cotonnade et une grosse épingle d'ivoire sculpté est fixée dans ses cheveux crépus. A sa droite, son premier ministre et d'autres dignitaires; à sa gauche et à distance, des hommes réparent le filet dont on se sert aux pêches royales; il est immense. Devant la 


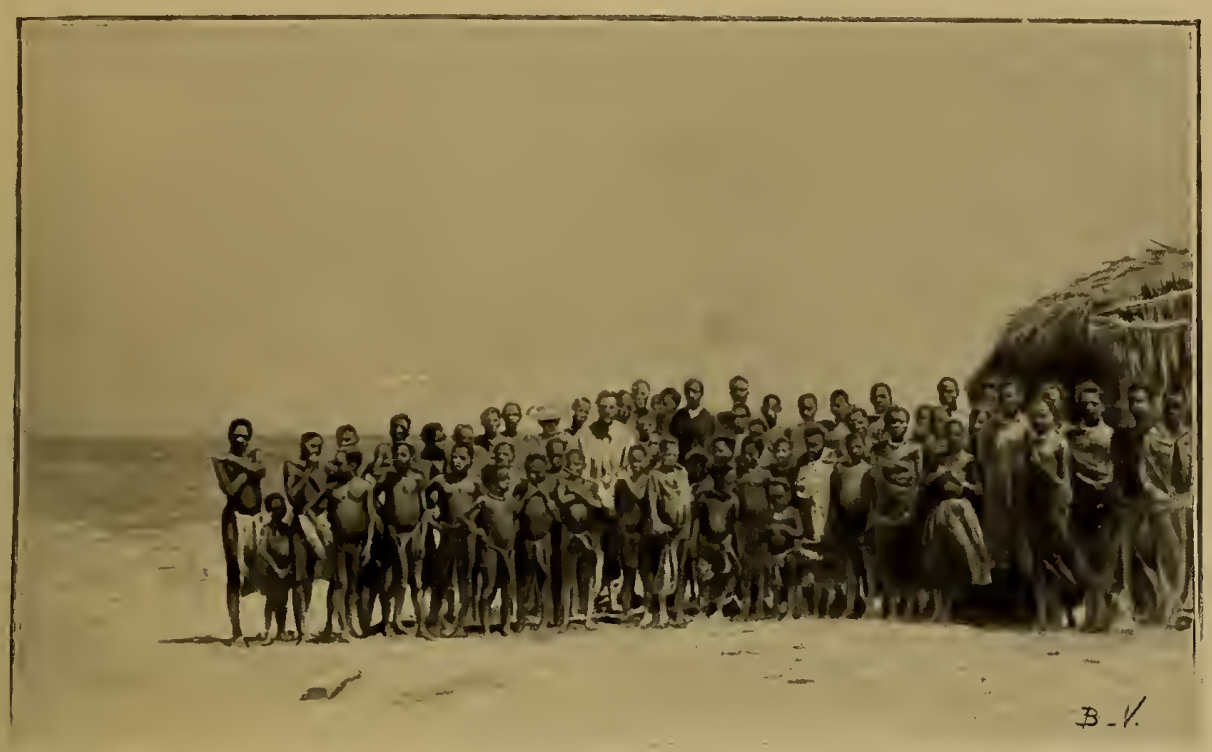

ÉCOLE DE M. ET DE M $\mathrm{M}^{\text {me }}$ BGGLiN A NALOLo.

D'apris une photographie de l'auteur.

reine, ses musieiens; quand elle éternue, aussitòt suivant l'éliquette, ils jouent de leurs instruments et tout le monde frappe des mains.

Puis nous visitons sa résidence, qui ressemble à celle de Léwanika; la salle d'honneur est couverte el tapissée de nattes de jonc. La reine, à l'occasion, ne dédaigne pas de fabriquer elle-même des nattes et de faire de la polerie; nous voyons là des fourrures splendides.

On nous apporte bientòt un mélange de maïs et de lait, boisson légìrement acidulée. Elle nous est servie avec soin par l'une des suivantes de la reine qui, avant de nous la présenter, enlève avec un bàtonnet les moindres parcelles de grain qui peuvent s'y trouver.

Aprés avoir pris congé, nous visitons les greniers royaux, construits en lerre au-dessus du sol sur des pieux et recouverts de chaume.

En revenant, nous entrons à l'école qui dépand de la station el où 
une cinquantaine d'enfants, parmi lesquels les petites filles de Mokouaé, chantent des canliques à gorge déployée.

La reine m’envoie dans la journée une provision de maïs. Le lendemain, elle vient chez M. et Mme Béguin prendre part au déjeuner. Elle a un vêtement clair et est en outre drapée dans une large pièce d'étoffe aux couleurs voyantes; autour de sa tète, un turban rouge. On dit que cette reine que je vois aujourd'hui s'agenouiller pour la prière, a tué de sa propre main, il y a quelques années, l'un de ses dignitaires àgé dont elle n'était pas satisfaite. Elle me fait demander si lorsque je retournerai dans mon pays, je me servirai du chariot de feu (chemin de fer) et du bateau de feu (steamer).

Après le repas, la reine monte dans son canot pour se rendre compte par elle-même, du travail de ses esclaves qui cultivent les champs.

Le mari de Mokouaé, qui est absent, porte le titre de Mokuentounga; il est l'intermédiaire entre elle et la nation.

Nalolo contient environ 2000 habitants; à l'inverse des autres centres importants du Pays des ba-Rotsi, cette bourgade est située sur la rive droite dı Zambèze, à l'entrée d'une grande plaine de sable aride qui, à l'ouest, s'étend jusqu'ì la rivière Linyanti (Chobé).

Nalolo a l'avantage d'avoir de l'eau potable en abondance, ce qui est loin d'être le cas à Léalouyi; les missionnaires n'ont ni fruits, ni légumes; en cela Nalolo parlage le sort des autres stations.

La localité possède passablement de bétail; mais ce bétail, comme celui de la capitale, doit être envoyé dans la forèt pendant les inondations; done, à cette époque, très peu de lait.

Beaucoup d'insectes; l'un des plus redoutés est le séroui, ces terribles fourmis guerrières dont les troupes serrées ne dévient jamais de leur chemin. Lorsqu'elles pénètrent dans me habitation, ce qui arrive fréquemment, il faut leur laisser le passage sous peine d'ètre 
mangé vivant. Ce sont les termiles pourtant, qui, dans cette partie de l'Ifrique, font le plus de dégàts; elles s'attaquent ì tout, excepté aux matières grasses. Au moyen d'un suc qu'elles sćcrètent, elles couvrent les objets d'une couche de terre humide, à l'abri de laquelle elles peuvent dévorer tout ì leur aise, en quelques heures, les habits, les livies, ete.

Quelle vie remplie que celle d'un missionnaire! Outre ses occupations diverses de chaque instant, M. Béguin a, du $1^{\text {er }}$ juin au 31 août, donné des soins à plus de 280 patients!

Le dimanche, la moyenne des auditeurs au temple est de 250 a 300 , y compris Moliouaé elle-mème.

J'ai emporté de mon séjour à Nalolo et du bon accueil que m'ont réservé M. et Mme Béguin un excellent souvenir.

$$
\text { *** }
$$

9 septembre. - J'étais de retour à Léalonyi depuis quelques jours. lorsque a eu lieu une conférence des missionnaires du Zambèze, à laquelle assistaient $M$. et Mme Adolphe Jalla qui résident ici, M. Davit, récemment arrivé d'Europe, M. et Mme Béguin, de Nalolo, M. et Mme Goy, de Séshéké, M. et Mme Louis Jalla, de Kazoungoula, qui n'ont pas craint d'affronter les dangers de la navigation du Zambèze pour venir, pendant quelque temps, se grouper autour de II. Coillard, afin de mettre en commun leur expérience el discuter les intérèts de la mission. Qıoique gravement malade, M. Coillard a pu, grâce à son énergie, assister à quelques séances.

lmpossible de donner un résumé de tout ce que j’ai vu et entendu d'intéressant. Mais, il me semble que chacun peut ètre frappé du dévouement absolu de ces missionnaires à leur ouvre, malgré les privations qui sont leur lot quotidien. Les résultats que cette poignée 
d'Européens, animés par l'esprit qui les a fait agir, ont obtenus sont étonnants. Avant leur arrivíe, cette contrée pouvait être appelée à juste titre un pays de sang. Le roi Léwanika lui-mème en donnait l'exemple. N'est-ce pas lui qui, peu après l'arrivée de M. Coillard, lui faisait dire que lorsqu'il voudrait se débarrasser d'un chef, il ne répandrait désormais plus son sang, mais qu'il ferait mettre du poison dans la bière qui lui serait offerte?

Ce même Léwanika que nous voyons aujourd'hui discutant les enseignements des missionnaires, il y a une dizaine d'années, lécrétait la mort par la faim de l'un de ses frères qui lui faisait opposition? Vivant, et le corps entouré d'étoffe blanche, il reçut les honneurs de la sépulture royale, puis il fut enfermé dans une hutte à l'entrée de la capitale: il y vécut cinq jours encore avant de mourir de faim.

Nous avons été visiter le campement du métis portugais, marchand d'esclaves, auquel le roi a interdit de pénétrer plus avant sur son territoire. Il vient de Benguéla et il a avec lui des indigènes du Bihé; la coiffure des femmes rappelle celles que l'on observe sur les anciens monuments égyptiens.

Nous avons vu récemment trois natifs de l'Est, soit du pays de Gaza; ils appartiennent à la tribu des Ngungunyané; ces hommes aux corps musculeux aiment à se parer de peaux de léopards; ils sont venus dans le bo-Rotsi se procurer des produits du pays.

J'ai déjà dit, je crois, que le roi Léwanika, ainsi que sa sour aînée la reine Mokouaé, sont les représentants de l'absolutisme le plus complet. En principe, le sol el tout ce qu'il renferme, y compris les habitants, leur appartiennent; pas un de leurs sujets n'est libre de ses actions. C'est pour cela que, accompagné de M. Jalla, j’ai été rappeler à Léwanika la promesse qu'il m'a faite de me donner trois 
pirogues et leurs équipages pour descendre, suivant mon projel, le Zambèze jusqu’à Kazoungoula. Le roi, selon son habilude, nous recoit tròs bien; il est au liashandi et il nous présente séance tenante, Boumoé son neveu, tout jeune homme qui accompagnera les canots jusqu'à destination.

Chaque année, le roi et sa sœur ainće, la reine Mokouać, reçoivent

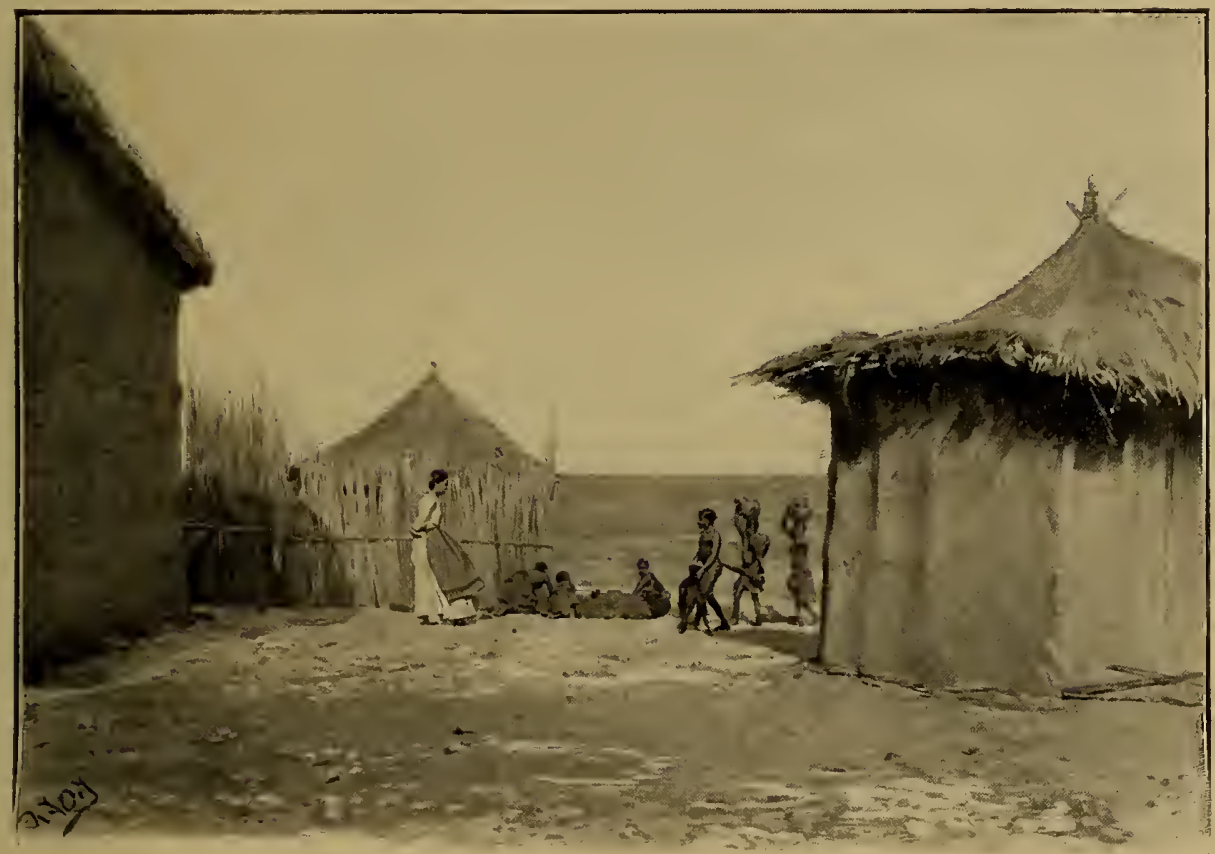

LES DÉPEXD.ANCES DE LA STATION MISSIONNAIRE DE LÉALOUYI. - Nine ADOLPUE JALLA ET QUELQUES-UNS DE SES ÉLÈVES.

Dessin d'Oulevay. D'après une photographie de l'auteur.

parmi leurs nombreux tributs, un convoi d'enfants des deux sexes, sorte d'esclaves qui deviennent leurs serviteurs. Ils distribuent le surplus à leurs chefs et à quelques autres personnes. Le roi ou la reine seuls peuvent les libérer; c'est ainsi que, par l'intermédiaire de M. et Mme A. Jalla, le petit Kaićka, actuellement leur aide, est derenu un homme libre. Les enfants des ba-Rotsi, la race clominante, ne peuvent pas êlre esclaves. 
Dans une tribu récemment soumise par Léwanika, un jeune homme ou une jeune fille sont encore payés sept ou huit houes.

En revenant à la station, nous apercevons dans le lointain un groupe

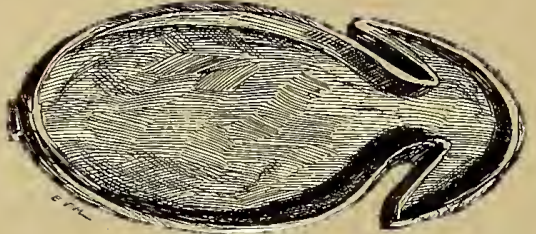

PLAT a POISSON (BOIS) GÉdÉ PAK LE kOL LÉWANIKA.

Croquis de Van Muyden. Collection de l'auteur. d’indigènes chargés de défenses d'éléphants; ils les portent au roi ; c'est l'un de ses principaux revenus. On peut calculer qu’à Léalouyi la livre d'ivoire vaut de six à sept francs.

Tout ce qui est tué en fait d'animaux sauvages revient de droit au roi; de plus le miel, la graisse des hippopotames. Un certain nombre de canots lui sont coupés dans la forêt; plus une quantité déterminée de bètes à cornes, de lances, de haches, de houes, du grain, doivent lui être remis chaque année.

Lorsque les tributs sont apportés à Léalouyi, le roi prend immédiatement ce qui lui convient. Puis ces tributs sont transportés sur la place publique, où le roi en prélève encore une partie. Il distribue le reste à ses chefs, en commençant par les principaux.

Les bateliers, qui ont reçu l'ordre d'avoir à se tenir prêts pour le départ, sont venus se présenter aujourd'hui et nous pourrons nous embarquer demain. Il faut nourrir ces hommes; or comme je l'ai déjà dit, les sauterelles dévastent la contrée et par conséquent la famine règne dans le pays; j'aurais eu donc beaucoup de peine à me procurer la nourriture nécessaire, sans le secours de mes hôtes qui veulent bien me remettre deux cents livres de millet et de maïs.

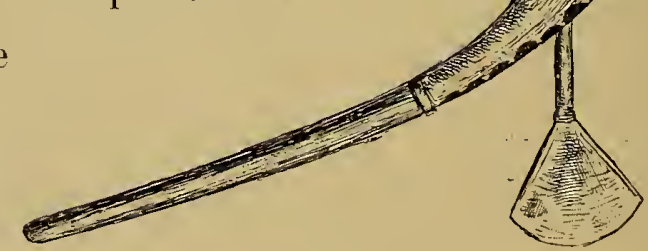

UNe llACHe, PRÉSENT de LÉWANIKA, ROI DEs bA-ROTSI. Croquis de Van Muyden. Collection de l'auteur. 


$$
\text { *** }
$$

11 septembre. - Iccompagné de M. Jalla, je vais prendre congé de Léwanilia. Il rend la juslice au lékhotla. L'un de ses joueurs d'instruments, vieillard presque aveugle, chante d'une voix lente el douce les hauts faits de son auguste maitre.

Léwanika, accroupi sur une nalle, nous touche la main; je le

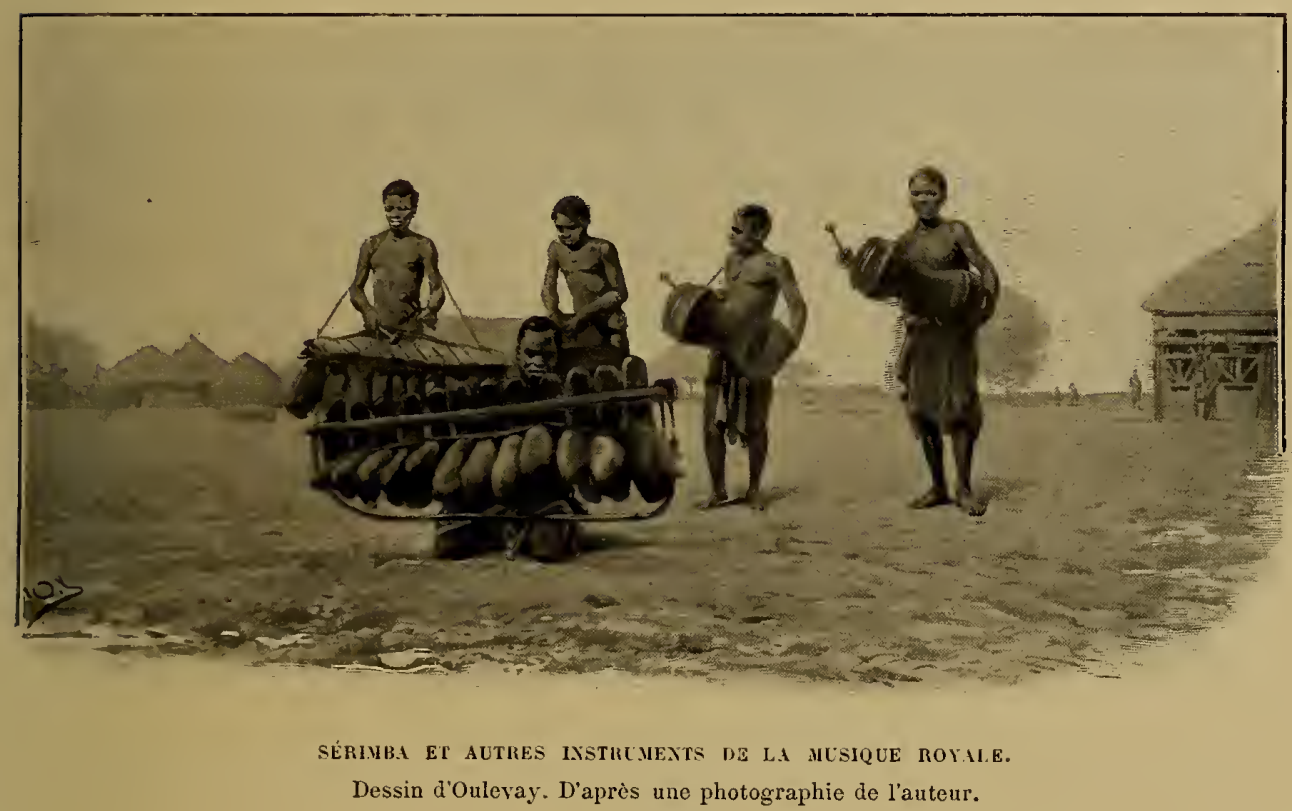

remercie de tout ce qu'il a fait pour moi pendant mon séjour dans son pays. Il me répond qu'il sera heureux d'apprendre que je suis arrivé à bon port à liazoungoula. Il me dit, en outre, qu'il a envoyé un messager dans ses postes de bétail le long du fleuve, afin d'averlir ses bergers d'avoir à me fournir du lait.

Je vais prendre congé de Katoka, søur cadelte du roi, et de son mari, Mamoiumba; ce dernier est l'un des fidèles qui ont suivi le roi lors de la dernière révolution, en 1884, alors qu'il a été obligé de 
s'enfuir de sa capilale; ces révolulions sont suivies de terribles ma:sacres. Mes hòtes moffrent un panier de patates douces. En revenant à la station, je reçois encore du roi une tubana de lait caillé et du maïs; gràce à ces dons, je suis pour le moment délivré du souci de la famine.

Nous prenons chez le vénéré M. Coillard un dernier repas auquel le roi assiste en personne; je dois ajouter que Léwanika a adressé une allocution à ses bateliers, il leur a dit que celui sur lequel il recevrait un rapport facheux, serait un homme mort!

Les embarcations sont chargées, les bateliers attendent, c'est le moment du départ. Nous allons nous quitter. Comment remercier M. Coillard, M. et Mme Adolphe Jalla et leurs amis, qui ont été si bons pour moi?

Un dernier serrement de mains, un dernier " au revoir ", et, de mon canot, je vois bientòt Léalouyi disparaître à mes regards. 
CHAPITRE IX

\section{EN PIROGUE}

DESCENTE DU ZAMBÈZE. - LA RÉGION DES RAPIDES. - SÉSliéKÉ

TELDi, 12 septembre, la flottille est composée de six pirogues ou e canots, dont trois sont à ma disposition. J'ai le mien, Klass Ifrica et son aide Sibouzenga sont installés dans l'un, Watcher, Sibette et le chien Punch dans l'autre. Matériel et bagages sont répartis dans nos embarcations. Les trois autres canots qui sont envoyés par le roi Léwanika à Kazoungoula renferment des peaux de girafes, des défenses d'éléphants. Le jeune chef Boumoé, neveu de Léwanika, monte l'un de ces canots, puisqu'il doit accompagner la flottille.

Chaque embarcation est creusée dans un tronc d'arbre, sans un assemblage ni un clou; pour toutes, la construction est la mème; clles varient seulement dr taille et de qualités nautiques.

Mon bateau, rapide et léger, a six mètres de longueur sur soixante centimètres de largeur; la poupe est légèrement plus relevée que la proue; son équipage se compose de quatre bateliers. Chacun a une rame en main; elle est longue de trois mètres vingt. Ils s'en servent comme d'une pagaie et en mème temps de balancier; ils sont debout 
et en véritables équilibristes, ils maintiennent ces pirogues à flot, tout en les faisant avancer rapidement.

Siabousiou, le pilote de mon canot, se tient à la poupe; c'est lui qui par le maniement de sa pagaie, doit diriger l'embarcation. Son costume outre son pagne, consiste en un collier de cuir et un cliapeau de paille conique. Le second en dignité se nomme Simaciko, il est à la proue; c’est lui qui l'œil toujours aux aguets, doit éviter les écueils, les bancs de sable et ne pas se laisser surprendre par les hippopotames; à còté de lui, il a trois lances à sa disposition.

Ses prétentions à la toilette sont différentes de celles de Siabousiou; son pagne, à larges raies bleues et blanches, est retenu à la ceinture par une peau de serpent, de laquelle pend aussi le mouchoir de poche indigène, dont nous avons déjà parlé. Il porte un collier de perles de verre claires, plus deux bracelets, dont l'un est en cuir d'éléphant; des plumes sont fixées à son chapeau.

Les autres bateliers, Moukoudou et Witchimbamtcha, sont un peu eı arrière du centre du bateau; ils doivent régler leurs coups de pagaie d'après ceux de l'homme debout à la proue.

J'ai juste la place pour m'asseoir ou plutôt pour m'étendre derrière Simaciko, sur des nattes de jonc; j'en ai une aussi au-dessus de ma tête qui me préserve plus ou moins des rayons d'un soleil tropical; mes valises me servent de coussins. A côté de moi, mes fusils. Les hippopotames sont très nombreux dans ces parages et ils attaquent souvent les embarcations.

En somme, la chose la plus importante pour le voyageur est de ne pas bouger, un rien jeut faire chavirer une pirogue zambézienne.

Nous suivons le canal Liaboa '; les eaux sont basses et les batelier's

1. Ce canal a été ouvert par les ordres du roi Léwanika lorsque M. Coillard eut fait, après des difficultés inimaginables, creuser un premier canal reliant Séfoula au Zambèze. 
à différentes reprises, doivent sauter par-dessus bord pour se dégager des bancs de sable. Le reste de la floltille est resté en arrière; jo fais déposer mes conrertures pour la nuit sous un grand arbre et nons allumons du feu.

$$
\text { *** }
$$

13 septembre. - Nous naviguons toujours sur le canal; un grand nombre d'oiseaux aquatiques de toutes les tailles et aux formes de becs les plus diverses, habitent ses bords. J'admire une colonie de ravissants oiseaux au plumage étincelant où la pourpre et l'azur dominent; une quantité de trous creusés régulièrement dans la terre de la berge leur servent de nids.

Les riverains établissent des barrages en roseaux ì travers le courant pour prendre du poisson. Nous croisons aussi des pècheurs montés dans des canots plus frèles encore que les nôtres el qui, armés de longues lances flexibles, transpercent les habitants des ondes avec une adresse remarquable.

Dans le courant de la matinće, nous arrivons au Zambèze proprement dit. 1 l'endroit où nous sommes, le fleuve superbe par le volume de ses eaux, coule avec lenteur et majesté; à peu de distance nous apercevons deux hippopotames. Après quelques heures de navigation nous abordons à Nalolo; nous avons une grande avance sur les autres canots qui ne rallient que plus tard.

La reine Moliouaé m'envoie du lait frais et du lait caillé; je vais la remercier. Au retour elle me fait escorter par l'un de ses serviteurs qui me présente un bœuf, second cadeau de Mokouaé, don un peu embarrassant, mais bonne aubaine pour mes gens; on ne tarde pas à l'abattre. Je vais chercher un repos bien mérité dans l'une des chambres de la station missionnaire que M. Béguin, actuellement à 
Léalouyi, a bien voulu mettre à ma disposition. J'allais m'endormir, lorsqu'une irruption de fourmis me force à déguerpir au plus vite!!

$$
*^{*} *
$$

14 septembre. - Ce matin, nous reprenons la navigation; la largeur du fleure varie entre 300 et 400 mètres; berges dénudées; plusieurs villages composés de huttes rondes en chaume se confondent avec la teinte du paysage; pas un arbre. Beaucoup de bestiaux; grâce aux ordres donnés par Léwanika au chef Boumoé, j’ai du lait en abondance. Nous avons vu une vingtaine d'hippopotames; ils ne montrent en général leurs tètes monstrueuses hors de l'eau que pendant quelques minutes pour respirer bruyamment, puis ils plongent pour reparaitre de nouveau. Les batcliers les craignent beaucoup; ils font de nombreux délour's pour les éviter el, si cela n'est pas possible, ils avancent très rapidement. J'ai aussi vu plusieurs crocodiles et beaucoup d'oiseaux aquatiques, en particulier un superbe vol de canards.

L’après-midi étail déjà sur son déclin, lorsque nous apercevons tout d'un coup un canot monté par un blanc; il vient dans notre direction. C'est le capilaine Saint-Hill Gibbons. Une bonne poignée de main; puis, malgré le soleil qui nous brûle, la théière chante bientòt sur la rive. Pony, qui lui sert de cuisinier, a son bonnet rouge fixé tout à fait au sommet de la tète, signe indiscutable de grande chaleur. Gibbons me raconte qu’il s'est laissé attarder dans son itinéraire; il fait force de rames pour atteindre Léalouyi, où il doit offrir ses hommages au roi, après avoir fait un travail spécial sur ces régions; il tàchera de revenir au plus vite afin de ne pas manquer le rendez-vous général fixé a Kazoungoula; arrivera-t-il it temps? "That is the question."

J'apprends qu'entre autres incidents, il a été " at close (quarters " 


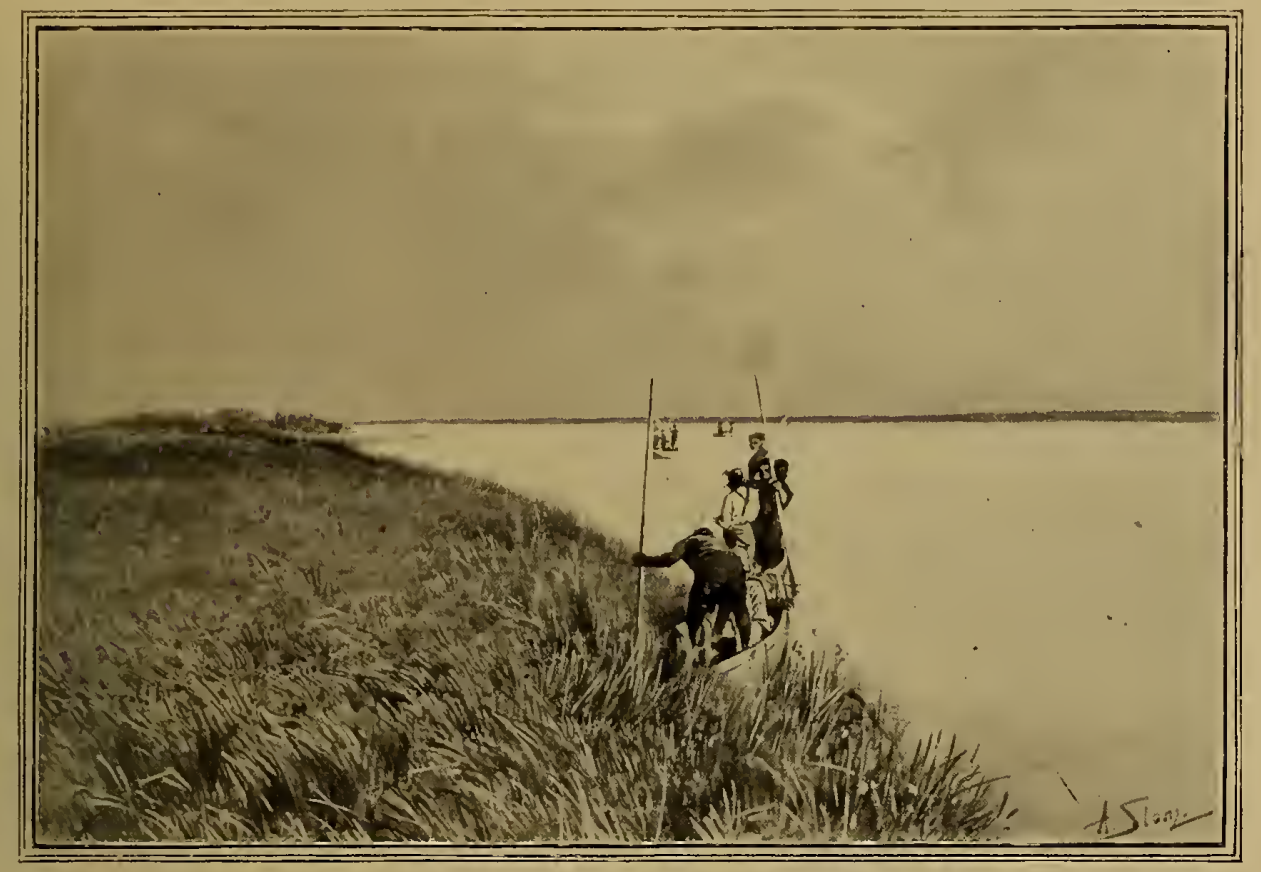

BEYCONTRE DU CAPITAINE SAITT-IILL GIIBONS.

D’après une plrotographie de lanteur.

arec une lionne, dont il rapporte la peau. Mais le temps s'envole, et il nous faut chacun reprendre notre roule, avec l'espoir d'un prochain revoir. I la tombée de la nuit, nous campons sur le sable de la rive droite du Zambèze.

Iprès que l'ordre a été établi au campement, Klass Africa me raconte que son canot a passé non loin d'une mère hippopotame qui avait son petit sur son dos; elle lui a fait un accueil peu aimable en ourrant une gueule formidable, ce qui a donné des loras aux bateliers!

$$
*^{*} *
$$

15 septembre. - Dimanche; jour de repos. A midi $+38^{\circ}$ G. dans l“intérieur de ma tente. Pour se mettre à l'abri, mes hommes se construisent rapidement des huttes sur la grève. A la tombéc de la nuit, 
des quantités de mouches élisent domicile dans ma tente; malgré toutes mes tentatives, il ne m'est pas possible de les en chasser.

$$
\text { *** } *
$$

Lundi 16 septembre. - Nous n'avions pas fait trois heures de marche lorsque, à mon étonnement, les pirogues s'arrêtent sur la rive gauche et sans ordre, les bateliers descendent à terre. J'en demande la raison au chef Boumoé, qui me répond que nous sommes près de Matongo, endroit où se trouve le tombeau de Monambi, le célèbre chef des ba-Rotsi; ses hommes doivent s'arrèter pour faire leurs dévotions, et obtenir un voyage heureux. Ils ne vont pas jusqu'au tombeau, qui est à une certaine distance; Boumoé se met à leur tête et ils se rendent devant une petite hutte en roseaux construite au bord du fleuve et occupée par le gardien du tombeau de Monambi. Ils s'accroupissent devant lui et, commençant leurs dévotions, ils frappent des mains, jettent des cris, tout en s'inclinant profondément.

Plus loin, les bateliers veulent de nouveau s'arrèter, cette fois seulement pour priser du tabac. Comme je sais par expérience qu'il faut être ferme, surtout dans les commencements sous peine d'avoir beaucoup d'ennuis, ils rentrent lestement dans leurs canots respectifs.

Trois hippopotames; le fleuve superbe coule, entre des rives de 400 à 500 mètres de largeur. Le paysage change, des massifs d'arbres apparaissent à droite et à gauche; nous doublons la grande ile Matanda qui est habitée, et, au milieu du jour, nous faisons une halte non loin du village de Sénanga, sur la rive gauche du fleuve dans un groupe de cocotiers. $\Lambda$ cet endroit, le Zambèze donne l'illusion d'un lac, avec de nombreuses îles boisées.

Dans le courant de l'après-midi, nous nous arrêtons sur la rive 


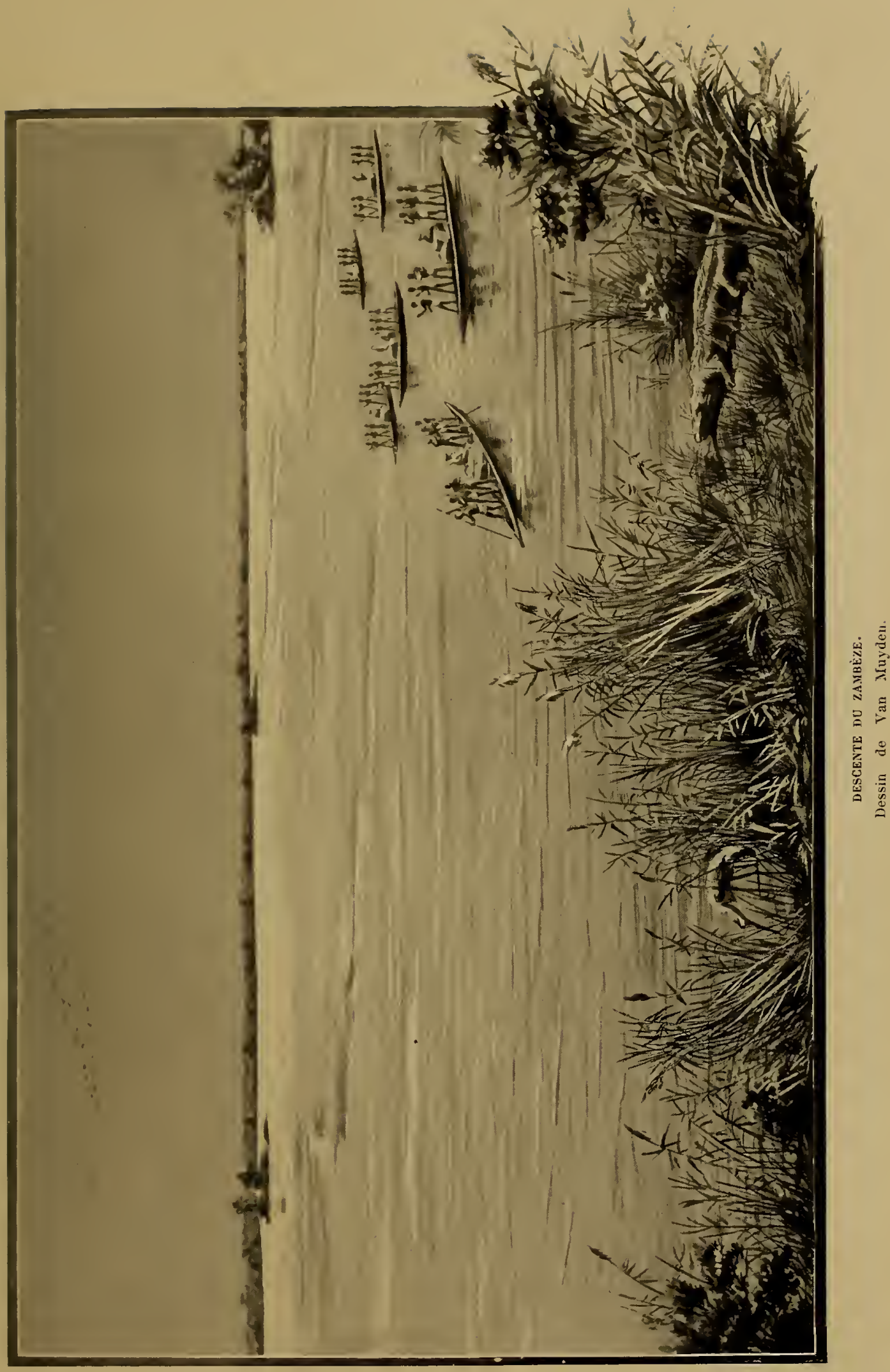



droile, au village de Lilomoniya; c'est le dernier enclos à bélail du roi Léwanilia: pour la deruière fois aussi, Boumoé m’y fait ehercher de l'exeellent lait caillé.

Plus de bétail! La mouche tsé-tsé peprend son empire; nous verrons donc bientòt des buffles car, comme nous l'avons déjà observé, la Isé-lsé se rencontre dans les régions fréquentées par ces animaux; est-il nécessaire de répéter que les bètes sauvages ainsi que les hommes sont réfractaires à la piquure de la mouche tsé-tsé, mortelle seulement pour les animaux domestiques?

Nous rencontrons, à deux reprises, trois hippopotames. En aspirant l'eau qu'ils rejettent bruyamment, ils s'ébrouent, comme le feraient de puissants chevaux; ils plongent, puis ils reparaissent à la surface.

La rive gauche du fleuve est garnie d'une épaisse bordure de grands roseaux à grappes blanches. Avant la tombée de la nuit, nous franchissons les petits rapides de Mouchia. Un hippopotame nous salue d'un grognement sonore, sans harmonie. Nous établissons le campement sur un ilot couvert d'un sable blane qui grince sous les pieds d'une manière étrange.

En face de nous, sur un bas-fond, à environ 200 mètres, une paire d'hippopotames se disposent au repos de la nuit. L'un d'eux a son corps énorme et inesthétique presque entièrement hors de l'eau. J'ai entendu dire par un chasseur africain très expérimenté, que ces bêtes clırgent quelquefois sur terre ferme; mais un rien les arrête, car leur structure ne leur permet pas d'enjamber le moindre obstacle.

Jusqu'à Sénanga, nous étions dans la plaine du bo-Rotsi. Les rives du fleuve sont plus ou moins dénudées; grande plaine avec nombreux villages et postes de bétail. I partir de Sénanga, nous sommes dans les gorges du bo-Rotsi. Sur les deux rives les deux chaines de collines 
se resserrent; le fleuve, partagé par de nombreuses îles plus ou moins boisées, se divise en plusieurs bras; paysage pittoresque; quelques petits rapides.

$$
\text { *** } *
$$

17 septembre. - Nous ne tardons pas à naviguer le long d'un véritable canal encadré d'une verdure qui retombe gracieusement dans l'eau, et nous passons à gauche de la grande île boisée de Mbeta. Suivant les exigences de cette navigation fort difficile, nous serons forcés de passer souvent d'une rive à l'aulre. I neuf heures, nous sommes sur la rive gauche, à l'embouchure de la rivière Louyi (Lui), déjà reconnue. Nous y perdons une heure à cause d'un batelier qui se déclare malade et désire se faire soigner dans un village voisin. Selon toutes probabilités, sa maladie provient du fait que nous approchons de la région des rapides dangereux de Séoma. Nous naviguons à travers un groupe d'îles boisées le long desquelles serpente le grand fleuve.

Au milieu du jour, nous arrivons à l'embouchure de la rivière Katengué (Limanika); elle prend sa source, si je ne me trompe, à la lagune Kramba, près de laquelle j’ai passé lorsque je me dirigeai vers Léalouyi. Nous glissons sous un berceau de verdure; ma pirogue touche un récif et penche considérablement.

Au moment de la halte, les hommes sortent une longue pipe, formée d'un tuyau en bois, dont l'une des extrémités est terminée par un récipient bourré de chanvre; l'autre extrémité aboutit à une corne qu'on remplit d'eau, afin que la fumée se refroidisse. L'un des bateliers y applique ses levres et aspire violemment trois ou quatre fois; il la passe ensuite à son voisin; une prise de tabac complète immédiatement la première opéralion; viennent alors des éternuements el des toux à plein gosier à u'en pas finir. 
Pendant l'après-midi, nous franchissons les rapides de Mouloungou, après lesquels le fleuve śélargit et forme un lac aux courbes gracieuses. Les rives en sont ondulées et boisées; iei et là des îles recouvertes d'une vígétation touffue. Au coucher du soleil, deux hippopotames viennent troubler le silence de la nature assoupie.

$$
*^{*} *
$$

18 septembre. - De bonne heure, nous abordons à Síoma, rive gauche. Nous sommes à l'entrée de la région des rapides proprement dits. Pour éviter les chutes infranchissables de Ngonyé (Gonye), les canols sont déchargés, mis à terre et traînés à bras d'hommes sur un espace de près die cinq kilomètres; ils sont ensuite remis à flot et rechargés. Ifin de surveiller le transbordement des, canots, le roi Léwanilia a établi à cet endroit deux chefs, Sékomé et Moliuala.

Je sais par expérience que la maxime " time is money " n'est pas pratiquée sur terre africaine. Je dis à Boumoé de faire chercher les deux chefs, puis comme ils ne viennent pas, d'y aller lui-mème. Deux heures s'écoulent; enfin, accompagnés de quelques-uns de leurs sujets, ils font leur apparition.

Chose très rare chez un indigène, Séliomé est chauve.

Après les salutations d'usage, très variées dans ce pays, aujourd'hui plusicurs bateliers viennent déposer un baiser dans la main droite des chefs. Séliomé m’informe que je serai obligé de rester quatre ou cinq jours à Séoma, car, me dit-il, la famine est grande; mes hommes sont dispersés dans la contrée pour chercher des vivres.

Cela ne rentre absolument pas dans mes plans et la figure rusée de Séliomé me prouve qu'il faut user d'autorité avec lui. Ses arguments sont réduits à néant... "Mais pourquoi es-lu ici? lui dis-je; tu n'es pas un chef si tu ne sais pas faire marcher tes hommes..." 
Enfin, Séliomé finit par promettre que les canots seront tirés sur la grève dès demain. "J'ai ta parole. " "C'est bien ", me répond-il.

Le campement est établi sous un beau mochaba, espèce de figuier, à l'écorce claire et au bois très tendre. Cet arbre a douze mètres de circonférence; il est enlacé par une plante grimpante aux fleurs blanches dont la forme et le parfum rappellent le jasmin; des palmiers nains croissent à sa base. Une fois toutes choses en ordre et l'esprit en repos, je liens à examiner à loisir cette admirable vue.

Devant nous, le Zambèze se divise en plusieurs bras, au milieu desquels se trouvent des îles. Le fleuve tourne brusquement au sud-est pour former les chutes de Ngonyé (Gronye), vers lesquelles nous nous dirigcons. Nous traversons l'un de ses bras en sautant de pierre en pierrc et nous arrivons à la chute elle-même. Depuis les énormes blocs de la rive gauche sur lesquels nous nous trouvons, le flcuve tourbillonne au milieu des rochers; au centre, il forme un vaste entonnoir où tout est écume et bouillonnement. Sur la rive droite, il tombe par une chute verticale d'environ 25 mètres de hauteur; l'ensemble doit avoir une largeur de 200 mètres. Quelque splendide que soit ce spectacle, il n'est sans doute pas à comparer avec celui qui nous attend dans quelques semaines aux "Victoria Falls " ou "Chutes du Zambèze " proprement dites.

En revenant, je tire un crocodile paresseusement étendu au soleil. Nous apprenons que tout à l'heure, une embarcation où élaient des indigènes et qui remontait le courant, a été entraînée dans les rapides; dcux enfants ont disparu dans les flots.

En guise d'avertissement, Sékomé nous dit que lorsque nous descendrons le fleuve, nous rencontrerons des mères hippopotames avec leurs petits; elles sont très dangereuses. 11 paraît que lorsque le petit hippopotame est né, sa mère lui fait un refuge au bord de l'eau dans les 


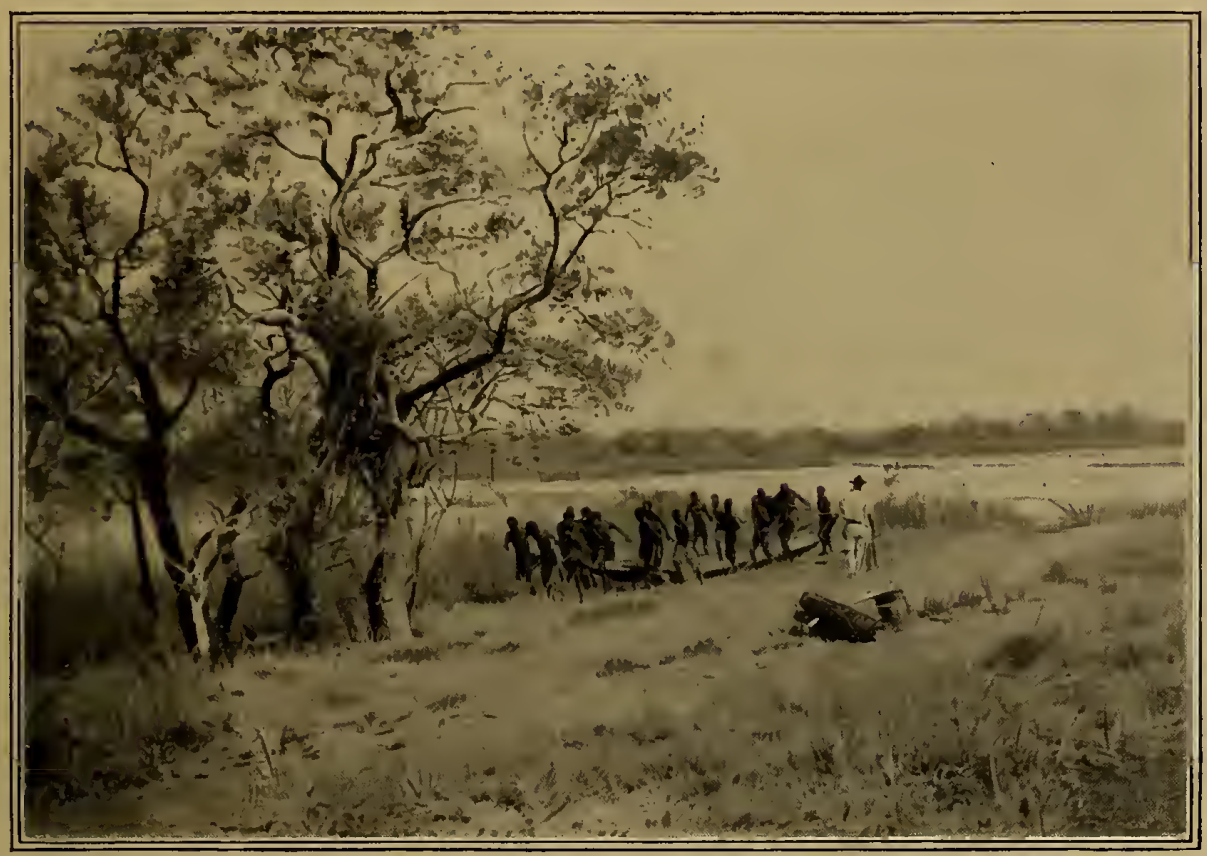

LE ILALAgE DES PIROgLes.

D'après une photographie de l'auter:r.

roseaux; si par mégarde un canot s'en approche, elle fond sur lui pour le mettre en pieces. Au bout de quelques jours, elles portent leur progéniture sur leur dos. En outre, comme chacun le sait, les hippopotames peuvent rester plusieurs minutes sous l'eau; il arrive fréquemment qu'en venant respirer à la surface, ils font chavirer les pirogues.

$$
* * *
$$

19 septembre. - Séliomé a tenu parole; au jour fixé, ses hommes arrivent pour tirer les canots sur la terre ferme. Les environs de Séoma sont malsains; la fièvre y fait beaucoup de victimes. A cinq minutes du campement, nous visitons un vaste terrain où nous trouvons une quantité de tombes disséminées au milieu des broussailles; elles sont rondes et couvertes de débris. Les objets ayant appartenu au défunt sont brisés sur sa fosse; ici des récipients en bois nous indiquent le 
lieu de repos d'un homme, car les hommes seuls fabriquent ces ustensiles, tandis que là, des restes de poterie nous montrent le tombeau d'une femme; seules, elles s'adonnent ì ce genre de travail.

Plus loin, une queue de buffle fixée en terre au bout d'un bâton, nous donne à coup sùr l'emplacement de la dernière demeure d'un chasseur; sur une autre tombe, la hulte du défunt a été transportée et brùlée, signe certain qu’il a été pendant sa vie un méchant homme. En agissant de cetle manière, ses proches croient l'empêcher de revenir sur terre. De la bière, du grain sont souvent répandus sur ces tertres pour l'usage du trépassé.

Chose triste à dire, aussitòt qu'une personne est moribonde, on creuse la fosse; parfois, l'individu est mis en terre ràlant encore.

La fièvre et la petite vérole sont les maux dont les indigènes souffrent le plus. Sékomé m'apprend que dix de ses enfants sont morts de la petite rérole; pour cette dernière maladie, le seul remède employé - consiste à tremper le malade dans l'cau, alors qu'il en est à la période la plus aiguë de la maladic. Il est évident que seules les personnes robustes peuvent résister à ce traitement énergique! Sékomé, comme du reste beaucoup de ses compatriotes, porte sur son visage des cicatrices profondes laissées par cette terrible maladic.

$$
*^{*} *
$$

20 septembre. - J'ai payé au chef trois setsiba (une brasse ou une demi-brasse de calicot blanc) pour le passage de mes canots et tout est prêt pour le départ; nous nous embarquons dans la matinée. Après quelques heures de navigation, nous doublons l'embouchure de la rivière Loumbé (Lumbi), qui opère sa jonction avec le Zambèze d'une manière assez tumultueuse. Une oie superbe fait une excellente diversion au menu quotidien. Nous sommes harcelés par la mouche tsé-tsé; 


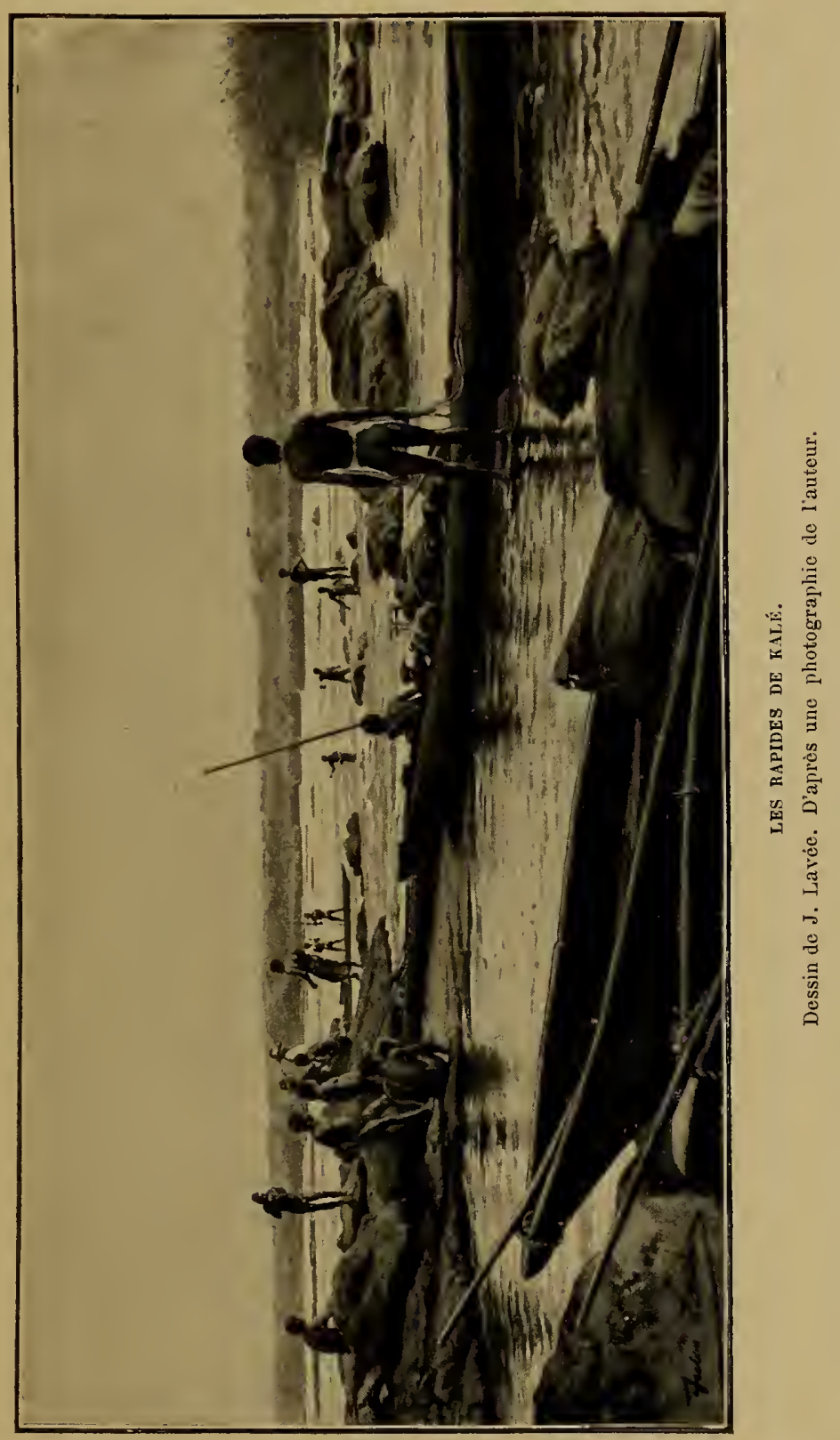



ce soir autour du campement on voit un grand nombre d'empreintes de buffles. Nous apercevons trois de ces animaux; la nuit noire arrête notre poursuite.

$$
\text { *** }
$$

2/ septemlie. - Le soleil se lève à l'horizon; Klass et moi, nous descendons sur la rive gauche afin de suivre les traces d'un buffle blessé la veille; nous rejoignons les canols après leur passage dans les rapides de Kalé (Kali). I notre retour, nous apprenons l'aventure arrivée à mon cuisinier Watcher, le mo-Kóololo, très indépendant de nature et brave aussi, je dois le reconnaître. Cette aventure aurait bien pu ìtre la derniẹre! Pendant que j’étais avec Ḱlass Africa à la poursuite des buffles, Watcher s'est fait descendre sur la rive droite du fleuve, sans m'én avoir demandé l'autorisation. Sans armes, il marchait le long de lia grève, lorsque tout à coup il se trouva en présence de deux lions qui s'acharnaient au cadarre d'un buffle. ll s'est tiré de cette rencontre en restant complètement immobile. Espérons que cette leçon sera salutaire pour lui... mais j'en doute.

Nous franchissons les rapides de Bomboé (Bumbui), les plus importants que nous ayons rencontrés sur notre route jusqu'à maintenant. Le Zambèze se resserre et gronde en se brisant contre les rochers. Les bateliers se mettent eux-mèmes à l'eau et, dans les endroits les plus difficiles, ils passent les pirogues une à une en les maintenant avec beaucoup d'adresse à l'aide de cordes, faites de feuilles de palmier, fixées à la proue et à la poupe. Peu à peu le Zambèze s'élargit d'environ un demi-kilomètre et il nous donne de nouveau l'illusion d'un lac enchanteur aux ondes tranquilles, parsemées de nombreux îlots.

Comme les jours précédents, la tsé-tsé nous tourmente; quoique l'homme soit réfractaire au venin de cet insecte à peine plus gros qu'une mouche ordinaire, sa piqùre n'en est pas moins douloureuse. 
Au coucher du soleil, des buffles sont signalés; nous débarquons, Klass et moi, sur la rive droite. Nous approchons à portée d'un buffle qui est à moitié eaché dans les taillis. Je fais feu! Prompte comme l'éclair, la bète blessée opère un demi-tour et tète baissée, queue en l'air, nous charge à fond de train. Kilass, à quelques pas derrière moi, me crie : "Look out, they are coming "! Attention, ils viennent! Trois autres buffles, que nous n'avions pas vus et qui paissaient dans un repli de terrain à notre gauche, attirés par la décharge, arrivent au galop, passent à angle droit à quelques pas de moi et entrâ̂nent avec eux la bète furieuse qui était sur le point de m'atteindre!

Pas un passereau ne tombe à terre sans la volonté de Celui qui tient nos vies entre ses mains.

Peu de temps après, la bète poursuivie a été achevée. Ce buffle doit peser de mille à deux mille livres; il est dépecé au clair de la lune. Cette abonlance de viande, quoiqu'elle soit loin d'ùtre appétissante, remplit de joie les bateliers; elle a un fumet très prononcé. Le lendemain, jour de repos; le "beltong ", longues lanières de chair, suspendues à des chevalets improvisés, sèche de tous côtés au soleil. Avec le dur travail des hommes. ce surplus de nourriture est loin d'ètre un luxe.

Trois hippopotames prennent leurs ébats dans le fleuve vis-ì-vis du campement.

$$
\text { *** }
$$

23 septembre. - Nous reprenons nos canots ce matin de bonne heure et nous passons sur les ondes bleues du beau fleuve entre des ìles et des îlots verdoyants. Les bateliers aiment à lutter de vitesse entre eux en s'excitant par des cris; mais ils ne dédaignent pas non plus de ralentir leur marehe pour causer, rire el surtout s'offrir réci- 


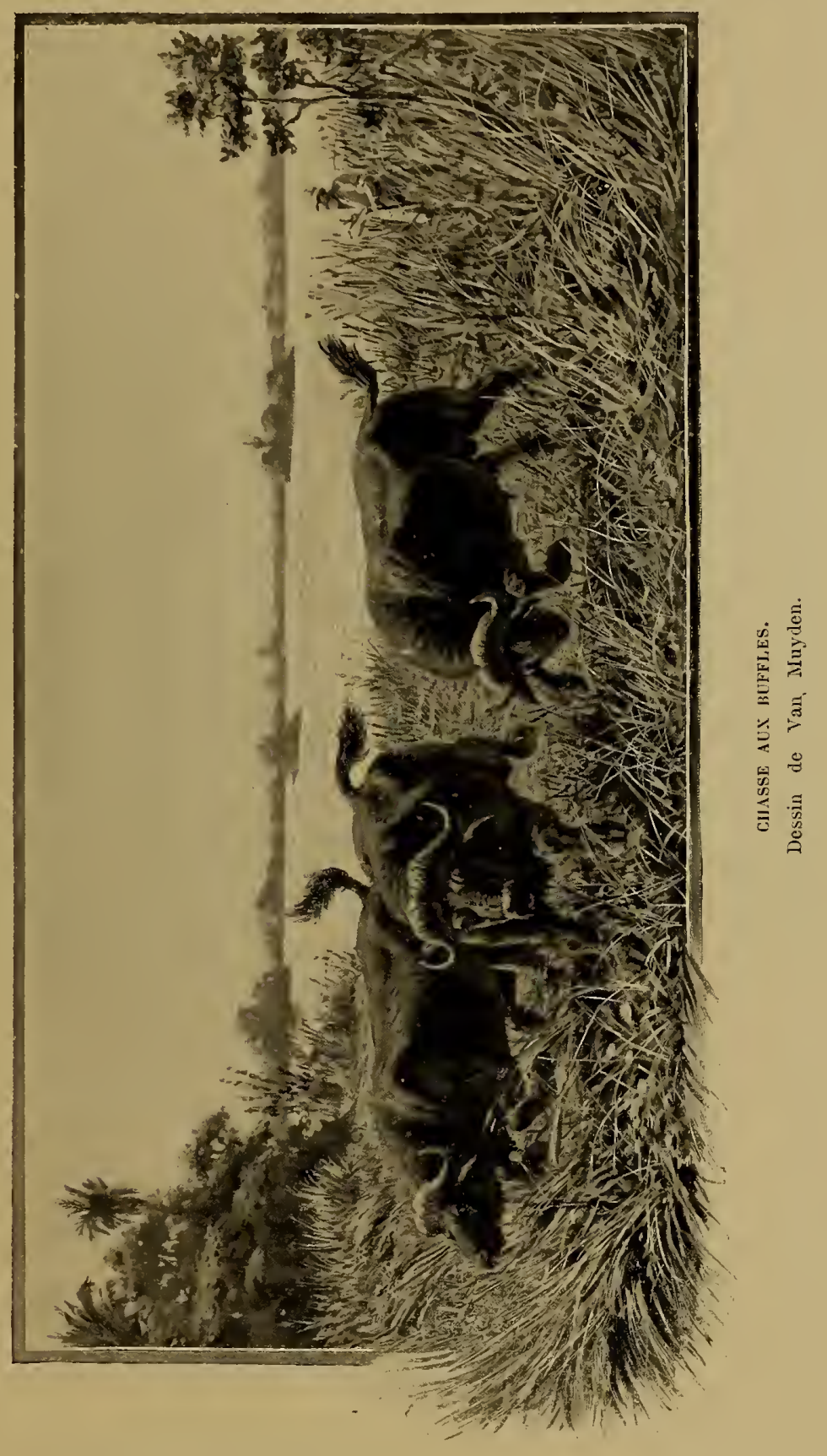



proquement leur désagréable tabac à priser. Ils le conservent dans une petite calcbasse suspendue ì leur ceinture. Je vois l'homme de la proue, sa lance effiléc en main, piquer avec une dextérité remarquable un gros poisson que les indigènes appellent dombé; sa chair jaunàle, très succulente, me procure à l'embouchure du Njoko,

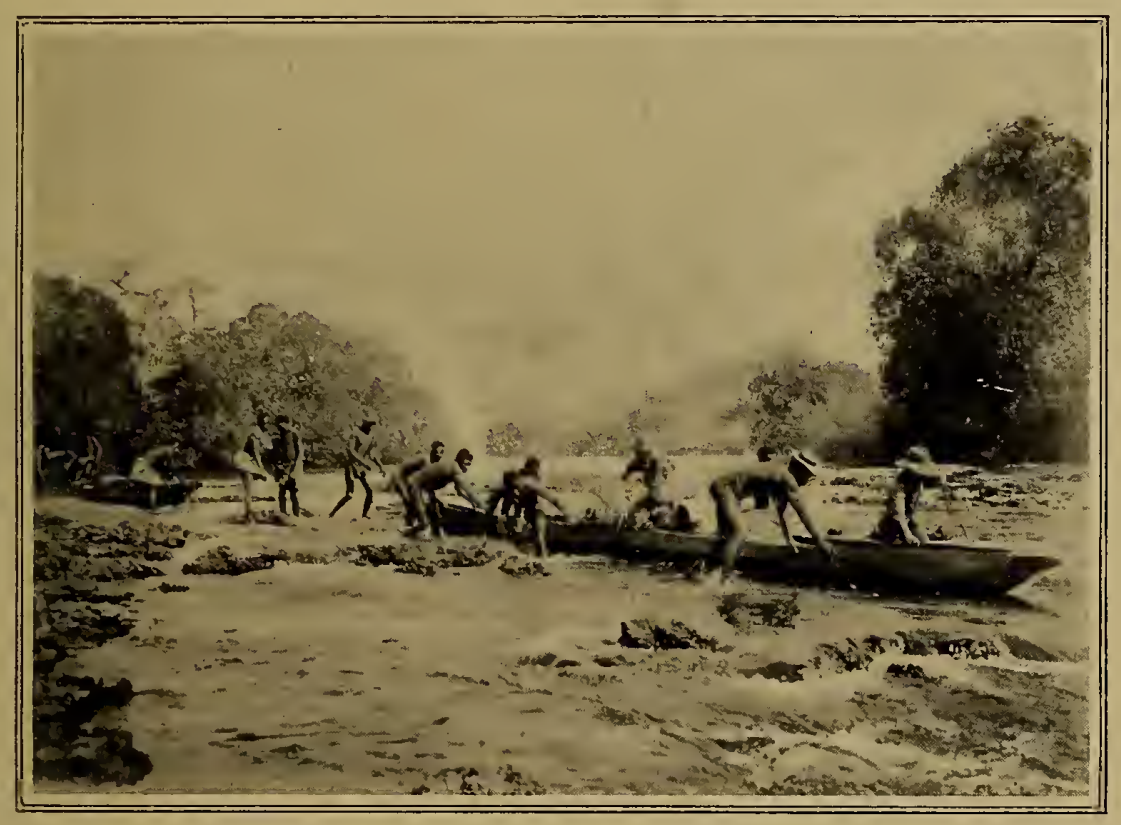

PRÈS DE LOLSHOU (R.APIDES DE LA MORT).

D'apres une photographie de l'auteur.

où nous faisons la halte ordinaire au milieu du jour, un excellent repas.

Nous traversons ensuite plusieurs rapides; les plus importants sont ceux de Loushou (Lusu), que les indigènes appellent " Rapides de la mort ». Un Européen s'y est noyé il y a quelques années. Mes hommes sont admirables d'adresse et de sang-froid; les muscles tendus, ils évitent les récifs plus ou moins cachés par les eaux et les remous perfides. Le moindre choc inattendu ferait chavirer nos frêles embarcations. Et de quelle manière ils savent profiter du courant! Ils ont 
une sainte terreur des hippopotames qui abondent dans ces parages.

Nous voyons défiler un nuage de sauterelles. Les bateliers qui ont l'œil aux aguets, trouvent dans les roseaux un petit crocodile vert; ils le remorquent sur le plus prochain îlot où ils le tuent. Ils se régaleront ce soir de sa chair et sont en particulier très friands de sa queue.

Nous campons en amont des chutes de Ngamboué (Ngambwe).

$$
*^{*} *
$$

24 septembre. - Les moustiques nous ont tourmentés la nuit dernière; je suis couvert de piqûres. Ce matin, afin d'éviter les chutes qui ne peuvent pas être franchies, les canots sont de nouveau déchargés, mis hor's de l'eau et tirés ì force de bras, cette fois-ci pour un petit parcours, puis rechargés; opération très intéressante : tous les bateliers s'attaquent à un canot et le traìnent en s'accompagnant de chants rythmés.

Le paysage aux chutes du Ngamboué est pittoresque; d'énormes rochers forment un barrage naturel aux eaux qui viennent s'y briser en écumant. Le fleuve très large, est zébré d'une quantité d'îlots couverts de végétation; ça et là des palmiers.

Avant midi tout est terminé et nous franchissons une succession de rapides où les hommes luttent d'adresse; ils se servent de leurs longues rames comme de véritables balanciers; les rapides les plus sérieux sont ceux de Manyekanga.

Nous campons sur une île sablonneuse qui fait partie du groupe de Katima-Molilo, traduction littérale : " qui éteint le feu ". A l'heure qu'il est, les hommes dressent très rapidement la tente; l'ordre est promptement établi. J'admire l'ingéniosité avec laquelle ils improvisent en quelques minutes leurs abris pour la nuit. Ils coupent des 


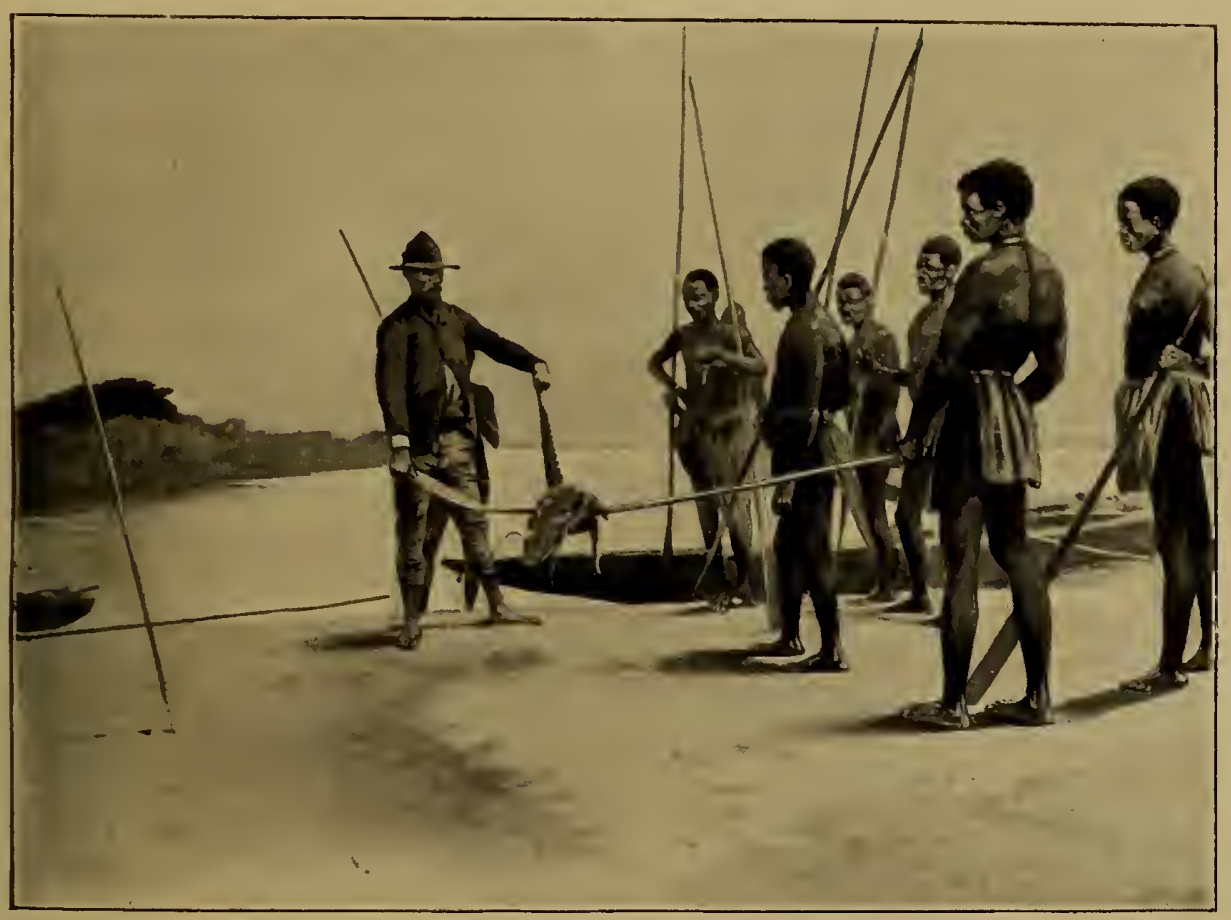

C.APTURE D'CX CROCODILE.

Dessin de Thiriat. D'après une photographie de l'auteur.

roseaux, y intercalent leurs nattes entre les rames plantées en terre, qui leur servent de charpente. Les feux ne tardent pas à s'allumer et les vases en grès sont mis sur le feu; mais quelle race rieuse! Comme à l'ordinaire, les "prises de tabac " sont constamment offertes et les eh! eh! ah wouah! ah wouah!..... d'éclater de toutes parts.

Je remarque que lorsque les hommes ont des altercations entre cux, elles ne durent pas longtemps.

Kilass me raconte souvent des épisodes de sa carrière de vingt années de chasse en Afrique, carrière qu'il a commencée avec son père à l'âge de quinze ans; il a, paraît-il, tué deux cents éléphants, vingt lions, etc. ll me confirme, ce que j'avais déjà lu, que la chasse aux buffles est considérée comme l'une des plus dangereuses. Il m'assure que j’ai échappé à la mort de bien près l'autre jour. 


$$
*^{*} *
$$

25 septembre. - Pour éviter les grands rapides de Katima-Molilo, nous nous engageons dans un chenal où les canots restent quelque temps échoués sur les galets; les hommes n'ont pas une tàche facile. Nous retrouvons l'eau profonde et nous naviguons sous des ombrages épais. Nous rencontrons bientôt huit hippopotames.

La région des rapides est franchic; le paysage est moins pittoresque, les berges se dénudent et s'abaissent; la grande plaine s'étend sur les deux rives; en un mot la contrée ressemble à celle que nous avons vue en amont de Séoma.

Fort vent et fleuve agité, grands bancs de sable. Nous passons près du village de Sélihosé (Selihosi); du bétail paît dans les environs.

Nous nous embarquons ce matin à l'heure habituelle. Beaucoup d'oiseaux aquatiques; une oie vient enrichir mon garde-manger. A neuf heures nous sommes arrêtés par une bande de dix hippopotames qui nous barrent le passage; nous sommes obligés, Klass et moi, de descendre sur un banc de sable et de faire feu afin de nous ouvril un chemin, ce qui ne fut pas chose facile; ils s'inquiétaient autant de nos balles que si elles eussent été des pierres. Les bateliers font voler les embarcations, la peur leur avait donné des forces. Vu trois crocodiles. Il me serait difficile de dire combien de fois déjà, pendant lé cours de cette navigation, j’ai entendu mes hommes prononcer avec plus ou moins de vivacité, les mots de "lioubou " (hippopotame) et de " liuéna " (crocodile); ces animaux tiennent certainement une grande place dans leurs préoccupations.

A trois heures nous arrivons à Séshélié après avoir serpenté èntre les îles formées par les embranchements du Zambèze. 


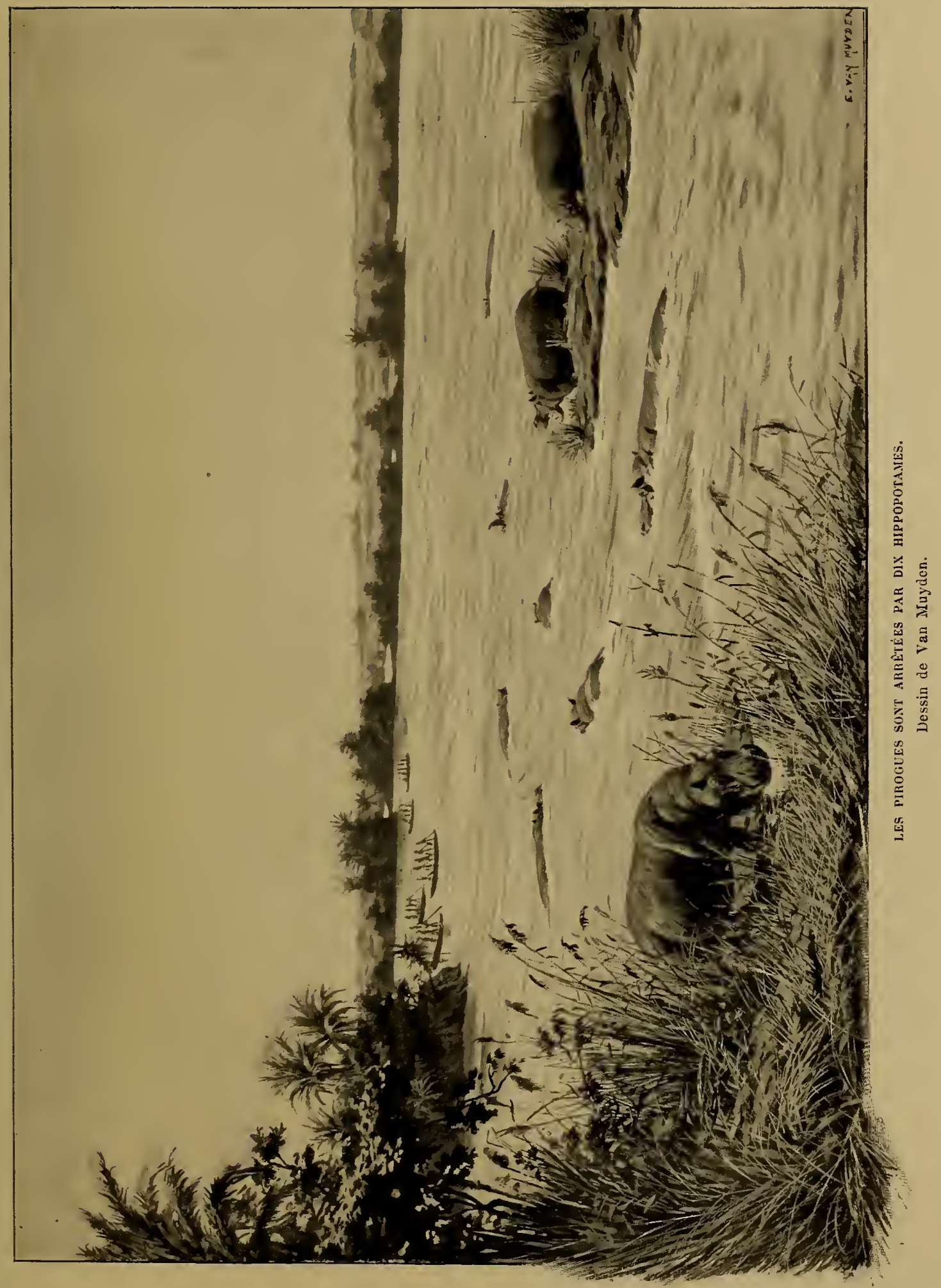



Watcher, mon cuisinier, me raconte qu'il se souvient fort bien, étant enfant, l’avoir vu Livingstone à Séshélié.

$$
* * *
$$

26 septembre. - M. le missionnaire et Mme Goy, de Vevey, dont j'ai eu le plaisir de faire récemment la connaissance à la capitale Léalouyi où ils s'étaient rendus pour la réunion dont j’ai parlé, m’ont aimablement engagé à m'arrèter à leur station, quoiqu'ils ne dussent y revenir que dans quelques jours. J'y fus très bien reçu par l'évangéliste mo-Souto Aarone. Le pauvre Klass Afriea a appris une triste nouvelle en arrivant ici; pendant son absence sa femme était morte ainsi que son beau-frère. Dans ce pays, plus peut-être qu'ailleurs, la vie, même pour les plus robustes, semble plus fragile.

Séshéké a été de tout temps un centre important; une quinzaine de chefs y ont leur résidence. La princesse de Séshéké est Akanangisa, fille de Mokouaé de Nalolo et nièce du roi Léwanika. Comme le veulent les usages, je vais me présenter à elle ainsi qu'à son mari Mokua. Le soleil est déjà couché lorsque j’arrive; ils me reçoivent dans la cour de leur habitation où brûle un bon feu. Ils sont encore très jeunes tous deux. Une grande ligne noire, habilement dessinée, part verticalement du front de la princesse et entoure ses yeux; elle est drapée dans une étoffe rouge et verte. Elle souffle à son mari tout ce qu'il doit me répondre. J'offre comme cadeau une couverture; après quelques minutes, une peau de loutre m'est présentée en retour.

$$
\text { *** }
$$

27 septembre. - Cie matin je reçois un grand vase de lait caillé; Akanangisa, ainsi que son mari Mokua, viennent me rendre ma visite. 
Le temps est plutòt frais et ils sont tous les deux enveloppés de pèlerines de fourrures splendides.

Séshélié est situé sur la berge du Zambèze, assez élevée à cel endroit. Les crocodiles y sont un véritable fléau. Il y a quelques années encore, au temps du roi Sépopa, les malfaiteurs ‘taient jetés au fleuve; ces amphibies en ont gardé le goût de la chair lımuaine. Ils commettent des méfaits sans nombre et sont toujours à l'affût près de l'endroit où l'eau est puisée. Ils attendent le moment où leur victime se baisse, pour l'abattre d'un formidable coup de queue, se retournent vivement, l'entraînent dans l'eau et la noient. Deux des enfants indigènes de la station ont ainsi disparu, l'un pendant qu'il lavait; le second, qui jouait avec d'autres enfants, fut enlevé sous les yeux de ses camarades. Une jeune fille qui allait remplir sa cruche subit le même sort. Les indigènes croient que les crocodiles sont des êtres humains décédés, qui reviennent sous cette forme, tourmenter les vivants; ils les dénomment en disant : celui-là, c'est un tèl, de tel village!

Séshéké est compris dans le territoire de la tribu soumise des maSoubia, qui va de Sékhosé jusqu'en amont de Kiazoungoula, y compris le pays qui s'élend dans le triangle formé par le Zambèze et la rivière que plusieurs cartes géographiques désignent à lort sous le nom de Chobé. Elle est appelée Kúundo dans son cours supérieur et Linyanti depuis l'ancienne capitale des ma-liololo jusqu'à son embouchure dans le Zambèze, près de Kazoungoula.

M. Coillard arriva pour la première fois, en 1878, à Séshéké; il y rencontra le voyageur porlugais Serpa-Pinto, alors malade de la fièvre; il l'emmena à Leshoma où il le soigna el il le conduisit à Mangwato (Béchuanaland). Aussi le major Serpa-Pinto a-t-il dédié à II. et à Mme Coillard, en souvenir de toutes leurs bontis à son égard, liun des volumes concernant son exploration. 
M. Coillard et M. Jeanmairet fonderent la station missionnaire de Séshélié en $1883 ̈$; M. le missionnaire Goy, arrivé en 1889 sur cette terro africaine, pril quelque trmps après la direction de ce poste. Il y aurail beaucoup de choses à raconter sur l'ánergique el dérouć missionnaire do Séshélié qui sauva la vie du missionnaire anglais Baldwin, que les indigènes aceusaient de sorecllerie et auquel on allait faire un maurais parti. Celle stalion, très prospère, a une moyenne de quatrevingts catéchumènes et de cinquante onfauts à l'écolo; le dimanche, un auditoire d'environ cent cinquante personnes, sans en excepter la princesse Mlianangisa ot son mari Molua, remplissent la jolie chapelle '.

$$
\text { *** }
$$

28 septembre. - Au matin, nous reprenons nos canots; Rhatô, chef influent de Séshóké, vient assister à notre départ. La tète peu engageante d'un crocodile sort de l'eau; peu après nous en apercevons deux autres, qui se chauffent au soleil. Trois hippopotames nous saluent de leurs grognements. A 11 heures, hourra! nous arrivons a l'embouchure de la rivière Machilé, dont nous avons remonté le cours jusqu'à sa source. De la berge, je vois à une distance de quatre ou cinq kilomètres, le bouquet d’arbres où la rivière Kasaia opère sa jonction arec la Vachilé avant que cette derniere se jette dans le grand fleuve. Nous avons établi près de là l'un de nos premiers campements, lors de notre arrivéc dans cette contréc. Klass Africa me dit que entre Kiazoungoula et Léalouyi, la Machilé est lo seul des affluents du Zambèze où vivent les hippopotames.

Plus loin, le fleuve est partagé en deux bras par l'île Katira. Que

1. Le 25 mars 1896 , M. Goy tombait au champ d'honneur, enlevé à l'âge de trentetrois ans, par Ies fièvres du pays. 
d'oiseaux sur les rives du Zambèze! L'un des plus communs est l'aigle pêcheur entièrement blanc, sauf les ailes qui sont noires. Les bateliers zambéziens, comme je l'ai vu de mes yeux, savent employer ce bel oiseau pour fournir leur garde-manger. Lorsque l'aigle pècheur s'est emparé d'un poisson et qu'il se retire sur la grève pour le dévorer, ils lui jettent avec beaucoup d'habileté un bàton dans les pattes. L'oiseau effrayé s'envole et parfois leur abandonne sa proie. Quelle variété d'échassiers, depuis le pélican au bec disproportionné, jusqu'aux mignons petits volatiles qui se confondent presque avec le sol. Un vol de canards passe au-dessus de nous; espérons qu'ils seront aussi succulents qu'ils sont beaux; la tête est à moitié blanche et noire, la gorge brun rouge, les ailes et le milieu de la poitrine noirs, les côtés sont cendrés. Ivant de dresser la tente pour la nuit, nous doublons l'embouchure de la rivière Ngguézi (Ungwezi). Plusieurs crocodiles rôdent dans les environs; pendant que nous établissons le campement, nous en apercevons trois qui disparaissent sous l'eau en recevant nos coups de feu.

$$
\text { *** }
$$

29 septembre. - De bonne heure ce matin, un indigène vient me vendre une sorte de poisson plat dont j’ignore le nom et qui est loin de valoir le délicat dombé de l'autre jour.

Nous glissons à travers un dédale d'ìles et d'ìlots qui appartiennent au groupe de Mambova; elles sont en bonne partie, ainsi que les rives, couvertes de grands et élégants roseaux à panaches blancs. Les collines se sont de nouveau resserrées et nous arrivons aux rapides de Mambova, les derniers avant d'atteindre Kazoungoula. Nous nous y engageons; soudain, mon canot qui tenait la tête, touche de flanc un gros récif. En quelques secondes, nous sombrons et l'eau 
coule par-dessus bords. Il faut opérer le sanvelage de mes effets personnels et consacrer la journée à un séchage général sur la rive voisine qui se trouve bientòt émaillée des objets les plus disparates. Cette tàche est facilitée par l'ardeur du soleil; à \&́ heures de l'après-midi, tout est de nouveau en ordre; aucun dégàl sérieux, à part un certain nombre de mes clichés photographiques que je n'avais pu ramener jusqu'ici qu’à grand'peine el qui prennent un bain des plus malencontreux. Établi dans une hutle indigène, malgré la chaleur de la journée, j'ouvris toutes les boîtes les unes après les autres et changeai les papiers qui me semblaient humides; j'espère en avoir sauvé ainsi une bonne partie. Enfin après avoir pris quelque nourriture, nous continuons notre route. Boumoé semble chagriné de cette aventure: ce jeune chef ì la figure mobile et presque toujours souriante est intéressant; il a un grand désir de bien faire. Une touffe de poils blancs d'un animal sauvage est fixée dans ses cheveux crèpus. Il change de toilette plusieurs fois par jour : le matin à la première heure, il se revêt volontiers d'un ample manteau de fourrure; plus tard, il jelte sur ses épaules une pièce de cotonnade rouge et blanche; son costume favori se compose d'une chemise et d'un gilet. Comme ses compatriotes en général, il aime à avoir la tête découverte; mais, il pense sûrement qu'il convient à sa dignité de se coiffer de temps en temps d'un feutre souple café au lait, ornementé d'une plume d'autruche noire. 



\section{CHAPITRE X}

\section{LES GRANDES CATARACTES}

RETOUR A KAZOUNGOULA ET VISITE 'AUX CHUTES DU ZAMBÈze

(VICTORIA FALLS)

$\mathrm{L}^{\prime \prime}$

E fleuve est de nouveau calme et majestueux. Le 30 septembre, tôt dans la matinée, j’aperçois les toits de chaume de la station missionnaire de Kazoungoula; me voici donc arrivé à l'endroit où nous sommes entrés dans le Pays des ba-Rotsi et d'où nous en ressortirons.

M. et Mme Louis Jalla sont encore à Léalouyi ; mais j'ai le plaisir de retrouver à Kazoungoula M. et Mme Boiteux, de Neuchâtel, missionnaires tout nouvellement arrivés. Nous avons fait bonne connaissance ¿ Palapye, alors qu'eux aussi étaient en route pour le Zambèze. Je me réjouis des quelques jours que je vais passer avec eux; ils m'installent confortablement dans leur grand chariot.

J'apprends que Pirie a eu la dysenterie; il a précédé Reid de quelques jours et il a établi son campement sur la rive droite. Je lui fais porter immédiatement un billet afin de savoir si je puis lui être de quelque utilité. Une heure ne s'était pas écoulée, lorsque j'entends deux voix connues; Reid est venu ce matin au rassemblement convenu 
et a traversé le fleuve, accompagné de Pirie, qui va beaucoup mieux, pour me serrer la main; elle a été cordiale, cette poignée de main! Puis suivant le contrat que j'ai fait avec les bateliers, je leur donne à chacun en guise de payement, une couverture de coton et un setsiba de calicot blanc. Au jeune chef Boumoé, j'offre l'une de mes propres

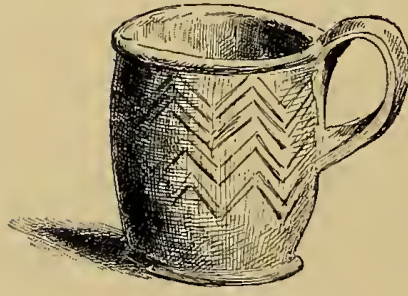

COLPE EN TERRE CUITE DU CHEF BOUYOF́, NEVEU DU ROI LÉWANIKA. Croquis Van Muyden. Collection de l'auteur. couvertures rouges et bleues; il m'apporte en retour sa " coupe à boire " en terre cuite.

M. et Mme Boiteux nous font le plaisir de nous réunir tous les trois pour le repas du milieu du jour. Nous décidons, Reid, Pirie et moi, de partir à pied à la fin de la semaine, pour aller visiter les célèbres chutes de Victoria (Victoria Falls). De là, nous passerons par Panda-Matenga, et nous retrouverons ì Gazuma-Vley nos chevaux, nos bœufs et nos chariots; nous pensons être rejoints à bref délai par le capitaine Saint-Hill Gibbons '.

$$
\text { *** }
$$

2 octobre. - L'arrivée du prince Litia, absent de sa résidence ces derniers temps, est annoncée par crieur public et nous nous rendons, M., Mme Boiteux et moi, au village indigène pour voir les honneurs qu'on rendra au prince ì sa rentrée. Les chefs sont déjà sur la place publique où ils attendent, avec la patience qui les caractérise, leur seigneur et maître. Les principaux sont Indie, au nez recourbé, qui dit pouvoir faire venir la pluie à volonté; Momballa, le roi des crocodiles qui lui, se flatte d'avoir un pouvoir spécial sur ces animaux,

1. Il n'a pas pu rejoindre à temps car, à lui non plus, les péripélies émouvantes n'ont pas manqué. Sans parler de la fièvre et de la dysenterie qui l'ont terrassé, il a failli au retour tomber entre les mains des cruels ma-Tébélé, alors en pleine révolte. Bref, nous ne nous sommes retrouvés qu'à Londres et nous avons pu échanger nos impressions au diner que nous a offert le « Geographical Club $\triangleright$. 
ce qui n'empìche que l'un d'eux ne lui ait pourtant enlevé une vache récemment! Puis voici Loukoukou; il est chrétien et le favori du prince.

La princesse, l'unique femme de Litia, en tête d'un cortìge composé de ses suivantes, de ses parentes et des femmes des chefs au nombre d'environ cent cinquante, va se placer sous un grand arbre non loin du fleuve.

Les chefs et les notables de l'endroit forment un groupe de nombre à peu près égal. Ils se tiennent à part.

La caravane du prince est signalée au loin. Suivant l'usage du pays, les femmes se rendent au fleuve pour s'asperger d'eau; elles se mettent en arrière des hommes qui se portent en avant lorsque Litia approche. Ils font alors, selon l'étiquette des ba-Rotsi, la salutation appelée sloaléla, qu'ils excutent en criant et en portant les mains en l'air; ensuite ils s'accroupissent et s'inclinent; ils répètent ce cérémonial à plusieurs reprises.

Les femmes sont accroupies et sans élever les mains en l'air, elles s'inclinent profondément en criant la salutation de bienvenue. Les deux groupes se joignent à la suite du prince et arrivés à la place publique, les salutations déjà décrites recommencent. Sur ce, les femmes se dispersent et les hommes restent au lékholla pour entendre ce que le prince va leur dire. Choses importantes, parait-il, qui ne doivent pas frapper les oreilles d'un étranger.

Quelques gouttes d'eau, les premières depuis que nous sommes dans le pays, commencent à tomber. L atmosphère est brûlante, la pluic serait la bienvenue, elle n'est malheureusement que passagère!

$$
* * *
$$

3 octobre. - Afin de pouvoir mettre mes notes, mon journal de voyage et mon courrier à jour, je n'ai dormi qu'ıne heure durant la 
nuit dernière. Personne ne se doute, avec la vie que nous menons, de la difficulté qu'il y a à exécuter régulièrement ce travail.

$$
\text { *** }
$$

4 octobre. - Le chef Rhatò, homme de confiance du roi Léwanika, est arrivé aujourd'hui de Séshéké; son maître voudrait que nous lui cédions de la poudre et du plomb que nous avons de trop, contre une défense d'éléphant qui pèse 73 livres. Par déférence pour les missionnaires, nous n'avons voulu procéder à cet échange qu'après avoir pris leur avis ì ce sujet.

J'ai le privilège d'accompagner M., Mme Boiteux et Mlle Kiener dans l'une de leurs tournées d'évangélisation. Nous entrons en particulier chez une pauvre vieille femme aveugle, à laquelle les jeunes filles élevées à la station apportent une part de leur nourriture; elles se cotisent entre elles pour adopter des malheureux!... Véritable miracle pour qui connaît les noirs.

Comme à Léalouyi, - Nalolo, - Séshéké, - je ne saurais comment remercier les missionnaires de Kazoungoula pour leur hospitalité et tout ce qu'ils ont fait pour moi. Le moment toujours pénible du départ approche... les enfants de la mission viennent me saluer par ces mots : ntaté louméla, adieu, mon père; sala hantlé, porte-toi bien.

Mes lecteur's me permettront peut-ître, au moinent où je quitte le Pays des ba-Rotsi, de résumer en quelques lignes mes impressions sur l'œuvre accomplie par les missionnaires en ces contrées sauvages.

Comment ne pas reconnaitre combien M. Coillard a été heureusement inspiré, en s'attaquant à cette importante nation des ba-Rotsi, dont toutes les tribus voisines sont les vassales.

C'est lui, qui le premier en 1884, au prix de difficultés iuouies, est venu fonder cette mission où il est si bien secondé par ses collabo- 
rateurs. Aujourdhui la mission du Zambèe, qui se rattache, comme chacun le sait, ì l'ouve génélale des missions évangéliques de l’aris, comple six missionnaires européens el six ou sept évangélistes noirs venant du lé-Souto.

Jentendais un jour M. Coillard dire qu'il faudrait à l'heure qu'il est, quinze missionnaires europíens ef une trentaine d'évangélistes indigènes, afin de pouvoir occuper les points importants du pays, avant l'arrivée des aventuriers blancs qui trop souvent déshonorent le nom d'Européens. Mais, pour cela, la fondation dans le pays même d'une école d'évangélistes, doublée d'une école industrielle, s’impose; or huit jeunes ba-Rotsi sont déjà assez bien préparés pour former un premier noyau d'évangélistes.

Nous ne pouvons pas, en Europe, avec la meilleure volonté, nous faire une idée de ce qu'est la vie du missionnaire en ces pays-là. Seul, le voyageur qui a vu de ses yeux ce qui en est, peut s'en rendre clairement compte.

On ne pense pas assez, qu'au point de vue matériel, le missionnaire ne doit compter que sur lui. Il doit être à la fois son propre charpentier, menuisier, forgeron, architecte, ingénieur, et il manque de tout; en outre, à côté de l'œuvre spirituelle et d'éducation qu'il fait, il faut ètre encore le médecin, le conseiller de chacun.... Sa porte est continuellement assiégée.

Citerai-je aussi tous les services que les missionnaires ont, d'une 
manière générale, rendus ì la science et combien, comme explorateurs, ils ont augmenté le champ des connaissances humaines! Je ne puis m'empècher de rappeler que, il y a quelques années, la Société de Géographie de Paris a honoré M. Coillard en lui conférant une médaille.

Enfin, comment mentionner les difficultés et les privations qui sont leur pain quotidien?

Les insectes de tous genres constituent un véritable fléau; les plus redoutés sont les termites, dont j'ai déjà raconté les méfaits, ainsi que les seroui, fourmis guerrières. Des légions de souris et de rats causent des dégâts incalculables; il en est de même des sauterelies, des serpents, sans parler des fauves ni des moustiques.

Et puis, que dire de ce soleil perfide et surtout de cette terrible fièvre qui, en quelques heures, abat les plus courageux!...

A ce sujet, j'attirerai l'attention sur le fait que les blancs qui sont condamnés - nous en avons fait l'expérience nous-mêmes - à un régime de viande et de farineux, voient peu ì peu leurs forces décliner. Aussi je sens que mon devoir est d'insister pour que l'on envoie aux missionnaires du Zambèze, le plus possible de fruits et de légumes verts conservés.

Habitués que nous sommes, dès l'enfance, à n'avoir jamais manqué de ce qui est nécessaire pour la vie. ces détails semblent peut-être ne pas avoir grande importance; $\ldots$ seul le voyageur qui, pendant un certain temps, a souffert de ces privations, peut les comprendre!

Parlerai-je encore de l'hostilité des chefs... des horreurs du paganisme! Enfin a-t-on jamais réfléchi à l'isolement moral de cette poignée d'Européens, lesquels, à des milliers de lieues de leur patrie, sont obligés de voir, d'entendre et de combattre, dans la 
proportion de un contre des multitudes, un ordre de choses engendré par le mal naturel qui existe dans le cœur de toul homme laissé à lui-mème. Si nous n'avons pas subi cet isolement, nous ne pouvons nous le figurer, nous surtout, qui avons eu le bonheur de naître en pays civilisé el qui, tous, bénéficions, mème ceux qui ne veulent pas

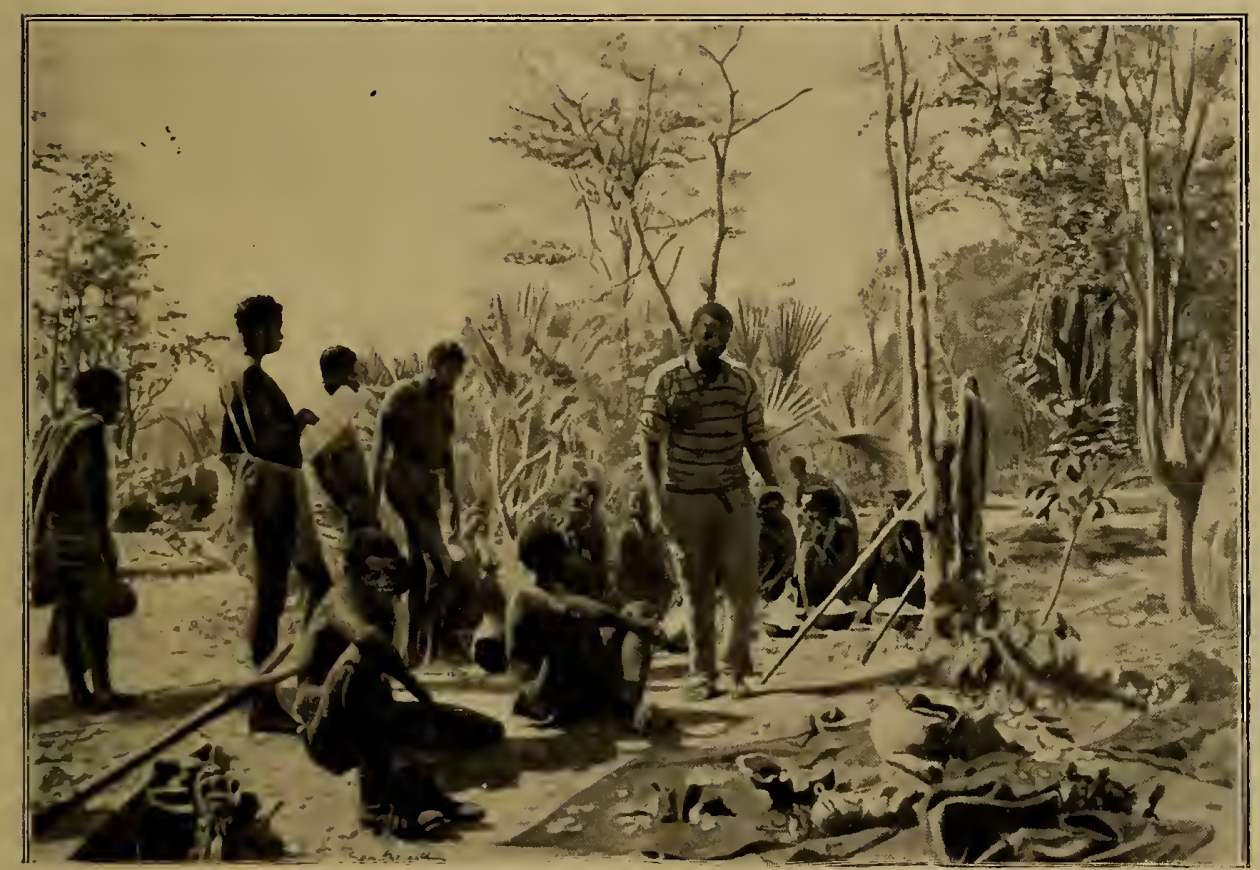

PRSS DES CIICES VICTORIA.

Daprès une photographie de l'auteur.

le reconnaître, de cette influence bienfaisante apportée sur la terre par le christianisme.

En terminant ces quelques réflexions, j’ajouterai que, voyageur impartial, il m'a été impossible de ne pas être frappé du dévouement entier et complet de ces missionnaires à leur œuvre, en dépit des difficultés et des privations chaque jour renouvelées. Malgré tout, je l'ai déjà dit, comme ils savent être joyeux, hospitaliers et boṇs!

Quelle leçon vivante que celle de ces héroïques pionniers, ne se 
plaignant jamais et cependant toujours à la brèche, toujours prêts à payer de leur personne. Et quelle belle tâche que celle de ces femmes de missionnaires, les dignes émules de leurs maris! Pour les païens, chez lesquels la femme est un être si inférieur à l'homme, quel exemple est celui donné par la famille chrétienne!

Combien, d'une manière générale, cette phalange de "braves ", disséminés dans les parties les plus reculées du monde, - les missionnaires, - ne devraient-ils pas ètre davantage encore entourés de sympathie et surtout airlés matériellement. Leur œuvre est une œuvre civilisatrice dans l'acception du mot la plus noble et la plus élevée.

M. Boiteux lui-même me fait traverser le Zambèze dans son canot; arrivés sur la rive droite du fleuve, la dernière parole prononcée est : "Au revoir").

Vers le soir, je rejoins Pirie et Reid qui, depuis hier, sont partis en avant.

$$
\text { *** }
$$

5-6 octobre. - Nous franchissons à pied la distance qui sépare Kazoungoula des chutes Victoria (Victoria Falls), en suivant plus ou moins le cours du Zambèze à travers une contrée rocailleuse, souvent couverte de taillis, ondulée et coupée par des cours d'eaux qui vont se jeter dans le fleuve. Comme à l'ordinaire, notre vie est assez mouvementée. L'un de nos hommes, Watcher, toujours imprudent, s'est trouvé, non armé, presque nez à nez avec un léopard qui, heureusement, faisait sa sieste. Il nous raconte qu'il a dû se blottir à terre pour ne pas le réveiller et se tirer de ce mauvais pas sain et sauf.

Tout fier de sa trouvaille, Jonnes, le cuisinier, nous apporte un jour une tortue d'eau, du poids de huit à dix livres. 
Pendant la nuit, surtout, les moustiques nous font une guerre acharnée, malgré les feux allumés devant et autour de la tente. II nous est parfois impossible de dormir, et, pour échapper à leurs piqûres, nous nous mettons dans la fuméc.

$$
\text { *** }
$$

I octobre. - Au matin, nous apercevons dans le lointain les vapeurs qui se dégagent des chutes et nous en entendons le grondement. Si I'on reut avoir une idée des Victoria Falls ${ }^{1}$, il faut se représenter le Zambèze, très large et roulant ses eaux d'une manière normale, au milieu d'ìles plantées de palmiers, lorsque soudain, sur sa route se présente une coupure de rochers plus ou moins à pic, d'un profil d'environ seize cents mètres, et profonde de cent à cent vingt. C'est dans ce gouffre, dont la largeur varie approximativement de quarante à quatre-vingts mètres, que le fleuve se précipite en faisant presque à angle droit un coude au sud-est.

Pour admirer dans toute sa majesté cette merveille de la nature, nous nous plaçons sur l'autre rive du gouffre, par conséquent en face mème des chutes. Nous marchons au milieu de grands arbres reliés entre eux par des lianes flexibles, peuplés de nombreux singes. lci et là, des massifs de fougères aux teintes claires se détachent du sol.

En partant de l'ouest, nous voyons la première chute, la moins considérable comme abondance. Contrairement aux autres chutes, ses ondes frémissantes glissent sur les rochers en suivant un plan incliné. Elle est séparéc de la seconde par l’ìle Livingstone, ainsi nommée en

1. Les indigènes désignent les chutes sous le nom de « Mousi oa Thounya „ (fumée qui tonne). 
souvenir de l'illustre voyageur qui, le premier, aborda ces parages. Cette seconde chute est verticale. Une île la sépare aussi de la suivante; mais à cet endroit, la vapeur qui se dégage du tourbillonnement de cetle avalanche liquide est telle qu'il n'est pas possible de la distinguer; les deux chutes semblent n'en former qu'une seule. C'est, ì notre avis, la partie la plus grandiose des Victoria Falls. Il est impossible de ne pas ètre fasciné par cette énorme masse d'eau qui tombe avec fracas, rebondit et s'éparpille en poussière. Elle constitue l'atmosphère opaque que nous avons sous les yeux; le soleil s'y joue et forme des ares-en-ciel superposés d'une grande beauté.

Cependant, pour ne pas prendre un bain trop prononcé, nous derons nous arracher it notre contemplation et continuer notre promenade. En effet, quoique le ciel soit d'un bleu intense, nous sommes imprégnés d'eau; à de certains moments, la pluie ne pourrait pas mieux faire. C'est une véritable température de serre chaude.

Encore une île, cetle fois-ci bien visible et nous sommes en vue de la quatrième et dernière chute. Elle s'étend sur un long parcours et si, à cette époque de l'année, elle n'impressionne pas comme ses sœurs, son caractère n'en frappe pas moins le spertateur : ses eaux divisées par les rochers forment une succession de gerbes qui affectent des formes diverses.

Il m'est difficile d'établir une comparaison entre le Niagara que j'ai visité il y a quelques années et les Victoria Falls. Elles ne sont guère comparables. Grâce à leur volume d'eau très considérable, les chutes américaines sont peut-être plus imposantes, tandis que les chutes africaines l'emportent en tout cas au point de vue du pittoresque. Mais qui dira l'impression produite an moment de la saison des pluies par ce spectacle grandiose!

Nous avons le plaisir de rencontrer aux Victoria Falls le $D^{\mathrm{r}}$ Arnold- 


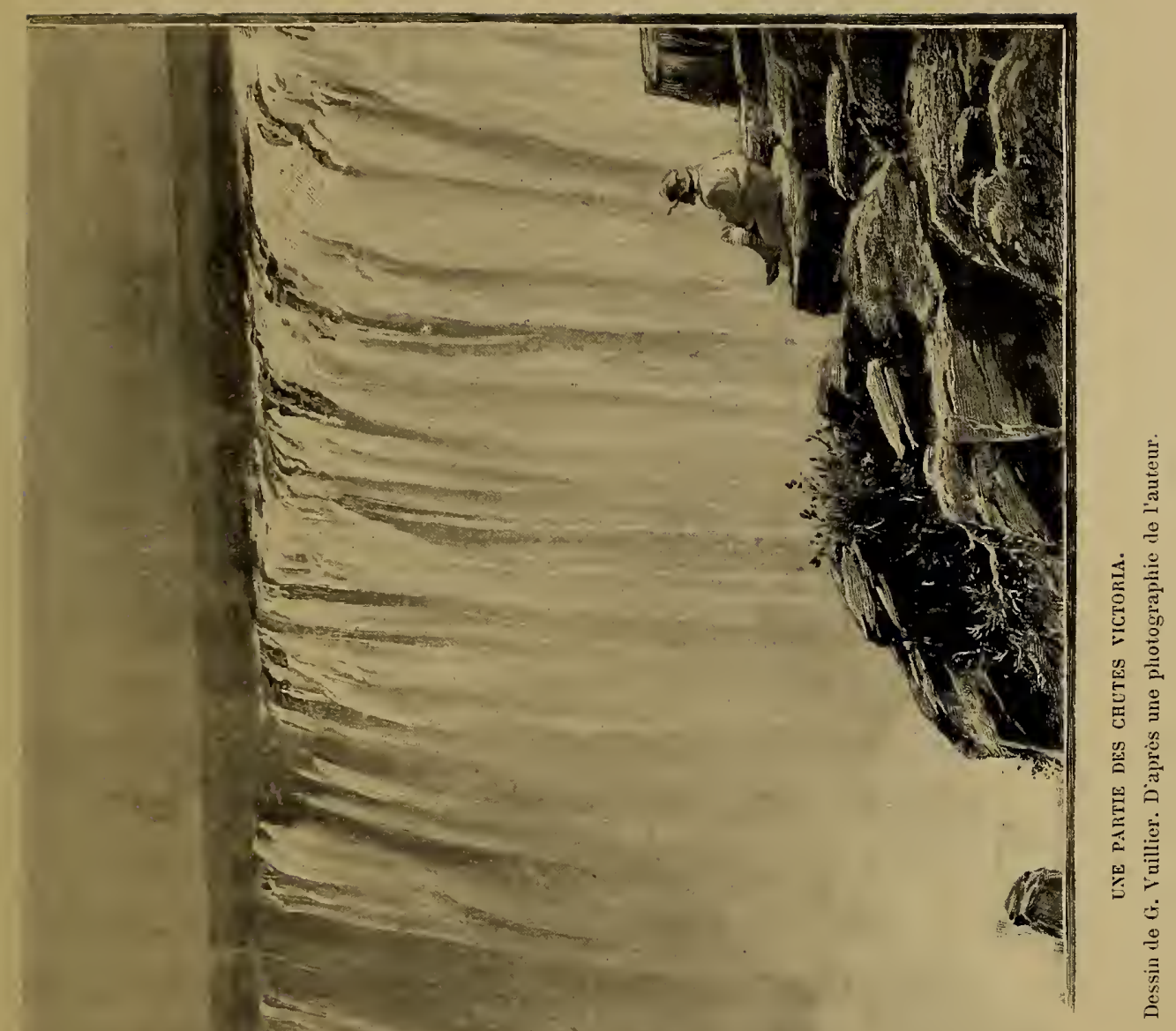



Winkelried Penther, voyageur autrichien, arrivé il y a quelques semaines et dont le séjour n'est pas près de finir. Son arrière-garde l'attend au sud à Tamasetsie. Il s'est à juste titre enthousiasmé pour ces merveilleux sites du Zambèze et il les éludie sous tous leur's aspects. C'est lui qui a bien voulu me communiquer les quelques chiffres cités plus haut et qu'il m'a dit ètre approximatifs.

Le $\mathrm{D}^{\mathrm{r}}$ Penther a perdu douze de ses bœufs! Cela le met dans une position critique. 



\section{EN DÉTRESSE}

des chutes victorla a PaNda-nitenga. - LA GRANdE piste dE LA SOIF. LA RIVIÈrE GWAY (FRONTIÈRE DU MATÉBÉLÉLAND) ET BOULOUWAYO

u soir du 8 octobre, notre tente est repliée, nous prenons congé
du $\mathrm{D}^{\mathrm{r}}$ Penther; comme à l'ordinaire, celui-ci partage encore notre repas. A l'improviste, arrive un autre blanc, M. R..., mort depuis lors.

Il nous raconte qu'il revient d'une expédition au pays des maShoukouloumboué et que son compagnon d'infortune, Anglais comme lui, est fort malade; il a dù, tant bien que mal, être transporté sur un espace de deux cents kilomètres.

De plus, leur " head boy ", serviteur de confiance, se meurt de la fièvre. Nous lui donnons les médicaments dont il a besoin. Puis nous marchons jusqu'à minuit à destination de Panda-Matenga (direct. S.).

C'est près de là, à Gazouma-Vley que nous retrouverons les chariots à bœufs, ainsi que les chevaux de réserve que nous avions laissés, avant de passer sur la rive gauche du Zambèze. 


$$
\text { *** }
$$

9 octobre. - Nous avons marché pendant une partie de la nuit dernière; après quelques heures d'un repos trop court, ce qui n'est plus une surprise, nous reprenons la marche à cinq heures du matin. Selon notre habitude, nous nous trouvons bientôt, Reid, Pirie et moi, à une bonne distance en avant de notre colonne. Dans le courant de la journée, nos gens s'égarent; nous devons nous arranger pour passer la nuit le mieux possible; nous nous couvrons tant bien que mal d'herbe sèche et nous nous tenons près du feu. Durant le jour, la chaleur continue à être très forte et les nuits sont fraîches.

$$
\text { *** }
$$

10 octobre. - Jonction avec la colonne qui, cette fois, ainsi que Reid et Pirie, se porte rapidement en avant en quête d'eau. La troupe est en marche et pour la première fois, je me sens faiblir subitement. Pour la première fois aussi, je reste en arrière et je suis obligé de me séparer de mon fusil. Je le donne à porter au dernier homme de la colonne, l'un des ma-Saroua. Malgré mes instances, il ne m’attend pas et me répond par ces mots qui pour lui, résument toute la situation : metsie, metsie, "l'eau, l'eau!"

Mes camarades en tète de la colonne ne se doutent pas de ce qui m'arrive, aussi je me trouve bientôt seul en compagnie des deux chiens Bless et Punch, qui ne m'ont pas quitté.

La chaleur est terrible, véritable fournaise et les taillis qui bordent la piste n'offrent point d'ombrage.

Je tâche d'avancer; mais je suis obligé à plusieurs reprises de me laisser tomber sur le sable brûlant. Je souffre sans doute d'une insolation ou des fièvres. Ma respiration se précipite, ma langue s'épaissit, 
puis surviennent les troubles de la vue. I mesure que javance, il me semble voir Reid ou Pirie devant moi... lls disparaissent lorsque japproche.... Nirage trompeur!

Autre mirage : je crois voir notre tente dresséc à quelque distance... Nouvelle déception cruelle! Tous ces symptòmes fàcheux vont s'accenluant; je suis seul el je me sens perdu. Je demande à Dicu son sceours et j’ai encore la force de me traîner péniblement durant une heure. Puis mes jambes me refusent tout service; je n'en puis plus. Mais, véritable exaucement de la prière : à ce moment, à quelques mètres devant moi, se dresse un grand boabab, le seul aperçu de la journée; el couché à l'ombre de son tronc, l'homme qui avait la charge du sac contenant mes effets personnels! Fatigué, il se reposait là, comptant rejoindre la colonne plus tard. Quelle délivrance! Je m'étends derrière le tronc et je me couvre des vètements renfermés dans mon sac, pour me garantir autant que possible, des rayons perfides du soleil.

En altendant le secours désormais assuré, je tourne, avec l'ombre, autour du tronc, à mesure que le soleil avance. Enfin à cinq heures arrivent Reid et Pirie; soutenu par eux, je puis rejoindre le campement élabli près d'unc mare à quelques kilomètres de là. Une fois installé sous la tente, Reid m'administre de l'cau bouillante aux pieds ainsi que des aspersions froides sur la lète et à l'épine dorsale; ce traitement me soulage. Il en était temps.

$$
\text { *** }
$$

V'endredi 11 octobre. - Grâce à la médication énergique de Reid, j'ai passé une assez bonne nuit et je crois pouvoir, au malin, me mettre en selle.

Dans l'intervalle, Reid avait fail chercher les chevaux à Gazouma- 
Vley où, comme je l'ai dit, nous avions laissé notre arrière-garde avant de traverser le Zambèze.

Nous arrivons de bonne heure à Panda-Matenga. C'est là que la British Chartered Company a, dans cette partie du pays, son poste le plus avancé. Il se compose de quelques huttes en terre, dont la principale est habitée par B..., le " field coronet ». Ce dernier, voyant mon triste état, m'offre l'hospitalité. La hutte est divisée en deux parties, on me couche dans celle qui sert d'entrepôt aux marchandises. Cellesci se composent principalement de dépouilles de bêtes sauvages. En guise de lit, un soubassement adossé à la muraille, de deux ou trois pieds de hauteur, sur lequel des perches posées transversalement soutiennent de la paille. Pendant la journée, c'est un va-et-vient continuel de moricauds; je suis trop malade et trop faible pour y faire attention.

Malgré la commotion dont j'avais souffert la veille, je me remis, à tort, en selle dès le lendemain matin. Je ne tardai pas à me rendre compte de ma faiblesse car, du 11 au 15 octobre, une crise aiguë se déclara. Je fus pendant plusieurs jours dans une situation très critique. Cependant je ne perdis jamais connaissance, ce qui entre autres choses, me permit un jour d'entendre B... dire à Reid : "I thought he was a dead man ", J'ai cru qu'il était un homme mort.

Tout mon sang afffuait à la tête, il s'ensuivait des bourdonnements désagréables. Je souffrais aussi de transpirations excessives qui réduisirent mon corps à sa plus simple expression; ma langue devint noire à plusieurs reprises.

J'ajouterai que B... et Reid, se rendant compte de la gravité du mal, me soignèrent de leur mieux et selon les moyens qu'ils avaient ì leur disposition. Une nuit, B... qui veillait dans le réduit séparé du mien par une large ouverture, se précipite près de moi armé de son fusil. "Take this lantern ". _ "Prenez cette lanterno ", me dit-il 
vivement; ce que je fis avec peine. Un coup de feu retentit à mon oreille; mais vu mon état de prostration, j'étais indifférent à ce qui se passait autour de moi : il venait de tuer à bout portant un serpent venimeux qu'il avait entendu s'introduire en sifflant dans la hutte.

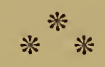

15 octobre. - Aussitôt que je puis me tenir debout, dès le cinquième jour après l'accident, les chariots sont attelés; bientôt tout est prèt pour le départ dans la direction du sud. Dans cette première période de ma convalescence, chaque effort représente pour moi une souffrance; le cahotement du chariot, ainsi que les privations de toute espèce, ne sont guère de nature à hâter mon rétablissement. Moins de vingt-quatre heures après notre départ, nous arrivons sans accident à la mare de Daka, où nous trouvons de l'eau.

Les difficultés vont recommencer; la première mare que nous rencontrerons sera celle de Tamasetsie. Pour y arriver, nous devons franchir environ quatre-vingts kilomètres à travers un sable épais et pénible pour les attelages; c'est le " thirst track", piste de la Soif, tant redouté des voyageurs.

$$
\text { *** }
$$

18 oclobre. - Quelle journée!! nous sommes en détresse dans le sable par une chaleur torride. Les bœufs du grand chariot, dont les roues sont actuellement presque hors de service, ne peuvent pas, malgré tous les efforts, faire un pas de plus.

Nous avons heureusement derrière nous M. S..., un Irlandais qui revient des chutes Victoria et avec qui nous avons fait bonne connaissance à Panda-Matenga. Sa caravane se compose de trois grands 
wagons et d'une cinquantaine de bœufs. Ces derniers sont plus petits, moins vigoureux que les nôtres et il aura aussi de la peine à traverser le " thirst".

Le soir, il arrive. Nous lui soumettons le projet suivant qu'il accepte: nous abandonnerons notre grand chariot au milieu des sables, comme une épave en pleine mer. De plus, nous lui offrons une partie de nos attelages comme renfort et il se chargera de nos colis qui ne trouveront pas place dans notre petit chariot et qui seront chargés sur l'un de ses wagons. C'est là que je dus, hélas! laisser la peau du buffle qui avait manqué de m'éventrer.

Je l'avais préparée avec soin, et transportée à grand'peine jusqu'ici ; cette peau pesait soixante-quinze livres. Je me faisais un plaisir de pouvoir l'offrir au musée de Genève.

Aussitôt dit, aussitôt fait; et les attelages ainsi combinés fournissent encore une longue marche de nuit.

$$
* *
$$

19 octobre. - Quoique la journée soit déjà avancée, entre quatre et cinq heures du soir, le thermomètre, à l'ombre du chariot, indique plus de $3 \check{3}$ degrés centigrades. Les ombrages manquent totalement; il nous faut, lors des haltes, chercher un abri sous les véhicules. Dans la nuit du 19 au 20, les attelages sont en détresse, épuisés par la fatigue et surtout par la soif. Sous peine de les perdre et de nous trouver dans une position désespérée, nous devons, quitte à les faire chercher plus tard, laisser de nouveau sur place trois des chariots; puis diriger le plus rapidement possible les hommes et animaux vers la mare de Tamasetsie. Au bout de quelques heures, il faut agir de la même manière avec le seul attelage qui nous reste, composé des trente bêtes les plus valides. 


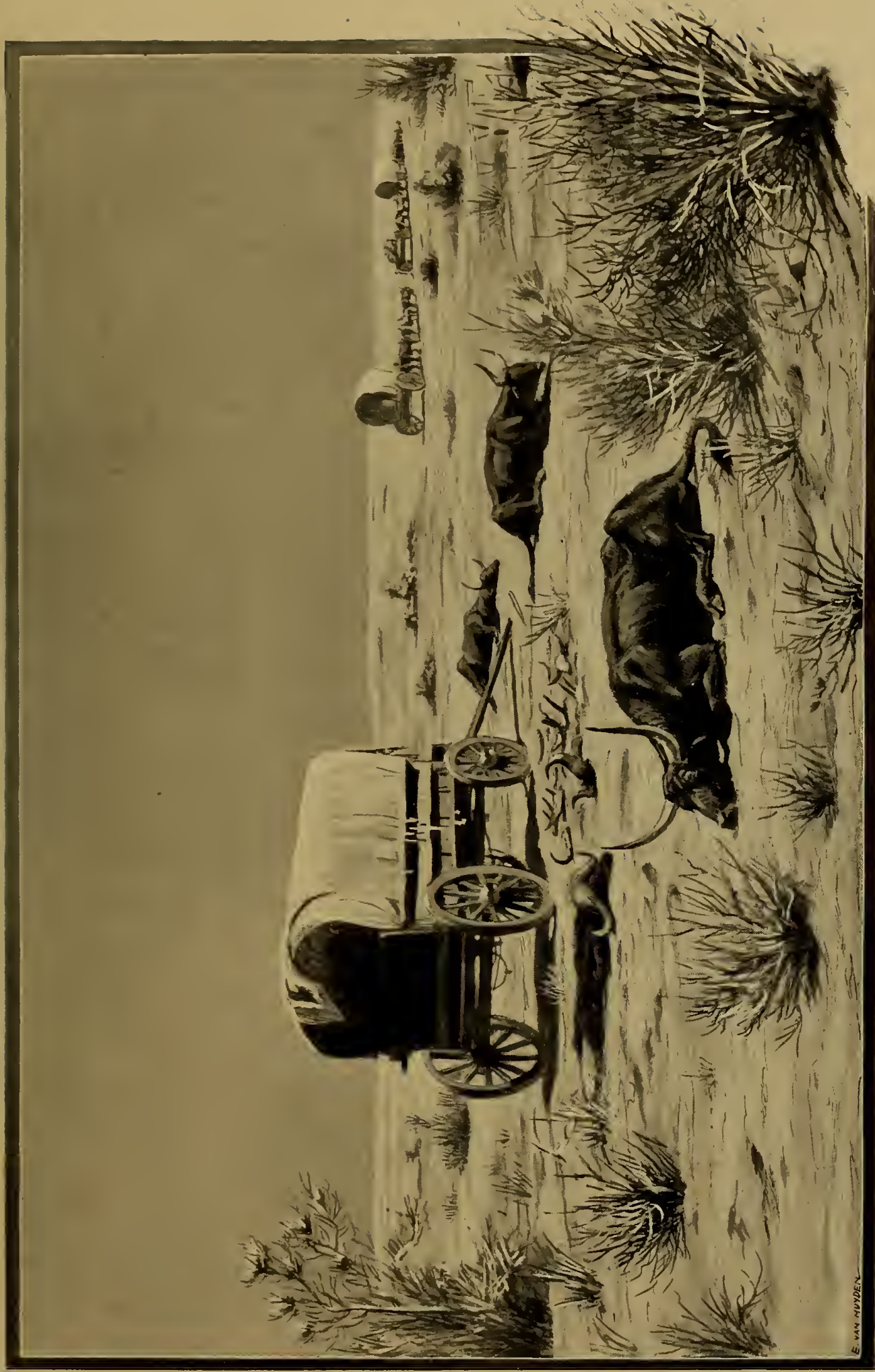

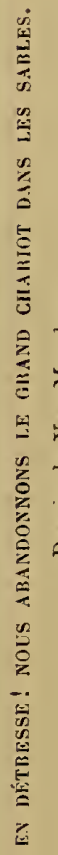





$$
* * *
$$

20 octobre. - I l'aube, Pirie el Reid partent à cheval pour la mare de Tamasetsie, où nous espérons que nos gens sont arrivés. S... et moi nous restons au wagon jusquà la fin de la journée.

Nous avons lì sous les yeux une scène navrante, le triste défilé des boufs de S... les plus faibles sont laissés en arrière, et plusieurs n’atteindrout pas Tamasetsie. Leur's naseaux parcheminés ne subiront plus le contact bienfaisant de l'eau. Ils tournent autour de nous et semblent nous implorer de leurs grands yeux humides; mais hélas! nous ne pouvons rien faire pour eux. Ivant le coucher du soleil, bien que très souffrant, je monte à cheval avec S... et à la nuit noire, nous nous trouvons tous réunis a Tamasetsie avec de l'eau en abondance. Il était temps d'arriver, car les bœufs qui ont survécu sont restés en moyenne trois jours et trois nuits sans être abreuvés.

$$
*^{*} *
$$

21 octobre. - La nuit dernière un lion, par de magnifiques rugissements, signale sa présence dans les environs, et, à son réveil, S... peut se rendre compte que ce voisin non invité lui a égorgé l'une de ses plus belles bètes. Il en a déjà perdu dix à travers le "thirst ». L'un de ses meilleurs boufs est devenu fou furieux lorsque, après de longues privations, il a été de nouveau en présence de l'eau; il est mort au bout de quelques heures sans avoir pu boire. Notre expédition dans le " thirst " a eu la bonne fortune de ne pas laisser un seul animal en arrière.

Nous trourons à la mare de Tamasetsie un Allemand, M. H..., qui a eharge de l'arrière-garde du $D^{r}$ Penther, le voyageur autrichien que nous avons rencontré aux chutes du Zambèze.

Comme mon état est toujours très grave, il me recueille dans son 
campement, alors que Reid, Pirie et S... procèdent au sauvetage des chariots laissés en arrière. Le souvenir de cet homme de bien ne s'effacera jamais de mon esprit; pendant toute une semaine, il me soigna comme un frère. Extrêmement faible, je passai toutes mes journées dans son campement, étendu à terre, enveloppé de couvertures, la tête entourée d'une épaisse serviette continuellement imbibée d'eau; cette précaution est indispensable en pareil cas, dès qu'on peut enfin user à discrétion de ce précieux liquide.

II... s'ingéniait à me préserver de son mieux des rayons du soleil brûlant et il me préparait lui-même de la nourriture avec les faibles ressources qu'il avait ì sa disposition.

Nos hommes établissent des " kraals" où les animaux sont renfermés chaque soir. Deux girafes tuées dans ces parages donnent de la viande fraîche; au bout d'une semaine tout le matériel est de nouveau réuni, excepté le premier chariot abandonné trop loin, pour qu'il soit possible d'aller le chercher, à cause de l'épuisement de nos attelages.

$$
\text { *** }
$$

26 octobre. - Nous décidons, Reid et moi, de partir demain soir pour Boulouwayo, ville principale du Matébéléland.

$$
\text { *** }
$$

27 octobre. - Après avoir pris congé de H..., nous nous mettons en route. Nous voyageons dans le " scotch cart ", petit chariot à deux roues, attelé de dix bœufs. Cinq hommes nous accompagnent, plus deux chevaux de selle. Puis nous congédions le reste de notre caravane, qui doit rentrer dans le Béchuanaland. Pirie et S... suivront notre piste plus tard, lorsque les attelages de ce dernier seront en 
bon état; nous lui laissons l'usage du surplus de nos boufs et il nous ramènera une partie de notre bagage.

$$
*^{*} *
$$

Je ne veux entrer ni dans les détails de notre vie ni faire la description du chemin parcouru entre Tamaselsie et Boulouwayo, direction générale sud-est, ce qui serait trop long.

Nous avons franchi cette distance, perdant un seul animal, en dix-sept jours, trajet pour lequel on compte ordinairement trois ou quatre semaines. Il a fallu de nombreuses marches de jour et de nuit, avec des alternances de sable et de terrain plus ou moins rocailleux.

Nous avons rencontré à différentes reprises des ma-Saroua qui nous donnent des indications à peu près exactes sur la piste à suivre, ainsi que sur les emplacements où nous trouverons de l'eau. En somme, dans ce trajet, l'eau ne nous a pas trop manqué, mais elle était souvent vaseuse. Nombreux vols de sauterelles et chaleur intense.

L'espace dont nous disposons, Reid et moi, dans l'intérieur du petit chariot n'est que de un mètre quatre-vingt-sept centimètres de longueur, un mètre cinquante centimètres de largeur et soixante-dix centimètres de hauteur; prise au hasard, la température que nous endurons sous notre toile dans une atmosphère absolument étouffante, est de $+36^{\circ} \mathrm{C}$., ce qui nous aurait quasiment permis d'y cuire des œufs à la coque! L'ombre donnée par le taillis étant presque nulle, il nous faut, bon gré mal gré, pendant les haltes, si nous voulons sortir de notre étroite prison, nous construire un " skerm ", mais il est bientôt transpercé par les rayons ardents du soleil.

Quoique Reid me soigne de son mieux, il est facile de comprendre qu'un trajet exécuté en de pareilles conditions ne peut se faire par 
un convalescent, tel que je le suis encore, sans souffrances de tous genres. Souvent il m'a fallu serrer les dents et faire appel à toute l'énergie dont j'étais capable. Combien un peu de repos, des cahotements moins prononcés, des fruits et des légumes frais, ou seulement de l'eau pure et glacée, m'eussent soulagé!

Les jours passent; enfin, le 7 novembre, nous apercevons dans le lointain la ligne bleue des collines derrière lesquelles se trouve Boulouwayo.

Nous recevons la visite de plusieurs ma-lialaka, ces anciens esclaves des cruels ma-Tébélé; ce sont de beaux hommes, bien découplés, et qui, eux aussi, ne dédaignent pas de se parer de verroteries.

La physionomie de la contrée change. Adieu les plaines; nous sommes dans la région des collines, sur les pierres desquelles notre chariot, dont la caisse repóse directement sur les essieux, fait des bonds désordonnés. Passages souvent difficiles, en particulier dans les lits encaissés des rivières, comme celui du Gway, dont les berges très escarpées, semblent défier la traversée pour quelque véhicule que ce soit.

Le 10 novembre, nous foulons le sol du Matébéléland; des “ kraals " apparaissent çà et là; les arbres sont touffus et l'air est plus vif; en outre, la piste devient meilleure. Il en est temps : quelques-uns des bœufs, les plus faibles, réduits à l'état de squelettes, se couchent pendant les marches; il faut alors les remettre sur leurs jambes et, suivant les cas, leur donner une autre place dans l'attelage. Il est douloureux de voir souffrir et d'entendre gémir ces pauvres animaux sans qu'il soit possible de les soulager"; mais il faut aller de l'avant, toujours de l'avant! Il y va de la vie. Un jour, Reid a dû abattre un bœuf qui décidément, ne pouvait plus avancer. 


$$
\text { ***** }
$$

13 novembre. - Vers le soir, nous sommes en vue de Boulouwayo '.

Guel contraste, après notre vie passée, de nous trouver, au bout de quelques heures, assis devant une table relativement bien fournie, puis de pouvoir dormir tranquillement dans un vrai lit!...

1. En pays francais, on a pris l'habitude d'écrire Boulouwayo; en anglais, Buluwayo; je conserverai l'orthographe française. D'après la langue du pays, on devrait écrirc, parait-il, Bolavayo ou Bolaouayo. 

CHAPITRE XII

\section{AUX AVANT-POSTES DE LA CIVILISATION}

BCUlouwayo, VILLE PRincipale du MatéBÉlÉlaNd

TEud 14 novembre. - Lorsque, au retour des pays sauvages el après toutes les privations endurées, après tous les dangers courus, le voyageur retrouve pour la première fois les avantages de la civilisation - mème à leur état rudimentaire, comme c'est actuellement le cas à Boulouwayo, - le voyageur, dis-je, habitué à se tirer d'affaire en toutes choses par lui-même, se trouve tout d'abord désorienté. Quoi! sans parler de tout le reste, ces dangers continuellement courus... ces anxiétés, ces inquiétudes au sujet de l'orientation, de la nourriture et surtout de l'eau... qui forment la préoccupation quotidienne de cette rude vie africaine, laquelle cependant a tant de charmes, car elle répond à la vraie nature de l'homme,... tout cela n'est plus qu'un rêve!

Quel changement et comme tout devient facile, lorsque, pour ainsi dire sans effort, l'homme peut se procurer ce qui est nécessaire à la vie. Combien d'Européens qui n'ont jamais quitté le sol natal et qui se plaignent des petites imperfections et contrariétés de la vie civilisée, 


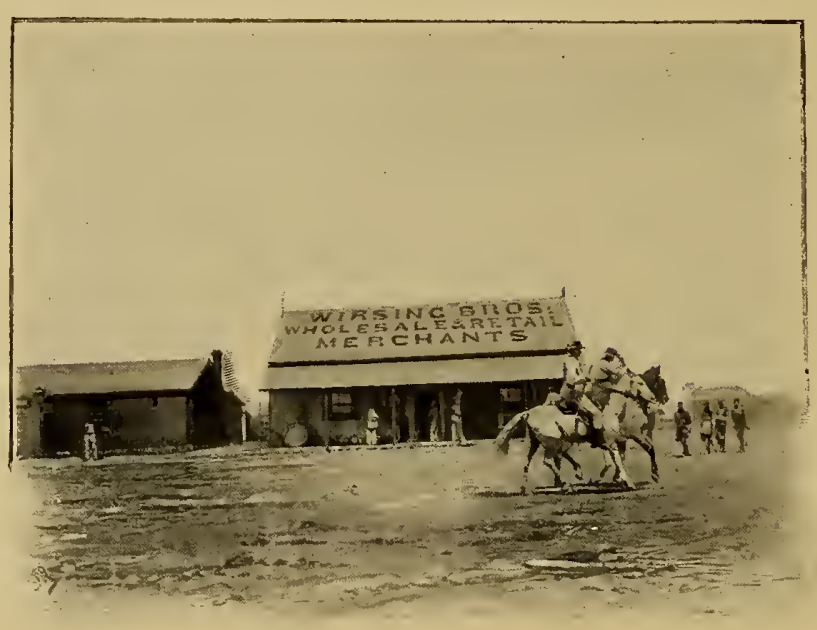

A Boulouwayo.

Dessin d'Oulevay. D'après une photographie de l'auteur. se doutant peu de tous les avantages dont ils jouissent!

lci, à Boulouwayo, comme de l'autre côté des mers, tout homme même le plus misérable, peut user à discrétion de ces deux bienfaits dont il faut avoir été

privé pour les apprécier à leur juste valeur : de l'eau fraîche et pure ainsi que du bon pain.

$$
*^{*} *
$$

15 novembre. - Ainsi qu'il a été convenu, c'est à Boulouwayo que notre expédition se termine. Sur ce marché favorable, les derniers chevaux, boufs, chariots, etc., ont été vendus. De plus, ceux de nos hommes que nous avions enrôlés jusqu'ici sont payés et licenciés.

Kanyé, le brave cheval sur lequel l'autre jour j'avais effectué la dernière traite, a péri subitement aujourd'hui pendant qu'on le promenait à la main... suite d'épuisement et des privations endurées.

$$
\text { *** }
$$

16 novembre. - Une fois toutes les affaires terminées, Reid qui connaît déjà la partie S.-E. de l'Afrique, se rend directement au Cap via Maféking. Quant à moi, je me propose d'effectuer plus tard le retour par le centre du Matébéléland et le Transvaal. Après avoir 
visité Jolannesburg "la ville le l'or", je m'embarquerai à Natal sur l'Oecian Indien.

$$
* * *
$$

18-95 novembre. - Il parait que depuis mon arrivée, javais abusé de mes forces; jai eu une forte rechute et jai élé obligé d'entrer le Is de ce mois à l’infirmerie de Boulouwayo. Quoique j’aie dlù garder le lit presque tout ee temps, j’apprécie ce séjour relativement très conforlable, en comparaison de ce que j’ai enduré auparavant lorsque je me trouvais dans les mèmes eirconstances. J'ai été bien soigné par le $\mathrm{D}^{\mathrm{r}} \mathrm{L} \ldots$...

$$
* * *
$$

96-30 novembre. - Périodle de convalescence.

$$
\text { *** }
$$

š decembre. - Arrivée de Pirie et de S... On se le rappelle, pour atteindre plus promptement Boulouwayo, Reid et moi, nous les avions laissés à Tamasetsie. Mais, ò déception! ils m’annoncent qu'ils ont ćté obligés, vu le mauvais élat de leurs attelages, d'abandonner a Tamasetsie le grand chariot appartenant à S..., précisément celui sur lequel se trouvent mes collections rassemblées à grand'peine lans le Pays des ba-Rotsi et transportées au prix de nombreuses difficultés.

S... me dit que depuis notre départ il a encore perdu dix bœufs, ce qui. depuis Daka, porte sa perte a vingt-un de ces animaux, plus qualques chevaux. Des bœufs de notre expédition que nous avions laissés à Pirie, trois seulement ont péri.

1. Blessé depuis dans la guerre contre les ma-Tébélé. 
En somme, Pirie et S..., chargés comme ils l'étaient, ont eu beaucoup de peine à atteindre Boulouwayo; depuis Tamasetsie, ce trajet leur a pris trente-deux jours, "it was hell " — c'était l'enfer, me dit Pirie.

$$
\text { *** }
$$

9 decembre. - La perte de mes collections m'est très sensible. L'expérience m'a appris que dans une expédition du genre de la nôtre, le premier principe pour réussir est de ne jamais se laisser décourager, quoi qu'il arrive et tant qu'une lueur d'espoir existe encore. Aussi je me mets en campagne. Grâce ì la complaisance de notre agent à Boulouwayo, M. Bl..., je tente le sauvetage de mes collections et je finis par trouver l'homme nécessaire en la personne de Harry, un métis. Il connaît, pour y avoir été, la mare de Tamasetsie; il partira demain avec un chariot léger et six boufs en bon état.

Je ne puis pas les attendre; mais je donne toutes les indications nécessaires à M. Bl..., pour qu'en cas de réussite il me les fasse parvenir en Europe '.

$$
\text { *** }
$$

Jeudi 12 déccmbre. - Je quitte Boulouwayo demain. Ce pays est encore si peu connu que je ne puis me remettre en route sans faire part de quelques observations et réflexions que m’a suggérées le séjour que j'y fis.

Quelle preuve de l'énergie de la race anglo-saxonne que la vitalité de Boulouwayo, cette ville née d'hier. Elle n'a pas deux années d'exis-

1. Il a réussi. Peu de temps après avoir débarqué en Europe, je reçus, à ma grande surprise et satisfaction, l'avis de l'arrivée de plusicurs de mes colis à Southampton; ce qui m'a permis de faire figurer du 4 juillet au 16 octobre 1896 à l'Exposition nationale suisse de Genève, la plus grande partie de mes collections. Ce qui manque a été probablement pillé par les indigènes. 


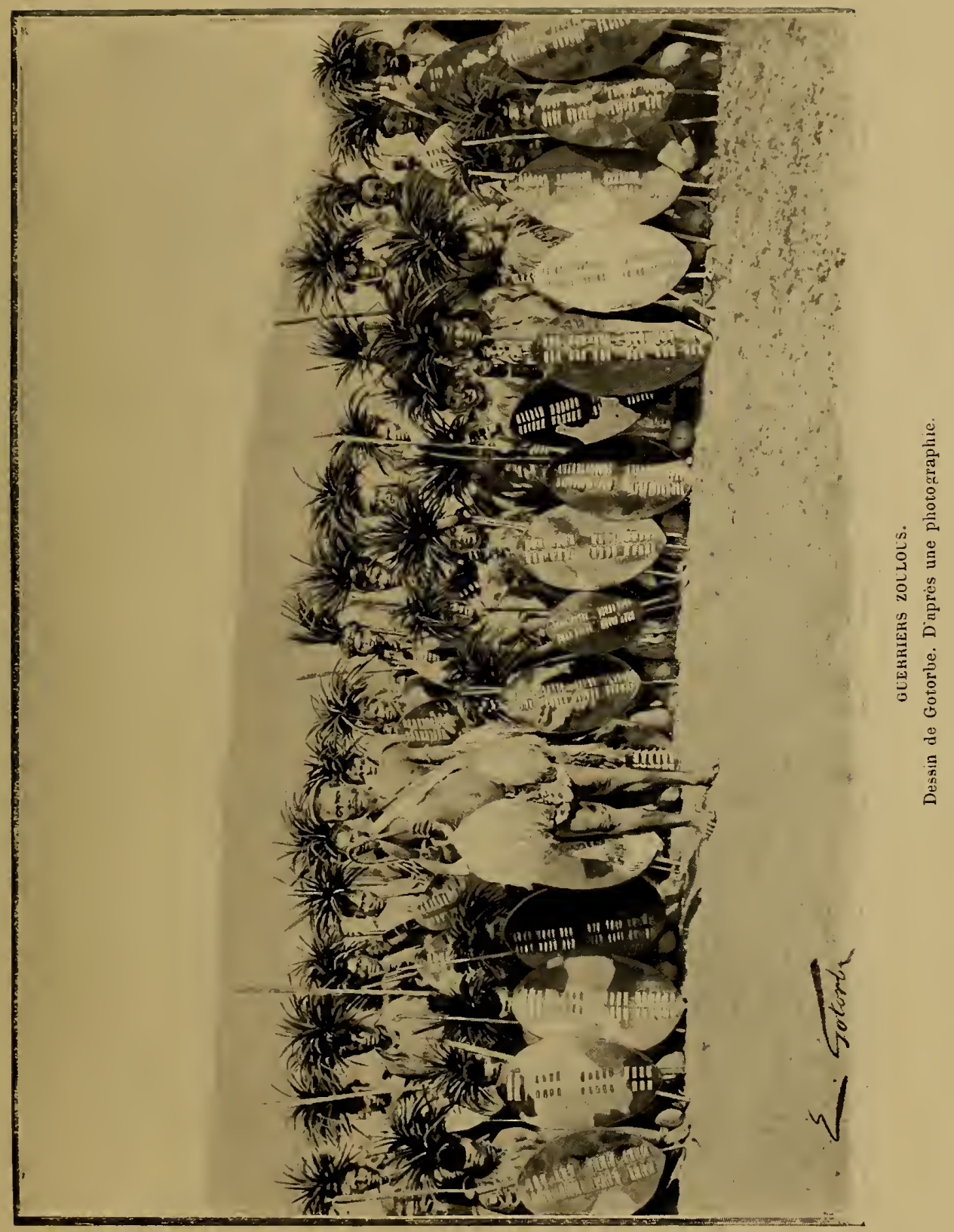



tence et doja elle a la prétention de se considérer comme la capilale de cette contréc nouvelle, le Matíbíléland. Si nous remontons it denx années en arriere, nous voyons que ce pays appartenait au roi Lobengoula. Grace à une convention conclue avec lui, la "Chartered Company " occupait déjà depuis un certain temps la région située à lest, soit le Mashonaland, lorsque, date néfaste pour le sort de sa nation, un parti de ses sujets pénétra à l’improviste lans le Mashoraland et massacra quelques-uns des blanes qui habitaient la petite ville ou le campement de Vicloria. En 1893, trois colonnes anglaises composées en grande partie de volontaires, partirent de trois points de rassemblement différents et ils infligèrent une sévère leçon aux ma-Tébélé . Dés lors, leur pays a passé sous la juridiction de la Chartered Company. Le Matébéléland est actuellement divisé en deux grands districts : Boulouwayo et Gwelo, qui sont partagés eux-mèmes en phusieurs divisions. A la tête de chacun de ces deux grands districts est placé un magistrat anglais, le " civil commissioner ". Le gourernement central de Rhodesia, désignation collective du Matébéléland et dı Mashonaland, siège à Salisbury, capitale de cette dernière contrée.

Le voyageur fraichement débarqué de son chariot à boufs, seul moyen, pour le moment d'atteindre cette oasis, ne peut pas s'empêeher de penser que Boulouwayo, l'une des créations de M. Cecil Rhodes, a de grandes ambitions. Tout y a été conçu largement; les rues de cette ville embryonnaire se coupent à angles droits, comme aux États-Unis, et, sans compter les trottoirs, elles ont une largeur moyenne de 30 mètres. Les territins qui les bordent sont fractionnés en "stands ", parcelles de 300 pieds de profondeur sur 1500 de

1. Les ma-Tébriki sont des Zoulous, qui sous la conduite du grand chef Mosélékatsi ont jadis imigrí. 
largeur, qui sont ventues aux enchères; elles sont vivement dispulées et quelques-uns des stands atteignent des prix qui ne seraient désavoués par aucune ville européenne.

A l'heure qu'il est, Boulouwayo offre encore l'aspect d'un immense campement. A còté de maisons en briques rouges bien construites et alignées, nous voyons beaucoup de cases en tòle galvanisée el de tentes błanches pittoresquement groupées. Les services s'organisent rapidement; des travaux sont en roie d'exécution pour fournir la ville d'eau polable amenée des collines environnantes, et l'éclairer à l'électricité. Sans parler des édifices réservés à l'administration, elle possède quatre édifices consacrés au culte; un hòpital admirablement tenu et organisé; une salle où l'on ne vendra aucune boisson alcoolique est aussi projetée; un hòtel des postes et télégraphes, un marché couvert, une Bourse, quatre maisons de banque, trois écoles, une prison, une station de police centrale. En outre, un large emplacement est réservé aux sports athlétiques; çà el là, nous voyons aussi de grands " stores ", véritables bazars où les marchandises et les produits les plus disparates se trouvent rassemblés. Il ne faut pas manquer de citer un club, dont j'ai eu l'honneur d'ètre membre honoraire pendant mon séjotr dans cette ville.

La presse locale est représentée par trois journaux. Deux paraissent deux fois par semaine, soit le Matabété Times et le Boulouwayo Chronicle. Le troisième, le Sketch, journal lithographié et illustré, publie jour ses lecteurs un numéro par semaine.

Boulouwayo sera bientôt dotée d'un conseil municipal. Elle est administrée pour le moment par un "Sanitary Board ", commission sanitaire composée de six membres, dont trois sont choisis par la Chartered Company et trois sont élus par la population.

Ont droit de voler tous les résidents qui ont une propriété ou qui 
parent doure lives sterling, soil trois cents lianes par mois pour lour pension et logement.

Sa population, sinns compter les noirs, dont il serait difficile d'évaluer le nombre, car il varie beatueoup, se monte a environ dens mille Europrens, la plupart Anglo-Saxons. Ordere parfail, de jour romme de nuil. Sans parler de la lénacilé, du respect de la loi inlérent ì la race anglo-saxonne, ainsi que de la grande liberlé laissée à l'effort individuel, l'une des causes principales du succès de sa puissance colonisatriec consiste, à mon avis, dans le fait que, en Angleterre, contrairement à ee qui souvent se passe ailleur's, les meilleurs ćléments de la nation ne craignent pas de s'expatrier; jetant ainsi les bases de colonies futures prospères et ajoulant de nouveaux fleurous i celle couronne, déjà si bien garnie.

Le còté pittoresque de cette ville en formation est fort intéressant it observer. Les hommes aux figures énergiques, bronzées, circulent laus les rues et vaquent à leurs affaires en tenue de cheval et les bras nus: ils sont coiffés d'un feutre aux vastes ailes. Montés, ils vont presque toujours au galop. Et que dire de ces types de "prospectors ", chercheur's d'or, qui après avoir, avec plus ou moins de succès, rreusé de nouveaux sillons, arrivent de l'intérieur du pays, tannés par le soleil ardent, et, aguerris par toutes les privations endurées. Les " desperados " ou bandits de profession sont rares, ils trouveraicnt ì qui parler.

Ictuellement, les chariots attelés d'interminables files de boufs, sont les seuls pourvoyeurs de Boulouwayo. Presque tous les approvisionnements nécessaires à ses habitants arrivent ainsi de Maféling; suivant l'état des pistes et le volıme d'eau des rivières à traverser, ils mettent de six semaines à quatre mois pour atteindre leur destination; par conséquent, il n'est pas rare que telle ou telle denrée, après 
avoir alteint des prix exorbitants, manque jusqu’à l'arrivée problématique du prochain convoi.

Le marché, dont la clientìle se compose exclusivement d'hommes, se lient le matin entre six et huit heures; les produits du sol doivent s'y vendre aux enchères. La culture des fruits et des légumes est a ses commencements. Suivant les dispositions des enchérisseurs et la rareté du produit, certains articles se vendront à des prix fabuleux; c'est ainsi que deux douzaines de figues fraìches ont trouvé des amateurs à dix-huit francs. Il y a six semaines, un chou s'est vendu vingtneuf francs; aujourd'lui, on peut se procurer ce mets luxueux pour un franc vingt-cing centimes. Quatre livres de pommes de terre sont enlevées pour quatre ou cinq francs. A Pàques, une douzaine d'oufs valait vingt francs; actuellement ils ne dépassent pas trois ou quatre francs; une bouteille de lail est taxéc à deux francs cinquante cenlimes, etc.

Il paraît que dans un rayon de près de cent kilomètres autour de Boulouwayo, tous les terrains susceptibles de culture sont déjà vendus. Ces fermes - j'ai eu le plaisir d'en visiter une - ont en moyenne une superficie de trois mille acres ou douze cents hectares.

En ce qui concerne les mines, chaque résilent - soit toute personne arrivant dans le pays et déclarant vouloir y travailler - a droit it dix " claims " mesurant quatre cents pieds de longueur sur six cents de largeur. La première formalité à remplir est de se rendre à l'office des mines et de demander une autorisation "for prospecting ", pour faire des recherches; elle est accordée moyennant une redevance de timbre qui vaut un shilling. Ce "prospector" a désormais le droit de parcourir le Matébéléland; lorsqu'il croil avoir trouvé un "reef "filon de quartz aurifère, il doit retourner à l'office des mines el faire enregistrer son " claim ". Il en devient, par celte inscription, le proprié- 


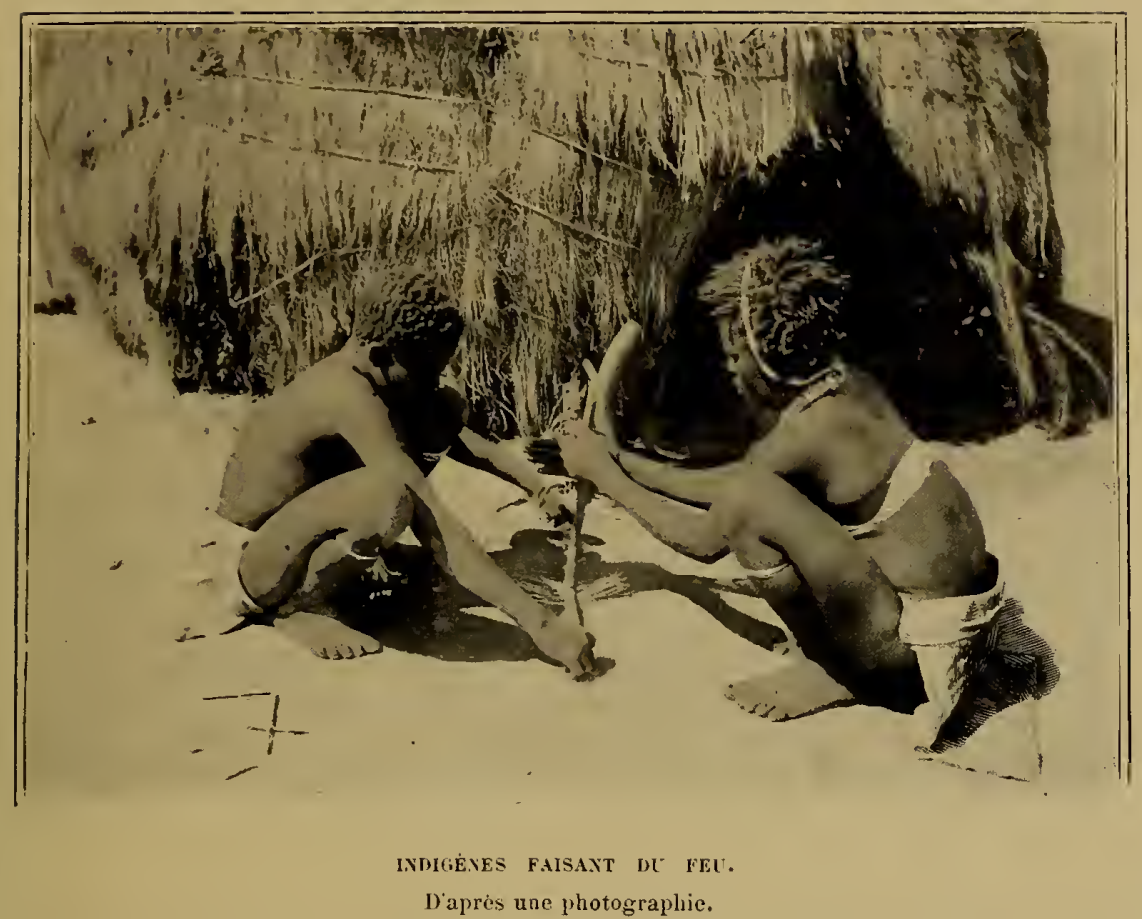

laire "owner prospector" ; il lui faut de plus, en trois mois, y creuser un puits "schaft" d'une certaine profondeur. Si le puits a été creusé dans le temps désigné et aux dimensions voulues, le commissaire des mines remet au nouveau propriétaire un certificat de protection valable pendant douze mois. Aucun autre mineur, sur un rayon fixé l'avance, n'a alors le droit de travailler dans les environs de son claim. Si les conditions n’ont pas été remplies, le claim est repris, à moins que le propriétaire ne puisse se justifier.

Lactirité déplogée par ces hardis pionniers leur amènera-t-elle la rémunération due à l'immense travail accompli en ces quelques mois?

C'est ce que l'avenir démontrera. A l'heure qu'il est, comme je viens de le dire, le plus grand obstacle naît de la difficulté du transport: les pionniers du Vatébéléland ont la ferme espérance que la 
ligne du chemin de fer de Maféking aboutira dans trois ans à Boulouwayo ${ }^{\text {. }}$

Les lignes de chemins de fer, au point de vue matériel, forment l'un des éléments les plus actifs de la civilisation; elles peuvent ètre comparées aux artères qui portent le sang dans le corps humain et en vivifient toutes les parties. Aussi, me semble-t-il que le pays n'aura sa valeur que lorsque, d'une part, Boulouwayo se verra reliée au sud a Maféking par la ligne du chemin de fer projetée, el que d'autre part. elle le sera à la còte de l'est par la prolongation non moins désirée du chemin de fer de Beïra.

Autre chose est de savoir si le pays peut tenir ses promesses tant au point de vue du rendement du quartz aurifère, que l'on croit renfermé dans ses profondeurs de manière appréciable, qu'au point de vue des produits du sol proprement dits.

En tout cas, ne peurent réussir à gagner leur vie dans ces pays nouveaux, que les hommes doués d'une grande énergie, prêts à travailler beaucoup plus qu'en Europe et capables de supprorter des privations, dont les nouveaux colons ne se font en général aucune idlée.

1. Les travaux de cette ligne out été menés avec une rare énergie par M. Cecil Rhodes : le 13 octobre 1897 la première locomotive arrivait à Boulouwayo, où quclques jours plus tard, le 4 novembre, eurent lieu les fètes d'inauguration. 
CHAPITRE XIII

\section{LE PAYS DES MINES D'OR}

DE bollouwayo par le matébélélayd aU transvall. prétoria. JOHANXESBURG, - LE RAID DE JAMESON

T 13 décembre. - Après une agréable soirée, passée la veille avec 1 le commissaire des mines, M. F..., le " coach " attelé de ses huit paires de mules se met en marche. Boulouwayo disparaît bientôt ì I'horizon et nous galopons à traver's une contrée couverte d'herbes. Git et lit, des ruines de villages détruits pendant la dernière guerre. Lattelage est crànement conduit à grande allure par deux "drivers". Le passage des cours d'eau - il n'est pas besoin de dire que les ponts n'existent pas - doit pourtant se faire ì marche plus lente; à certains endroits difficiles, il nous faut descendre et parfois pousser aux roues. Assis sur un siège élevé, le "driver " de gauche tient les guides; celui de droite est armé d'un immense fouet, qu'il manie des deux mains. Un petit postillon, d'une somplesse remarquable, se tient tantôt sur le marchepied, et tantôt court le long de l'attelage, pour remettre dans le mouvement les animaux récalcitrants ou paresseux. Le " coach", voiture de construction américaine, est très haut sur 
roues; sa caisse est ingénieusement suspendue au moyen de nombreux ressorts superposés, ce qui, en général, l'empêche de verser. Comme un bateau en mer, qui plonge et replonge avec la vague, il résiste aux inégalités du terrain, aux trous, aux pierres et aux ravines de la piste que nous suivons. Neuf places assises dans l'intérieur, sans compter celles de l'extérieur, et notre chargement est au complet. Jai la bonne fortune d'avoir comme voisin immédiat, le premier magistrat du Gazaland qui est atuellement en service provisoire au fort Tuli à la frontière du Transvaal, ainsi qu'un légiste de Boulouwayo.

Le reste de la compagnie est peut-être moins agréable; mais il rachèle ce défaut en étant pour moi une source inépuisable d'observations. La figure la plus sympathique est celle du pionnier Dan. II..., ancien cavalier-volontaire, qui a fait la guerre du Zoulouland et qui nous raconte nombre d'anecdotes sur sa vie passée; il possède maintenant une ferme dans le Matébéléland.

Nous avons des relais tous les 20 ou 30 lillomètres; aux heures des repas, forcément variables, nous nous asseyons à la table de petites hôtelleries où nous trouvons une nourriture surtout abondante. Nous parcourons pendant la journée, la région des collines de Malapo (Matapo Hills).

Ces collines granitiques sont pittoresques; elles sont en partie formées de gros blocs de rothers superposés et encadrés de verdure ". Le dernier relai pour aujourd'hui est Monsianana. Nous pouvons y dormir de dix heures du soir à quatre heures du matin, heure it laquelle rien ne nous empèche de reprendre dans le "coach " les conversations interrompues la veille.

1. Ciest dans cette contrée que quelques semaines plus tard, les ma-Tébélé se sont révoltés el ont massacré un grand nombre de colons blancs. 


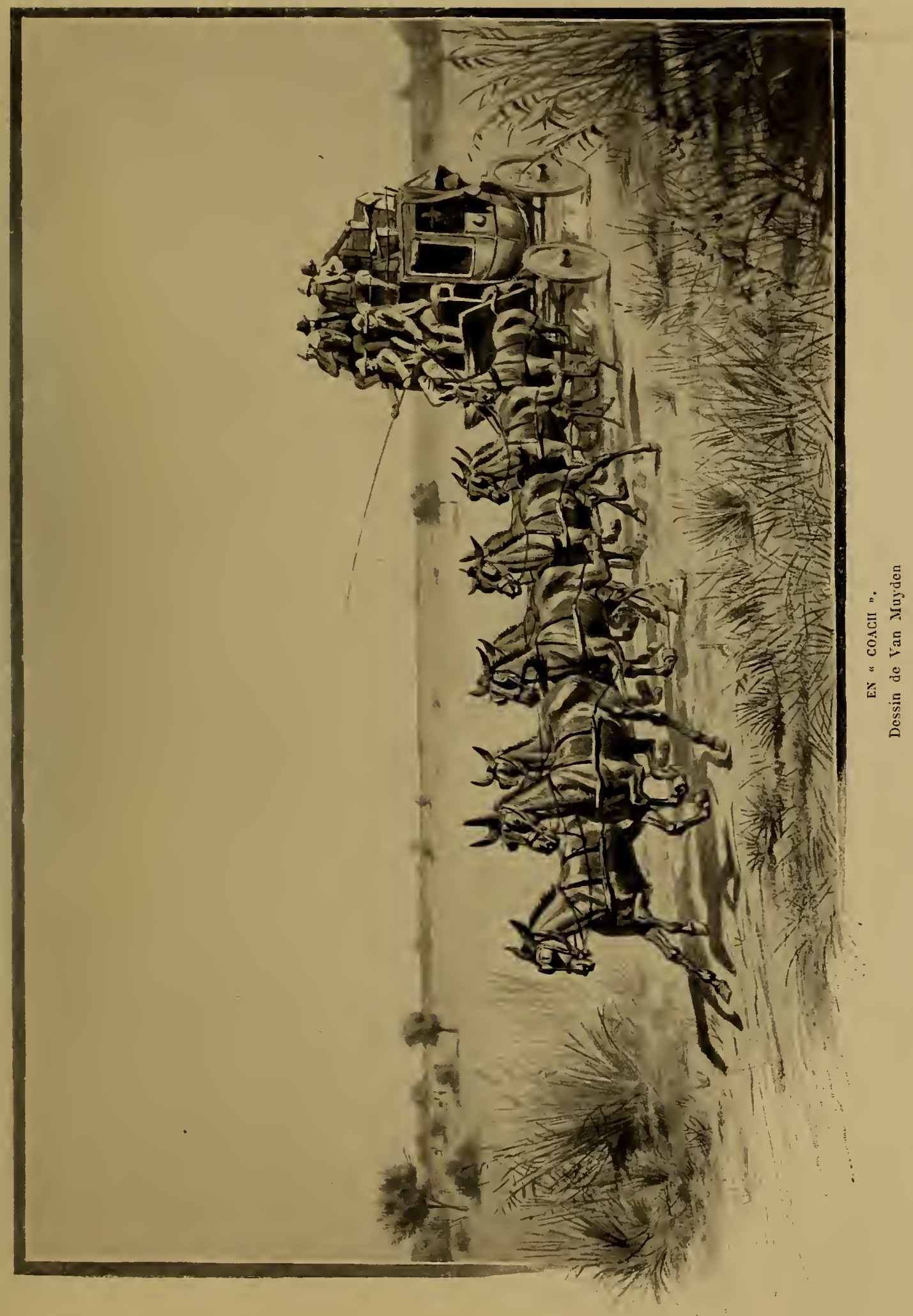





$$
*^{*} *
$$

If décembre. - Après le lunch, l'aspect du paysage change, nous sommes en plaine: au coucher du soleil, nous atteignons le fort Tuli, situé au bord de la rivière Shashi et à l'extrémité méridionale du pays. I notre arrivée l'un des voyageurs, des moins sympathiques, est obligé contre son gré, dinterrompre son voyage; il est en effet attendu par le commissaire de police. Après ret incident, nous allons dormir dans les petites huttes rondes qui sont les chambres a coucher de lauberge.

$$
* * *
$$

15 décembre. - Réveillés à une heure du matin par une sonnerie de trompette, nous continuons notre marche en avant. Nous

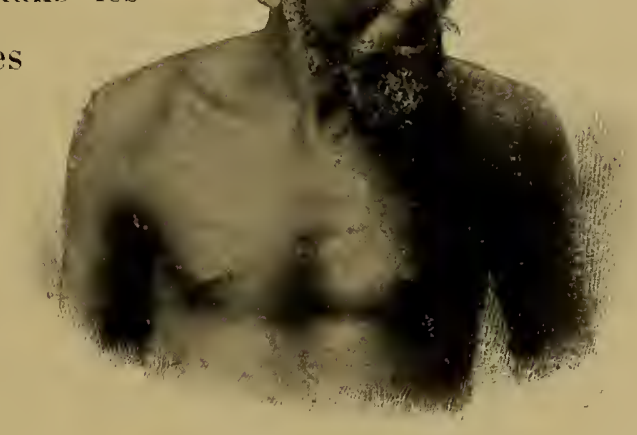

¿N GLERHER ZOULOU. Dapris une photographie. traversons sans peine la rivièe Shashi, qui est large, mais actuellement à sec; peu après il faut franchir le Limpopo, rivière des Crocodiles, qui est assez haute; les mules entrent bravement dans l'eau jusqu'au poitrail, l'eau pénètre dans le fond de la voiture.

Le Matébéléland est limité au sud par le Limpopo; en atteignant la rive droite du fleuve, nous foulons le sol du pays des Boers, la république du Transvaal. A l’aube, l'un des "drivers" tire sur une panthère et la manque. La piste est mauvaise; perché sur le sommet de la voiture, c'est un plaisir de voir l'adresse avec laquelle les "drivers " conduisent grand train, leur attelage de dix mules. Aux 
relais qui se composent la plupart du temps d'une écurie en terre, carrée, ouverte d'un còté et flanquée d'un "liraal ", les attelages gardés par un noir, attendent au dehors, rangés sur une ligne. Vu la simplicité du harnachement, les opérations de dételer el atteler s'accomplissent en quelques minutes. Les animaux, bien nourris et bien soignés, ont des formes superbes. Nous avons des attelages uniformes composés de mules baies, grises, alezanes; leurs croupes, leurs belles formes, rappellent celles du zèbre et, comme chez les fougueux habitants des grandes plaines, leurs jarrets sont souvent striés de bandes claires et foncées qui alternent.

Dans le courant de l'après-midi nous avous en vue devant nous, à l'ouest, la chaîne du Zoutfransberg et à l'est les Blaunberg ou montagnes Bleues. Ces dernières sont bien nommées et au coucher du soleil, après avoir passé par des colorations diverses, nous les voyous teintées du bleu le plus intense. Nous apercevons au loin des autruches en quête de leur repas du soir.

Nous arrivons à l'étape à sept heures; comme je l'ai déjà dit, les heures de sommeil sont courtes et nous sommes réveillés entre onze heures et minuit.

$$
* * *
$$

16 décembre. - Après avoir passé entre les deux chaìnes de montagnes mentionnées plus haut, nous galopons bientôt dans la plaine de Zoutfransberg; à de rares exceptions près, nous pouvions avoir le long du chemin parcouru jusqu'à maintenant, l’idée d'une vaste contrée inhabitée. Nous voyons aujourd'hui plusieurs grands villages nigres; les femmes travaillent aux champs et de jeunes bergers surveillent des troupeaux de bêtes à cormes; ça et là, quelques fermes disséminées à travers ce pays d'herbes; elles appartiennent à des Européens ou 
des Boers. Deux hemes viemuent de somner et nous arrivons à Pieterburge, on le reste de lapresin-midi est consacré au repos. Il n'y a pas. garand ehose à voir dans cetle petile ville, qui comple un millier d'habitanls, fètaut aujourd'hui l'une des victoires remportées par les Boers en 1838 ou 18 10.

$$
* * *
$$

fi décembre. - Départ à trois lieures du matin. Nous longeons une itroite el pittoresque vallée, sorte de grand col formé par les montagues de Fer. Quatre relais nous minent à Polgielerskut dont les quelques maisons blanches se cachent dans une luxuriante verdure ef sont entourées de plantations de bananiers. C'est dans l'une d'elles que pour la première fois depuis bien longlemps, je puis de nouveau manger des fruits, des grenadelles, des bananes et surlout de l'excellent raisin museal. La contrée ne tarde pas à s'élargir; puis pendant la seconde moilié de la journée, nous arrivons à la parlie la plus piltoresque du trajet, a la Waterberg-pass, formée par de hautes collines rocheuses, aux lignes gracieuses el recouvertes d'une fraiche verdure. Du sommet du col, nous jouissons d'une vue étendue sur la plaine, de laquelle émergent des sommités coniques plus ou moins dénudées, et qui est coupée par de nombreuses chaînes de montagnes. Entre cinq ot six heures, nous arrivons à une autre petite ville, Nylstroom, où nous passons la nuit. Depuis ce matin nous avons franchi 100 milles,

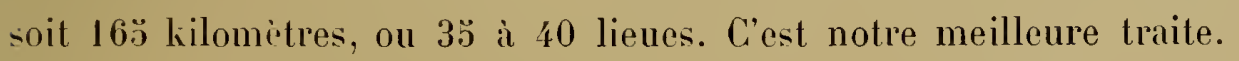

$$
*^{*} *
$$

18 dérembre. - Le départ pour notre dernière journée de " coach " $\therefore$ effectue à deux heures du matin; au milieu du jour, nous arrivons à une 'grande plaine marécageuse, où nous rencontrons une quantité de 
chariots de Boers en détresse. Notre attelage aux pieds léger's lui-même s'embourbe et à plusieurs reprises, nous sommes obligés de descendre pour l'aider à se tirer d'alfaire.

A mesure que nous avançons, la contrée cliange de nouveau d'aspect, elle devient riante, vallonnće et très verte; les fermes ainsi que les maisons d'habitations se rapprochent ol, à cinq heures de l'aprèsmidi, nous entrons à Prétoria.

J'ai donc parcouru en " coach ", pendant six jours et cinq nuits, sauf quelques heures de sommeil, les 800 kilomètres - 170 lieues qui séparent Boulouwayo de Prétoria, la capitale du Transvaal, cela en traversant au galop de huit ou dix mules, fréquemment relayées, le centre et le sud du Matébéléland ainsi que le pays des Boers, ce dernier dans presque toute sa longueur. Ce mode de locomotion et cette manière de royager, que beaucoup de personnes considèrent avec appréhension, peuvent après nos expériences passées, ètre envisagés comme très conforlables.

Cela n’empêche qu'en descendant du " coach ", le voyageur se trouve tellement imprégné de poussière, que ce n’est pas après un seul bain, qu’il peut reprendre figure humaine et se présenter au milieu de ses semblables.

Ce service du "coach" est bien organisé; il recoit une subvention du gouvernement. En temps ordinaire, il y a de Boulouwayo pour Prétoria, deux départs par semainr.

$$
\text { *** }
$$

98 décembre. - Prétoria, reliée d̀ la ligne des chemins de fer du Sud, jouit de tous les avantages de la civilisation. J'écris ces lignes de la cliambre d’un hôtel confortablement situé sur le Kerck-platz, grande place dominée par une église hollandaise et sur les bords de laquelle 
s'álevent le palais du gomernement, le batiment des postes, fólegraphes, ele.; cest de là aussi que part la rue principale, lierck-street, qui contient de nombreux magasins.

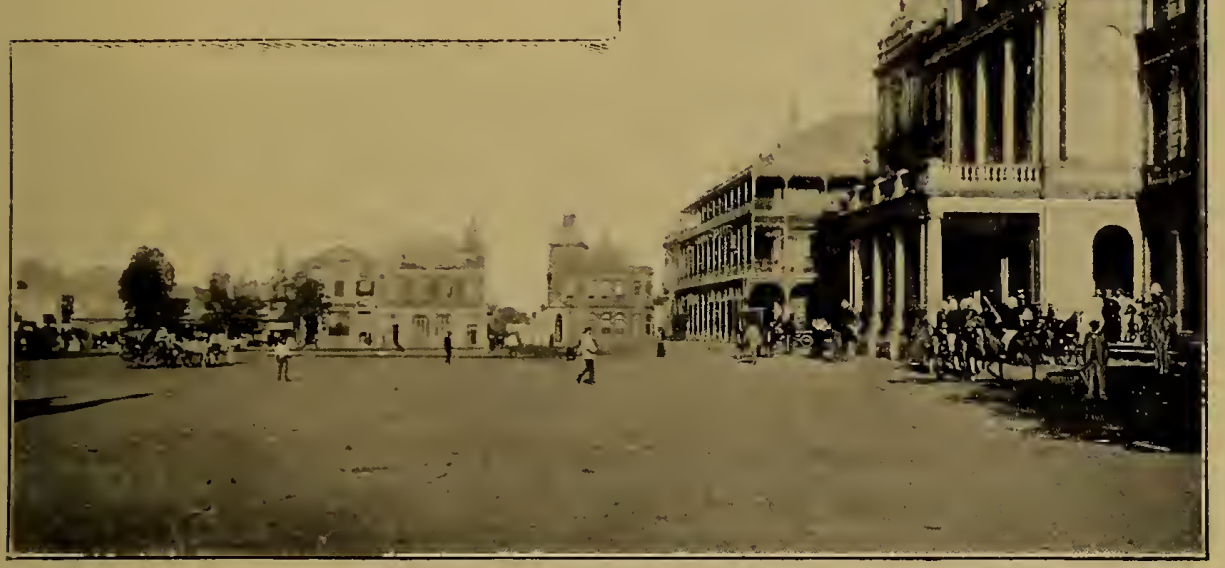

PRÉTORIA. - MALALS DU GOLVEREAENT. Daprès une photographic.

Un Transvaalien, le $D^{r}$ B..., directeur du musée, a rendu mon séjour ici très agréable en me présentant à plusieurs des notabilités de la ville. Mes habits de cérémonie étant au Cap, à quelques centaines de lieues de lì, force me fut d'assister à ces réceptions en tenue de voyage, pour ne pas dire de chasse, c'est-i-dire en veston court, gilet de flanelle et linicker-bokers, ce qui ne laisse pas de produire un contraste avec les élégantes toilettes des dames et les habits noirs des messieurs. Grande bienveillance dans la manière de recevoir; il faudrait bien des pages pour résumer toutes les conversations intéressantes entendues.

Quelques jours avant Noël, de nombreuses familles boers arrivent ì Prétoria des fermes environnantes, pour prendre partà la communion 
de la grande fète chrélienne. Pìres, mères, enfants et serviteurs, voyagent à la façon patriarcale dans leurs wagons attelés de boufs aux longues cornes. Ils plantent leurs tentes, ou habitent leurs chariots pittoresquement groupés, sur la place autour de l'église. J'ai assisté à un service divin accompagné de beaux chants.

Un Suisse, M. S.., arrivé au Transvaal il y a dix ans, m'engage à passer la Noël chez lui, dans la ferme qu'íl a louée à quinze liilomètres de Prétoria; très aimable réception. Pour un Européen, ccla fait une singulière impression de trouver dans la salle à manger abondamment garnie, un bel arbre de Noël et de voir au dehors, avec une température de juillet, les jardins en fleurs et les arbres couverts de fruits. Nous nous régalons de poires cueillies de nos mains.

Pendant les quelques jours passés chez M. S..., j’ai eu l'occasion de visiter sa ferme. Elle a une superficie de quatre mille hectares dont quarante seulement en champs irrigués. Lorsque ces derniers sont en outre bien fumés, ils peuvent rapporter jusqu'à trente sacs de grains par hectare; les parties non irriguées produisent cinq sacs seulement. Le domaine consiste surtout en prés. Les vaches du pays donnent en moyenne cinq litres de lait par jour et, chose curieuse, il faut leur laisser les veaux assez longtemps, sinon leur lait tarit immédiatement. Les vaches de Natal produisent environ le double de lait.

Des fruits el légumes européens croissent facilement; mais ils poussent trop vite et ils n'ont pas la même saveur que dans leur paỵs d'origine; les pommes, poires, pêches, abricols, coings, fraises, framboises, etc., șont récoltés de novembre à fin février. Cent livres de pois valent de trois à quatre francs.

Interrogé au point de vue de l'émigration, M. S..., d'après sa longue expérience, ne recommande pas aux jeunes Européens, de tenter l'agriculture dans le Transvaal et moins encore dans le Matébéléland. 
Il ne tombe pas une goutte de pluie du commencement de mai a fin aoùt; en ontre les saulerelles, les termites, la grềle, le gel, la sécheresse, les différentes maladies du bétail ', la " horse sickness " en particulier, affection spéciale du cheval, font une guerre acharnée à l’agriculteur.

Peu satisfait des résultats obtenus en agriculture proprement dite, II. S... a commencé il y a quelques années sur son domaine, une vaste entreprise, l'élablissement d'une forêt de 500 hectares, à 2500 plants par heclare. Il a choisi à cet effet deux espéces d'eucalyptus, le red-gum, qui résiste bien à la gelée, dont le bois s'emploie pour faire des traverses de chemins de fer et pour le travail des mines; Ie blue-gum croit rapidement, mais son bois est moins apprécié.

II. S... cultive plusieurs rariétés de ces deux espèces; voici en quelques mots sa manière d'opérer.

Les graines viennent à grands frais d'Australie. En décembre, il fait ses semis en serre. Au milieu de janvier, les plants sont repiqués à dix centimètres l'un de lautre et quatre semaines après ces arbustes ont déji une hauteur de dix centimètres. Ils sont alors mis en pots, puis transplantés dans le terrain qui sera plus tard la forêt et qui a été préparé dans ce but. Au bout d'un an, ces arbres sont hauts de dix à douze pieds; l'année suivante, lorsque les circonslances ont élé favorables, ils ont eu une croissance de six pieds. Après cinq années de plantation, les arbres atteignent une moyenne le cinquante à soixante pieds; le diamètre du tronc, mesuré à quatre mètres au-dessus du sol, est alors de vingt-cinq centimètres.

Prétoria, la capitale de la république du Transvaal, bien située

1. Au commencement de 1896 , la peste bovine (Rinderpest) a èclaté en Afrique, semant ta ruine, la Samine et la désolation après elle jusqu'au delà du Zambèze; les bestiaux, par centaines de milliers, ont ainsi disparu; on dit que dans le Béchuanaland seul, la perte se monte à huit cent mille bètes! 
au milieu d'un amphithéàtre de collines, est cachée au milieu des arbres, ce qui lui donne une physionomie spéciale. Sa population n’a pas encore été recensée; j’ai reçu poartant de deux sources autorisées les chiffres suivants : l'un compte douze mille blanes et dix-huit mille noirs; l'autre six mille blancs et quatre mille noirs; je pencherais plutôt du côté de cette dernière appréciation. Les blanes se subdivisent en Anglais, Hollandais et un grand nombre de ceux-ci oceupent de hautes fonctions officielles. Puis viennent les Allemands et enfin les Boers qui, dans leur propre capitale, ne forment qu'une infime minorité, car ils sont surtout cultivateurs.

Prétoria fait du commeree principalement avec le nord du pays.

$$
\text { *** }{ }^{*}
$$

29 décembre. - Je pars aujourd'hui pour Johannesburg, la ville des mines d'or; des menées révolutionnaires l'agitent depuis ees deıniers temps; beaucoup d'habitants ont déjà envoyé leurs femmes et leurs enfants au Cap.

Les nouveaux venus voudraient avoir ì donner leur opinion dans les affaires du Transvaal.

En compagnie du consul suisse, M. F..., de Zurich, je prends le train pour Johannesburg, au centre du district minier aurifère du Transvaal ; nous roulons bientòt à travers de grandes plaines ondulées et verdoyantes où paissent de nombreux troupeaux. C'est une véritable jouissance, après les différents modes de locomotion expérimentés depuis longtemps, de se sentir de nouveau emporté à toute vapeur. Cette voie date ì peine de deux ans et court bien des kilomètres avant d'arriver à destination. La ligne ferrée traverse le filon aurifère; de tous còtés s'élèvent les hautes cheminées des machines qu'emploient les compagnies qui exploitent le précieux métal; image du travail et de l'activité. 


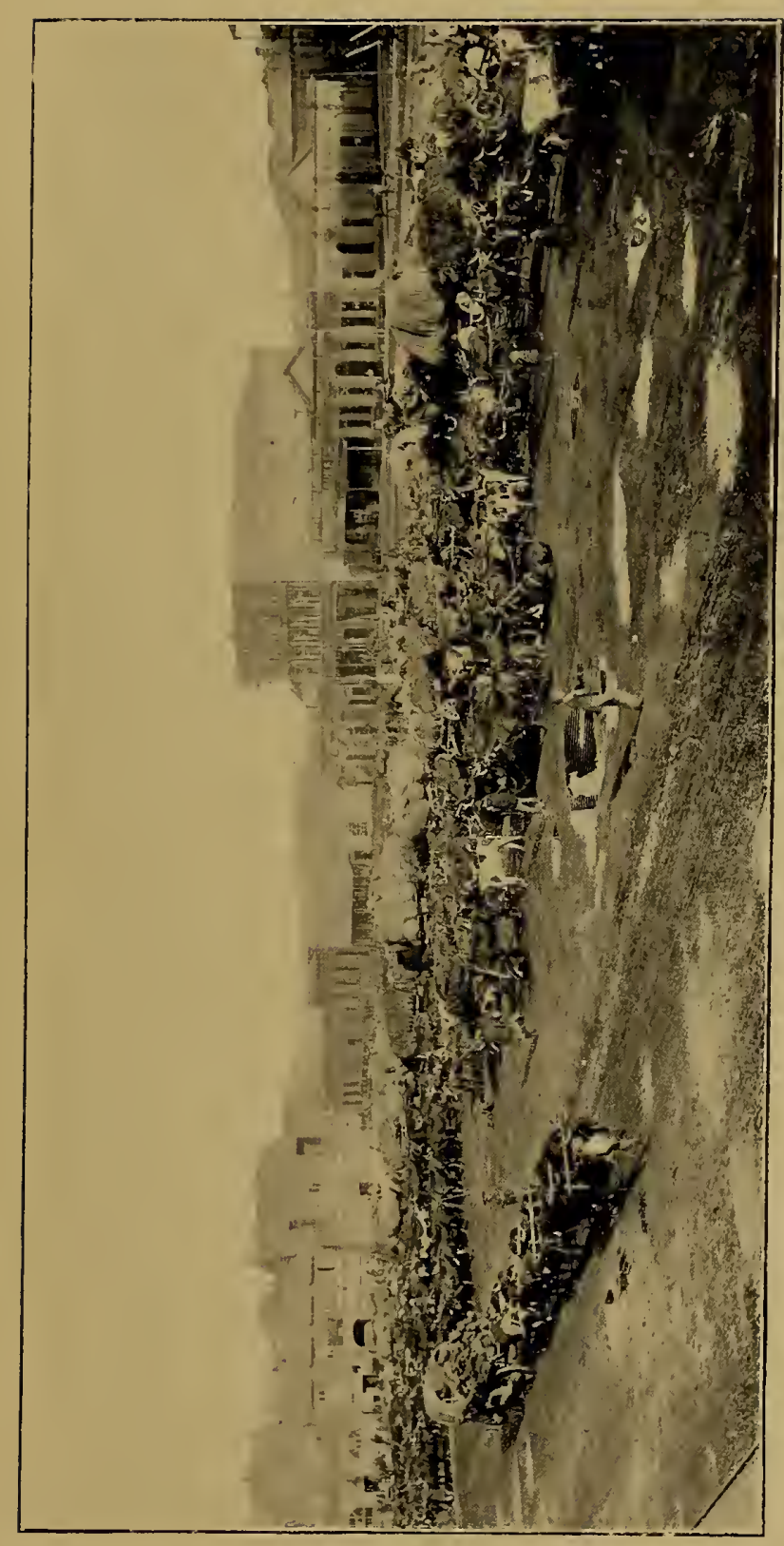

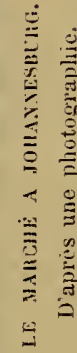



Les maisons et les collages sont plus denses; mous arrivons bientôt a P'ark Station, a Johammeshur. M. F... moffre l'hospitalite chez lui pentant mons sijour daus cetle ville.

Johinnesburg est en pleinc effervescence; il y rigne actuellement une graude panique. Les ehef's de famille mettent leurs femmes et leurs rnfants a l'abri d'un danger iventuel. Les trains pour le sud sont pris d'assiatl.

Lal rause de celle siluation anormale peut être expliquée en deux mots : la population de la ville comple an moins quatre-vingt mille labbitants dont soixante-quinze pour cent se composent d'étrangers les " uitlanders"; ce sont ces derniers qui ont fait la prospérité du pays. Pas besoin de dire que la majorité des " uillanders " est formée par des Inglo-Saxons. Ils demandent depuis longlenps au gouvernemenl du Transvaal le droit de vote, ainsi que certains autres avantag̣es, mais les aulorités du pays font systémaliquement la sourde oreille. Les " uillanders " ont-ils encore d'autres mobiles? C'est ce qüil ast difficile de savoir.

Quoi qüil en soit, afin de donner corps à leurs revendications et pour exercer une pression sur le gouvernement, ceur-ci ont fondé la " Yational Union " qui vient de lancer un manifeste au peuple du Transvaal où sont clairement énoncés soit les griefs, soit les droits dont veulent jouir les étrangers. Il est ouvertement question dans le public d'organiser une force armée volontaire; en un mot, Johanneslurge est sur le point d'entrer en rébellion.

$$
\because * *
$$

30 décembre. - Je vais remeltre une lettre d'introduction à II. L. P.... le président de la elıambre des mines. Il est aussi l'un des chefs du mouvement mentionné plus haut. Je recois de lui une carte 
qui me permettra de visiter la célèbre mine d'or "Robinson " le 2 janvier... si l'état dans lequel se trouve le pays ne la force pas d'arrîter le travail. Autre présentation à M. A. W..., le directeur de la "Transvaal Coal Trust Company ", mines de houille qui se trouvent à l'est du Rand et que je désirais voir aussi. L'autorisation demandée est aussitòt accordée, quoique M. A. W..., étant donnés les événements politiques qui se préparent, doute que je puisse réaliser ce projet. Aussi, comme la date n'est pas indiquée sur la carte d'entrée, je m'y rendrai à mes risques et périls demain matin.

A la station, au moment du départ, j’ai la bonne chance de faire la connaissance de M. E. W..., l'ingénieur en chef de la "Transvaal Coal Trust Company ». Il me domne pendant le trajet des détails du plus haut intérêt sur le bassin aurifère que nous traversons en diagonale, direction est, pour arriver à Brackpan, la plus importante des houillères exploitées par ladite compagnie.

Après le lunch, accompagné d'un ingénieur spécial nous descendons par un puits vertical, à une profondeur de cent trente pieds, jusqu'à la galerie principale creusée dans la houille. Elle est éclairée à l'électricité; l'ensemble des galeries comporte une longueur d'environ quarante kilomètres. Ce sont des équipes de noirs, surveillés par des blancs, qui armés de pioches, extraient la houille. Elle est ensuite entassée sur des wagonnets, lesquals sont remontés à la surface par des ascenseurs. Une ingénieuse machine trie alors le combustible, dont les jilus gros morceaux sont mis en sac et immédiatement chargés sur les wagons de la ligne ferrée qui aboutit à la houillère.

Après cette visite intéressante, l'ascenseur nous amène de nouveau à la lumière et nous pouvons constater que les événements se précipitent. L'ingénieur en chef, M. E. W..., arrive à son bureau armé d'un 
lusil; il va tenir conseil avec son état-major, composé de cinquante blancs, pour discuter les mesures ì prendre afin de sauvegarder les intérèts de la mine, où travaillent encore sept à huit cents noirs qui ignorent ce qui se passe.

Enchanté d'aroir r’éussi, j’ai juste le temps de changer l'équipement dont jai été revètu, contre mes vètements, et de reprendre le train pour Jolıannesburg.

Sur le parcours du chemin de fer à travers le Rand, de nombreux blanes et noirs quittent les mines. Énorme affluence a Parli-Station; en sortant de la gare, nous royons, premier signe des hostilités, une patrouille de cavalerie composée de volontaires, le mousqueton ì l'épaule. L'écusson fédéral resplendit sur la façade principale de la maison du consul suisse, M. F., lequel à tout hasard, a préparé ses armes.

Le mourement ítait peut-être concerté, et aujourd'hui la ville est en pleine révolution contre les autorités du Transvaal. Un gouvernement provisoire ou "Reform Committee " vient d'ètre nommé; il occupe le centre de la ville, les bàtiments du "Goldfield Office ». Une garde civique, un service de police spécial, des ambulances, des refuges pour les femmes et les enfants sont organisés. Une promenade en ville offre un spectacle inoubliable. Des milliers de rolontaires s'enròlent et sont armés dans les divers lieux de recrutement; les rues sont remplies d'une foule enthousiaste qui les acclame a leur passage; des chars de munitions circulent au grand trot ainsi que des réhicules de tous genres, sur lesquels se trouvent les bagages de personnes qui habitent les environs et qui viennent se réfugier à Johannesburg. Des estafettes brûlent le pavé au galop de leurs chevaux. Soudain, une grande nouvelle se répand comme la foudre et électrise des milliers de personnes : un corps de sept ou huit cents cavaliers de 
la Chartered Company, sous les ordres du Dr Jameson, a franchi la frontière du Béchuanaland; il a envahi le Transvaal et il avance i marches forcées au secours des "uitlander's " de Johannesburg.

$$
{ }^{*} * \text { * }
$$

fer janvier 189ö. - Journée resplendissante; le soleil brille dans tonte sa gloire, la nature est en fète, tout est vert et fleuri, les roses embaument; contraste frappant avec les inquiétudes qui r’ignent dans cette ville en rébellion. Combien de maisons fermées et divisées, de femmes et d'enfants enroyés à la hàte au loin, à l'abri de tout danger, pendant que les pères, les frères, les époux, restent sur place pour parer i toute éventualité.

L'effusion du sang pourra-t-elle ithe évitée? Le président de la République du Transvaal, M. Kröger, a, de Prétoria, proposé un armistice. Une députation de la National Union est partie ce matin pour la capitale; pourra-t-il en résulter un arrangement à l'amiable? C'est une question qui dans l'état où sont les esprpits, ne mettra pas beaucoup de temps à àtre résolue.

En ville, l'enthousiasme est à son comble; presque tous les sujets des différentes branches de la race anglo-saxonne domiciliés ì Johannesburg, y compris les Américains ot les Australiens, ont adhéré au gouvernement provisoire ou "Reform Committee "; la majorité des Français et des Allemands semble vouloir rester neutre.

Cing eamps composés de volontaires, forment au dehors de la ville une ligne de grand'gardes et défendent ses approches. Ouoique la révolte existe, un ordre excellent règne dans ces rues où la police légale a été retirée el remplacée par des constables volontaires. La plupart des magasins ont barricadé leurs devantures avec des planches ou des plaques de tôle. Un peu partout, des affiches indiquent 
soit les lieux de rassemblement de la trompe, soit les locaux où les femmes, enfants et nécessiteux, pourront trouver aide et protection. Sur les places publiques, les différents corps eomposés de volontaires, qui se distinguent par des cocardes de différentes coulenrs, sont exprés par des gens, qui me font l'effet d'être d'anciens officiers ou sous-olfieicrs. lls sont tous armés d'un excellent fusil à magasin.

Une grande foule stationne devant le siege du gouvernement provisoire: les entrées sont gardées par une lile de douze sentinelles langíes sur deux rangs, l'arme au pied. De nombreuses estafeltes, lancées à fond de train, apportent des nouvelles dı dehors ou viennent chercher des ordres. Des bruits divers cireulent sur l'approche des forees de Jameson qui sont allendues avec impatience.

Iu Rand club, nous apprenons l'accident de chemin de fer yni a en lieu sur la ligne ouverte il y a quelques jours seulement et qui relie le Transval à Natal. Quarante-trois lués et un certain nombre de blessis ; ce train contenait beaucoup de femmes, d'enfants qui fuyaient la révolution.

Dans le courant de l'après-midi, le "Reform Committee " fait annonece publiquement que le gouvernement de la République surafricaine a accepté l'offre de médiation du haut commissaire anglais, sir Hercules Robinson. Il quittera le Cap incessamment et arrivera à Pritoria samedi prochain, dans trois jours.

$$
\text { *** }
$$

2.jancier. - Après une journée passée avec des phases d'espoir et l'anxiété, la ville consternéc arquiert la certitude que la troupe de Jameson vient d'être défaitc à vingt-cinq kilomètres de Johannesburg.

Tout en reconnaissant que celte troupe, envahissant en pleine paix un pays voisin, commettait un acte contraire au droit des gens, il est 
impossible de ne pas constater - comme du reste beaucoup de Boers l'ont fait eux-mêmes - la bravoure de ces quelques centaines de cavaliers accomplissant en trois jours et trois nuits, presque sans sommeil et sans avoir le temps de prendre de la nourriture, une marche forcée de près de trois cents libmetres; ils ont, en une journée, franchi une distance de cent quarante-quatre lilomètres.

Suivant leur tactique, les Boers, qui sont d'excellents tireurs, les ont attendus dans une posilion où ils avaient tous les avantages. Les cavaliers de Jameson ont perdu un septième ou un huilième de leur effectif, environ quatre-vingts tués ou blessés et ils ne se sont rendus qu'à la dernière extrémité.

Voici d'ailleurs en résumé le récit de celte incursion par un homme qui a accompagné la colonne: je le traduis d'après l'un des journaux locaux qui l'ont publié :

— "C'est dans la nuit du 30-3I décembre, entre onze lıeures et minuit et en deçà de Krügersdorpr, qu un premier corps de Boers lâche de nous arrêter; nous sommes sur une colline et les Boers font feu sur nous; nous déblayons le terrain avec les milrailleuses Maxim et nous reprenons notre marche.

"Nous avons assez de vivres; mais le temps nous manque pour manger et nous reposer. Depuis que nous avons franchi la frontièe du Transvaal, nous avons eu seulement une heure de sommeil, cela lors du premier engagement dont jai parlí et après la dispersion des Bocrs; le reste du temps, nous avons marché.

"De bonne heure, au matin du 31 décenbre, nous tirons quelques coups de canon; les Boers avancent du còté de hrügersdorp. I onze heures du matin, nous pouvons manger et avoir un peu de repos; à une heure de l'après-midi, nous reprenons la marche toujours en deçi de Krügersilorp. Pròs de là, les Boers s'étaient retranchés dans une 
mine dont ils oceupent les parties áleves: nous bombardons lenr posilion aree nos pieves de campagne; le feu dura toule la muit el

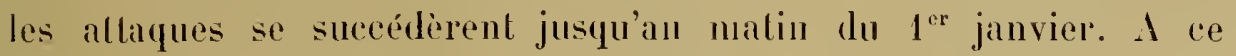
moment notre campl venait d'ètre formé, l'ordre de desseller n'avait pas encore éti domné, lorspue nous fùmes accablés par le feu des Boels.

"La dernière bataille a lieu non loin de Dornkop, où les Boers trnaient une posilion dominante; un détachement d'hommes de notre colomne, avec une mitrailleuse Maxim et un canon de eampagne, sont envoyés dans cette direction; une fois leur but atteint, ils reconnaissent que les Boers occupent une seconde position en arrière de la première el notre corps principal est bientòl pris entre leurs deux feux. C'était le seul endroit oì nous pouvions nous frayer un passage; mais c'étail une opcration dangereuse. "

Le gouvernement provisoire ou "Reform Committee " fait afficlier le 3 janvier les deux proclamations qui suivent :

“ 1. De la part du reprísentant de Sa Majesté au secrélaire du "Reform Commiltee ", Johannesburg :

"Sur la requèle de la députation que vous m'avez envoyée, je me suis mis en rapport avec son Honneur le présirlent du Transvaal et il ma donné l'assurance que, jusqu’a l'arrivée du haul commissaire, qui a quitté le Cap ce soir, Jolannesburg ne sera pas envahi par les Boers, cela à la condition que le peuple de Johannesburg n'enfreigne pas la loi et ne commette aucun acte d'hostilité contre le gouvernement.

(Signé) J. A. DE WET, chargé d'affaires de Sa Majesté.

" 2. "Reform Committee " notice : Le comité reconnaît que, à l'heure qu’il est, la situation où se trouve le docteur Jameson est de 
toute gravilé et que toute aclion agressive dudit Comité compliquerail gravement sa position. Sir Hercules Robinson, le laaut commissaire de Sa Majesté la reine Victoria, arrivera samedi prochain à Prétoria. Le Comité espère que les habitants de Johannesburg comprendront l'absolue nécessité de la préservation de l'ordre.

" Le gouvernement du Transvaal a donné l'assurance que ses troupes ne marcheront pas contre Johannesburg; il ajoute en outre, qu’il ne donnera pas de prétexte à un conflit. Néanmoins, le Comité a pris les précautions nécessaires pour ce qui regarde la sécurité publique. "

Par ordre du Comití :

(Signé) Le secrétaire, J. Percy Filzpatrick.

Aussitôt après la bataille de Dornkop, les Boers on temmené Jameson et le reste de sa troupe comme prisonniers à Préloria; le butin de guerre comprend huit mitrailleuses Maxim et trois canons de campagne du calibre 0,07 ว.

Les Boers se concentrent de toutes les parties du pays; la population de Johannesburg est moins démonstrative que les jours précédents. Quoique la ville n'ait rien perdu de son aspect guerrier et que les volontaires continuent énergiquement à s'exercer, aujourd'hui samedi, l'arrivée du haut commissaire anglais à Prétoria est attendue avec impatience.

Johannesburg est déjà entourée, à une certaine distance, par un cordon de plusieurs milliers de Boers; mais il est à prévoir qu'aucun événement important ne se produira avant après-demain, car les Boers, fait à noter et tout à leur honneur, ne se mettent jamais en campagne le dimanche; le président lirüger ne permet, sous aucun prétexte, que les affaires d'État soient engagées ce jour-là. 
Le jo janvier nous avons été jusqu’au camp des volontaires qui gardent le nord de la ville. Ils sont cantonnés dans un orphelinat; canpement pittoresque : ici des chevaux sont au piquet, là des tentes sont dressées el de tous les còtés nous voyons des groupes de volontaires accoutrés d'une manière disparate. Ils appartiennent à diverses ratégories sociales. Nous nous avançons en voiture jusque près de l'endroit où doivent se trouver les premières avant-gardes des Boers. Comme toujours, selon leur tactique habituelle, ces hommes sont invisibles; nous u'apercevons que des chevaux qui paissent tranquillement. Cette belle matince ensoleilléc au milieu de cette campagne verdoyante n’évoque que des idées de paix.

$$
* * *
$$

6 janvier. - Ce soir, le "Reform Commiltee " reçoit de Prétoria, par le chargé d’affaires de Sa Majesté, l'avis suivant du gouvernement du Transvaal : Johannesburg doit, avant tout, déposer les armes avant que les griefs de sa population soient discutés. A cette condition seulement, Jameson et sa troupe seront remis entre les mains des autorités impériales de l'Angleterre pour être jugés. La réponse à cet ultimatum devra etre faite dans les vingt-quatre heures, - jusqu'à mardi à quatre heures du soir.

Le "Reform Committee » finit par accepter cette proposition.

$$
\text { *** }{ }^{*}
$$

7 janvier. - Le chargé d'affaires de l'Angleterre au Transvaal, sir J. de Wet, arrive à Johannesburg. En présence de sept mille hommes, il prononce un discours éloquent, par lequel il engage chacun à accepter la proposition du gouvernement afin de sauver la vie de Jameson et d'empêcher un conflit qui pourrait avoir des conséquences terribles. 
Les armes sont déposées. Un mouvement de détente évident se manifeste dans la population. Les magasins rouvrent leurs devantures; les gens paisibles se rendent de nouveau à leurs affaires et la ville reprend peu à peu sa physionomic lıabituelle. Le drapeau de la Convention de Genève, la croix rouge sur fond blanc, l'emblème reconnu de la paix et de la charité, a été en évidence ces jours derniers à Johannesburg, où de nombreuses ambulances avaient été organisées. Il flotte encore fièrement sur le bel hôpital qui domine la ville.

Le haut commissaire anglais, sir II. Robinson, doit avoir poussé un soupir de soulagement lorsque la nouvelle du désarmement lui est arrivée. Les revendications des "uitlander's " pourront être discutées a loisir avec le président hirüger. L'un de leurs principaux griefs consiste dans ce fait, que les lois existantes ne leur donnent aucun espoir d'acquérir le droit de vote, ni pour le présent ni pour l'avenir.

En tout cas, les observateurs impartiaux ne peuvent pas faire autrement, que de rendre justice à l'ordre parfait qui a régné dans cette ville en révolution. Les milliers de mineurs blancs et noirs qui y ont afflué à ce moment critique, sans parler des gens sans aveu, qui ne manquent jamais dans une ville de quatre-vingt mille habitants, auraient pu être à première vue un sujet d'inquiétude. Mais ils devaient savoir que toute tentative de désordre serait réprimée avec la dernière énergie par une population qui, sur ce point, n'aurait pas hésité.

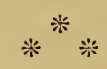

9 jancier. - Après cette période agitée, le calme étant plus ou moins revenu, je puis enfin réaliser un vơu que j’avais formé dès longtemps 
el visiter la célèbre mine d'or "Robinson ». Elle demanderait des pages pour la décrire; je dois me borner à un résumé de quelques lignes.

Aceompagné par un homme do la mine, nous prenons place dans le wagonnet qui, par un plan incliné, nous amène à la dernière galerie. La profondeur de cette dernière est, horizontalement, de onze cents pieds, et, verticalement, de sept cents pieds. Nous y voyons distinctement les trois filons de quartz aurifère, soit le Southrcef, le Mainreefleader et le Mainreef.

Voici par quelles opérations passe le précieux métal depuis qu'il est arraché aux entrailles de la terre jusqu'au moment où il est converti en lingots.

Le " banket ", conglomérat aurifère, est détaché à l'aide de la dynamite, puis il est chargé sur des "slips" en fer. Arrivé à l'orifice du puits d'extraction, il est versé dans un réservoir où se fait le travail de classement et après que la roche stérile a été enlevée, le congloméral aurifère va ì la " crushing machine ", qui broie les minerais jusqu'à un quart de pouce d'épaisseur. Ensuite, il tombe dans des réservoirs, au bas desquels se trouvent des portes automatiques et des wagonnets sur rails le transportent aux pilons de broyage.

Les pilons sont groupés par cinq; il y a vingt-quatre de ces groupes pour former la batterie. Quand le minerai y a été broyé en poussière trìs fine, il passe ì travers un tamis et s'écoule sur une table de cuivre pur, recouverte de mercure, où les parcelles d'or s'amalgament. Les tables de cuivre sont nettoyées une ou deux fois par jour, selon la richesse du minerai, puis l'amalgame est distillé dans des cornues. Le mereure, après avoir été vaporisé, se condense dans l'eau; l'or est ensuite fondu avec du borax dans des creusets en graphite et coulé en lingots.

La pulpe qui s'écoule des plaques de cuivre, se compose à ce moment 
de sable plus ou moins fin en suspension dans l'eau, et contenant de l'or sous une forme non amalgamable, combiné probablement avec les pyrites qui se trouvent toujours dans ces minerais. Pour extraire ces pyrites et, par conséquent, l'or, la pulpe passe par des concentrateurs (frue vanners) qui la séparent en deux produits : primo, une proportion plus ou moins faible $(\because 0 / 0)$ de concentrés contenant toules les pyrites; secoñdo, quelques sables mélangés.

Ces concentrés renferment de très fortes proportions d'or; ils subissent un grillage dans des fours à longue sole et sont ainsi transformés en oxyde de fer contenant de l'or. Ce produit oxydé est ensuite soumis au procédé de chloruration qui recueille $930 / 0$ de l'or contenu dans les concentrés.

Les sables (tailings), qui s'écoulent des concentrateurs, contiennent encore une certaine proportion d'or et sont traités par des solutions de cyanure de potassium; ce dernier produil dissont l'or qui est ensuite précipité par du zinc métallique en copeaux.

Le mélange de zinc et d'or " cyanite slimes " qui en résulte, se traite par l'acide sulfurique pour dissoudre la plus grande partie du zinc; la matière qui provient de cette opération est sćchée, grillée et fondue avec du borax, dans des creusets en graphite, puis l'or est transformé en lingots.

Je suis redevable de cette description ì l'un des ingénieurs distingués du Witwatersrand; je la terminerai en disant que la "Robinson " a, comme moyenne, un état-major de trois cent cinquante blanes et plus de mille ouvriers noirs.

$$
* * *
$$

10 janvier. - La ville continue à être calme, quoique cinquantesix membres de l'ex-Reform-Committee aient été arrêtés et conduits à 


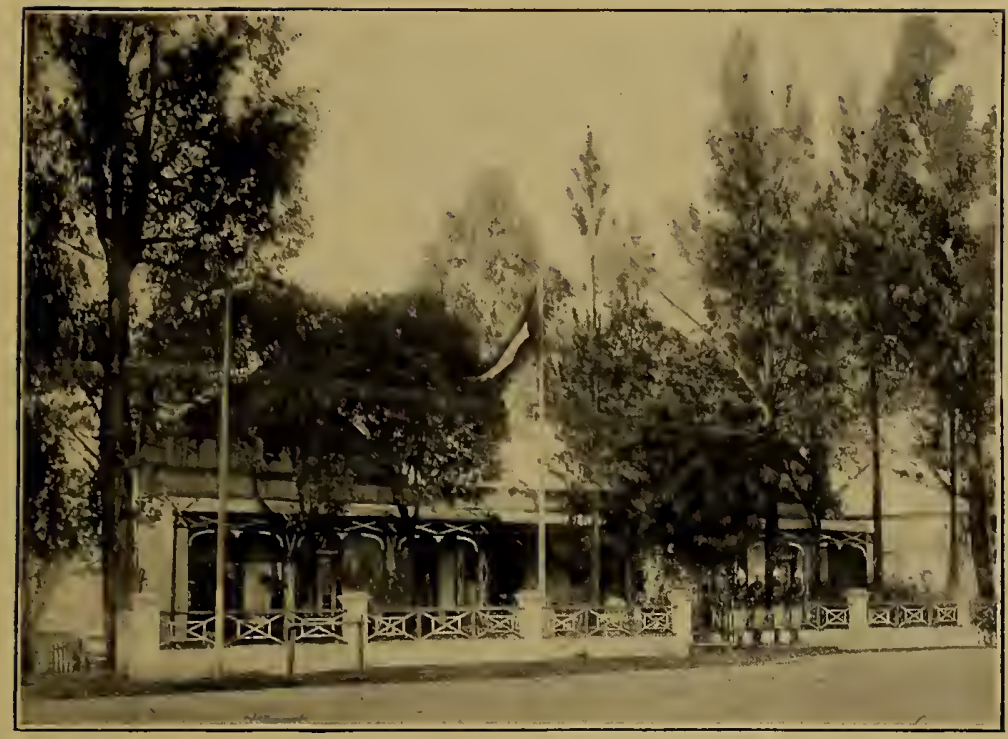

RÉsIDEXCE dC PIÉSIJENT KRÜGER A PRÉTOLIA.

D'après une photographie.

Prétoria, où ils vont être jugés. En outre, pendant deux ou trois jours, personne n'a pu entrer par chemin de fer à Johannesburg, ou en sortir, sans une autorisation écrite du gouvernement du Transvaal. Voici, au sujet de ce gouvernement, quelques notes tirées du "Official Handbook of the Cape " : Le président de la République du i'ransvaal, actuellement, M. S.-J.-P. lírüger, est élu par la majorité des "burghers ". Il a la charge du pouvoir exécutif, lont il est responsable vis-à-vis des chambres (Volksraad). ll propose les lois qui lui semblent nécessaires ou qui lui sont suggérées par les burghers; il doit chaque année visiter toutes les villes de la république et il ne peut pas s'absenter du pays sans le consentement des Chambres.

Le président exerce le pouroir conjointement avec le conseil exécutif, qui se compose du commandant-général, M. J.-P. Joubert, ce dernier nommé par le peuple pour dix ans; de deux membres choisis par le Yolksraad pour deux ans, et du secrélaire d'État élu par le Volksraad 
pour quatre ans. Le superintendant " of native affairs" et le "keeper of the minutes" sont de droit membres dudit conseil. En outre, le président peut inviter les différents chefs de départements à être présents et à émettre un vote au Conseil exéculif, pour tout ce qui concerne leurs départements respectifs.

Le président de la République et les membres du Conseil exécutif ont un siège dans les deux Chambres; ils n'ont pas le droit de vote.

Chacune des deux Chambres se compose de vingt-quatre citoyens, âgés d'au moins trente ans, propriétaires, et qui se rattachent à l'Église protestante.

Les arrêtés que prend la deuxième Chambre doivent être, dans les quarante-huit heures, notifiés au président de la République ainsi qu'à la première Chambre. Cette dernière peut, de son initiative ou sur l'avis du président, revenir sur les décisions de la deuxième Chambre, les confirmer ou les désavouer.

Le hollandais est la langue officielle.

J'ajouterai que le président de la République reçoit un traitement annuel de deux cent mille franes; il touche en outre une somme de sept mille cinq cents francs, destinée en partie à payer le café qu'il offre aux personnes reçues en audience le matin, entre six et luit heures, ou le soir. Je regrette que, pendant mon séjour à Prétoria, les circonstances politiques m'aient empêché de donner suite au projet que j'avais, d'ètre présenté au président de la République.

Les trois quarts de la population du Transvaal, population qui se monte à quelques centaines de milliers d'habitants, se composent d'étrangers (uitlanders). En général, ce sont des gens intelligents, énergiques et entreprenants. A l'heure qu'il est, nous le savons déjì, ils sont entièrement tenus en dehors des affaires du pays. Johannesburg, la " ville d'or ", qui a été sur le point, ces jours dernier's, d'être 
réduite à feu of à sang, leur doit pourtant son existence. Ce sont en affel les uitlanders, les étrangers, qui ont déconvert el mis en rxploitation ce distriet aurifere, of comme me le disait l'un des premiers Européens arrivís dans ces parages, l’emplacement où s’élève aujourd'hui celle ville bien construile chail, il y a dix ans, une vaste plaine.

D’un autre còté, les Boers craignent, peut-ître avec raison, que le Transval ne perde son indépendance, lorsque les étrangers pourront arriver facilement ì la dignité de "burghers ", c'est-àdire à la qualité de citoyens.

$$
*^{*} *
$$

13.jancier. - Départ de Johannesburg. 



\title{
LE JARDIN DE L'AFRIQUE MÉRIDIONALE LE RETOUR
}

\author{
DE JOHANNesburg a DURban (NATAL). - EAST-LONdON. \\ PORT-ÉLIZABETH. - LE CAP ET RETOUR EN EUROPE
}

Près une nuit passée en wagon, réveil à la frontière du Natal le
$1-4$ janvier. Cette nouvelle ligne, qui relie Johannesburg à Durban, sur l'océan Indien, a élé inauguréc il y a quelques jours seulement. Nous traversons différentes ramifications de la chaîne du Drakensberg. Çà et là, la voie se développe en nombreux lacets et nous avons de riants points de vue pittoresques sur la contrée environnante, qui est plus ou moins coupée et boisée. Dans le courant de la matinée, nous croisons sept voitures chargées des débris du train dont j’ai parlé à propos de Johannesburg et qui a déraillé le 31 décembre dernier non loin de Glencoe-Junction; une quarantaine de personnes ont été tuées ou blessées.

Nous arrivons tard dans la soirée à Durban, le principal port de mer du pays. Je vais visiter un de mes cousins, M. C. M..., d'origine genevoise, ancien officier de la marine de guerre anglaise, qui a depuis 
quelques années établi une plantation de thé dans la province de Victoria. Pour s'y rendre, il faut prendre la voie du North Coast railway, qui franchit plusieurs jolies collines et vallons, où la vue est charmée par des fleurs nombreuses, des plantations de cannes à sucre, des cultures variées, jusqu'à son point terminus, la petite ville de Verulam. Là, un " coach " à deux roues, attelé de six chevaux, conduit le voyageur par monts et vallées en quelques heures à Stanger. Arrivé à cet endroit j'enfourche un poney, envoyé à mon intention, et une chevauchée de quatorze ou quinze kilomètres à travers un pays montagneux et boisé, m'amène rapidement à Mérindol, le domaine en question. Un accueil chaleureux m'y atlend.

Il y a six années que M. C. M... a créé cette propriété, admirablement située. Elle s'étend sur trois collines; la maison, entourée de bananiers, d'eucalyptus, de bambous et d'arbustes variés, domine la contrée environnante. De la véranda enguirlandée de chèvrefeuilles et de rosiers, l'horizon se développe à l'est sur un espace de vingt kilomètres jusqu'à l'océan Indien, visible à l'œil nu.

La culture dı thé a commencé à Natal en 1877, époque où quelques acres furent plantés à titre d'expérience. Aujourd'hui ce pays possède trois mille acres d'arbrisseaux en plein rapport, qui produisent annuellement un million de livres de thé. Le thé de Natal se répand rapidement sur les marchés de l'Afrique du sud et de l'Angleterre. Il a été comparé avec avantage aux récoltes d'autres pays. Le climat et la nature du sol produisent à Natal un thé moins àcre et moins fort que ceux de l'Inde et de Ceylan, et qui a cependant un corps et un parfum, qui lui permettent d'être consommé pur, sans ètre mélangé à d'autres thés.

Cette culture doit être faite avec beaucoup de soins. Après que le terrain favorable pour la future plantation a été trouvé, le sol est labouré, hersé, puis il est divisé en lignes qui doivent avoir entre 


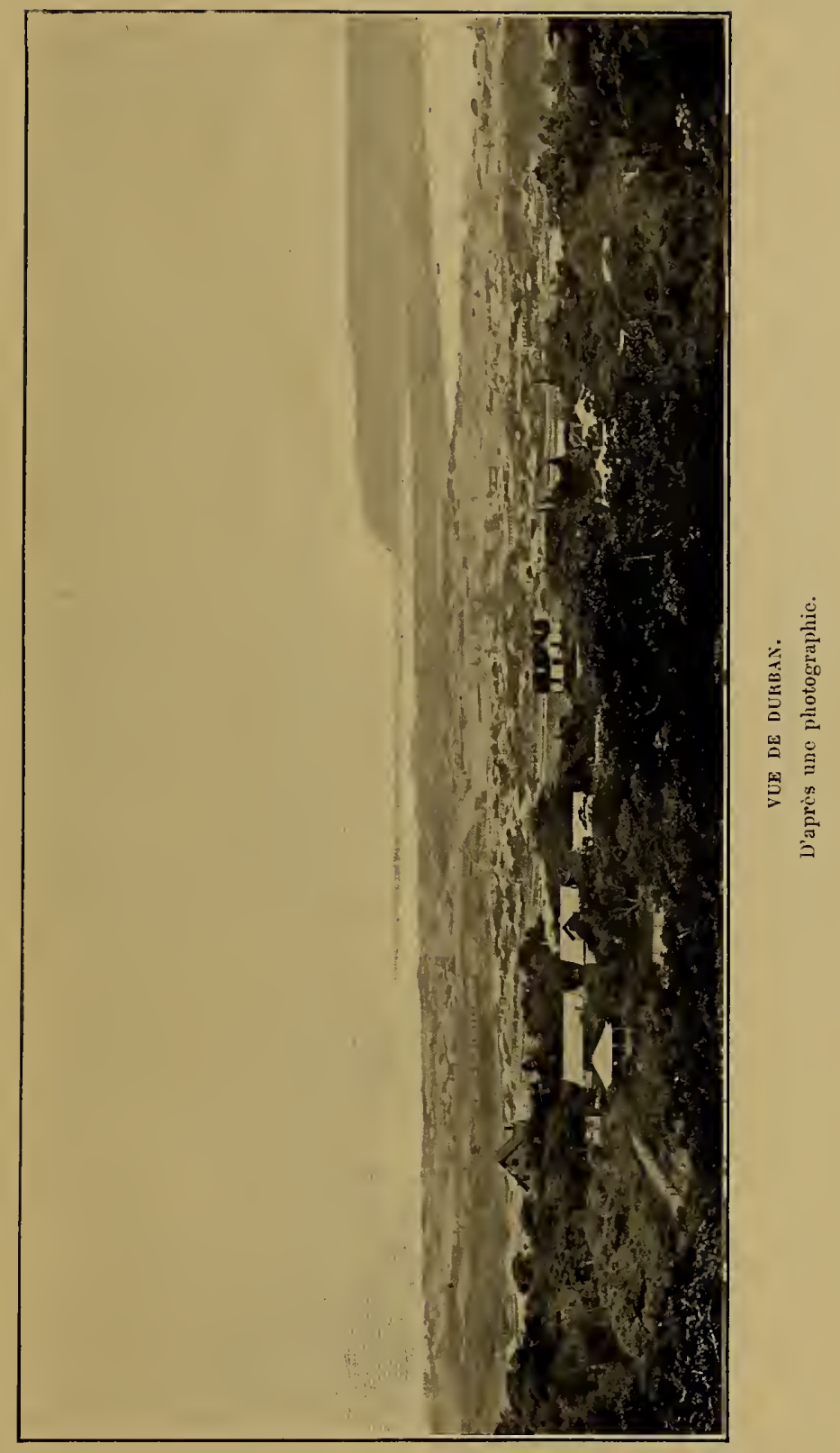



elles un espace variant de quatre pieds el demi it eing pieds et demi. Ces lignes sont jalonnées tous les quatre ou cincf pieds; des creux d'une pelletée de profondeur sont pratiqués auprès de elaque jalon, ils sont remplis d'une terre bien réduite et les jeunes plants de thé, qui ont élé semés et gardés à couvert pendant quelques semaines, sont alors repiquís par un temps humicle. La future plan-

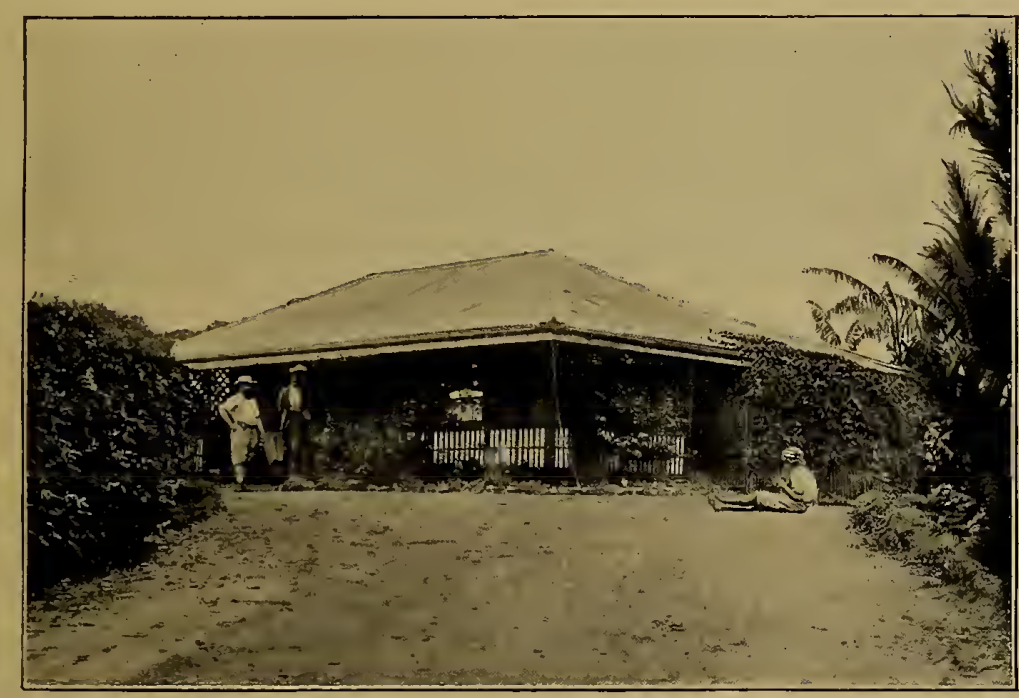

MAISON JE PLAYTELR.

D'après une photographie.

tation doit être très surveillée et le terrain drainé par des rigoles ì ciel ouvert. Des avenues d'arbres, souvent des bananiers, y sont établies afin de les protéger contre la force des vents.

Après la seconde année, les jeunes plantes se sont développées en arbrisseaux de trois à quatre pieds de haut; à ce moment, afin de leur donner une grande largeur et pour que les ouvriers puissent, au moment des cueillettes, accomplir rapidement leur travail, on les taille au sommet, à trois pieds au-dessus du sol.

La première cueillette de thé se fait dans le cours de la quatrième année, quand les pluies commencent à tomber. Pour les années sui- 
vantes, les récoltes peuvent se répéter tous les dix ou quinze jours pendant la saison humide, de fin septembre à fin mai. $\Lambda$ plusieurs reprises, nous assistons aux cueillettes. C'est un coup d'œil qui ne manque pas de charme que celui donné par ces lignes de jolis arbrisseaux vert foncé, tirées au cordeau, encadrées par de longues files de bananiers dont les feuilles claires retombent avec élégance. Sur ce fond de verdure se détachent les coolies hindous, drapés dans des étoffes aux couleurs voyantes et qui sous la direction vigilante du " sirdar ", entassent avec activité les feuilles tendres dans des sacs de toile; ils pincent seulement le sommet des jeunes pousses et ils enlèvent ainsi quatre ou cing feuilles à la fois.

Une plantation de thé en plein rapport fournit deux mille à deux mille quatre cents livres de feuilles vertes, par acre ${ }^{1}$ et par année. Quatre livres de feuilles vertes sont considérées comme l'équivalent d'une livre de thé préparé.

Un bon ouvrier peut cueillir de quatre-vingts à cent livres de feuilles journellement; la moyenne est de cinquante livres.

Actuellement, il y a dans le district de Kearsney, cinq manufactures de thé, où de nombreux planteurs envoient leurs récoltes de feuilles vertes deux fois par jour. Nous assistons dans l'une d'elles aux différentes opérations très délicates, par lesquelles les feuilles doivent passer avant d'atteindre l'état définitif, alor's qu'elles sont prêtes à ètre infusées pour donner l'excellent breuvage, que nous apprécions tous les jours.

Après que chaque sac a été pesé et marqué en présence du propriétaire, les feuilles, une fois parvenues à la manufacture, sont d'abord étendues sur des séchoirs en tôle sur lesquels passe un courant d'air 


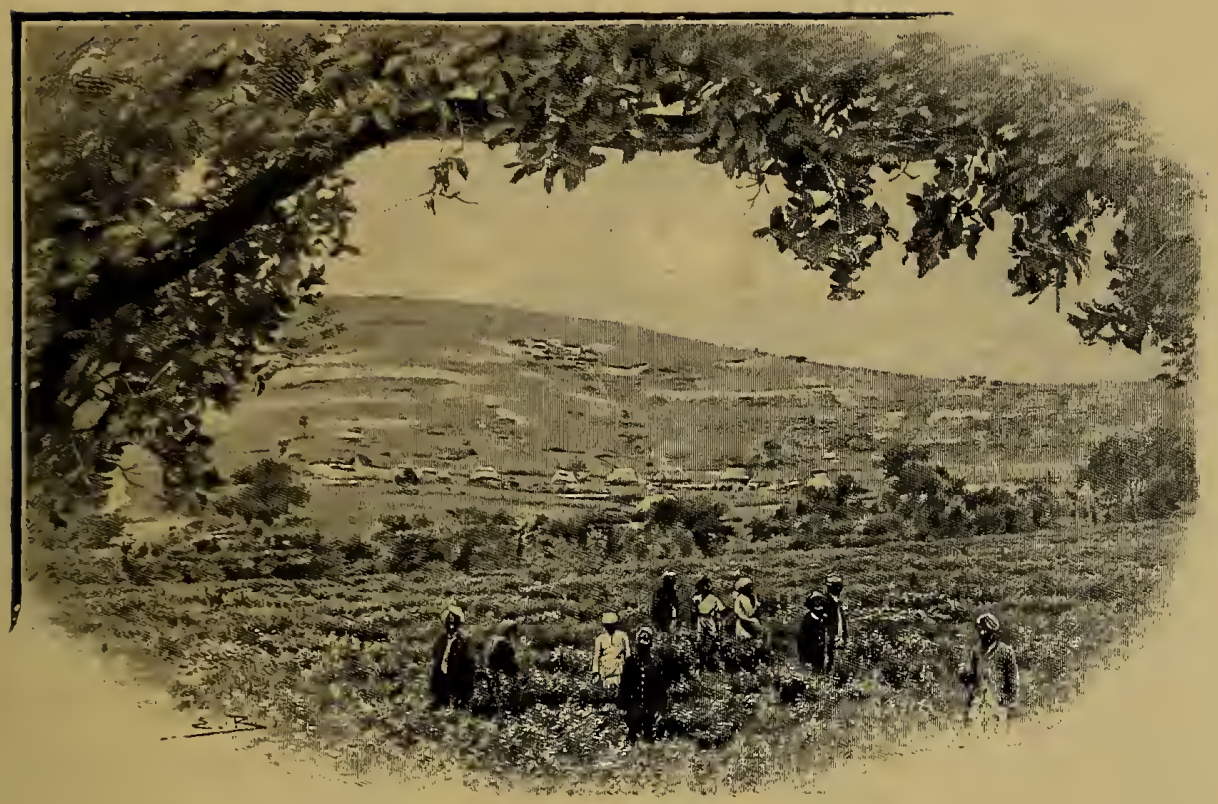

CUEILlETTE DU THÉ PAK LES COOLIES IHWHOCS.

Dessin de Boudier. D'après une photographie.

chaud, où elles flétrissent, dans un délai d'une vingtaine d'heures au maximum. Puis elles sont jetées dans le rouleau à vapeur par une ourerture centrale pratiquée au sommet de la partie supéricure. Cette ingénieuse machine est composée de deux plaques, qui se trouvent à une distance égale l'une de l'autre et qui sont mues circulairement. Son travail peut être comparé à celui que feraient deux mains gigantesques frottées l'une contre l'autre. On enlève alors ces feuilles pressćes et roulées en une masse, pour les placer ordinairement dans des caisses couvertes, pendant environ une demi-heure; il faut les surveiller soigneusement durant ce temps pour les amener au degré de fermentation nécessaire. Après cette fermentation, les feuilles acquièrent une riche et chaude couleur foncée ainsi que leur parfum spécial.

L'une des dernières opérations consiste à faire sécher le thé dans le " down draught sirocco ", machine à sécher. L'air chaud y est introduit par en haut dans une caisse en fer qui contient plusieurs tiroirs. 
Le thé fermenté est premièrement placé dans le tiroir du bas et il suit une gradation jusqu'ì ce qu'il arrive au tiroir le plus élevé, où l'opération du séchage se termine. Nous avons alors sous les yeux un thé préparé et sec. Par le moyen d'une autre machine, il est trié et assorti en trois qualités différentes; ensuite il est mis en paquets ct il est prêt à ètre expédié au loin.

Les coolies hindous qui travaillent dans ces plantations dépendent

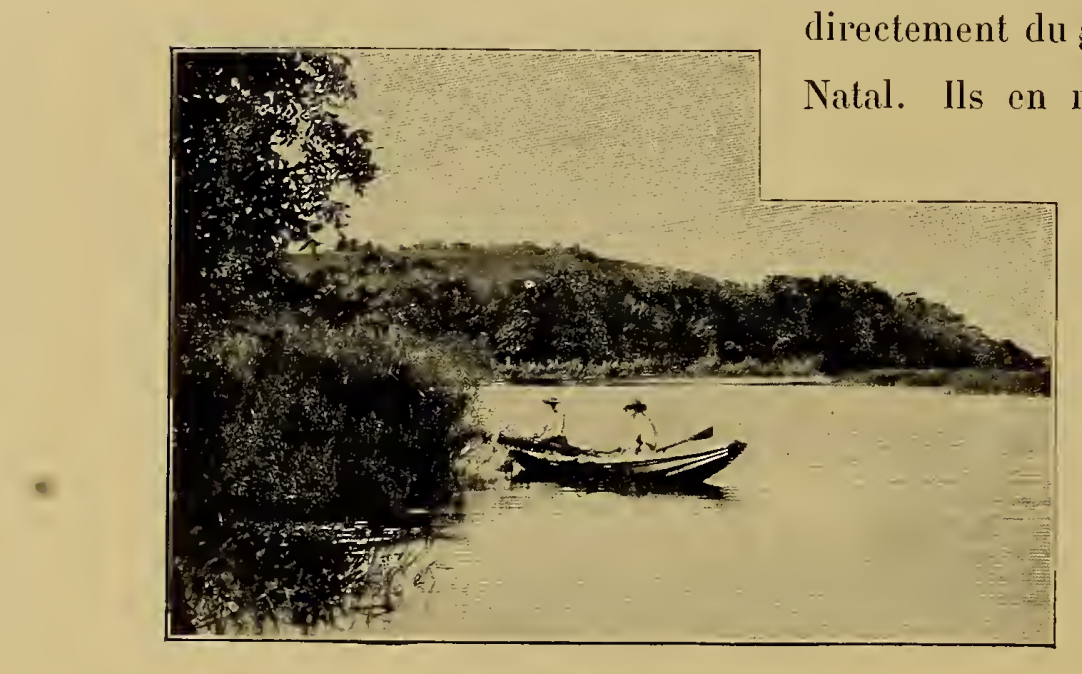

LA Rivière de mérindol (Natal). D'après une plotographie.$$
\text { Dapres une photographie. }
$$
directement du gouvernement du

$$
\begin{aligned}
& \text { protection, et } \\
& \text { c'est au "Protec- } \\
& \text { tor ", résidant à } \\
& \text { Durban, que s'a- } \\
& \text { dresse le plan- } \\
& \text { teur qui requiert } \\
& \text { leurs services. } \\
& \text { Les coolies } \\
& \text { sont recrutés } \\
& \text { principalement }
\end{aligned}
$$

dans les provinces de Calcutta et de Madras; ils signent un engagement de cinq années auprès du gouvernement. Ce temps expiré, ils peuvent de nouveau se réengager pour la mème période, année par année seulement, car les autorités ne désirent pas qu'ils s'établissent à poste fixe dans le pays. Ils font leur voyage, aller et retour payé. Ils reçoivent du planteur un salaire fixe, ainsi qu'un terrain sur sa propriété, où ils établissent leurs huttes et leurs jardins.Le planteur leur fournit en outre des vivres; la quantité et la qualité en sont déterminées à l'avance. En cas de maladie, les coolies sont visités par des médecins et soignés gratuitement dans des hòpitaux spéciaux. 
Le coolie qui a des plaintes a formuler peut se rendre auprès des magistrats locaux, ou bien attendre les inspections régulieres du "Protector" ou celle de ses agents. Le "Protector" a he plus, le droit, de visiter les livres que tout planteur doit tenir à jour et dans lesquels le travail et lo payement de ses coolies sont ronsignés, ainsi que le livret des malades; ce dernier pour témoigner de la visite du médecin. Le planteur ne peut pas, pendant la durée du contrat, renroyer les coolies de sa propriélé; mais il a le droit de sévir de différentes manières et il en réfère pour les cas graves, au magistrat.

Mon séjour tranquille, dans cette maison amie où l'hospitalité est si cordiale, au milieu de ce pays si bien partagé quant à la nature et au climal, offre un grand contraste avec les journées passées dernièrement à Johannesburg en pleine ébullition.

Nous sommes en été; à cette altitude (330 mètres) la température n’a jusqu'ì présent rien d'excessif, rafraîchie qu'elle est par des brises de iner. Les ananas, semblables à de grosses boules d'or', sont mûrs et nous allons en cueillir pour le déjeuner. Des millions de sauterelles viemnent de faire irruption à Natal. Leurs cohortes nombreuses se jettent un peu partout et font beaucoup de dégâts. Fait curieux, elles ne s'attaquent heureusement pas au thé. Pour les écarter, de grands feur sont allumés dans les campagnes et les coolies parcourent les diverses plantations en faisant le plus de bruit possible.

Nous avons récemment joui, du sommet du Red Hill, d'une vue splendide sur la contrée environnante : un véritable dédale de collines boisées et de verts vallons, bornés à l'est par l'océan Indien et au nord, par la chaîne de hautes montagnes qui court à travers le pays des Zoulous, dont nous voyons la frontière à vingt kilomètres environ. Les Zoulous sont réputés comme les plus vaillants guerriers de l'Afrique méridionale. 


$$
\text { *** }
$$

19 janvier. - Mujourd'luui dimanche, mon cousin et moi nous avons été invités, dans sa belle propriété de Kearsney, chez l’honorable J. Liege-Huet, membre du Parlement. Il a été l'un des premiers iniliateurs de la culture du thé dans le pays et il est actuellement le plus important planteur de Natal. Avant le repas du milieu du jour, M. Liege-Huet dit lui-mème un service religieux, simple et vibrant, dans la petite chapelle bâtie sur ses terres. Lorsque je le vis ensuite à table entouré de sa nombreuse famille, une vive image de la vie patriarcale s'éveilla soudain en mon esprit. Certainement, ce sont les hommes de sa trempe qui font la force et la grandeur de la colonisation anglaise.

$$
\because *
$$

23 janvier. - Pendant la dernière journée passéc à Mérindol, un mamba, serpent particulièrement venimeux, a été tué sur un arbre proche de la maison. Les sauterelles couvrent le pays; elles forment un tapis vivant et les belles feuilles des bananiers se trouvent dévorées en un clin d'œil. La verdure d'un cliamp de maïs voisin, mesurant cinquante acres, a en quelque sorte disparu.

M. Liege-Huet nous offre de nouveau l'hospitalité pour la dernière soirće que nous devons passer ensemble. Sa propriété est plus proche de Stanger, où passe à une heure matinale le " coach " à destination de Vérulam.

$$
* * *
$$

24 jancier. - Au moment de'monter en selle pour nous y rendre, nous apprenons que les places disponibles ont été retenues par les soldats de la garnison d'Eschowe à la frontière du Zoulouland, distante de quelques kilomètres. Comme les soldats passent toujours avant 


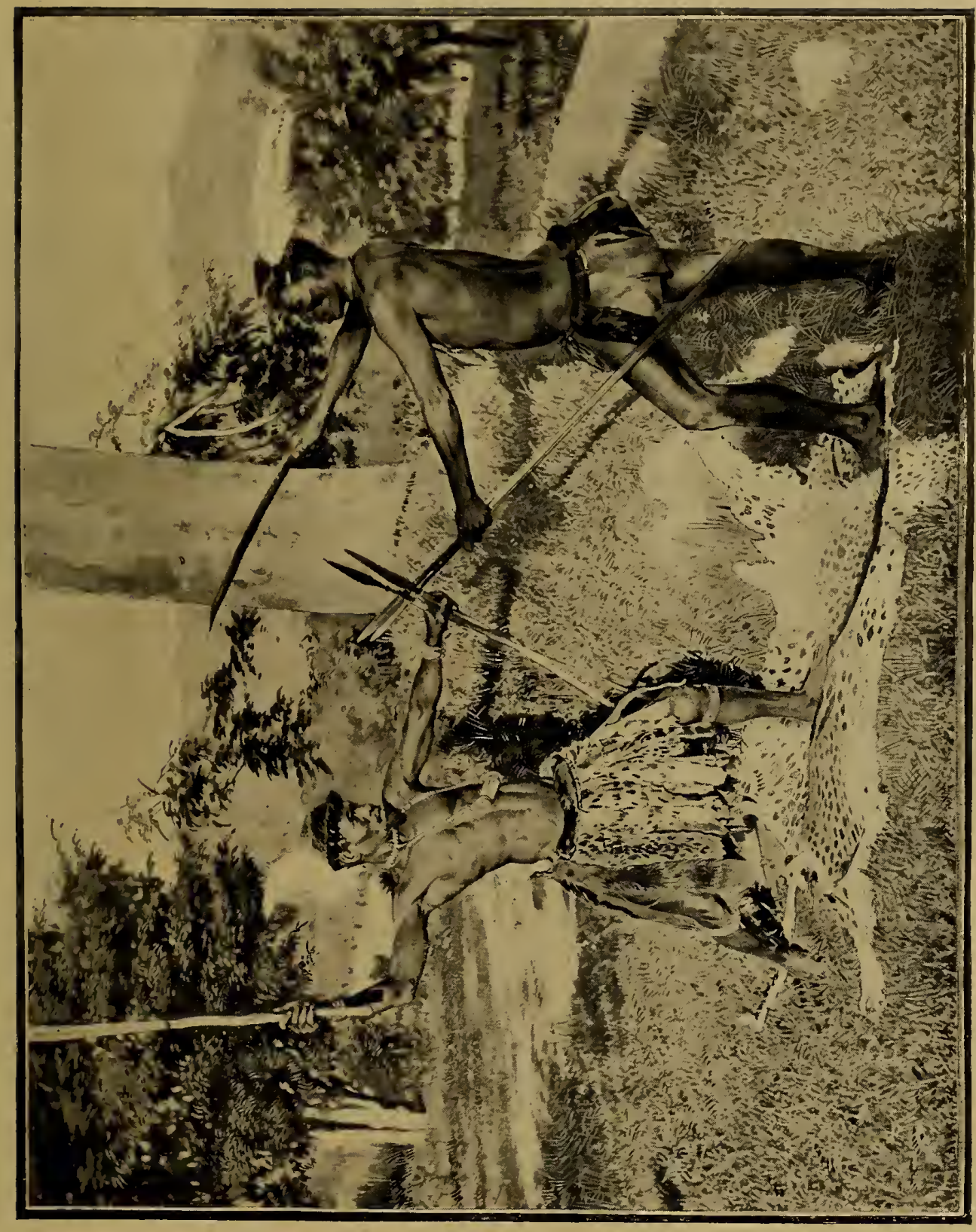

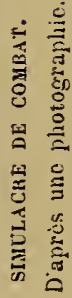





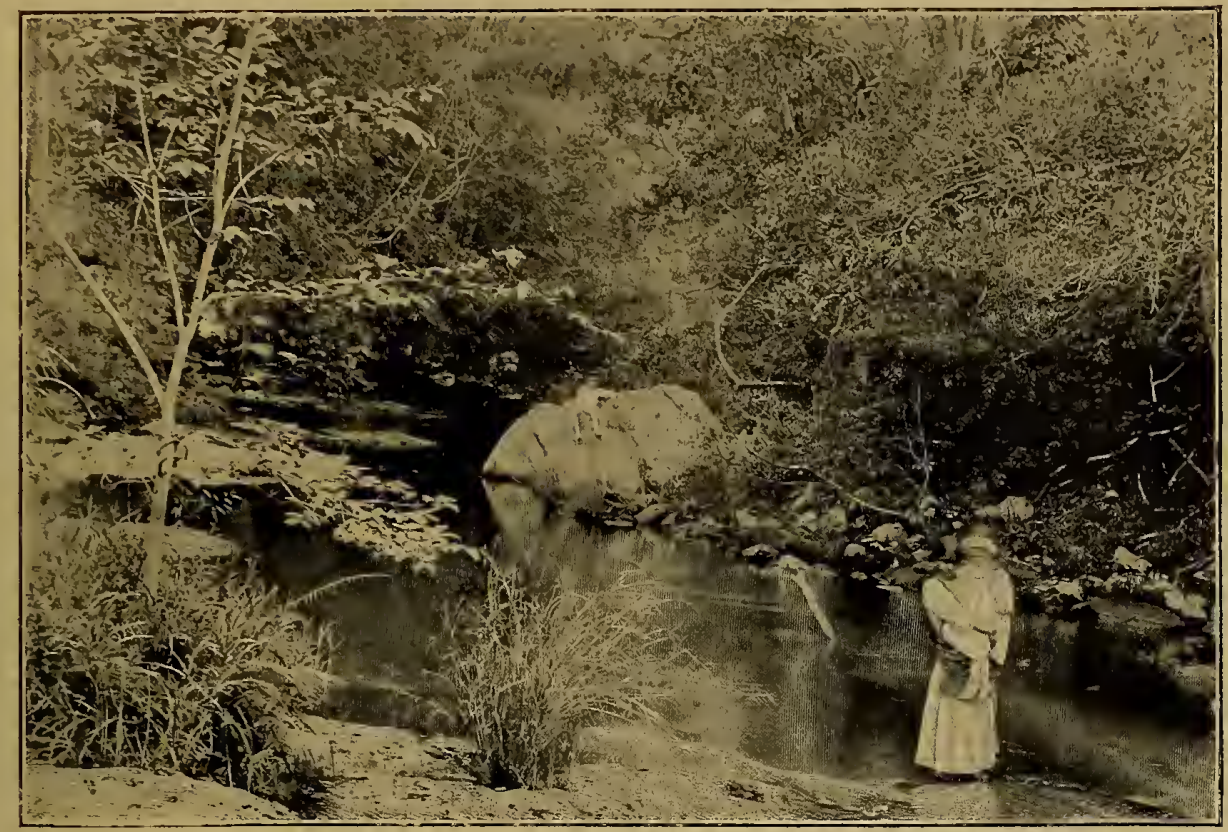

CN JOLI COIN PRÈS DE K:ARSNEY (NATAL).

Daprès une photographic.

les autres voyageurs, il n'y a qu'ì accepter le fait accompli. Je ne me lécourageai pas pour si peu et bien m'en prit, car arrivé à Stanger, un habitant me loua une voiture lígère attelée d'un cheval vigoureux. Prenant les rènes en mains, j’ai rapidement franchi les quarante-cinq kilomètres qui séparent cette localité de Vérulam, le terminus du chemin de fer, et j'arrive a temps pour prendre le train de l'après-midi.

Une lettre que M. Liege-Huet m'a remise au départ m'autorise à visiter en route la plus importante raffinerie du pays, la " Natal Central Sugar Company Factory "; bientòt je l'ai en vue et je descends à la station. Le bâtiment principal de la raffinerie est surmonté d'une cheminée de quatre-vingt-dix pieds de hauteur.

La canne à sucre est transportée par des wagonnets jusqu'au " roller", machine puissante qui la broie à deux reprises pour en 
extraire tout le suc pendant que le "baagas ", la partic fibreuse de la canne est rejeté à l'autre extrémité, où elle est séchée pour servir de combustible. Au moment du broyage, une véritable cascade de sirop remplit de larges cuves. Ensuite le fluide aqueux, verdâtre, est cuit dans des chaudières; après que de la vapeur d'acide sulfureux lui a enlevé ses principes colorants, il continue son voyage ì travers des clarificateurs qui le débarrassent des impuretés qu'il contient. La claux est en outre employée pour corriger son acidité naturelle.

Le liquide, ayant de nouveau passé par des filtres, arrive successivement à la "machine à triple effet ", où l'eau s'évapore et au "vacuum pans ", où le sucre se cristallise. Il faut qu'il soit refroidi avant d'ètre jeté dans l'une des seize machines centrifuges qui le séparent de la mélasse. Nous avons alors un beau sucre blanc de première qualité; il est séché et prêt pour le marché. La mélasse restante est cuite à nouveau et remise dans les centrifuges; le résultat donne un sucre de seconde qualité. Mème procédé pour la troisième; le résilu est distillé et employé comme engrais.

$$
\text { *** }
$$

24 janvier. - Pour rejoindre la maison de campagne de l'obligeant directeur de cette belle entreprise industrielle, il faut longer de nombreux champs de cannes à sucre. Il ma aimablement retenu che\% lui et ne me permet de le quitter que ce matin, non sans mavoir donné de nombreux détails sur la culture et le rendement de la canne.

$\Lambda$ ce jour, les plantations de cannes à sucre occupent dans la colonie de Natal une superficie de vingt mille acres de terain, qui donnent un rendement annuel de vingt mille tonnes, soit plus de qua- 


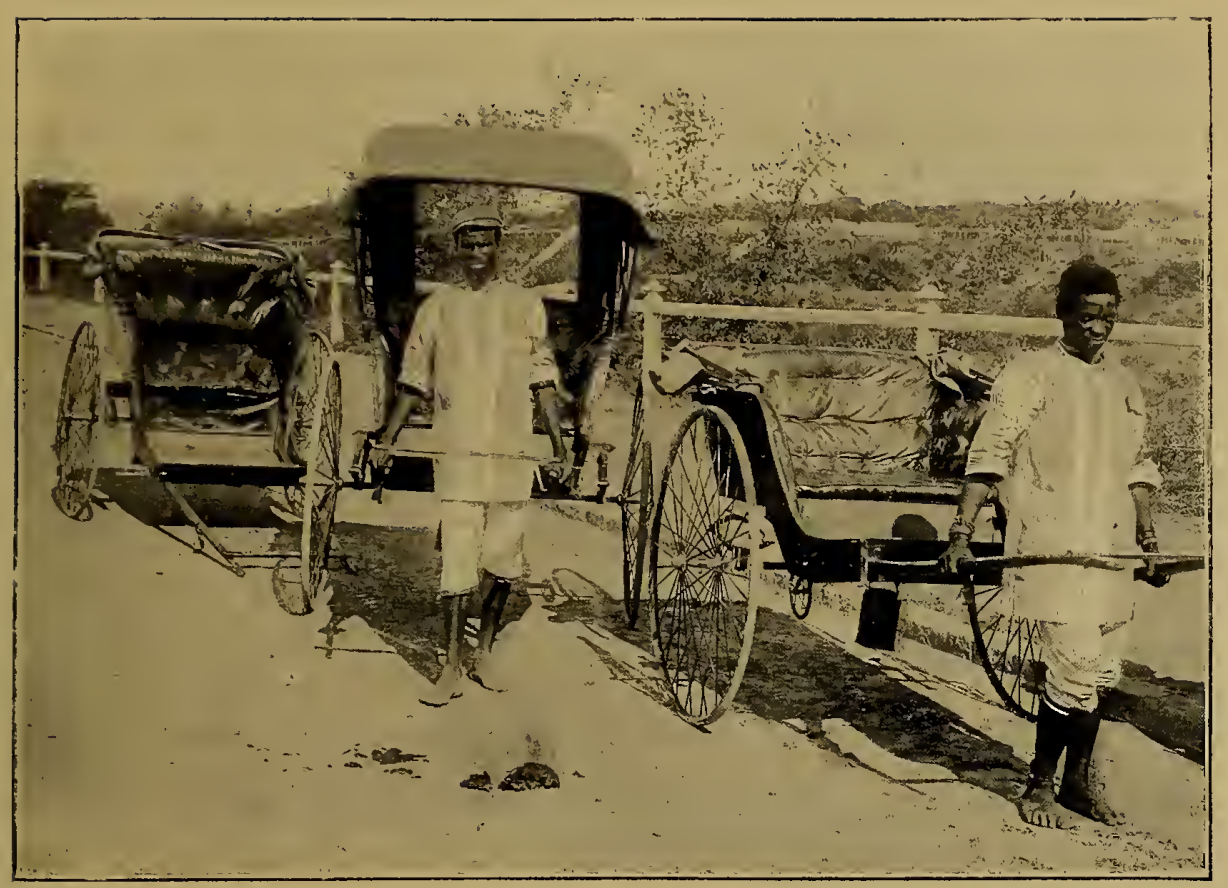

LES VOITURES DE DERBAX.

D’après une photographie.

rante millions de lives de sucre. Sur ce total, la "Natal Central Sugar Company Factory" cultive cinq mille acres, produisant par année quatre mille tonnes, soit plus de huit millions de livres de sucre.

Durban, avec sa population de 30000 habitants; est non seulement le port de Tatal, mais encore une place commerçante d'une grande importanee, et aussi la plus jolie ville de cette partie de l'Afrique. Elle est bien construite et d'une grande propreté. Le meilleur moyen pour la parcourir consiste à monter dans l'une de ces nombreuses petites roitures tirées à bras d'lomme qui circulent sans cesse, le mode de locomotion le plus pratique et qui rappelle les " djinrilishas " en usage au Japon.

Il ne faut pas oublier non plus de voir le marché, qui donne une 
idée de la richesse et de la variété des fruits croissant dans cet heureux pays. Suivant la saison, l'on y trouve les différents fruits européens mêlés aux bananes, ananas, naatjes, mandarines, citrons, oranges, mangoustes, guavas.

La ville s'étend le long de la baie, puis elle s'étage sur les flancs de la colline Béréa, où les plus gracieuses résidences se cachent au milieu des arbres et des fleurs des tropiques. De la Béréa, le point de vue est admirable; la baie semblable à un lac tranquille, est reliée à la mer par un canal qui baigne la base d'une falaise couverte de verdure, à l'extrémité de laquelle se trouve un phare: au delà, l'océan Indien, d'un bleu foncé. Les vagues qui rident sa surface semblent le franger d'argent et plusieurs grands navires ì l'ancre sont balancés doucement sur ses flots.

Durban fait honneur à Natal, l'une des colonies anglaises les plus favorisées de l'Afrique. Vasco de Gama a découvert ce pays le jour de Noël 1497; il l'a baptisé Terra Natalis. Sa superficie est égale à celles de l'Angleterre et du pays de Galles réunies, soit environ 32000 kilomètres carrés; elle est habitée par 45000 Anglais, Hollandais et Allemands, 40000 coolies hindous et 430000 a 500000 noirs.

Natal est, depuis le 23 juillet 1893 , une "self governing colony "; le gouvernement se compose de deux Chambres.

$$
*^{*} *
$$

26 janvier. - En mer! Quelle jouissance de respirer enfin la bonne brise salée!

Les sujets d'intérêt ne manquent pas à bord du Roslyn-Castle, steamer sur lequel je m'embarque à destination du Cap, ville où j'ai de nombreux bagages à réclamer ainsi que d'autres formalités à remplir. Nous avons, parmi les passagers, quatre-vingt-dix des hommes de 
Jameson qui ont pris part à la récente invasion du Transvaal, y compris trois officiers, prisonniers sur parole, sous la responsabilité de notre commandant. Ils seront débarqués dans les différents ports. Ces soldats, qui complent parmi eux quelques représentants de bonnes familles anglaises, semblent ìre forts et déterminés. Ils sont accoutrés de la façon la plus disparate, car ils ont presque tout perdu sur le champ de bataille. Quelques-uns pourtant sont encore revètus du coquet uniforme de leur régiment, du justaucorps et des culottes de cheval en "velvet cord " brun très clair. Comme coiffure, ils portent le feutre aux larges ailes, fièrement retroussé sur le côté gauche. Ils ont beaucoup souffert; mais ils se louent de la manière dont les Bocrs les ont traités lors de leur captivité à Prétoria.

L'un d'eux me montre le projectile reçu au feu qui, après lui avoir traversé le poumon, est ressorti par le dos. Heureusement pour lui, cette balle provenait du nouveau fusil, le Lee Metord. Les armes à petit calibre semblent, suivant les dernières expériences, moins meurtrières que les anciennes; leur force de projection est si forte que les balles, très minces et allongées, traver'sent les chairs sans les déchirer et sans briser les os.

Quelques heures après le déparl, nous avons en vue les côtes découpées et montueuses du Pondoland, l'une des récentes acquisitions de l'Angleterre. Voici en particulier la pittoresque embouchure de la rivière Saint-John (Umzimvubo); elle se jetle dans la mer, enclavée par de hautes falaises couvertes d'arbres.

Cette après-midi j'ai assisté à un incident caractéristique : un commandant boer et un groupe d'officiers qui ont pris part au raid de Jameson sont fraternellement assis à la poupe et conversent courtoisement, tout en discutant les fautes de tactique qui ont été commises de part et d'autre, lors de la dernière campagne. 


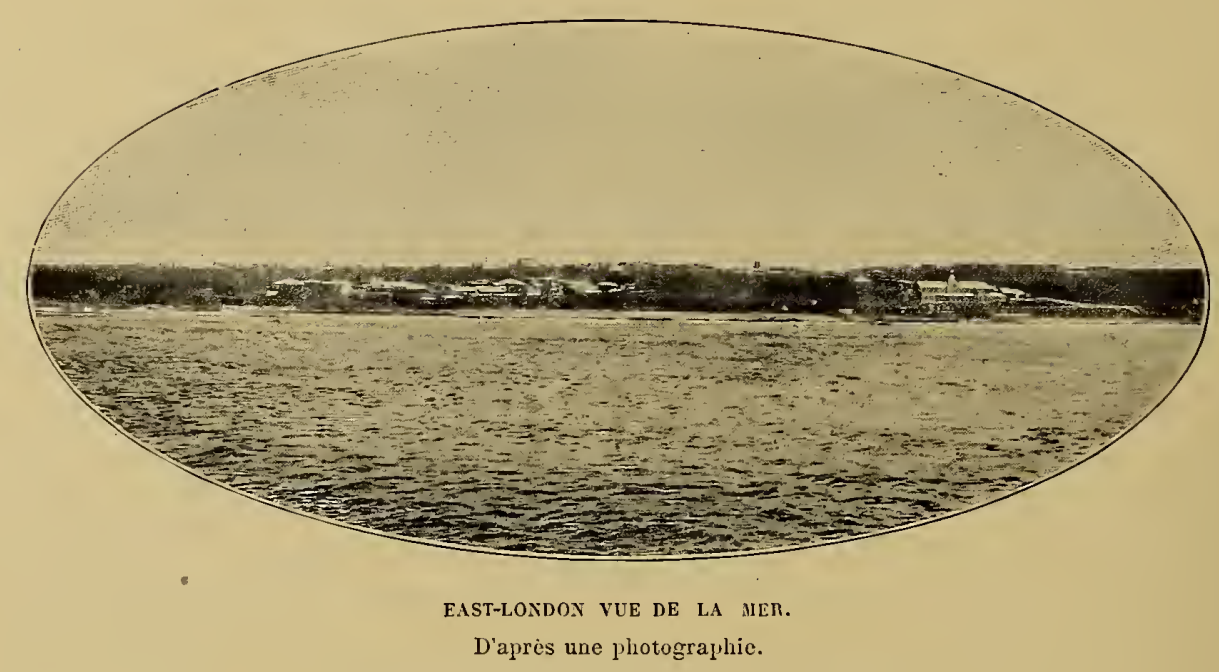

27 janvicr. - De bonne heure, nous stoppons près d'East-London, située sur les bords de la rivière Buffalo. La ville se dessine bien avec ses maisons aux toits rouges, gracieusement disséminées sur les flancs de la colline. Les steamers sont obligés d'amarrer à une certaine distance du rivage. La barre d'East-London a mauvaise réputation et les passagers qui veulent aller à terre sont descendus à bord du " tug " dans un grand panier fermé, mis en mouvement par une machine à vapeur; la mer houleuse ne rend pas cette opération facile à exécuter. Les vagues déferlent avec violence lorsque nous franchissons la barre, et une épave nous prouve que les naufrages n'y sont pas rares. Nous remontons la rivière Buffalo sur un espace de deux ou trois kilomètres; nous sommes bientòt à East-London, le troisième port comme importance de la colonie du Cap, ville bien construite, dont les vastes rues sont bordées de larges maisons à un étage. La plage non abordable, située à l'est de la ville, tapissée d'un sable aussi blanc que la neige, sur lequel viennent mourir les vagues de l'Océan, est superbe. 


\begin{abstract}
$* * *$
98 janvier.

- Le Roslyn-

cástle a em-

barqué un

fort chargement de ballots de laine. Dansla soirée nous reprenons la mer.

$$
*^{*} *
$$

29 janvier.

- Au matin, nous arrivons ¿̇ Port-Élizabeth qui,
\end{abstract} quoique bien situće au

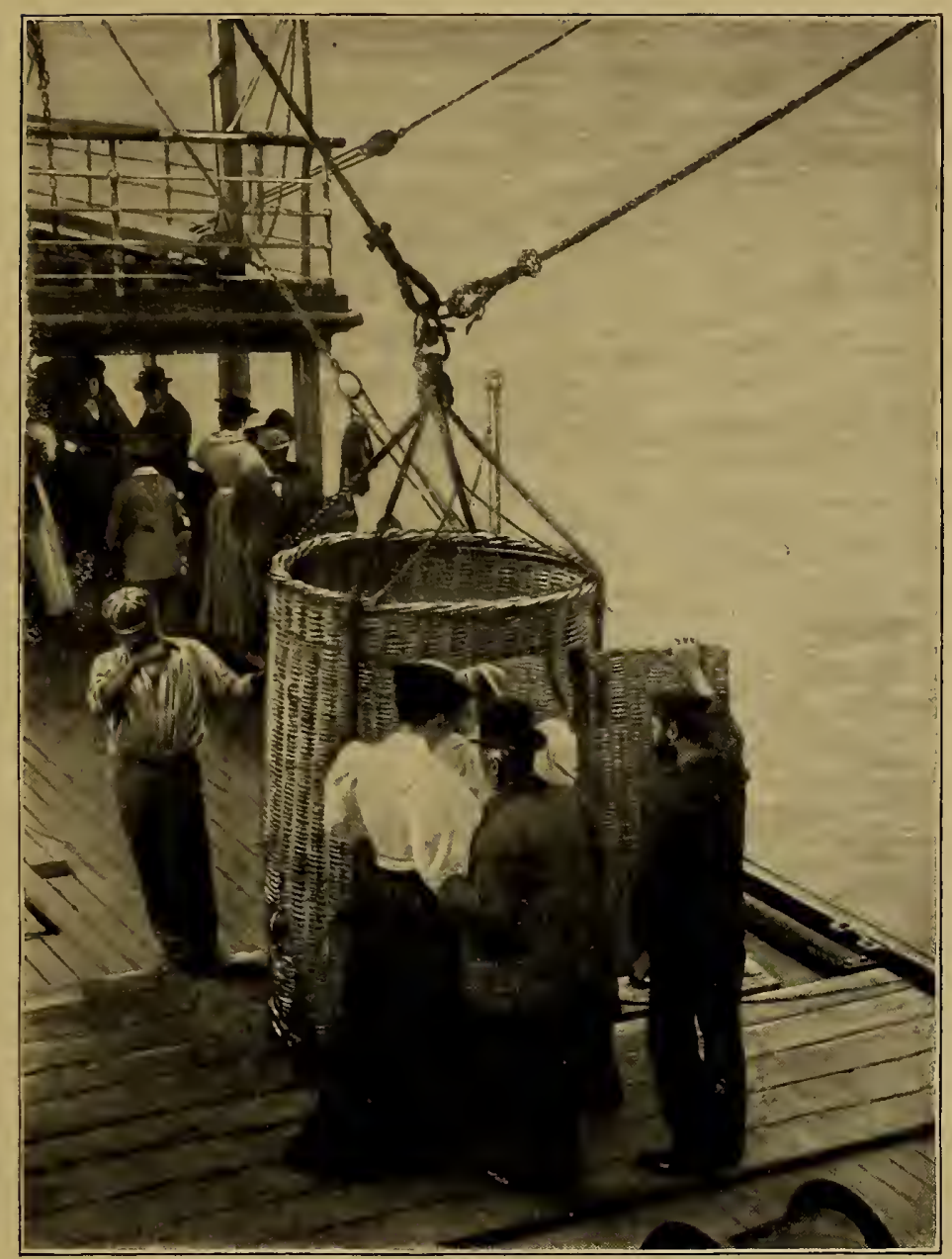
COMNENT L'ON DÉBARQLe A EAST-LONUON ET A PORT-Él.IZ.AEEII. Dessin de Thiriat. D’après une photographie.

nord-est du bon ancrage protégé des vents; le steamer doit y compléter sa cargaison et nous devons y rester quelques jours. L'un des passagers, M. G.-R. Halkett, de Londres, correspondant politique de la Pall Mall Gazette, homme des plus aimables et avec qui chacun peut être assuré d'apprendre des choses intéressantes, m'engage à l'accompagner aux montagnes du Zuurberg. Nous foulons bientôt une jetée où se 
dressent de nombreuses machines à vapeur, indice de l'activité commerciale de la ville et nous arrivons dans Main Street, la rue principale, à l'extrémité de laquelle se trouve l'hôtel de ville, orné d'une fontaine monumentale en forme d'obélisque, ainsi qu'un grand marché couvert où les plumes d'autruches sont vendues chaque semaine.

Une ligne ferrée nous mène en quelques heures, dans la direction du nord, à Coerney, où nous arrivons à la nuit noire et où nous trouvons un gîte dans l'unique petit hôtel de l'endroit. Coerney est fréquemment visité par des éléphants sauvages. Il y a en outre dans les environs plusieurs fermes pour l'élevage des autruches.

Le lendemain, nous voyons nombre de ces énormes oiseaux. Quoique l'autruche n'habite que l'Afrique, les belles plumes de cet animal ont été recherchées de tout temps et par toutes les nations du globe. Les Anglais les ont surtout appréciées depuis l'époque où le Prince Noir, après avoir tué le roi de Bohème à la bataille de Crécy (1346), enleva les plumes d'autruche qui flottaient sur le casque du vaincu et les plaça sur le sien; depuis lors les plumes d'autruche ont toujours figuré sur le blason du prince de Galles.

En 1860, les autruches sauvages, pourchassées, semblaient destinées à disparaître peu à peu, lorsque l'idée vint à quelques colons de les apprivoiser, d'en propager l'espèce et d'obtenir ainsi, gràce à leur plumage, une souree de revenus permanents. En 1865, on comptait dans la colonie du Cap et les environs, 80 autruches apprivoisées, tandis que le dernier recensement de 1891, donne un total de 154880 autruches domestiques. Cette énorme production fit baisser les prix d'une manière sensible; en effet, le recensement de 1882 nous donne un rendement de 253954 livres de plumes, représentant une valeur de vingt-sept millions de francs, tandis que celui de 1892 
indique un revenu de 237027 livres de plumes, qui ne sont pas taxíes à plus de treize millions de franes.

$$
\text { *** }
$$

30 janvier. - Au milieu de l'après-midi, nous montons dans un " cart " attelé de deux chevaux, eonduits par un nègre, à destination du col de Zuurberg. Nous ne tardons pas à traverser l'une des fermes mentionnées plus haut, où nous croisons de nombreuses autruches, noires, blanches, grises; vues de près, leur corps donne l'idéc d'une grande force de résistance. Les pattes bien musclées doivent ètre une arme redoutable; leur long cou est surmonté d'une tête très petite. De toutes jeunes autruches, couvertes de duvet clair, et qui ont déjà la taille d'un dindon, circulent gravement autour de leurs parents.

Nous ne tardons pas à arriver au flanc de la montagne couvert d'une belle végétation, émaillée elle-mème par de ravissantes plantes grimpantes, dont des milliers de fleurs bleues ont la forme de celles du jasmin; cà et la nous voyons encore des groupes de palmiers et d'euphorbes. Nous admirons plusieurs beaux points de vue; en arrivant au sommet du col, nous embrassons toute la vaste contrée qui s'étend jusqu'à l'océan Indien.

Le propriétaire de l'hòtel du Zuurberg Pass, M. S. D. B..., est un naturaliste; entre autres curiosités, il nous montre des cufs de l'Achatina :ebra, grand escargot de terre qui peut atteindre une longueur de trois quarts de pied.

La chaìne de montagnes où nous nous trouvons nous sépare du plateau de Karroo, distant d'environ trente kilomètres; si nous suivions la route que nous avons sous les yeux, nous arriverions à Kimberley. A cette altitude, 2300 pieds, les montagnes sont dépourvues de 
grands arbres; elles sont couvertes d'une herbe fine et leur configuration rappelle celle des " moors » de l'Écosse.

$$
*^{*} *
$$

$1^{\text {er }}$ février. - Nous reprenons la vie de mer à bord du Roslyn-Castle. Port-Élizabeth disparaît bientòt à l'horizon; elle est appelée, vu son grand commerce, le Liverpool de cette partie de l'Afrique.

La mer nous est propice; le 2 février nous mouillons non loin de Mossel-Bay, port excellent préservé des vents de l'ouest, à moitié chemin entre le Cap et son énergique rivale Port-Élizabeth. Dans la nuit du 3 février, nous doublons le cap Agulhas, l'extrémité géographique du continent noir; comme on le sait il partage, par le vingtième méridien de longitude est, les caux de l'Atlantique et celles de l'océan Indien. Au matin, nous passons au large du Cap de BonneEspérance, immortalisé dans les Lusiades par le poète portugais Camoëns. Quelques heures plus tard, les belles montagnes la Tête de Lion, la Table, le Pic du Diable, au pied desquelles Capetown s'étage coquettement, sont en vue et je me retrouve dans cette ville du Cap que j’avais quittée au mois d'avril 1893 .

$$
\text { *** } *
$$

Le Cap, 3-13 février. - Tout en mettant ordre à mes affaires, je profite de mon séjour au Cap pour me rendre compte par moi-même de certaines choses que j’avais dû forcément négliger à mon arrivée l'année dernière, telles la visite du vignoble.

Un jour je me rendis à Constantia pour voir les vignes qui s'étalent non loin de la côte sur les contreforts de la montagne de la Table. Contrairement à ce qui se passe ailleurs, je suis surpris de voir 


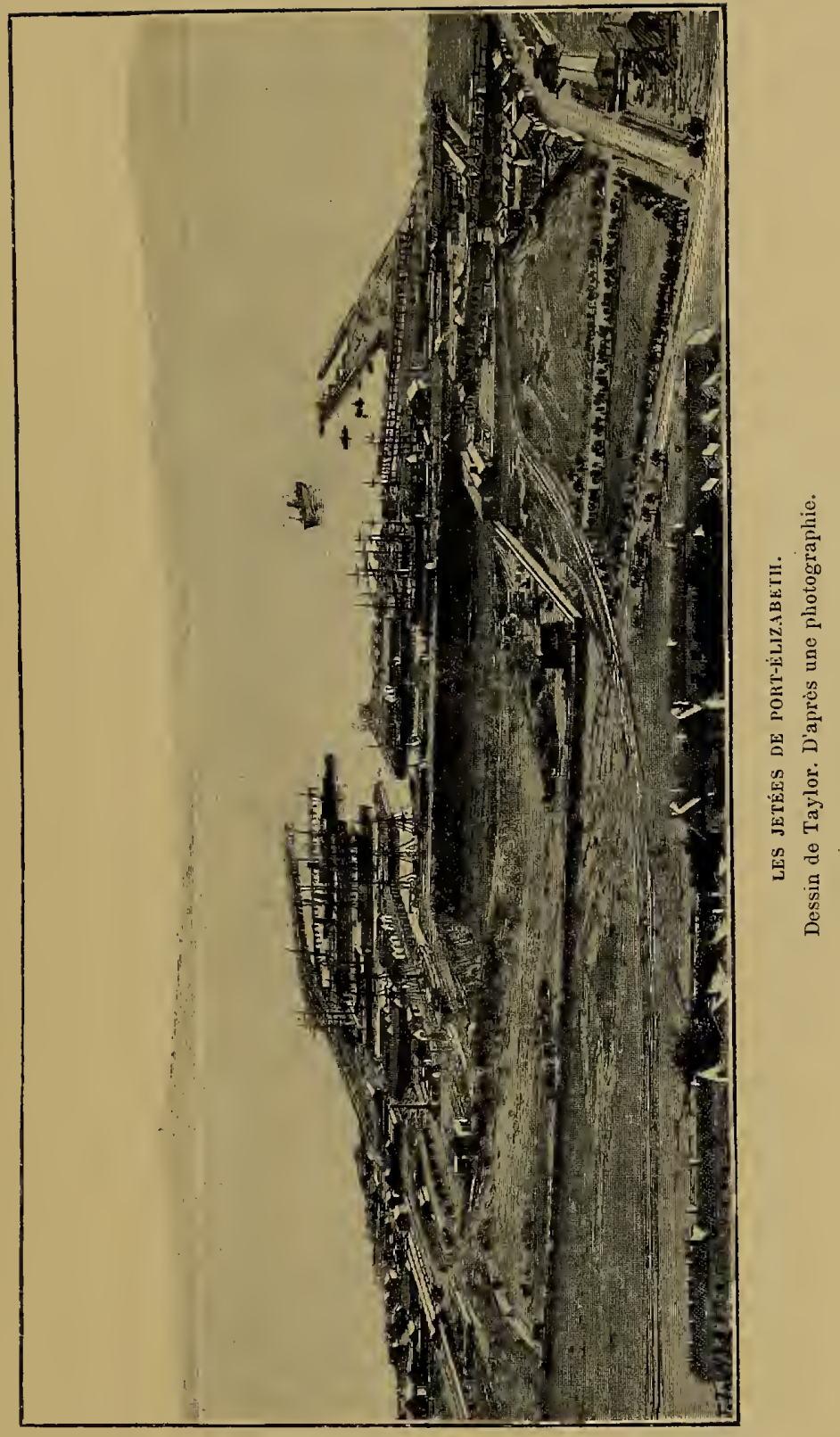



que chaque ecp, sans itre soulenu par un ćchalas, forme un petit arblisseau bien garni, de deux ou trois pieds de hauleur. Je puis déjì cueillir de l'excellent raisin muscat rouge; la vendange commencera dans une quinzaine de jours, ì la fin de février.

Il n'est peut-être pas inulile de remarquer que les colons du Cap, graice a leurs immenses vignobles, sont parmi les plus importants producteurs de vins du monde entier.

Le phylloxera y fait aussi de sérieux ravages, quoique des mesures énergiques aient été prises pour le combattre.

Il parait, chose intéressante, que les vignobles situés, comme celui que je viens de visiter, à proximité de la còte, ont peu souffert du redoutable insecte, parce qu'il est repoussé plus en avant dans l'intérieur du pays par les vents extrèmement violents qui soufflent de la mer.

Je me rendis un autre jour au Musée de la ville, remarquablement tenu. Il est à voir, ne serait-ce que pour admirer les superbes spécimens de la faune africaine, tombés sous les balles de Sealous, le voyageur si counu dans cette région.

Le directeur m’annonce qu'à son dernier passage, Reid a offert au Musée la belle collection de papillons qu’il avait rassemblée avec tant de peine et tant de persévérance pendant notre voyage.

$$
* * *
$$

12 ferrier. - Faut-il maintenant parler de "Groote-Shuur ", la splendide propriété du premier ministre du Cap; de "Sea-point ", la promenade pittoresque le long de la côte, et de tant d'autres particularités de ce curieux pays.... Non! Car voici en rade le Mexican de l'Union line, un steamer jaugeant 4600 tonnes, sur lequel je vais m'embarquer. 


$$
\text { *** }
$$

13-28 fevrier. - Quelle satisfaction, tout en respirant avec délices les vivifiants effluves maritimes et en jouissant du spectacle varié qu'offre l'Océan en ses aspects divers, de pouvoir se dire que le but proposé au départ de notre lointaine expédition, a été atteint.....

Elle se tourne, la dernière page de ce chapitre émouvant, dont le souvenir restera gravé au plus profond de mon âme.

A bord, un lien vivant me relie encore à cette terre africaine qui une fois entrevue, en dépit de tout, ne peut être oubliée. Sur ce navire, qui m'emporte vers les brumes du Nord, je retrouve des zèbres, des singes, des oiseaux de tous genres : malheureux captifs qui, au loin de leur lumineuse patrie, s'en vont peupler les jardins zoologiques de l'Europe. Souvent je vais les visiter et je les plains : plus jamais ils ne se mêleront à ces brillants escadrons qui, en un galop effréné, brûlent l'espace des solitudes immenses.... Une cage étroite, aux barreaux rigides, remplacera pour eux les splendeurs de la forèt vierge.... Ils ne pourront plus déployer leurs ailes sous l'immensité de la voûte azurée du ciel africain....

$$
\text { *** }
$$

$1^{\text {er }}$ mars. - Tout le monde sur le pont!... Le phare d'Ouessant, dressé sur les côtes de Bretagne, est en vue : avec son apparition dans la nuit, nous saluons la vieille Europe....

$$
\text { *** }
$$

2 mars. - Nous débarquons à Southampton.

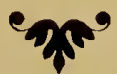


Pour terminer ce livre, je ne saurais mieux faire que de témoigner une fois de plus ì M. Coillard, le vénéré fondateur de la Mission du Zambèze, ainsi qu'ì ses Collaborateurs, ma haute estime pour la belle œuvre de civilisation chrétienne qu'ils ont entreprise au Pays des ba-Rotsi.

Je tiens, en outre, à remercier les Missionnaires du Zambèze de leur excellent accueil, à les assurer de mes sentiments d'amitić et des bons souvenirs que je leur garderai.

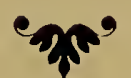



APPENDIGES 



\section{APPENDIGE I}

Voici, en résumé, quelques notes générales sur le royaume des ba-Rotsi, encore si peu connu. Je dois bon nombre de ces informations à la grande bienveillance des Missionnaires du Zambèze; d'autres sont le résultat d'observations personnelles.

Les ba-Rotsi ou ma-Rotsi, la tribu régnante, viennent du sud de l'Afrique; Histoire. ils ne connaissent ni l'époque, ni la région d'où ils sont partis; M. Coillard, le missionnaire-explorateur bien connu, pense qu'ils sont sortis du bo-Nyai, territoire voisin de celui des ma-Tébélé.

En 1823, les ma-Kololo quiltèrent le lé-Souto; ils s'avancèrent peu à peu au nord en guerroyant contre les Béchuanas, les ma-Tébélé ct d'autres peuplades. En 1840, ils traversèrent le Zambèze et vainquirent les ba-Rotsi, qui occupaient déjà le pays et qui furent assujetis aux ma-Kololo.

La domination des ma-Kololo fut cruelle; les chef's luttèrent entre eux; bientôt les vaincus se disposèrent à la révolte.

En 1864, les ba-Rotsi se soulevèrent, ayant à leur tète Sépopa, l'un des nombreux fils du roi Moramboa, qui avait été détrôné par les ma-Kololo. Poussés à bout par la tyrannie du roi Sépopa, les ba-Rotsi le tuèrent en 1877 et son neveu Nguana-Wina s'empara du pouvoir à son tour. Il en abusa à tel point qu'il dut. s'enfuir après huit ou dix mois de règne; Léwanika, le neveu de Sépopa, fut alors nommé roi. Après une révolution et une contre-révolution, le roi Léwanika a pu, depuis $188 \%$, assurer son pouvoir.

Dès leur arrivée dans cette contrée, les ba-Rotsi, race supérieure, s'établirent dans la plaine du bo-Rotsi, qui s’étend du village de Néjulona au 
nord, à celui de Séoma au sud, et dans les gorges du bo-Rotsi, qui comprennent le pays situé entre Séoma au nord et les rapides de Katima-Molilo, au sud. Ils soumirent peu à peu les tribus environnantes, aujourd'hui, au nombre de vingt-cinq ou trente. Je citerai entre elles :

Tribus. Les ma-Totéla, qui habitent le bassin inférieur de la rivière Loumbé [Lumbi], du Njoko et de la rivière Loanja; ils travaillent le fer et le bois; ils sont aussi agriculteurs, principalement les ma-Totéla du Njoko, qui élèvent du gros bétail.

Les ma-Soubia (masubia), pêcheurs et bateliers; leur territoire s'étend dc Sekosé jusqu'en amont de Kazoungoula ct dans le triangle formé par le Zambèze et la rivière Linyanti.

Les ba-Toka (matoka) vivent à l'est de Kazoungoula et, au nord, ils vont jusqu'à la rivière Nguézi [Umgwezi]; chasscurs et agriculteurs, ils possèdent peu de gros bétail, mais beaucoup de chèvres et de brebis.

Les ma-Nkoya campent dans les bassins supérieurs des rivières Machilé, Njoko et Loumbé; presque uniquement chasseurs, ils vivent des fruits de la forêt lorsque leurs flèches ne leur procurent pas de gibier.

Les ma-Shoukouloumboué (mashikoloumbwe) occupent la contrée à l'est des ma-Nkoya, soit le nord-est du pays; ils habitent ạussi les bords de la rivière Kafoukué; agriculteurs, ils élèvent du bétail à cornes.

Les ma-Mbounda, qui s'adonnent à la médecine, à la sorcellerie, sont groupés dans les différentes parties de la contrée.

Les ma-Kuangoa (Makwenga) vivent lc long de la rivière Louyi (Lui) jusqu’à Séfoula; ils travaillent le fer et ils possèdent du gros bétail.

Ces diverses peuplades émigrent souvent par groupes et sont réparties dans tout le pays.

La superficie du royaume des ba-Rotsi, est selon toute probalité, supéricurc Frontieres. à cellc de la France.

Sa frontière nord, inconnuc, doit toucher à la ligne du partage des eaux du Congo et du Zambèzc; à l'est elle confine à la rivière Kafoukué et à l'ouest, au $20^{\text {e }}$ degré de longitude est de Greenwich; sa frontièrc sud est formée naturellement en partie par le Zambèze ct le cours du Linyanti.

Par conséquent, le bo-Rotsi est approximativement compris entre le 12e et le $18^{\circ}$ degrć de latitude sud et le $20^{\circ}$ et le $29^{\circ}$ degré de longitude cst (Grecnwich).

Prèrogatives Le roi, autocrate absolu, a droit de vie et de mort sur tous ses sujets. du roi. Les habitants, lc sol et ce qu'il renferme, y compris les produits de la tcrre, 
les poissons de la rivière, ainsi que le gibier, tout appartient théoriquement au roi.

Les questions importantes eoneernant la sùreté de l'État, le gouvernement de ses sujets, lui sont soumises; il rend souvent la justiec le matin et l'aprèsmidi au lékhotla, "l'assemblée délibérative "; ses jugements ont foree de loi; il représente à lui seul le tribunal, la cour d'appel et la eour de eassation. Dans les causes ordinaires, on lui communique la décision des chefs. Tous les hornmes peuvent assister au lékhotla.

Le royaume des ba-Rotsi est divisé en ee que nous appellerions en Europe, des arrondissements. Les grands ehefs sont ehoisis par le roi et ils sont en Administration. majorité ba-Rotsi.

Ces grands ehefs doivent demeurer dans la eapitale et prendre part au lékhotla présidé par le roi.

La polygamic a, dans ec pays, un rôle politique important; en effet, chaeune des femmes du roi représente une tribu ou un groupe de villages.

Des chefs subalternes, élus aussi par le roi, résident dans les villages, où ils reçoivent les ordres de lcurs ehefs supéricurs; ils règlent les aflaires eourantes et veillent à ee que les tributs ou impôts soient apportés régulièrement au roi.

La représentation de la proprićlé de ehaeun de ees ehefs est réglée par son rang. Personne ne peut eonstruire de hutles, porter des ornements aussi Règles hiérarchiques. coûteux que ceux de son supéricur en dignité; en particulier les peaux des lions, léopards, ehats sauvages, loutres, reviennent directement au roi, qui les distribue d'après les règles hiérarehiques en usage dans le pays.

Les épingles et les braeelets d'ivoire, eertaines formes d'ustensiles de ménage, une eoupe de eheveux partieulic̀re et la eoutume du limage des dents, sont réservés à l'usage exclusif de la famille royale.

Il en est de même pour toutes les eatégories de chefs. Il est inutile d'ajouter que ces derniers vivent en général d'exaetions et de pillage.

Le nom des villages ou divers rassemblements de huttes, est déterminé d'après le nom du ehef. Los ehefs peuvent enlever dans l'ẹnsemble des familles, Esclaves. dont les membres ne sont pas des ba-Rotsi, un enfant qui devient alors eselave. Il doit tout son travail à son maitre, qui a droil de vie et de mort sur lui; il ne peut être libéré que par le roi. Le roi et sa sœur aînée, la reine Mokouaé, reçoivent aussi chaque année, eomme tribut, un convoi d'enfants des deux sexes, qui deviennent leurs serviteurs.

Suivant leur bon plaisir, ils cèdent ceux de leurs serviteurs dont ils n'ont pas besoin, à leurs chefs ou à d'autres personnes. 
Les ba-Rotsi, eux-mêmes, ne peuvent pas être réduits à l'esclavage.

Razzias. En temps de guerre, des razzias sont opérées en grand; les esclaves doivent être présentés au roi avant d'appartenir à leurs maîtres.

Corvées. Tous les sujets du roi, excepté les ba-Rolsi, sont corvéables. Les champs de Léwanika, qui couvrent le pays, sont cultivés par les corvéables. Ce sont en général des femmes qui travaillent la terre ct construisent les huttes.

Du haut en bas de l'échelle hiérarchique, les chefs peuvent exiger des corvées et le malheureux qui dépend souvent de plusieurs maîtres, doit, à première réquisition, quitter son propre travail; il ne peut réclamer aucun payement ni aucune nourriture.

Les corvées comprennent aussi les services de messagers, de bateliers, de pêcheurs, de chasseurs, de porteurs, de coupeurs de bois, d'herbe, de roseaux, etc.

Tributs et

Les Maboutou.

Les

Likomboa.

Gambèla ou Premier Ministre.
En ontre, certaines peuplades doivent annuellement au roi un tribut déterminé de canols, de bois de construction, de bétail, de grain, de lait, de miel sauvage, de poisson, de gibier, de peaux de fauves, de fers de lances, de houes, de haches, elc. Coutume singulière : lorsque les tributs sont apportés au roi, il en prélève lui-même de nuit ce qui lui convient; ils sont ensuite transportés sur la place publique où le roi s'en approprie encore, par un second choix, une partic, puis il distribue le reste à ses chefs.

L’ivoire constitue l'un des revenus les plus imporlants du roi Léwanika; on peut calculer que la livre d'ivoire vaudrait à Léalouyi de 6 à 7 francs.

Les maboufou sont en général des fils de chefs, des jeunes gens dont le roi fait sa garde personnelle. Ils sont âgés de quinze à trente ans; ils couchent devant la porte du roi ou dans les environs immédiats de sa résidence. Chacun a une tâche spéciale; les uns sont chargés de préparer la nourriture du roi, de couper son bois, de piler son grain, tandis que d'autres nettoient ses fourrures, sa literie; ils doivent suivre le roi dans tous ses déplacements.

Les Maboutou peuvent devenir des cliefs plus ou moins importants, des sortes de gérants, et suivant leurs capacités arriver à la dignité de likomboa. Cie sont des hommes de tout âge, que le roi choisit lui-même et qui sont ses serviteurs personnels. Ils ont leurs huttes à part; ils surveillent les différents services de la maison du roi, font travailler ses esclaves, serrer le grain dans les greniers; ils inspectent le bétail; leur situation est très enviée et très appréciée. Au point de vue politique, les likomboa doivent toujours prendre le parti du roi; au lékhotla, ils sont assis à sa gauche.

La charge du pays la plus en vue est celle de gambéla ou premier ministre qui reçoit les affaires et les présente au roi sous leur forme la plus brère. 
Puis vicment d'autres ministres. Les membres de la famille royale prennent part au lékholla.

Inconséquence curieuse déjà mentionnée, chez les ba-Rotsi oủ, comme dans toutes les contrées non soumises à l'influence du christianisme, la femme est très loin d'ètre l'égale de l'homme, la socur aînée du roi jouit pourtant des mèmes droits que son frèrc, les mèmes tribuls lui sont payés; ellc porte le titre de Mokouaé, soit de reine; ellc a unc résidence particulière.

La liste des ehâtiments et des supplices scrait bien longuc à énumérer : pour rien, un relard, un ordre mal cxécuté, un ustensile brisé, le scrvitcur, l'csclave, l'cnfant, aura le cou serré par les mains du maître jusqu'à tombcr

\section{Châtiments et Supplices.} à tcrre sans connaissanec; quclqucfois le malheureux ne revicnt pas à la vic; comıne cela est arrivé récemment à Séshéké, où, sur l'ordre de la princesse, unc servante qui sélait servie d'un objet qu'elle n'aurait pas dû toucher, fut punie de ectte manièrc. Que dire aussi de la terrible courbache dont chaque coup entame la chair!

L’annéc dernière, une pelite fille de Kazoungoula vola du maïs; la propriétaire du champ, unc femme âgée, saisit l'enfant et lui mit la main dans le feu jusqu'ì ee qu'elle fût carbonisée; l'cnfant mourut le lendemain.

Un voleur de chèrres fut puni d'une autre manière : le malheureux cut les mains ct les pieds liés, puis pendant tout un jour, il fut couché sur le dos. la face au soleil ardcnl; le chcf, à la fin de la journée, ne considérant pas la punition comme suffisante, lui coupa de ses propres mains les deux oreilles.

Un malfaiteur sera ligolté, puis placé sur le passage d'une colonne de sérouri, les terribles fourmis guerrières, et il sera graducllement dévoré vivant par elles. $\Lambda$ Léalouyi II. Coillard est pourlant arrivé à supprimer l'épreuve terrible de l'eau bouillante; le malheurcux, accusé d'avoir jcté un mauvais sort à l'un de ses semblables, devait tremper scs mains dans de l'eau en ébullition. Une fois les mains échaudées, l'aceusé étail placé de force sur un chevalet et un poison violcnt lui était administré; puis il était brûlé vivant encore.

Quant à la religion naturelle des Zambézicns je ne puis pas mieux faire Religion. que de reproduire, arec son aulorisation, l’appréciation de M. Coillard.

"Chez les Zambézicns, le sentiment religicux est plus développé que dans aucune autre tribu de ectte partie de l'Afrique. Sans avoir d'idoles et de fétiches ils renḍcnt hommagc non sculement aux mânes de leurs ancêtres, qu'ils eonsultent ou apaisent au besoin par un sacrifice, mais aussi à un être suprême (Nyambé) qui symbolise le soleil et dont la fcmme est symbolisće par la lune. 
Celte femme dans la nuit légendaire était devenue l'épouse de leur dieu. Elle donne naissance aux animaux puis à l'homme. Bientôt il y eut conflit entre Nyambé et l'homme. Nyambé manifestait sa puissance en ressuscitant les animaux que l'lıomme mettait à mort; mais, d'un autre cỏté, I'homme était si intelligent que Nyambé prit peur et se sauva au ciel par une toile d'araignée; c'est depuis lors, disent-ils, qu'il est invisible. Les indigènes de certaines tribus croient à la métempsycose, et de son vivant, chacun choisit l'animal dont il reut revêtir le corps, puis se soumet à un rite d'initiation qui consiste à avaler les vers de la chair corrompue de l'animal de son choix; il participe dès lors à sa nature. Aussi à l'occasion d'un deuil, pendant que les femmes se livrent à certaines lamentations, vous voyez un homme ramper à terre comme un boa ou un crocodile, un autre ricaner et bondir comme une panthère, un troisième aboyer comme le chacal, rugir comme le lion ou grogner comme l'hippopotame et imiter à la perfection le caractère de ces différents animaux. "

Superstitions et

Sorciers.

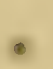

et Folygamie.

La Naissance.
Les ba-Rotsi sont très superstitieux et ils portent des amulettes, consistant en morceaux de bois, de corne, d'écorce, des graines, soit pour éloigner leurs ennemis, soit pour d'autres motifs; ils croient que s’ils ne sont pas aussi adroits au tir que les blancs, la raison en csl que ces derniers portent au poignet un charme quils ne connaissent pas.

Ils déposent des médecines dans les empreintes des bêtes féroces pour arrêter leurs approches. Avant de faire traverser le fleuve à leurs troupeaux, ils jettent une médecine à l'eau afin d'écarter les crocodiles; ils possèdent des charmes de différentes espèces, même pour se préserver des sauterelles!

Des griots ou sorcicrs voyagent de village en village avec des remèdes, qu'ils font cuire dans de grands pots, pour faire pleuvoir.

Ils croient que les morts reviennent sous la forme de serpents, de hyènes, de crocodiles, pour tourmenter les vivants.

Avant de partir pour la chasse ou la guerre, un chef ira au tombeau de son père; il y déposera sa lance ainsi qu'un baquet plein d'eau, puis il intercédera auprès de ses mânes.

On amène le bétail près des tombes afin d'obtenir sa fécondité.

Les liens de la famille, en dehors de l'influence chrétienne, sont très relâchés. La polygamie est pratiquée; les femmes, dont la condition est très inférieure à celle de l'homme, doivent travailler aux champs et nourrir leur mari; elles ne mangent jamais avec lui et elles le servent. Les mariages se font et se défont facilement; il en résulte beaucoup d'immoralité.

Excepté pour un enfant royal, la naissance n'est pas considérée comme un 
événement henreux; l'élat civil n'existc sous aucune forme; sculs les missionnaires l'ont introduit dans leurs stations. Les enfants sont abandonnés à enxmèmes; très jeunes ils doivent se tirer d'affaire. Chez les ba-Rotsi, les vieillards sont respectés et consultés, ce qui n’est pas toujour's lo cas pour dautres peuplades soumises.

Lorsqu'un chef vient à mourir, il est immédiatement enveloppé d'une couverture et mis en terre peu d'heures après son décès; si le décès a lieu dans la journée, il est enseveli au coucher du soleil; s'il est mort pendant la nuit, il est entcré arant l'aurore. On n'attend pas toujours la fin d'un moribond pour creuser sa tombe et il arrive qu'il ràle encore lorsqu'on l'ensevelit. Ses femmes cnlèrent tous leurs ornements et amulettes, elles pleurent le mort pendant trois jours et trois nuits, au bout desquels les huttes du chef sont démolies, et la chevelure de ses femmes est rasée. Ces femmes deviennent alors la propriété du chef qui remplacera le défunt.

Les ba-Rotsi n'ont en général pas de cimetières et chacun peut ensevelir ses morts où bon lui semble; un chef considère comme un honneur d'être enseveli au milicu de son kraal, c'est-à-dire dans l'enceinte à bétail. Les gens du peuple respectent la tombe de leur père; ils s'y rendent dans les grandes occasions.

Les tombeaux royaux sont entourés d'une haie d'arbres verts; ils sont considérés dans le pays comme des sanctuaires, qui sont invoqués aux périodes de calamilés, de maladies, de sécheresse. Du bétail et du grain y sont sacrifiés. En temps de guerre, les armes y sont portées pour qu'elles soient bénies.

Le type de la population varie à l'infini suivant les différentes peuplades. Il y a un grand mélange de sang entre elles.

La race supérieure des ba-Rotsi est composée en général d'hommes plutôt grands et bien constitués : leur front est souvent bombé, les yeux intelligents, l'ovale de la figure assez régulier, la barbe clairsemée; les lèvres ne sont pas très épaisses.

Les femmes s'enduisent parfois le corps d'une graisse qui leur donne une teinte claire el bronzée.

Parmi les riverains du Zambèze, nous voyons des individus superbes et à puissante musculature. Nous avons rencontré sur les bords du Njoko, des ma-Totéla, lesquels abstraction faite de leur peau, avaient une sorte de ressemblance avec le type juif.

Considérés dans leur état naturel, les ba-Rotsi sont légers et immoraux, généreux par intérêt, ironiques et moqueurs. Nullement prévoyants cn temps d'abondancc, ils savent se contenter de fort peu de chose en temps de disctte. 
lls sont très habiles à travailler le fer et le bois; en un mot industrieux, intelligents, observateurs. lls sont excellents rameurs et bons marcheurs.

Langage Le sé-Rotsi, l'une des nombreuses langues bantoues, est le langage officiel. Littérature. Il n'est pas écrit. Les ba-Rotsi sont polyglolles et presque tous comprennent le $s \dot{e}$-Kololo, une corruption du sé-Souto; ils se servent volontiers de plusieurs idiomes en modifiant les mots; en outre, de nombreux dialectes sont parlés par ces diverses tribus.

Leirr litlérature consiste en contes et en cliants, qu ils se transmettent oralement de père en fils, et qui se rapportent à des hauts faits de guerre et de chasse.

Musique. Ils possèdent plusieurs instruments de musique, entre autres le sérim/a, qui se compose d'une rangée de calebasses évidées, sur lesquelles sont placées des planchettes de bois sonore, qui sont frappées par le moyen d'un petit marteau. Ils ont différentes espèces de tambours; de plus le kangombio, formé de dix lamelles de métal fixées à une plaque de bois dur, qui est à son tour posé sur une calebasse évidée; ces dix lamelles produisent une octare mineure. Les ba-Rotsi emportent ce dernier instrument avec eux en voyage; le soir, à notre bivouac, sourent un homme de la troupe racontait, en chantant et en s'accompagnant du kangombio, les incidents qui s'étaient passés pendant la journée; cela produit une sorte de mélopée triste et parfois très douce.

Art. Chez les Zambéziens, l'art est encore dans sa première période; ils font pourtant de jolies ornementations sur bois el sur métal et ils sculptent l’ivoire. Avec la racine d'un arbuste, ils tressent des paniers dont la finesse, la forme et les dessins, dénotent déjà un sens artistique prononcé.

Industrie. $\Lambda u$ point de vue industriel, les Zambéziens sont tris habiles à travailler le bois et le fer; grâce au minerai de fer, qui existe dans le pays à l'élat presque pur, et qu'ils travaillent dans des hauts fourneaux de leur invention, ils arrivent à aroir un métal résistant. Quoique leur outillage soit plus que rudimentaire, ils fabriquent des armes, des lances, des haches, des couteaux excellents.

Les ba-Rotsi ont aussi des aptitudes spéciales pour tout ce qui est travail mécanique et M. Coillard roudrait arriver à développer les indigènes dans ce sens, en fondant une école industrielle.

Avec l'écorce d'une plante qui croît pendant les inondations el qui se récolte lorsque les eaux se sont retirées, ils font des cordes et de la ficelle qui peurent rivaliser avec nos produils curopéens.

Les femmes fabriquent des poteries qu'elles font cuire et les hommes savent 
admirablement préparer des fourrures, dont ils eonfeetionnent de superbes manteaux pour les cliefs.

A l'extéricur, le eomneree est presque nul; les mombari, métis portugais, Commerce. viennent périodiquement au bo-Rotsi aeheter de l'ivoire et des eselaves; pour ee qui eoneerne ee dernier artiele, le roi Léwanika, grâee à l'influenee des missionnaires du Zambèze, s'y oppose graduellement.

En fait d'agrieulture, les indigènes tirent du sol les prineipaux produits Agriculture. suivants : le sorgho, le maïs, le millet, les araehides, les patates douees, le manioe, les eourges, les melons d'eau, le tabae ${ }^{1}$.

Comme bétail, ils élèvent des bœufs et des vaehes de deux espèees; l'une grande, la raee du bo-Rotsi et l'autre plus petite, originaire du pays des ma-Shoukouloumboué. Ils possèdent aussi des ehèvres et des moutons de raee dégénérée qui viennent du bo-Toka, ainsi que des poules éliques.

Le miel de l'abeille sauvage, mouka, est une ressouree, aussi bien que eelui de la petite mouehe à miel, ntsi, dont les indigènes sont très friands.

Comme berger's ou éleveurs, ils n'ont aueune pratique sérieuse; les vaehes donnent si peu de lait qu'elles peuvent souvent à peine nourrir leurs propres reaux.

Les habitants eroient que le lait frais est malsain; ils se nourrissent par contre du lait eaillé; eertains d'entre eux trouvent que le meilleur moyen pour arriver à ee résultat est de ne pas neltoyer les réeipients qui le eonliennent.

Les ressourees naturelles du pays ne sont pas eneore eonnues : outre le minerai de fer, il faut pourtant mentionner les grandes forèts à nombreuses essenees; parmi les prineipales nous eiterons: le mockengé à haute tige, à feuilles persistantes, au bois très dur. Le motsaosli (massivi), arbre au port majestueux, rappelant le ehêne; son bois qui ressemble à l'aeajou, est eelıi que les indigènes emploient surtout pour la fabrieation de leurs canots; une fois seiés, les gros trones peurent servir eomme bois de eonstruetion; en outre il porte des baies rouges dont les indigènes sont friands. Le mochaba est aussi un arbre de hante futaie, il devient énorme; il eroît près des endroits humides; son bois est très tendre et l'éeoree, purgative.

Le mohonono, propre à la construetion, est très dur el résistant. Le moboula 
qui ressemble à l'érable ou au charme, est un bois de menuiserie, il porte un fruit comestible à noyau. Le motondo, au f́cuillage clair, à fibres droites s'emploie pour la fabrication des manches de haches, de houes. Le mokoa est moins beau que les précédents; avcc son bois on fait des rames, des petits canots insubmersiblcs, ainsi que des ustensiles de ménage; il ne porte pas de fruits. Puis vient le majongolo, qui sert à confcctionncr des cuillers et qui a des fruits comestibles. Citons encore le moholouholou, arbre dc petite taille; son fruit, extérieurcment semblable à une grosse orange, peut causcr la dysenterie aux Européens.

Caoutchouc. Cotonnier.

Le caoutchouc croît spontanément. Avec la bourre du cotonnier sauvage les indigènes tissent de grossièrcs étoffes. Nous voyons aussi des orchidées, malheureusement ce n'est pas l'époque de leur floraison.

Animaux sauvages.

Les animaux sauvages sont, suivant les régions, nombreux et variés : buffles, lions, léopards ou panthèrcs, hyèncs, chacals. Les éléphants et les rhinocéros, dont nous avons vu des traces, mais que nous n'avons jamais approchés, tendent, paraît-il, à diminuer.

Grande variété d'antilopes depuis le minuscule oribi (Nanotragus scoparius) l'unc des plus petites antilopes connues, puis le steinbucli (Nanotragus tragulus), ct le duiker (Cephalophus mergens) jusqu'aux lourds élands 'Oreas canna) qui peuvent peser de 800 à 1000 livres. Le koodoo (Strepsciceros kudu) a vec les corncs cn spirales; l'antilope noire ou sable anlelope (Hippotragus niger) au garrot relevé; l'élégant waterbuck (Cobus ellipsiprymnus) à robe grisaillée; le reedbuck (Cervicapra arundinacea) au pelage fauve; le lechwe (Cobus leche) qui vit dans les marécages; le bubale ou Lichtensteins hartebeest (Alcephalus lichtensteini) à la tête allongée, aux cornes renversées, etc.

Mentionnons encore parmi les antilopes:

L'antilope rouanne (Hippotragus leucophoeus).

Le pooko (Cobus vardoni).

Le bushbuck (Tragelaphus sylvaticus).

Le roybuck (Aipyceros melampus).

La situtunga (Tragelaphus spelii).

La tsessebe (Alcephalus lunatus).

Le sanglier (Wart hog) (Phacochoerus rethiopicus) vit aussi dans ces régions.

Nous avons à différentes rcprises rencontré des troupeaux de gnous bleus (Catoblepas gorgon) el de zèbres (Burchells'zebra) qui comptaicnt plusieurs centaines de têtes. L'autruche ct la girafe, qui se trouvent au sud du Zambèze, n'existcnt pas dans la partie du pays des ba-Rotsi située au nord du grand flcuve. 
De nombreux hippopotames et crocodiles vivent dans les eaux du Zambèze: nous en avons vu aussi dans la rivière Machilé. Il faut aussi mentionner beaueoup de serpents de toutes longueur's '.

Le bo-Rotsi possède de nombreux oiseaux aquatiques : des ibis, des hérons, Oiseaux. des pélicans, des grues, des pluviers; différentes espèces d'oies, de canards, de sareelles. Citons aussi l'aigle-pêcheur blane arce les ailes noires et enfin, trois ou quatre espèees de francolins, deux espèees de pintades, etc.

Le pays a des rats et des souris ainsi que des rongeurs de différentes espèces. Au moment des inondations, ces animaux viennent chercher un refuge dans les huttes.

Les insectes se eomptent par légions et sont un véritable fléau, telles : les séroui ou fourmis guerrières dont les hordes serrées ne dèvient jamais de leur chemin; les termites, désignées à tort sous le nom de fourmis blanches, malfaisantes par excellenee et qui s'attaquent à tout ce qui n'est pas matière grasse. Les kolioanci-nisou, petites fourmis noires, pénètrent dans la nourriture, ete. Les sauterelles (tsie) sont rouges de corps et portent des ailes striées de noir et de blanc; elles anéantissent en peu de temps les cultures. Les mo:iches et les moustiques petits et gros tourmentent les voyageurs.

Les séboulé sont des araignées venimeuses; les sèkioko, énormes araignées Arachnides. plates, inoflensives, courent dans les hutles le long des murailles. Les scorpions sont plus ou moins venimeux.

Terminons celle nomenclature par la tsé-tsé; cette mouche habite eerlaines régions déterminées; sa piøùre n’a pas de suites mortelles pour les hommes blanes ou noirs, ni pour les animaux sauvages, mais elle fait périr, plus ou moins rapidement, presque tous les animaux domestiques, surtout les bœufs, les cheraux, les chiens; ee sont les ânes qui résistent le plus longtemps.

Nous avons observé que la tsé-tsé vit dans les mêmes parages que le buffie; serait-clle peut-ètre l'un de ses parasites et trouverait-elle son venin dans les excréments du buffle ou ailleurs? Le savant qui réussirait à déterminer le virus de ect insecte el à l'inoculer en Afrique aux animaux domestiques, comme cela a été fait en Europe pour le charbon ou d'autres maladies,

1. Non loin des bor'ds de la rivière Machilé, nos hommes ont lué un serpent gris brun foncé dont la structure nous étonna : $2 \mathrm{~m}$. 40 de longueur; la partie la plus volumineuse de son corps mesure $0 \mathrm{~m}$. 130 . Tèle très petite et légèrement aplatic. A partir de $1 \mathrm{~m}$. 90 son corps s'amincit considérablement et l'extrémité de sa queue est à peine plus grosse qu'une aiguille à tricoter. Ce serpent est, parait-il, venimeux. 
rendrait un serviee signalé; en effet, de vastes étendues de pays sont plus ou moins inaccessibles par la présence de eette terrible tsé-tsé, à peine plus grosse qu'une mouehe ordinaire.

Les animaux domestiques réfraetaires au venin de la tsé-tsé forment une très faible minorité. lls sont désignés sous le nom de " salted" et ils sont fort recherehés. Cette immunité augmente eonsidérablement leur valeur intrinsèque.

Nouvelles espèces.

Distribution du temps.

Saisons.
Lors de son retour en Europe, M. le missionnaire Louis Jalla a fait don au Musée de zoologie et d'anatomie comparée de l'Université R. de Turin, d'une collection zoologique reeueillie lors de son séjour de dix années dans le HautZambèze. Cette colleetion renferme des spécimens d'Ophidiens, de Laeertiens, d'Orthoptères, de Diplopodes, d'Araehnides '.

Il a ainsi ajouté plusieurs espèces nouvelles, à eelles qui étaient déjà eonnues; à juste titre quelques-unes d'entre elles ont été désignées par l'autorité seientifique portée dans la nomenclature, d'après le nom de M. Jalla.

Je mentionnerai entre autres, dans la elasse des Arachnides, la nouvelle espèee Hyllus Jallae et parmi les Diplopodes les nouvelles espèees Odonlopyge Jallae. - Odontopyge exquisila. - Archispirostreplus Jallae. - Archispirostreptus dexter. - Lophostreplus Cameranii.

Comme distribution du temps, les ba-Rotsi ont l'année lunaire; ehaeun en connaît les différentes phases. A ehaque renouvellement de lune, il y a interruption de travail, puis des danses pendant l'après-midi et la soirée.

Grâce à l'influenee des missionnaires, le roi Léwanika lui-même respeete actuellement le dimanehe ehrétien.

Les indigènes ont des notions très vagues sur leur âge; ils diront par exemple : je suis né lors de telle guerre, à l'époque de telle grande famine ou inondation.

Pour ee qui coneerne les saisons, sans fixer de jour préeis à cet égard, l'année finit pour les ba-Rotsi à la moisson.

Elle a deux grandes divisions:

Léchlaboula, ou été.

Mariha, ou hiver.

L'été se divise encore en mboumbi, du 10 août à la fin de novembre. Le moment le plus ehaud de l'année va de la fin d'octobre à la mi-novembre, époque où les vents soufflent et où la chaleur est la plus forte; e'est la saison

1. Voir les bulletins du musée de zoologie et d'anatomie comparée de l'Université R. de Turin, 1S96, vol. $1 \mathrm{X}, \mathrm{n}^{\text {os }} 23 \mathrm{3} 3-257-271-209$. 
sèehe, préećdant la saison des pluies ou léchlaboula proprement dile, qui comprend la période de novembre à fin février. De la mi-février au mois de mai, période des inondations appelée mounda.

Le marika ou le véritable hiver eommenee it la fin de mai el se termine au milieu d'aoùt.

Il n'est pas besoin d'ajouter que ees dates ne sont pas fixes et qu'elles varient suivant les années.

"Rísumé d'observations eoneernant la température, faites pendant dix anıées par M. Ie missionnaire Louis Jalla à Kazoungoula.

\section{Saison chaUde}

\section{Maximum.}

$\left.\begin{array}{l}+47^{\circ} \mathrm{C} \text {. à l'ombre de } 2 \text { à } 4 \text { heures } \\ +20^{\circ} \text { à } 22^{\circ} \mathrm{C} \text {. pendant la nuit }\end{array}\right\}$ fin oetobre.

NorA. $+47^{\circ} \mathrm{C}$. eonstaté une fois n'est peut-être pas le maximum annuel.

\section{Moyenne.}

$\left.\begin{array}{l}+39^{\circ} \text { à } 40^{\circ} \mathrm{C} \text {. pendant le jour } \\ +20^{\circ} \text { à } 22^{\circ} \mathrm{C} \text {. pendant la nuit }\end{array}\right\}$ fin oetobre.

\section{SAISON FROIDE}

Moyenne.

$\left.\begin{array}{l}+24^{\circ} \text { à } 23^{\circ} \mathrm{C} \text {. pendant le jour } \\ +6^{\circ} \text { à } 10^{\circ} \mathrm{C} \text {. pendant la nuit }\end{array}\right\}$ mai-juin-juillet.

Ces différentes températures ont toujours été prises à l'ombre.

Dans le eourant de la saison ehaude, le thermomètre, mis au soleil, monta jusqu'à $+60^{\circ} \mathrm{C}$., et il fallut l'enlever, afin d'empêeher le verre d'éelater. "

Dans l'intérieur du pays, sur les hauts plateaux, la différenee dans la température est aussi très forte.

Reid et moi, nous avions déjà vu une forte gelée blanehe dans la nuit du 31 juillet, alors que nous eampions près de la source de la rivière Machilé.

Je mentionnerai à ee sujet les observations suivantes que je fis, lorsque je traversai, direetion N.-O., la partie du pays des ba-Rotsi, qui s'étend entre la rivière Machilé et la eapitale Léalouyi.

Au campement du 7 août, sur la rive droite de la rivière Kuemba (affluent du Njoko), mon thermomètre, à 6 h. 30 du matin, était à + 2", ö C.

Le 9 août, eampé sur les bords de la rivière Loumbé, le thermomètre, 
placé au soleil devant ma tente, indiquait, à 3 heures de l’après-midi, $+12^{\circ} \mathrm{C}$.

Le lendemain matin, à 6 heures, au même emplacement, il ne marquait que $+1^{\circ} \mathrm{C}$.

Le 12 août, 6 heures du matin, à quelques heures de marche de la rivière Motondo (affluent du Louyi ou Lui), le thermomètre descendit au point de congélation.

Hauteur d'eau de pluie.

Climat. D’une manière générale, le climat est malsain; les indigènes. souffrent principalement des fièvres et de la petite vérole; plusieurs affections des yeux sont la suite de eette dernière maladie. Les missionnaires ont introduit le vaecin dans le pays; des centaines d'indigènes ont été vaccinés par leurs soins.

L'époque la plus dangereuse est eelle qui suit la période des inondations, où l'eau, en se retirant, laisse sur le terrain des détrilus qui se décomposent sous l'action des rayons du soleil brûlant.

Réflexions M. Coillard.

M. Coillard qui, annuellement, a enregistré et cela pendant plusieurs années, la chute d'cau dans le Haut-Zambèze, arrive à une moyenne de 863,6 millimètres. Cette moyenne est constante. Si, au moment de la saison des pluies, léchlaboula, la quantité d'eau tombée est au-dessous de la moyenne, il arrive invariablement, à la fin de la saison, de grands orages qui la foṇt remonter près du chiffre mentionné préeédemment.

Je voudrais eneore citer les réflexions suivantes, que j'ai entendu M. Coillard prononcer réccmment, lors d'une conférence qui lui avait été demandée par une Société de géographie.

Est-il nécessaire d'insister sur l'autorité que donne aux lignes qui vont suirre, les trente-cinq ou quarante années que ce vaillant homme a eonsacrées à l'Afrique? " Je n'ai ricn dit de l'abîme de corruption dans lequel gisent ces populations, ni des souffrances physiques et morales dont elles sont les vietimes; le sujet est trop doulourcux et trop vaste.

"De loin sans donte, ces populations primitives, insoueiantes, impréroyantes, jamais sûres du lendemain, et qui chantent au clair de la lune, peuvent apparaître en Europe entourées d'une certaine auréole de poésie. Et pourtant, disons-le, elles n'ont jamais eonnu le bonheur.

"Entendez leurs ehants en mineur, ce sont des gémissements. Écoutez-les vous dire que leur eœur est noir, c'est-à-dire qu'il est triste,... noir, oui comme leur peau, et ainsi du berceau jusqu’à la tombe, ils portent toujours à travers la vic lc symbole et la livrée de la souffrance. Pourquoi nous occupons-nous de géographie, messieurs, e'est que le monde est notre patrimoine, et les hommes, quels que soient leur race, leur couleur, leur nationalité ou leur degré social, tous sont nos frères. 
"Pendant des siècles l'Afrique a élé pour l'Lurope autant que pour ellemème, le continent noir, mystérieux, inconnu. Aujourd'hni efle s'ouvre an monde et absorbe son attention. Elle se transforme arec une rapillité qui nous émeul.

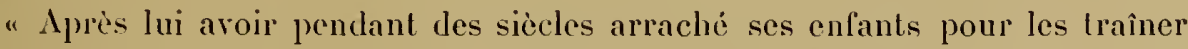
sur les marchés et les y rendre comme des bites de somme, l'Europe lui arrache aujourd hui les richesses de ses entrailles. Et mue par l'appat de richesses encore inconnues, roici limmigration européenne qui, comme une puissante marée que nulle digue ne peut arrèler, monte et jette son écume vers le creur mème du continent. Et au milieu de cette étrange commotion que deviennent les Africains cux-mèmes? la race noire, ou va-t-elle? quel est son avenir? Scrait-ce celui des Incliens de l'Amérique du Nord? Dieu l'en préserve; notre cœur d'homme et de chrétien se révolte et s'indigne à la suggestion seule d'une telle perspective. Une chose nous rassure, c'est la vitalité étonnante de celte race. Il y a soixante et quelques années, qu'était la nation des ba-Souto, par exemple? quelques hameaux dispersés dans les montagnes que groupait Moshélé et que les missionnaires entouraient de sollicitude, la sollicitude d'une nourrice pour son enfant débile. Vers 1870 le gouvernement fit un premier recensement qui donna le chiffre de soixante mille habitants.

" Et le dernier recensement a constaté qu'il est exactement de deux cent soixante mille habitants, sans compter des milliers qui sont dispersés dans toute la colonie du Cap.

"Que seront les ba-Souto dans vingt, trente ou cinquante ans, si rien ne vient détruire leur autonomie?

"Les mèmes faits se constatent partout. Done la race noire a un avenir. Mais quel est-il? Il est sans doute ce que la puissance intellectuelle, morale et matérielle de la race blanche le fera. Mais, pour le philanthrope et le philanthrope chrétien, il y a un deroir à accomplir, une tâche qui s'impose, digne des plus grandes libéralités et du sacrifice des plus belles vies. C'est une ouvre de sauretage." 



\section{APPENDIGE II}

Notices sur les rapports présentés le 4 janvier 1897 à la Société Royale de Géographie de Londres concernant un voyage d'exploration au Pays des ba-Rotsi (Haut-Zambèze) par le capitaine Alfred Saint-Hill Gibbons, M. PercyC. Reid et le capitaine Alfred Bertrand.

Il n'est pas néeessaire de rappeler que l'expédition s'organise à Maféking, à 1400 kilomètres du Cap; Maféking était alors le point terminus de la ligne du chemin de fer.

La direetion suivie est le nord par Molépololé, territoire de la tribu des ba-Ḱuena, el Kanyé où est fixée la tribu des ba-Rnaketsé, pour longer ensuite le désert du Kalahari et arriver à Palapye, la résidence de Khama, roi des ba-Mangwato. Plus tard, l'expédition suit la partie est du grand lac salé Makarikari; puis elle traverse la eontrée appelée "Land of the thousand vleys".

Bref, l'expédition frauchit en soixante-quatre jours la distanee qui sépare Maféking du grand fleuve, qu'elle reneontre non loin de son confluent avec la rivière Linyanti (Chobe).

Après avoir passé sur la rive gauehe du Zambèze et pénétré dans le pays des ba-Rotsi, l'exploration proprement dite commenee.

C'est à ce point que le capitaine A. Saint-Hill Gibbons se sépare de ses compagnons de voyage, pour remonter direetement le Zambèze jusqu'à Léalouyi, puis explorer le pays des ba-Rotsi dans différentes direetions.

Voiei en quelques lignes, un résumé sueeinet de eette remarquable exploration, d’après la communication faite à la Société Royale de Géographie de Londres.

En remontant le Zambèze jusqu'à Léalouyi, résidenee du roi Léwanika, le 
capitaine A. Saint-Hill Giblons fait un grand nombre d'observations astronomiques et solaires; il rectifie ainsi sur les cartes le tracé du cours du Zambèze sur plusieurs points.

De Léalouyi, il prend d'abord, pour explorer le pays, la direction de l'est. Au delà de la plaine du bo-Rotsi, il découvre le bassin d'un lac, qui reçoit les eaux de la rivièrc Kande.

A 100 kilomètres à l'est de Léalouyi ct par $10^{\circ} 28^{\prime}$ de latitude sud, il atteint le Louyi (Lui). Il passe sur la rive gauche du Maüngu, croise la source des rivières Luwowa et Lioshamba, affluents du Iotondo, déterminant la source du Motondo lui-même, le plus important tributaire du Louyi (Lui). Il fixe approximalivement cette source à $15^{\circ} 27^{\prime} 17^{\prime \prime}$ de latitude sud et $24^{\circ} 39^{\prime}$ de longitude est. Le Motondo prend sa source à une altitude de 3980 pieds anglais (1220 mètres) au-dessus du niveau de la mer.

Continuant à l'est, lc capitaine Saint-Hill Gibbons arrive à la source du Loumbé (Lumbi), qu'il place par $1 \ddot{3}^{\circ} 28^{\prime} I^{\prime \prime}$ de latitude sud, puis il atteint unc petite rivière Nyambé Noka, qui cst un affluent de la rive gauche de la Luompa. La Luompa est un tributaire de la Lucna, laquelle, d'après le dire du roi Léwanika, se déverse dans un grand lac au sud du confluent du Kabompo et du Zambèze.

D'autres renseignements prouvent à l'explorateur que la rivière Luazanza, qui prend sa source approximativement par $1 \breve{3}^{\circ} 20^{\prime}$ de latitude sud et $2 \mathrm{\jmath}^{\circ} 30^{\prime}$ de longitudc est, sc trouve être un affluent de la rive gauche de la Luompa. Par conséquent, la Luompa doit prendre sa source plus au nord ct la Luena plus au nord-ouest; cette orographie complète ainsi l'espace laissé en blanc sur la carte, ct qui est bordé par le faîte des eaux du Kabompo et de la Kafoukué, et celui du Louyi (Lui) ct du Loumbé (Lumbi); il draine cette vaste étendue, à peu près dans la direction ouest.

Le capitaine Saint-Hill Gibbons suit le Nyambé jusquà sa source, qui se trouve par $10^{\circ} 43^{\prime} 7^{\prime \prime}$ de latitude sud, à une altitude de 3860 pieds (1180 mètres).

Puis l'explorateur prend la direction sud, rejoint le Njoko non loin de sa source; il suit son cours sur toute sa longueur.

De là il atteint la Loanja pour se rapprocher du Zambèze, et se retrouver à son point de départ Kazoungoula (jonction du Zambèzc et du Linyanti ou Chobe). Il souffrit d'une attaque de dysenterie qui lc réduisit presque à l'état de squelette.

Une fois remis, le capitaine A. Saint-IIill Gibbons entreprend unc autre exploration au nord-est dans lc territoire des ina-Shoukouloumbouè (mashikolumbwe), tribu fort redoutéc.

Il arrive au faite des eaux des tributaires de la rive gauchc de la Scjlefula. Il 
passe trois ou quatre aflluents de la rive gauche de la Machilé el entre dans le bassin hydrographique de la Kafoukué. Il traverse la rivière Nanzéla el arrive à la Nkala.

Il poursuit sa eourse le long du bassin de la Kafoukué, qu'il traverse à Kaigu; puis il prend la direction nord-est pour atteindre Kowetu, son point le plus extrème, à une altilude de 4000 pieds anglais (1220 mètres). A Musanana il trouve des sourees ehaudes ealcaires.

Eufin, le eapitaine Saint-Hill Gibbons revient à son point de départ, Kazoungoula, après avoir eu de nombreuses aventures; non loin de Nkala, en particulier, il a délivré le pays d'un lion qui, au dire des habitants, avait dévoré pendant les derniers jours de sa vie deux femmes, deux bœufs, deux ânes, un mouton, une chère et un agneau.

Le eapitaine a fait en route un grand nombre d'observations solaires ou autres pour déterminer la latitude de plusieurs points importants; il rapporte aussi beaueoup de renseignements sur le pays des ma-Shoukouloumboué.

Au point de vue géographique, le capitaine $\Lambda$. Saint-Hill Gibbons a exécuté dans le royaume du ba-Rotsi un parcours qui peut être évalué à plus de trois mille kilomètres.

Au sud du Zambèze, lors de son retour, il s'en est fallu de trois jours qu'il ne tombàt en pleine insurrection des ma-Tébélé, et sans ee hasard providentiel, il aurait été l'une de leurs nombreuses victimes.

Après nous être séparés du capitaine A. Saint-Hill Gibbons, nous nous mettons en route, II. Perey-C. Reid, Pirie et moi, pour remonter la rivière Nachilé (Machili), affluent de la rive gauche du Zambèze.

II. Perey-C. Reid doit, en outre, relever approximativement le cours de eetle rivière et en déterminer la source.

Il a fait un certain nombre d'observations solaires et astronomiques pour fixer la latitude des points importants et j'eus fréquemment l'oceasion de eollaborer à son travail, en lisant le ehronomètre alors qu'il maniait le sextant.

Je ne puis nieux faire que de reproduire les prineipaux passages du rapport que M. Percy-C. Reid a présenté à la Société Royale de Géographie de Londres :

a La rivière Machilé (Machili) prend sa souree sur le versant sud d'ıne ehaîne de hautes collines de formation sablonneuse, à une altitude d'environ 3900 pieds anglais (1290 mètres) au-dessus du niveau de la mer. Ce n'est pas une source jaillissante, mais plutôt une ravine large d'environ 100 mètres, eouverte d'herbes et bordée sur ses deux côtés par une forèt. En suivant le eours de eette ravine, on peut se rendre eompte que d'autres ravines plus petites aboutissent au lit de la rivière proprement dit, qui devient marécageux. La pente 
est assez rapide, de 50 pieds sur 3 lilomètres. Puis vient un affleurement rocheux; nous trouvons la première eau dans des mares entrecoupées de rochers. La direction suivie va du nord est au sud-ouest. Les versants de la vallée ne tardent pas à devenir plus escarpés; le lit de la rivière se remplit d'eau et le courant s'y dessine nettement.

A environ 8 kilomètres plus en aval, un affluent considérable, venant de l'est, se jelte dans la Machilé; il forme à son confluent avec cette dernière une large nappe d'eau, en aval de laquelle le courant est assez fort.

Suivant d'une manière générale cette direction, nous atteignons le point de $16^{\circ} 21^{\prime}$ de latitude. A la sortie d'un terrain pierreux, la vallée prend une largeur d'environ 1500 mètres; la rivière se dessèche peu à peu et ne se révèle que par de l'eau stagnante; mais aussitôt que le terrain devient rocheux, elle se dessine de nouveau, elle grossit en volume et coule rapidement, arec bruil. Près du point de $16^{\circ} 33^{\prime}$ de latitude, elle fail soudainement un coude prononcé à l'est et, après une course de 10 ou 12 lilomètres dans cette direction, elle sort d'une chaîne de collines rocheuses pour entrer, à une altitude approximative de 3400 pieds anglais (1040 mètres), dans une large vallée tourbeuse, où elle incline de nouveau brusquement vers le sud; elle semble de nouveau stagnante, presque à sec à cerlains endroits. $\Lambda$ un autre coude, mais moins prononcé, à l'est, par $16^{\circ} 48^{\prime}$ de latitude, le courant devient de nouveau perceptible. De ce point-là, en continuant la marche en avant nous observons, sur un espace de 70 à 80 kilomètres, les mèmes caractères el, de nouveau, la rivière consiste en une série d'étangs profonds séparés par des espaces de terrain sec. Elle est ici assez considérable pour que des hippopotames y vivent.

La contrée est maintenant moins vallonnée; la rivière relie des étangs et traverse des bandes de terrain desséché sur un parcours de 8 ou 10 kilomètres avant d'atteindre la Kasaia, qui clle-même se jette dans le Zambèze à 2 ou 3 kilomètres plus au sud; à ce point-là les mares cessent complèlement : tel est le régime de la Machilé pendant la saison sèche. A l'époque des pluies, cette rivière se remplit d'eau et coule depuis sa source jusqu'à son embouchure.

Il n'en reste pas moins ce fait curieux, que lorsque je l'ai rue, cette rivière présentait alternativement un courant et des mares stagnantes. Nlème dans la saison des pluies, elle se déverse dans un large marécage, dont les eaux sont drainées dans la liasaia. Parlout où le sous-sol est rocheux et où la pente est un peu prononcée, la Machilé coule en toute saison. Là où la contrée est moins accidentée et où le sol est tourbeux, les étangs, qui se succèdent, constituent à eux seuls toute la rivière, qui par places, est coupée dans son cours.

Si nous considérons la rivière depuis son embouchure, en amont, nous 
voyons que la pente est laible, jusqu’i ce que nous alleignons le point 16, 33', oì nous sortons de la vallée du Zambéze, pour pénétrer dans des collines rocheuses. Après les avoir traversées, on trouve au dela de ces dernières une chaine principale de collines sablonneuses ćlevées, qui forme le faile des eaux du Zambize el de la rivière lialoukué. Cetle chaine s'étend approximativement du nord-onest au sud-est. C'est dans cette chaine que tous les afluents de la rive gauche du Zambize, compris entre liazoungoula et Léalouyi, prennent leur source.

La région traversée est courerle par une épaisse végétation. Dans les parties du pays formées de terrains d'alluvion, elle se compose de hautes forêts par'semées de taillis. Dans les parties rocheuses, la forêt n’atteint pas les mèmes dimensions el les taillis sont beaucoup plus épais; ils forment même à de certains endroits une jungle presque impénélrable.

Pendant les mois d'hiver la température au milieu du jour et à l'ombre varie entre 23 et 30 degrés centigrades. Les nuits sont fraîches. Nous avons eu une forle gelée à la source de la Machilé par $16^{\circ} 9^{\prime}$ de latitude sud.

La population est clairsemée; il est difficile en Afrique de l'estimer, car les villages sont cachés dans les taillis; plusieurs tribus vassales des ba-Roisi habilent ce district; les habilants sont tous armés d'assagaies; les ma-Nkoya, ver's la source de la rivière, sont armés d'ares el de flèches empoisonnées.

Le gibier est très abondant : lions, buffles, zèbres, plusieurs varićtés d'antilopes; les hippopotames se trouvent dans la Machilé comme dans le Zambèze: les éléphants et les rhinocéros sont rares. Les girafes et les autruches ne se r.ncontrent pas sur la rive gauche du Zambèze. ”

Le chapitre de l'exploration qui va suirre a été aussi l'objet d'un rapporl que j’ai présenté à la même séance de la Société Royale de Géographie de Londres le 4 janvier 1897, rapport que j'ai remanié depuis.

Après l'exploration de la rivière Machilé, M. Percy-C. Reid considère la tâche qüil s'était imposée en partie terminée; nous nous donnons donc rendez-vous pour plus tard à Kiazoungoula, à la jonction du Linyanti et du Zambèze, et je me lécide à traverser, direction nord-ouest, le pays des ba-Rotsi jusqu'à Léalouyi, résidence du roi Léwanilia.

$f_{\text {er }}$ août. - Je pars avec vingt-cinq hommes et je campe à la nuit tombante sur les bords de la rivière Kakoma, aftluent de la rive droite de la Machilé.

2 août. - Après avoir traversé le lit marécageux d'un autre tributaire de la Machilé, la Ramaroba (Wanaroba), terrain mouvant recouvert d'herbes où nous enfonçons dans la boue jusquaux genoux, et le lit du Kamitué actuel- 
lement un marécage, nous abordons la Kamanga qui rejoint probablcment le Njoko, direction sud-ouest. Nous sommes dans le bassin hydrographique du Njoko; nous campons non loin de la Mania, affluent de sa rive gauche.

Pendant ces deux journées, nous avons marché à țravers une série de collines boisées très rapprochées les unes des autres et coupées par des vallons.

Nous n'avons pas vu un indigène ni aperçu trace de huttes. Le gros gibier est rare; il semble à cette époque émigrer dans d'autres districts, car, en remontant la Machilé, nous en avions rencontrć en abondance.

3 août. - Rassemblement de huttes ou villages qui, suivant l'usage, porte le nom de son chef Méori; nous sommes à la limite du territoire de la peuplade des ma-Nkoya que nous abandonnons pour pénétrer dans celui des ma-Totéla, tribu fort supérieure à la précédente; les ma-Nkoya sont uniquement chasseurs, tandis que les ma-Totéla sont aussi agriculteurs; en outre ils travaillent le fer qu'ils trouvent dans le sol.

Les ma-Totéla, dont le costume est réduit à sa plus simple expression, sont armés d'assagaies, quelques-uns portent aussi une lance effilée dont ils se servent pour prendre le poisson. Ils arrachent souvent leurs deux incisives centrales supérieures.

Fait à noter que plusieurs d'entre eux ont un profil régulier qui rappelle le "type juif ". Non loin du confluent du Nania et du Njoko, nous voyons le village du chef Siboupa; au milieu d'une enceinte, faite de grosses branches et haute de 6 à 10 pieds, se trouve une grande hutte centrale enlourée de onze plus petites; elles sont rondes, construites en roseaux et recouverles de chaume.

On trouve dans cette région des arbres de haute futaie, en particulier le matsoli (massivi) au port majestueux, au feuillage vert foncé; cet arbre porte un fruit rouge de la formc d'un haricot aplati; les indigènes en font grand usage.

La vallée du Njokio a une apparence riante, bordée comme elle l'est par des collines boisées, sur les flancs desquelles on voit ici et là des taches brunes qui en réalité, sont des villages entourés de plantations; culture du sorgho, des arachides, etc.; je puis faire provision de ces denrées en les échangcant contre des perles; celles en verre bleu sont très demandées. - Gros bétail.

5 août. - Nous passons sur la rive droite du Njoko, l'eau nous arrive à peine aux genoux; pendant la saison des pluies, il est navigable jusqu'au Zambèze. Des collines. Sur le versant de l'une d'elles, résidence du chef Souroukouroukourou. Avant de franchir la rivière Kambona, affluent du Njoko, nous parcourons une superbe forêt de haute futaie. 
6 août. - Je tronve un petit lac, long d'un demi-kilomètre environ, entouré de verdure, silué dans un gracieux vallon; en raison de sa couleur azurée je le baptise du nom de Blue Waler, c'est dans ce lac que la rivière Ikué (Ikwe) doil prendre sa source; celle rivière el celle que nous traversons ensuite, la Kuemba (liwemba), dont l'eau nous effleure les épaules, sont des affluents de la rive droite du Njoko. Le terrain est mouvant, spongieux.

7 août. - A 6 h. 30 du matin, le thermomètre enregistre + $2^{\circ}, 5$ C.

Suivant la configuration du terrain, nous abandonnons le bassin du Njoko ponr entrer dans celui du Loumbé (Lumbi).

Mentionnons encore le Njonjo et le Kaponé, qui se déversent probablement dans le Loumbé.

Pendant ces deux journées nous n'ảvons pas aperçu trace d'êtres humains.

$\delta$ août. - En aval de la jonclion du Maselli et du Loumbé, nous arrivons au village du chef Mayoumba; nous nous y approvisionnons, cette fois gràce à des perles de verre blanches, de sorgho, de fèves indigènes, de lait caillé. Avant d'alteindre le lit proprement dit du Loumbé pour passer sur sa rive droile, nous nous débattons dans la vase gluante de ses bords marécageux. Le Loumbé coule dans une vallée plus large mais moins belle que celle $\mathrm{du}$ Noko; les antilopes lechue (Cobus leche) vivent dans ces parages.

Depuis la source de la rivière Machilé jusqu'au Loumbé, la marche s'est poursuivie à travers une succession de collines en général boisées, rapprochées les unes des autres el entrecoupées de vallées et vallons.

Les principales essences que l'on trouve dans ces forèts et taillis sont, outre le matsaoli déjà nommé, dont le bois est très dur, le moboula, qui porte un fruit comestible à noyaux; le motondo au feuillage clair; le mokoa, le majongolo, etc. Il y a de nombreux moholouholou, arbusles portant de gros fruits ronds à écorce dure.

10 août. - Disons en passant que si les journées sont parfois chaudes nous approchons de l'été - les nuits peuvent être froides.

A mon campement de ce jour, sur les bords du Lounbé, le thermomètre à 6 heures du matin marque $+1^{\circ} \mathrm{C}$., tandis que hier après midi, au même emplacement el au soleil, il indiquait $+42^{\circ} \mathrm{C}$.

C'est dans les environs du Loumbé, que nous çroisons la piste que suivent les missionnaires, lorsquils se rendent par voie de terre de Kazoungoula à Léalouyi. Nous franchissons des plateaux boisés; près de la petite lagune Mousana nous voyons des traces el des empreintes d'éléphants. Nous passons sur les bords de la lagune Kamba (Kambai) qui est suivie d'une 
grande plaine avec des bouquets d'arbres; on y enfonce dans un sable blanc el épais.

11 août. - Grandes plaines renfermant à distance quelques bois, où nous voyons paître des zèbres (Burchell's Zebra) et des gnous (Çatollepas gorgon); nous longeons la lagune Kaaru.

12 août. - A $6 \mathrm{~h} .30$ ce matin, le thermomètre descend au point de congélation. Espaces boisés qui suivent de grandes étendues de sable fatigant pour la marche; ensuite plaine couvertc de termitières.

Nous franchissons le Motondo, affluent de la rive gauche du Louyi (Lui); un marécage composé de boue visqueuse borde la rivière proprement dite, où nous avons de l'eau jusqu'à la ceinture.

13 août. - Après avoir gravi une colline sablonncuse, plantée d'arbres, nous franchissons cncore un marécage avant de passer le Louyi (Lui) sur la rive droite duquel nous aboutissons au village du chef Moamanomné, où je me procure un approvisionnement de sorgho, de patates douces ct de lait caillé. Territoire de la tribu des ma-Kuangoa (Makwenga) qui possèdent du gros bétail et qui travaillent le fcr.

$\Lambda u$ tres collines avec de la verdure.

14 asût. - Interminables collines de sable plus ou moins couvertes d'arbres; il s'y trouve des perruches vertes. Au delà d'une plaine, nous arrivons sur les bords de la lagune Nanjékua, près de laquelle se trouve le village de Célibelo (Shiribero); on nous apporte du manioc.

15 août. - Collines plus ou moins garnies d'arbres, altcrnant avec des plaines, lagune Mukango; entre celle-ci et la lagune Njolo, le village de Kulima où j’obticns des patates séchées, du manioc, du lait caillé ainsi que du lait frais, ce dernier est une grande rareté dans ce pays. A partir de la lagune Njolo, la contrée se peuple de plus en plus; après un terrain sablonncux nous franchissons un mamelon boisé pour atleindre la localité appclée Lataba (Katalba), à l'ouest de laquelle s’étend une vaste plaine émaillée par les huttes rondes de plnsieurs grands villages; beaucoup de bétail. Plaine couverte de termitières, marécage, collincs sc succédant; enfin nous alteignons la lagune Ikulwe.

16 août. - Après avoir gravi unc longue colline pareille aux précédentes, où le silence n'est troublé que par le cri des pintades, nous aboutissons au vallon de Séfoula (Sefula), sillonné par la rivière de ce nom et bordé de nom. 
breux villages dont le principal, siege d'une station missionnaire, porte aussi le nom de Séfonla.

17 août. - Nous trarersons une grande plaine enclavée par des collines: celte plaine est sans doute le lit d’un ancien lac dessćché; les villages y sont établis sur des éminences de terrain, élevées par les termites. Celte plaine est sous l'eau pendant la saison des inondations; j'arrive à Léalouyi, résidence du roi Léwanika ainsi que du missionnaire M. Coillard.

Mon but est heureusement atteint.

Comme on vient de le voir, ce chapitre de l'exploration peut àtre divisé en deux sections.

$1^{\circ}$ La région du royaume des ba-Rolsi, située entre les rivières Maclilé el Loumbé, qui à cette latitude, au clire du roi Léwanika, n’a pas encore élé explorée; elle est laisséc en blanc sur la carte. Jaai constaté que celte région est courerte d'une cliaine de collines plus ou moins boisées, très rapprochées les unes des autres el séparćes par des vallées el vallons, où coulent les affluents des trois tributaires du Zambèze, Machilé, Njoko et Loumbé.

$2^{\circ} \mathrm{A}$ partir du Loumbé, nous croisons à différentes reprises la piste que suivent les missionnaires, lorsqu'ils se rendent par voie de terre du sud-est au norl-ouest, soit de Kazo ungoula à Léalouyi.

La nature de la contrée se modifie : les collines sont plus espacées, les vallées, plus larges, les cours d'eau moins nombreux. Les deux plus importants sont le IIotondo et le Louyi (Lui), qui se rejoignent avant d'atteindre le Zambèze. De rastes lagunes parsìnent cette région; quelques-unes d'entre elles communiquent, paraît-il, arec le Zambèze; elles en recerraient alors l'excédent d'eau pendant la saison des pluies ${ }^{1}$.

Une fois cette communication terminée, plusieurs personnes demandent la parole; entre autres sir John Kirck qui, en 1860, accompagnait Livingstone en Afrique, ainsi que l'amiral Wharton, le président de la sćance, et quelques autres personnes. Je note en particulier les paroles suivantes de M. F. G. R. Ravenstein, le distingué cartographe de la Société Royale de Géographie de Londres :

"Les longues explorations du capitaine A. Saint-Hill Gibbons sont carac-

1. Après un sẻjour plein d'intẻrêt à Léalouyi, je descends le Zambèze en pirogue et je traverse en partieulier les gorges dlu bo-Rotsi formant la belle série des rapides qui s'étend entre Séoma et Katima-Molilo. J'ai aussi visité Nalolo et Sesheké. A Kazoungoula je retrouve rieid et Pirie. Nous allons aux ehutes du Zambeze (Vietoria Falls)... spectaele grandiose, et nous rejoignons notre arrière-garde à Gazouma-Vley. Ensuite après une terrible traverséc. entre Daka et Tamasetsie, de la Grande Piste de la Soif, nous prenons la direction sud-est; en franehissant la rivière Gway, nous pénétrons dans le Matébẻlẻland. Notre expédition se termine à Boulouwayo. 
térisées par de nombreuses observations pour déterminer la position des points importants.... M. Percy-C. Reid, en relevant le cours de la rivière Machilé, a largement ajouté à nos connaissances; par la voie qu il a suivie de la source de la rivière Machilé à Léalouyi, le capitaine Bertrand a relié les itinéraires de ses collègues et contribué à remplir un espace vide sur la carte. ”

Plus tard M. F. G. R. Ravenstein ajoute encore que la carte partielle du pays des ba-Rotsi, exécutée pour cette occasion par la Société Royale de géographie de Londres, est en grande partie basée sur un relevé qu'a fait le capitaine A. Saint-Hill Gibbons, grâce à cinquante-quatre points différents dont il a fixé la latitude, soit en prenant la hauteur méridienne du soleil, soit en faisant d'autres observations astronomiques ${ }^{1}$.

" Non seulement, dit-il, elles sont concordantes entre elles, mais elles saccordent avec les observations d'autres voyageurs; ainsi, tandis que le capitaine A. Saint-Hill Gibbons place Séshéké par $17^{\circ} 31^{\prime} 18^{\prime \prime}$ latitude sud, le $\mathrm{D}^{\mathrm{r}}$ Livingstone, qui avait fait son observation sur la rive droite du Zambèze, place Séshéké par $17^{\circ} 31^{\prime} 38^{\prime \prime}$ de latitude sud. "

Nous avons tous rapporté des spécimens de la faune si riche et si variée du bo-Rotsi.

Des trois lions tombés sous les balles du capitaine A. Saint-Hill Gibbons l'un d'eux, un "maneater ", soit mangeur d'hommes, paraît comme taille, avoir le second rang parmi ceux tués dans cette partie de l'Afrique; à l'épaule il mesure $1 \mathrm{~m} .09$. Ce lion a été empaillé et présenté à la Séance de la Société Royale de Géographie de Londres du 4 janvier 1897.

Le capitaine A. Saint-Hill Gibbons a aussi collectionné des oiseaux et M. Percy-C. Reid, des papillons.

Pendant le cours de l'expédition, j’ai pris un bon nombre de clichés photographiques, de types et de paysages; la plupart de ces photographies ont été exposées à la séance du 4 janvier 1897 de la Société Royale de Géographie de Londres et à celle du 22 janvier de la Société de Géographie de Paris. En outre, j'ai eu la bonne fortune de pouvoir rapporter une collection ethnographique d'objets divers, concernant l'art et l'industrie des ba-Rotsi; elle a figuré à la séance du 26 mai 1896 du XIe congrès des Sociétés suisses de Géographie, tenu à Genève sous les auspices de la Société de Géographie de cette ville, ainsi qu'à l'Exposition nationale suisse qui a eu lieu à Genève en 1896.

1. Voir le Geographical Journal (organe de la Société Royale de Géographie de Londres, février 1897, vol. IX, $\left.\mathrm{n}^{\circ} 2\right)$. 


\section{TABLES}





\section{TABLE DES GRAVURES}

Frontispice. - Portrait de l'auteur.

I. - La ville du Cap et la montagne de la Table. - Effet d'orage, d'après une photographie ................. 9

II. - Avenue de Wynberg, d'après une photographie. . . . . . . . . 11

III. - Récréation des mineurs dans le "Compound ", d'après une photographic. . . . . . . . . . . . . . . . 15

IV. - A Maféking, notre point de départ, dessin de Boudier, d'après une photographie de l'auteur . . . . . . . . . . 20

v. - Fin d'un "trek ", photographie de l'auteur . . . . . . . 2ä

VI. - Notre arrivée à Kanyé, dessin de Boudier, d'après une photographie de l'auteur ................... 27

VII. - Les princesses de Kanyé, dessin de Gotorbe, d'après une photographie de l'auteur. . . . . . . . . . . . . . . 29

VIII. - Nos chariots, dessin de Gotorbe, d'après une photographie de l'auteur. 31

IX. - Outarde africaine, croquis de Van Iruyden, spécimen rapporté par l'auteur . . . . . . . . . . . . . . 35

X. - Le roi Khama, dessin de Gotorbe, d'après une photographie de l'auteur. $\quad 37$

XI. - Femmes construisant des huttes à Palapye, dessin de Gotorbe, d'après une photographie de l'auteur. . . . . . . . . . 39

XII. - L'expédition en marche, dessin de Van Muyden. . . . . . . . . . 41

XIII. - Gnou bleu, "Catoblepas gorgon ", croquis de Van Muyden, spécimen rapporté par l'auteur. .............. 49 
XIV. - L'expédition avance péniblement, dessin de Boudier, d'après une plotographie de l'auteur ............... . . 51

XV. - Chasse aux gnous, dessin de Van Muyden. . . . . . . . ร7

XVI. - Campement sous un acacia giraffa, dessin de Boudier, d'après une photographie de l'auteur .............. 59

XVIl. - Dans les taillis! d'après une photographie de l'auteur . . . . . . 61

XVIIl. - Baobab, d'après une photographie de l'auteur. . . . . . . . 63

XIX. - Duiker, "Cephalophus mergens ", croquis de Van Muyden, spécimen rapporté par l'auteur .............. 66

XX. - Un de nos dîners, dessin de Thiriat, d'après une photographie de lauteur....................... 66

XXI. - Le Zambèze près du confluent de la rivière Linyanti, dessin de Boudier, d'après une photographie de l'auteur. . . . . . . . 69

XX11. - Station missionnaire de I. et Mme Louis Jalla, dessin de Boudier, d'après une photographie de l'auteur . . . . . . . . . 72

XXIII. - Sortie de l'école à Ḱazoungoula, photographie de l’auteur. . . . . . 73

XXIV. - Le prince Litia sort du temple, photographie de l'auteur . . . . . 7ذ

XXV. - Types de la tribu des ma-Shoukouloumboué, photographie de M. Coillard. - Reproduction interdite. . . . . . . . . . . 77

XXVl. - Reedbuck, "Cervicapra arundinacea ", croquis de Van Muyden, spécimen rapporté par l'auteur ..............

XXVIl. - Livingstone's eland, "Oreas canna ", dessin de Van Muyden, spécinen rapporté par l'auteur. ..............

XxVIII. - Serpent tué sur les bords de la rivière Machilé, dessin de Van Muyden, spécimen rapporté par l'auteur. . . . . . . . . . . 84

Xxıx. - Troupeau de zèbres près de la rivière Machilé, dessin de Van Muyden.

XXX. - Campement près de la rivière Machilé, dessin de Gotorbe, d'après une photographie de l'auteur ............ 87

XXXI. - La lionne est transportée au campement, dessin de Van Muyden . . 89

XxxII. - Forgerons ma-Totéla, dessin de Thiriat, d'après une photographie de l'auteur. . . . . . . . . . . . . .

XXXılI. - Village ma-Totéla et greniers à grains, dessin d'Oulevay, d'après une photographie de l'auteur. . . . . . . . . . . .

XXXIV. - Mouchoirs de poche indigènes, croquis de Van Muyden, collection de lauteur . . . . . . . . . . . . . . 
XXXY - Are et flèches empoisonnées échangés sur le territoire de la tribu des ma-Nkoya, croquis de Vin Muyden, collection de l'auteur'. . .

XXXvi. - Koodoo, "Strepsiceros kudu ", croquis de Van Muyilen, spécimen rapporté par l'auteur. . . . . . . . . . . . . . . 99

xxxiII. - Waterbuck, "Cobus ellipsiprymnus ", croquis de Van Muyden, spécimen rapporté par l'auteur . . . . . . . . . . . . 100

XXxVIIl. - Types de la tribu des ma-Nkoya, d'après une plotographie de M. Coillard. - Reproduction interdite. . . . . . . . . . . 101

XxxIx. - Reid relevant une observation, dessin de Van Muyden . . . . . . 103

XL. - Peigne en bois sculpté, échangé sur les bords de la rivière Njoko, croquis de Van Muyilen, collection de l'auteur. . . . . . . 109

XLI. - Oreiller en bois sculpté, éclıangé sur les bords de la rivière Njoko, croquis de Van Muyden, collection de l'auteur. . . . . . . . 109

XLII. - Lances de guerre, de chasse et de pêche, échangées avec les indigènes, croquis de Van Muyden, collection de l'auteur . . . . . 110

XLIll. - Type ma-Totéla, d'après une pholographie de l'auteur . . . . . . 111

XLIV. - Intérieur de la lıutle du chef Siboupa sur les bords du Njoko, dessin de J. Lavée, d'après une photographie de l'auteur . . . . . . . . 113

XLV. - Indigènes assistant au passage du Njoko, dessin de Boudier, d'après une photographie de l'auteur. . . . . . . . . . . . 11 s

XLVI. - Le chef Souroukouroukourou, dessin de Thiriat, d'après une photographie de l'auteur. . . . . . . . . . . . 116

XLVII. - Le lac Blue Water, source présumée de la rivière Ikué, dessin de Boudier, d'après une photographie de l'auteur. . . . . . . . 117

XLVIII. - Sibette, d'après une photographie de l'auteur . . . . . . . . . . . 119

XLIX. - Passage de la rivière Njonjo sur des branchages, d'après une photographie de l'auteur. . . . . . . . . . . . 121

L. - "Mabona " et l'arbuste "Moholoulolou ", d'après une photographie de l'auteur . . . . . . . . . . . . 123

LI. - Un marché au village du chef Mayoumba, dessin de Bigot-Valentin, d'après une photographie de l'auteur. . . . . . . . . . . 125

LII. - Traversée des marécages, dessin de Van Muydlen. . . . . . . . 127

LIII. - Calebasse à boire et cuillers indigènes, croquis de Van Muyden, collection de l'auteur. . . . . . . . . . . . . 129

LIV. - Une halte! d'après une photographie de l'auteur . . . . . . . . 130 
LV. - Un paysage au pays des ba-Rotsi, dessin de Boudier, d'après une photographie de l'auteur. .............. 131

LVI. - Mes hommes dans la grande plaine du bo-Rotsi, photographie de l'auteur ................. . . 133

LVII. - L'église de la station missionnaire de Léalouyi apparaît au loin comme un phare..., d'après une photographie de l'auteur. . . . . . 135

LVIII. - M. le missionnaire Coillard, d'après une photographie de M. Boissonnas, à Genève. . . . . . . . . . . . . . . . . . 139

LIX. - Le roi Léwanika autrefois, d'après une photographie de I. Coillard. - Reproduction interdite ................ 140

LX. - Le roi Léwanika aujourd'hui, d'après une photographie de M. Coillard. - Rcproduction interdite.............. 141

LXI. - Plat royal en bois sculpté cédé par le roi Léwanika, croquis de Van Muyden, collection de l'auteur. . . . . . . . . . . 1

LXII. - Siège en bois sculpté cédé par le roi Léwanika, croquis de Van Muyden, collection de l'auteur. ............ 142

LXIII. - La " Nalikouanda ", embarcation royale, dessin de E. Gotorbe, d'après une photographie de $\mathrm{M}$. Coillard. - Reproduction interdite.

LXIV. - L'une des hultes du harem royal, d'après une photographie de

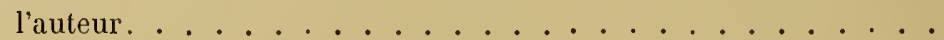

LXV. - Tubana (bois) cédée par le roi Léwanika, croquis de Vill IIuyden, collection de l'auteur ............... . . 147

LXVI. - L'un des conseillers du roi Léwanika, d'après une photographie de l'auteur. . . . . . . . . . . . . . . 149

LXVII. - Le roi Léwanika rendant la justice au lékhotla, dessin de Gotorbe, d'après une photographie de M. Coillard. - Reproduction interdite.

LXVIII. - La reineMlokouaé, de Nalolo, photographic de M. Coillard. - Reproduction interditc . . . . . . . . . . . . . . . . . . . . . . 15

LXIX. - École de M. et de Mme Béguin à Nalolo, d'après une plıtographie

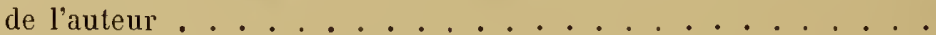

LXX. - Les dépendances de la station missionnaire de Léalouyi. Mme Adolphe Jalla et quelques-uns de ses élèves, dessin d'Oulevay, d'après une photographie de l'auteur ..............

LXXI. - Plat à poisson (bois) cédé par le roi Léwanika, croquis de Van Muyden, collection de l'auteur. ............ 160 
LXXII. - Lne hache, présent de Léwanika, roi des ba-Rotsi, croquis de Van Mujden, collection de l'auteur ............ 160

LXXIII. - Sćrimba et autres instruments de musique royale, dessin d’Oulevay, d'après une photographie de l'auteur. . . . . . . . . 161

LXXIV. - Rencontre du capitaine Saint-Hill Gibbons, d'après une photographie de l'auteur................ 167

LXXV. - Descente du Zambèze, dessin de Van Muyclen . . . . . . . . 169

LXXV. - Le halage des pirogues, d'après une photographie de l'auteur. . . 175

L.IXVIr. - Les rapides de Kalé, d'après une photographie de l'auteur. . . . . 177

L.XYIIl. - Chasse aux buffles, dessin de Van Muyden. . . . . . . . 181

Lixix. - Près de Loushou [Rapides de la Mort], photographie de l'auteur. 183

LXXX. - Capture d'un crocodile, dessin de Thiriat, d'après une photographie de l'auteur. .................. 185

LXXXI. - Les pirogues sont arrêtées par dix hippopotames, dessin de Van Muyden. ................... 187

LXXXIl. - Coupe en terre cuite du chef Boumoé, neveu du roi Léwanika, croquis de Van Muyden, collection de l'auteur . . . . . . 196

LxxxIIl. - Une défense d'éléphant pesant 75 livres, dessin d'Oulevay, d'après une pholographie de l'auteur. . . . . . . . . . . 199

LXXXIV. - Près des chutes Victoria, d'après une photographie de l'auteur. . 201

LXXXV. - Une partic des clutes Victoria, dessin de G. Vuillier, d'après une photographie de l'auteur .............. 205

LXXXVI. - En détresse! Nous abandonnons le grand chariot dans les sables, dessin de Van Muyden. . . . . . . . . . . . 215

LXXXVII. - A Boulouwayo, dessin d'Oulevay, d’après une photographie de l'auteur .................. 224

LXXXVIII. - Guerriers zoulous, dessin de Gotorbe, d’après une photographie. . 227

LXXXIX. - Indigènes faisant du feu, d'après une photographie. . . . . . . 233

XC. - En " coach ", dessin de Van Muyden. . . . . . . . . . 237

XCI. - Un guerrier zoulou, d'après une photographie . . . . . . 239

XCll. - Prétoria. - Palais du gouvernement, d'après une photographie. . 2ł3

XCIII. - Le marché à Johannesburg, d'après une photographie. . . . . . . 2'7 
XCIV. - Résidence du président Krüger à Prétoria, d'après une photographie. 261

XCV. - Vue de Durban, d'après une photographie. . . . . . . . . 267

XCVI. - Maison de planteur, d'après une photographie . . . . . . . . . 269

XCVII. - Cueillette du thé par les coolies lindous, dessin de Boudier, d'après une photographie. . . . . . . . . . . . 271

XCVIII. - La rivière de Mérindol (Natal), d'après une photographie. . . . . 272

XCIX. - Simulacre de combat, d'après une photographie. . . . . . . 2 73

C. - Un joli coin près de Kearsney (Natal), d'après une photographie. . 277

CI. - Les voitures de Durban, d'après une photographie. . . . . . . . 279

Cl1. - East-London vue de la mer, d'après une photographie . . . . . 282

CIII. - Comment l'on débarque à East-London et à Port-Élizabeth, dessin de Thiriat, d'après une photographie. . . . . . . . . . 283

CIV. - Les jetées de Port-Élizabeth, dessin de Taylor, d'après une photographie . . . . . . . . . . . . 287 


\title{
TABLE DES MATIËRES
}

\author{
CHAPITREI
}

\section{LA TRAVERSEE}

De Southampton au Cap sur le Norham-Castle . . . . . . . . . 1

$$
\text { CHAPITRE II }
$$

\section{AU PAYS DES MINES DE DIAMANTS}

Du Cap - via Kimberley — à Maféking . . . . . . . . . . . . 13

\section{CHAPITRE III \\ CHEZ LES BÉGHUANAS}

De Mafélíng à Palapye (capitale de Khama, roi des ba-Mangwato) par Kanyé (tribu des ba-Rnaketsé), Molépololé (tribu des ba-Kuéna) et la "Piste de la Soif ", près du désert de Kalahari . . . . . . . . .

\section{CHAPITREIV}

\section{AU DESERT}

A travers le territoire de Klıama. — Le grand lac salé Makarikari. — "Land of the thousand vleys $» . \ldots \ldots$. . . . . . . . . 


\section{CHAPITRE V}

\section{LE Z AMBÈZE}

Sur les bords du fleuve. - Kazoungoula (Pays des ba-Rotsi). . .

\section{CHAPITRE VI}

\section{AU PAYS DES BA-ROTSI. - LA RIVIẼRE MAGHILÉ}

A Kazoungoula. - Nous remontons le cours de la rivière Machilé. Arrivée à la source de la rivière Machilé, territoire de la tribu des ma-Nkoya . . . . . . . . . . . . . .

\section{CHAPITRE VII}

\section{A TRAVERS LE ROYAUME DES BA-ROTSI}

Traversée du pays des ba-Rotsi jusqu'à Léalouyi. - La rivière Njoko, territoire de la tribu des ma-Totéla. - La rivière Loumbé (Lumbi). — La rivière Louyi (Lui), territoire de la tribu des ma-Kuangoa (Makwenga).

- Séfoula.

\section{CHAPITRE VIII}

\section{LE ROI. LE WANIKA ET LE MISSIONNAIRE GOILLARD}

A Léalouyi, capitale du roi Léwanika. - Nalolo, résidence de la reine Mokouaé . . . . . . . . . . . . . . . . . 137

\section{CHAPITRE IX}

\section{EN PIROGUE}

Descente du Zambèze. — La région des rapides. — Séshéké. . . . . . . 163

$$
\text { CHAPITRE X }
$$

\section{LES GRANDES GATARACTES}

Retour à Kazoungoula et visıte aux chutes du Zambèze (Victoria Falls). . 193 


\section{CHAPITRE XI \\ EN DÉTRESSE}

Des chutes Victoria à Panda-Natenga. - Daka. - La Grande Piste de la

Soif. - La rivière Gway (Frontière du Matébéléland) et Boulouwayo. . 209

\section{CHAPITRE XII}

\section{AUX AVANT-POSTES DE LA CIVILISATION}

Boulouwayo, ville principale du Matébéléland. . . . . . . . . . . . 223

$$
\text { CHAPITRE XIII }
$$

\section{LE PAYS DES MINES D'OR}

De Boulouwayo par Ic Natébéléland au Transvaal. Prétoria. Johannesburg.

- Le raid de Jameson. . . . . . . . . . . . . . . . . . . 23د̆

$$
\text { CHAPITRE XIV }
$$

\section{LE JARDIN DE L'AFRIQUE MÉRIDIONALE. - LE RETOUR}

De Johannesburg à Durban (Natal). - East-London. - Port-Élizabeth. -

Le Cap et retour en Europe. . . . . . . . . . . . . . 263

APPENDICE I. . . . . . . . . . . . . . . . . . . . . . . . 29 כ̆

APPENDICE II. . . . . . . . . . . . . . . . . . . . . . . . . . . . . 311

Table des Gratlres. . . . . . . . . . . . . . . . . . . . 323

Carte I. - Partie du Pays des ba-Rotsi explorée par l'expédilion . . . . 333

Carte II. - Itinéraire de l'auteur. . . . . . . . . . . . . . . . . . 337

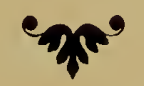



GARTE I 
La carte anglaise ci-contre est la carte originale que la Société Royale de Géographic de Londres a fait collationner et dessiner d'après les rapports des Explorateurs.

La Société Royale de Gíographie de Londres a bien voulu donner à l'auteur de ce livre l'autorisation de la reproduire dans son ouvrage; par conséquent l'orthographe des mots n'a pas été changée.

Nous rappelons qu'un statute mile vaut 1609 mètres. 


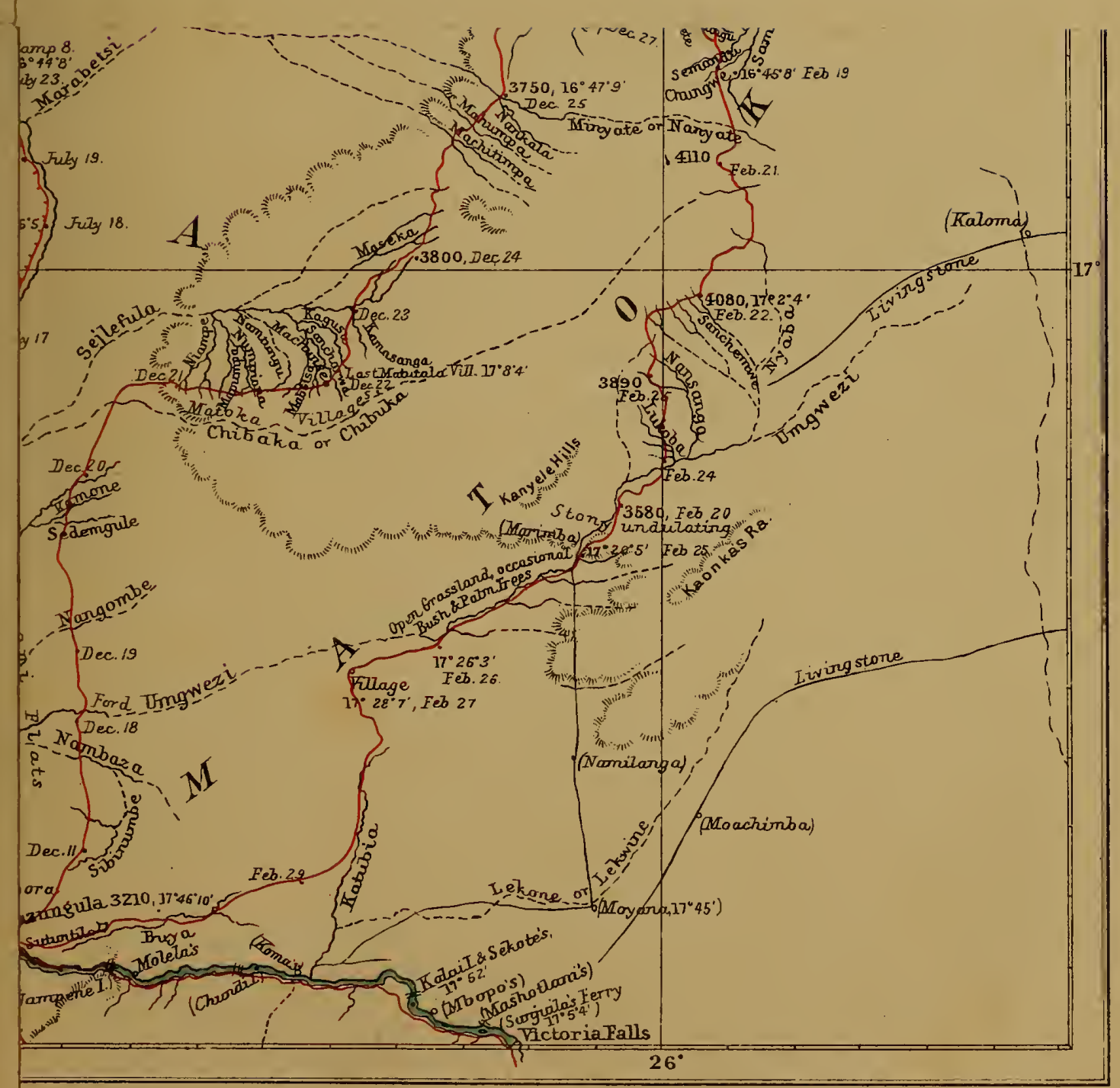

G. Phitip \& Son, London \& Liverpool 



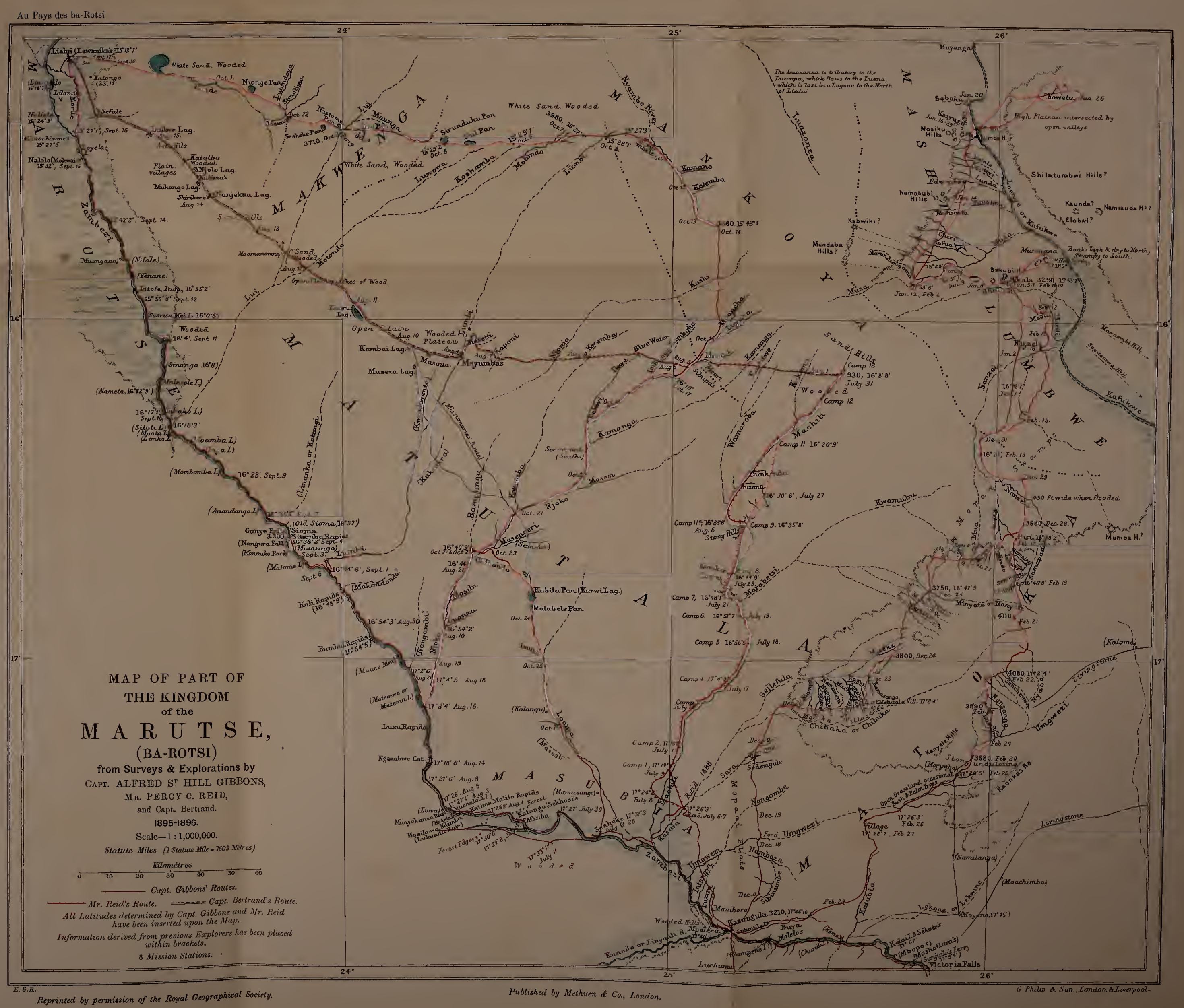



GARTE II 
Les endroits marqués sur la roule suivie du Makarikari au Zambèze ne sont pas, excepté Panda-Matenga, où se groupent quelques hulles, des localités habitées; mais les principaux emplacements recherchés pour l'eau.

Coulommiers. - Imp. PAUL BRODARD. - 180-97. 


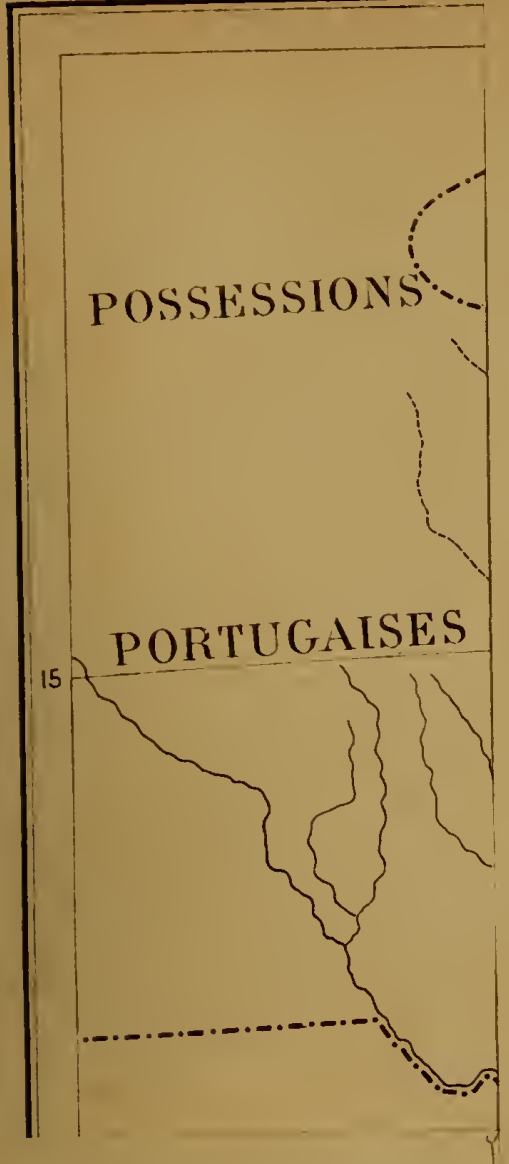





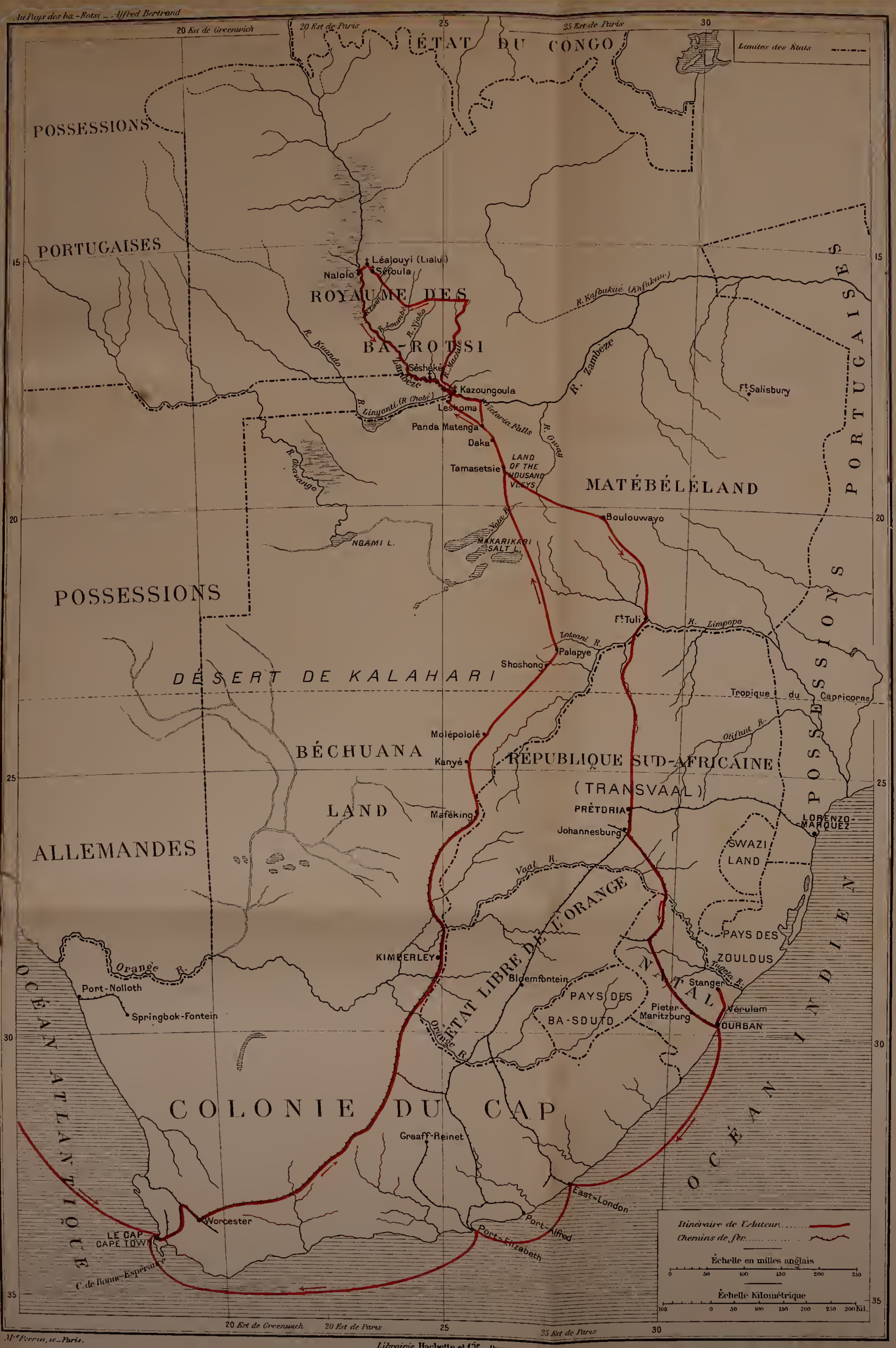




J.-H. JEHEBER, Éditeur, rue du Marché, 28, GENĖVE.

\section{LA FAMILLE \\ PAR

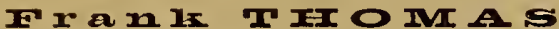

In volume in-12 de 326 pages, fr. $\mathbf{3 . -}$; relié toile, fr. $\mathbf{4 . 5 0}$; reliure amateur, fr. $\mathbf{8 . 5 0}$.

Table des matières : La Famille. - Les Ėpoux. - Le Père. - La Mère. LEufant. - Nos Fils. - Nos Filles. - Maitres et Serviteurs. - Sans Famille, - La grande Famille.

\section{OPINION DE LA PRESSE :}

Nous recommandons très particulièrement à nos lecteurs ce volume. L'auteur a su traiter l'important sujet de la famille sans répéter ce qu'avait dit excellemment le comte $\mathbf{A}$. de Gasparin et E. de Pressensé, d'une façon neuve, originale, actuelle, en tenant compte des circonstances et des besoins de l'époque présente. Ce livre est éminemment suggestif ; il fait réfléchir ; il signale nettement les ennemis qui menacent la famille; il inspire tout à la fois des pensées de regret et d'liumiliation, et des désirs de réparation et de relèvement; il indique clairement la base sur laquelle la famille doit être fondée et le secours divin par lequel elle peut devenir ce qu'elle doit être; sortant des généralités, il entre dans le détail de la vie et ne craint pas un réalisme de bon aloi qui donne ả son ensejgnement un relief saisissant ; rien n'y est banal, lout $\mathrm{y}$ est vrai et vivant; c'est une lecture instructive à faire, bien plus : c'est une lecture édifiante dans le plein sens du mot. (Le Journal religieux).

Nous ne saurions dire tout le bien que nous pensons de ce livre. Ce sont dix conférences ou causeries sans prétention, sur un sujet toujours actuel. Il n'y a là rien de pédant, de prêcheur, pas de note fausse uj d'exagération, mais anssi pas de faiblesse. C'est un homme, dans toute la force du terme, qui parle; son christianisme est humain, il est anssi viril.

(Journal des Unions).

Voila un livre que nous voudrions voir non seulement dans toutes les familles mais entre les mains de tous ceux qui veulent s'en créer une. 
Sans prétention littéraire ou philosophique, l'auteur considère la Famille dans son ensemble, ce qu'elle doit être lorsqu'une influence religieuse y règne et $\mathrm{y}$ domine, puis prenant à part successivement les époux, le père, la mère, l'enfant, nos fils, nos filles, maitres et serviteurs, il nous montre les devoirs de chacun et les mille moyens qu'il possède pour être utile et agréable aux autres et coopérer au bonheur de tous y compris le sien. Que de familles seraient plus heureuses et plus prospères si ce précieux livre était appliqué.

(Le Signal de Genève).

Les privilégiés qui ont entendu ces conférences ne les oublieront certes pas. Qu'ajouter aux appréciations si justes qui en ont déjà été données ? Nous dirons, comme ceux dont le jugement a précédé le nôtre, qu'il y a dans la lecture de cet ouvrage éminemment populaire, tant d'observations judicieuses, tant de conseils excellents a l'adresse de tous, qu'on ne saurait assez le recommander. - Pères. mères, fils, filles, serviteurs, servantes, se trouveront bien de méditer ces pages simples et émues qui, sorties du cœur, en prennent si facilement le chemin. Pour les jeunes gens il y a là une véritable révélation des trésors d'amour que la vie sous le regard de Dieu leur réserve. Quels encouragements au bien ils rencontrent dans ce livre!

Quant aux vieux, que de douces larmes font monter à leurs yeux les souvenírs bénis évoqués par les tableaux successifs où ils retrouvent les impressions et les expériences de leur propre vie! Le chapitre consacré à l'enfant remue doucement le cœur! Mais comme il nous fait comprendre notre responsabilité ! Comme il réveille notre conscience! Comme il nous apprend à demander an Seigneur d'être ouvrier avec nous dans cette noble et difficile tâche de l'éducation.

(La Lecture).

Livre d'un homme d'action, plus préoccupé de répandre un peu de bíenveillance et d'amour entre les hommes que de faire œuvre d'Art. Les dix conférences qui le composent ont entre elles un lien très apparent, et tendent toutes au même but, la glorification de la famille chrétienne.

La maison Jeheber présente ce volume au publíc à l'occasion de son centenaire. Elle n'aurait pu faire un meilleur choix.

(La Gazette de Lausanne).

Envoi contre remboursement en Suisse. 




$$
284=200
$$

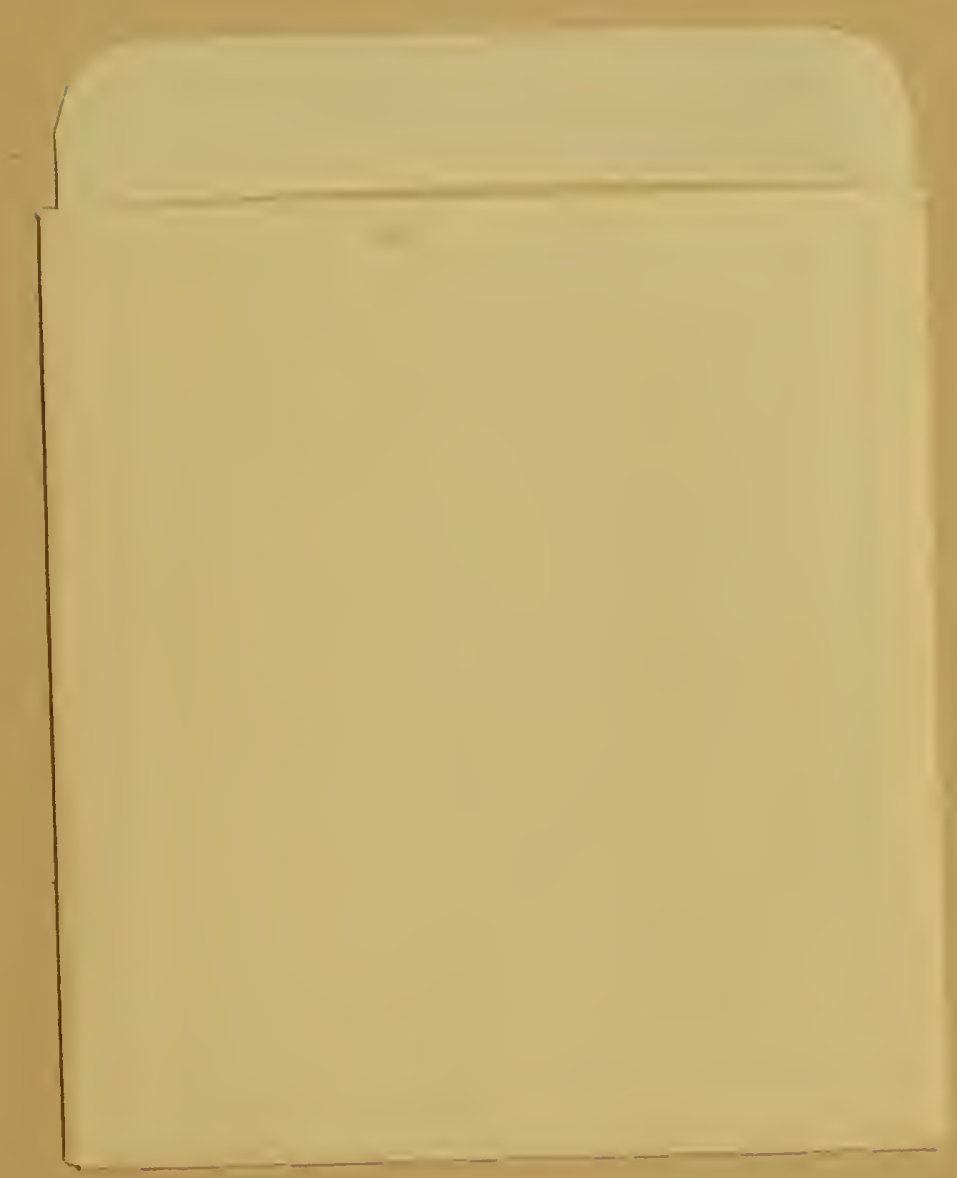


